\title{
Sistema de Medición Fasorial para Supervisar y Detectar Oscilaciones Subsincrónicas en Redes Eléctricas
}

\author{
Tesis de Doctorado \\ Pablo Ezequiel Leibovich
}

Presentada ante la Facultad de Ingeniería de la

Universidad Nacional de La Plata como requisito para la obtención del grado académico de DOCTOR EN INGENIERÍA

Dirección de Tesis:
Director: Fernando Issouribehere
Codirector: Juan C. Barbero

Jurado de Tesis:
Dr. Gonzalo Casaravilla (Udelar, Uruguay)
Dr. Ildemar C. Decker (UFSC, Brasil)
Dr. Miguel Ángel Mayosky (UNLP, Argentina)

Fecha de la defensa oral y pública: 16 de diciembre de 2019 



\section{Resumen}

En esta tesis se presenta el desarrollo e implementación de un sistema de medición fasorial completo, cubriendo todos los componentes que conforman un sistema de medición de sincrofasores. El sistema presentado incluye la implementación de una Unidad de Medición Fasorial (PMU), un Concentrador de Sincrofasores (PDC), un software para Almacenamiento de Sincrofasores como respaldo y un software de procesamiento online y offline de las mediciones.

El Sistema Argentino de Interconexión (SADI) ha sufrido grandes modificaciones y ampliaciones en los últimos años, que produjeron una modificación en su comportamiento dinámico, modificando los modos dominantes de oscilaciones electromecánicas, es decir los modos de oscilación entre máquinas sincrónicas con más bajos amortiguamientos. Esta nueva condición del Sistema hace que sea necesario profundizar el análisis de la estabilidad de los sistemas de potencia, con herramientas capaces de predecir el estado de operación del mismo, prácticamente en tiempo real. Para ello, la presente tesis presenta un sistema de medición fasorial diseñado para poder detectar, supervisar y caracterizar las oscilaciones subsincrónicas medidas mediante las PMUs conectadas al sistema

La tesis incluye el estudio de los sistemas de medición sincrofasoriales en la actualidad y su aplicación en las oscilaciones subsincrónicas. Para su implementación, se estudiaron en forma detallada los diferentes mecanismos de transmisión de sincrofasores y su aplicabilidad en sistemas de medición tanto de supervisión como de supervisión y control. A su vez, se presenta la evaluación de distintos algoritmos para la estimación de sincrofasores incluyendo la evaluación de los resultados obtenidos con dichos algoritmos cuando se los utiliza en aplicaciones reales.

En función de la necesidad de supervisar y detectar las oscilaciones subsincrónicas, se desarrolla también el estudio y comparación de diversas herramientas matemáticas que pueden utilizarse para la caracterización de las oscilaciones.

Finalmente, se presentan también los ensayos y evaluaciones llevadas a cabo tanto a la Unidad de Medición Fasorial como al Sistema de Medición Sincrofasorial completo. 


\section{Agradecimientos}

En primer lugar, quisiera agradecer a mis padres, Alberto y Beatriz, por brindarme incondicionalmente todo el apoyo, la guía, la fuerza para seguir adelante en todo momento y la educación para desarrollarme como profesional pero más aún como persona. A mi hermana, Fabiana, por su apoyo y su sostén permanente. A ellos tres, dedico este trabajo.

Quiero agradecer a mis amigos, por todas esas ausencias entendidas, por todas esas quejas escuchadas. Por todos esos momentos que estuvieron presentes cuando los necesité, por todos los momentos disfrutados, gracias.

Quisiera también agradecer a todos los integrantes del Instituto de Investigaciones Tecnológicas en Redes y Equipos Eléctricos - Laboratorio de Alta Tensión de la Facultad de Ingeniería, por brindarme el apoyo y todos los recursos necesarios para lograr el objetivo propuesto.

A mis directores de tesis, Fernando Issouribehere y Juan C. Barbero, por brindarme la oportunidad, ayudarme y guiarme.

Finalmente, recordar a esas personas que desde algún lado están presentes a su manera. A mis abuelos, Gregorio, Fanny y Pablo, y a Rodolfo, mi recuerdo inolvidable. 


\section{Índice}

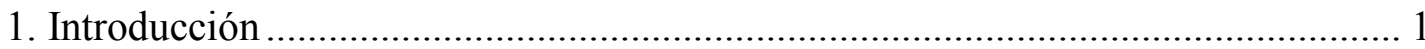

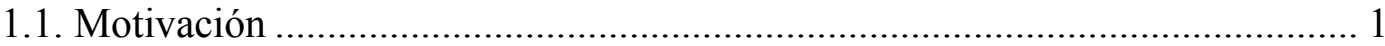

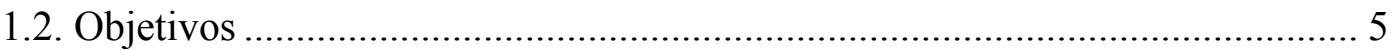

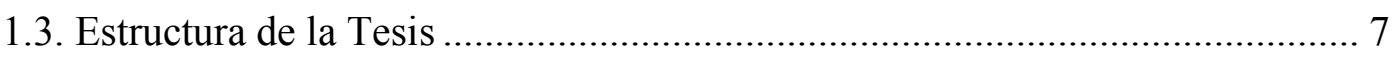

1.4. Publicaciones realizadas sobre el tema de tesis ............................................. 8

2. Oscilaciones subsincrónicas en sistemas eléctricos de potencia ............................ 10

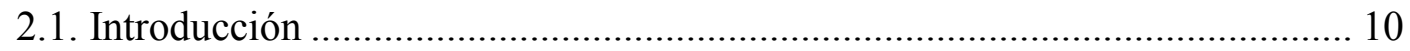

2.2. Estabilidad del ángulo de rotación de las máquinas generadoras .................... 12

2.3. Análisis de la estabilidad de pequeña señal ................................................... 14

2.4. Modos de Oscilación en el SADI................................................................. 17

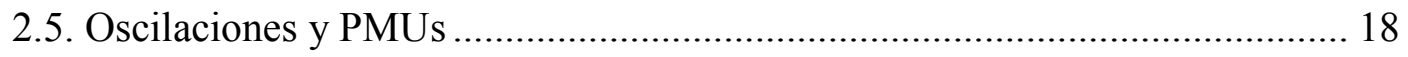

3. Sistema de medición sincrofasorial ................................................................. 22

3.1. Sincrofasor: Concepto y definición.............................................................. 22

3.1.1. Frecuencia y Tasa de Variación de Frecuencia (ROCOF) ........................ 24

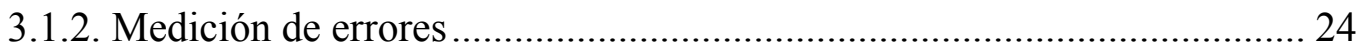

3.2. Estructura general de un Sistema de medición sincrofasorial.......................... 26

3.2.1. Software de procesamiento - Modulo Online ............................................ 29

3.2.2. Software de procesamiento - Modulo Offline ………………………....... 29

3.3. Sistema de medición sincrofasorial brasileño - Proyecto MedFasee y

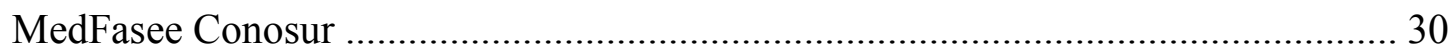

3.3.1. Corte de Suministro Eléctrico - La Plata - 19 de Enero de 2019............. 31

3.3.2. Corte de Suministro Eléctrico - Ciudad Autónoma de Buenos Aires- 22 de

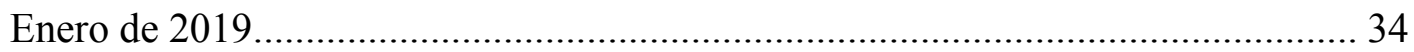

3.3.3. Blackout Argentino - 16 de Junio de 2019 ............................................. 36

3.4. Iniciativa Norteamericana de Sincrofasores (NASPI) - Estados Unidos ....... 41

3.5. Sistema de medición sincrofasorial - China ……………………………….... 42

3.6. Software de Código Abierto - Grid Protection Alliance ................................. 43

4. Comunicaciones y transmisión de sincrofasores .................................................... 47 


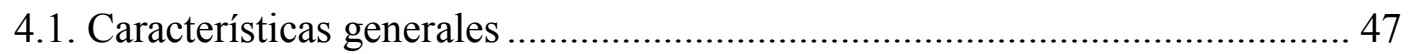

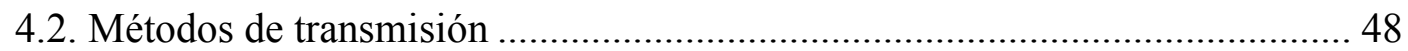

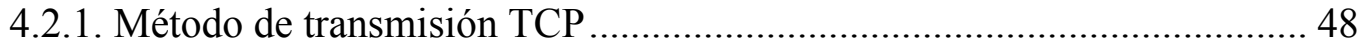

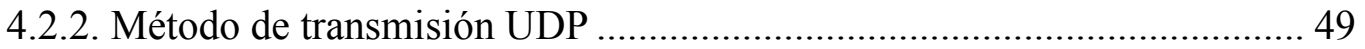

4.2.3. Estudio comparativo del ancho de banda entre ambos métodos ............. 49

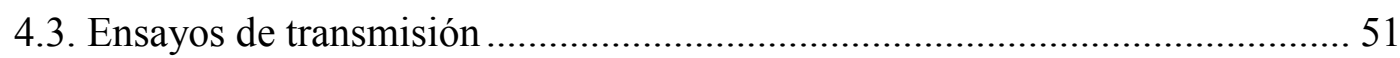

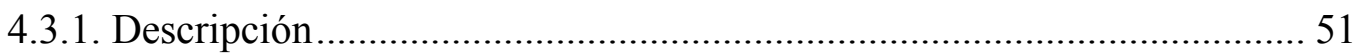

4.3.2. Análisis del orden de los conjuntos de datos recibido............................ 51

4.3.3. Análisis de los sincrofasores recibidos en paquetes de red ..................... 53

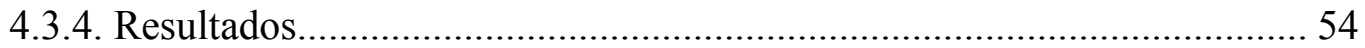

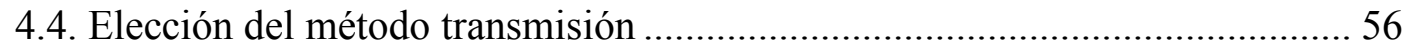

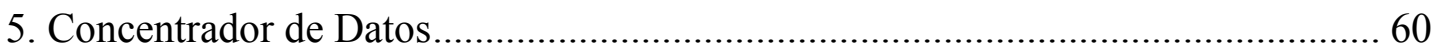

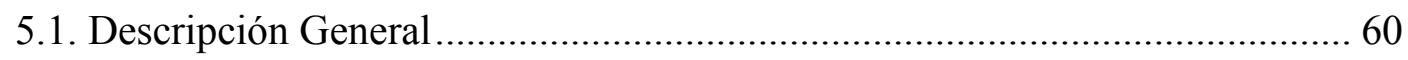

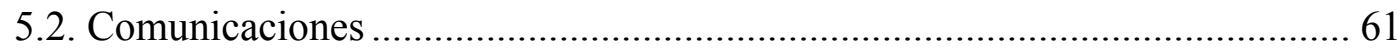

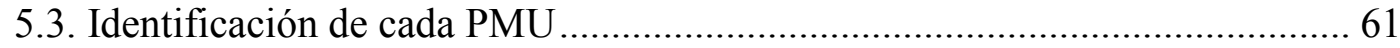

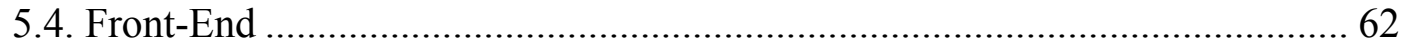

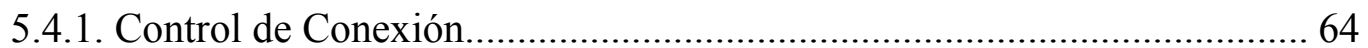

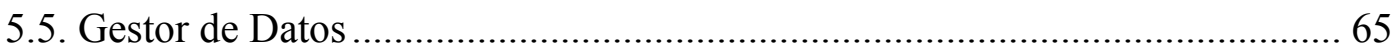

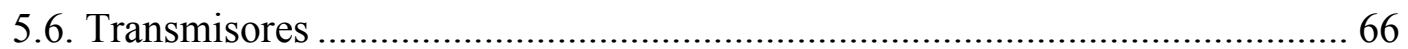

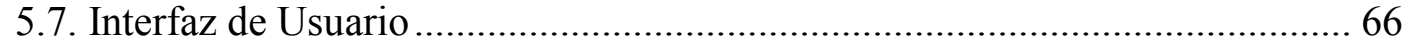

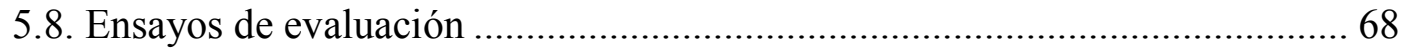

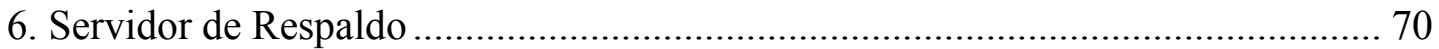

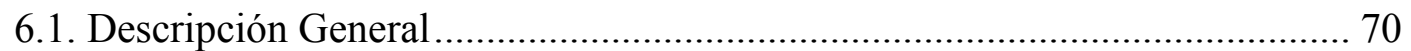

6.2. Componentes del Servidor de Respaldo ...................................................... 72

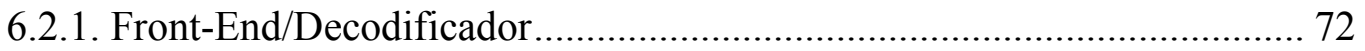

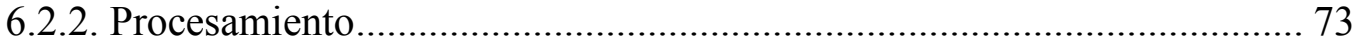

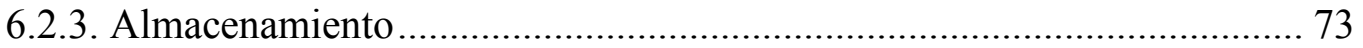

6.2.4. Esquema de la Base de Datos ................................................................... 74

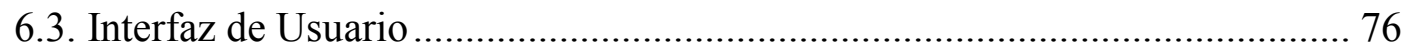

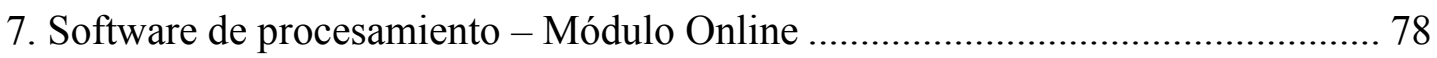

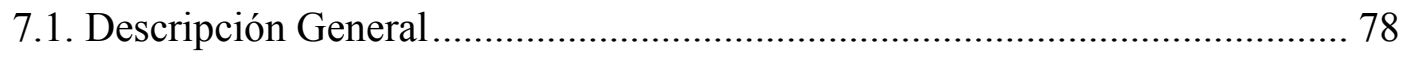

7.2. Selección del método de procesamiento online de sincrofasores .................... 79 
7.2.1. Descripción matemática del método de Prony ..........................................8 80

7.2.2. Comparación entre el análisis de Prony y la Transformada de Fourier ... 87

7.2.3. Comparación entre el análisis de Prony y la Transformada Wavelet...... 89

7.2.4. Implementación del método de Prony ....................................................... 95

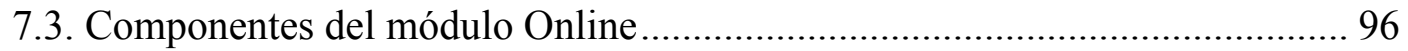

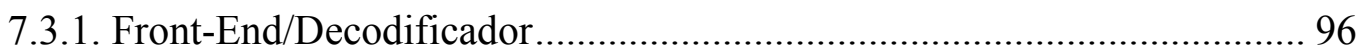

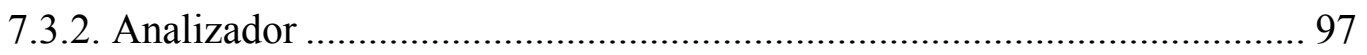

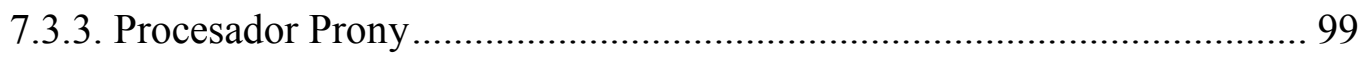

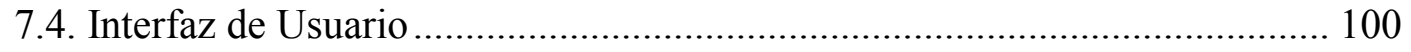

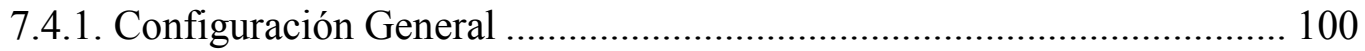

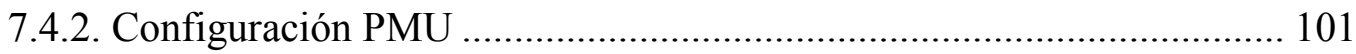

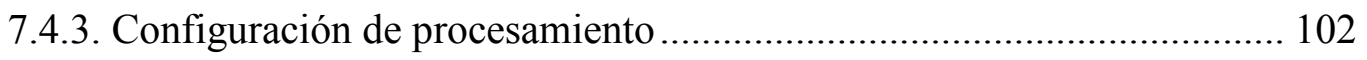

7.4.4. Configuración de Visualización ............................................................ 104

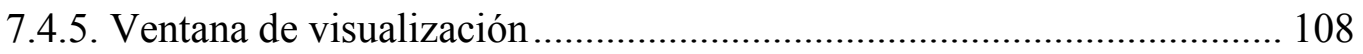

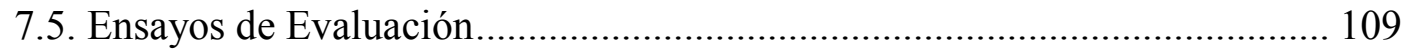

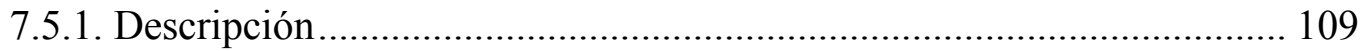

7.5.2. Registros de sincrofasores ....................................................................... 110

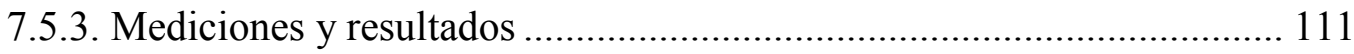

8. Software de procesamiento - Módulo Offline................................................. 120

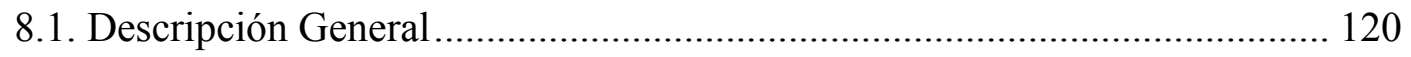

8.2. Componentes del módulo Offline ............................................................ 121

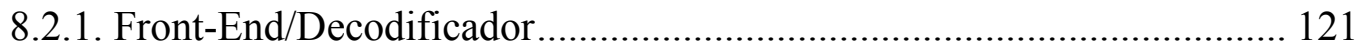

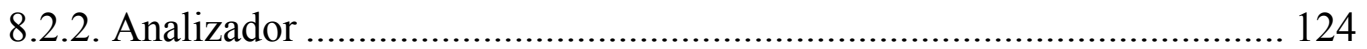

8.2.3. Procesador Matemático ........................................................................ 126

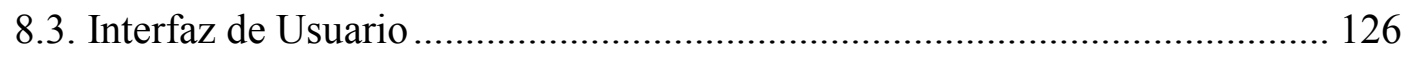

8.3.1. Configuración General ........................................................................ 127

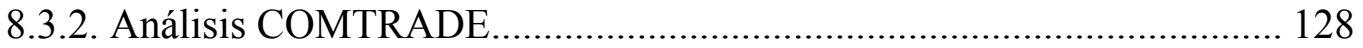

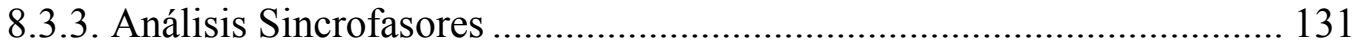

8.3.4. Análisis COMTRADE y Sincrofasores ................................................. 133

8.3.5. Explorador de Archivos COMTRADE ................................................ 135

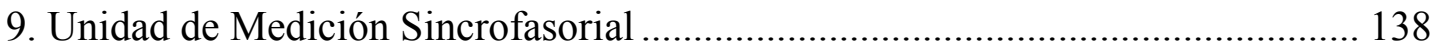

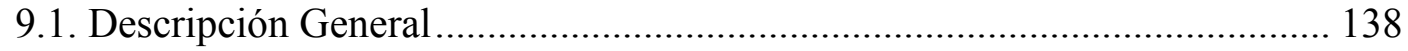


9.2. Técnicas de Estimación de Sincrofasores .................................................... 140

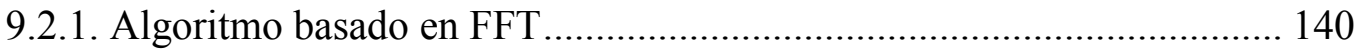

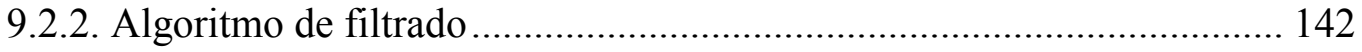

9.2.3. Simulación de Métodos de Estimación ................................................. 143

9.2.4. Evaluación en hardware de los Métodos de Estimación ........................ 146

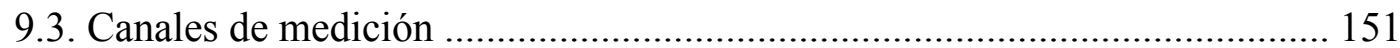

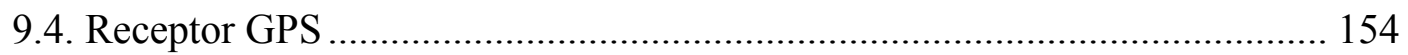

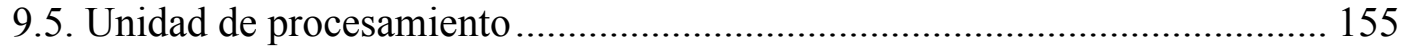

9.6. Módulo de Cálculo y Comunicaciones ........................................................ 157

9.7. Descripción física e Interfaz de Usuario ..................................................... 159

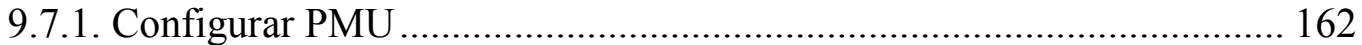

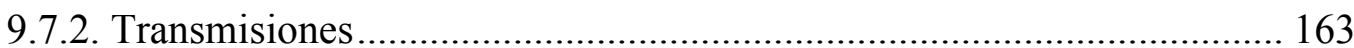

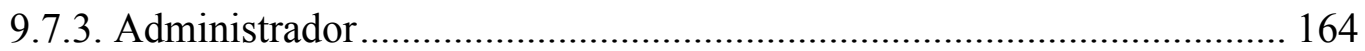

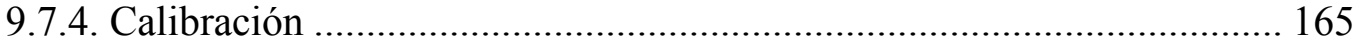

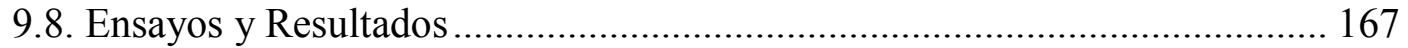

9.8.1. Caracterización de los canales de medición ......................................... 167

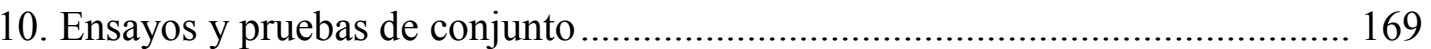

10.1. Evaluación de las mediciones realizadas por la PMU ................................ 169

10.2. Evaluación del funcionamiento del sistema en conjunto .......................... 174

10.2.1. Evaluación con rampa de frecuencia .................................................. 176

10.2.2. Evaluación con potencia oscilante amortiguada................................. 180

11. Conclusiones y Líneas Futuras ..................................................................... 186

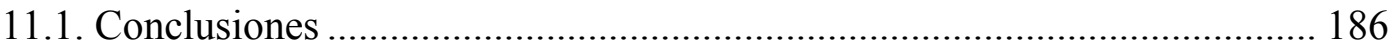

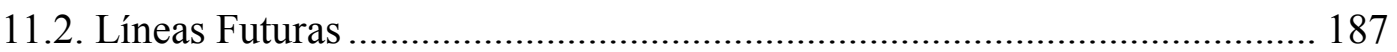

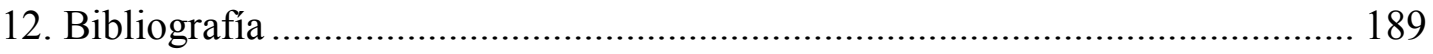




\section{Introducción}

\subsection{Motivación}

Los Sistemas Eléctricos de Potencia integrados a nivel de país o región requieren herramientas de control de su operación que permitan lograr los estándares siempre crecientes de confiabilidad requeridos por los usuarios y la industria [1][2].

Históricamente, la integración de redes contó con las tecnologías vigentes en su respectiva etapa de evolución. El Sistema Argentino de Interconexión (SADI) cubre actualmente la totalidad del territorio nacional, a nivel de redes de Extra Alta Tensión. El Despacho es único y lo realiza la Compañía Administradora del Mercado Mayorista Eléctrico (CAMMESA) desde su Centro de Control. En sus inicios, la información entre nodos del Sistema se realizaba en forma manual por voz o fax, evolucionando con el tiempo al Telecontrol con base de tiempo de actualización de minutos hasta el actual Sistema de Operación en Tiempo Real (SOTR) con base de tiempo de segundos [3].

Durante años, las mediciones tradicionales con Telecontrol o Control Supervisorio y Adquisición de Datos (SCADA, por sus siglas en inglés) han sido utilizadas para proveer la información del estado estacionario del sistema eléctrico de potencia. Sin embargo, las mediciones de SCADA en sistemas eléctricos de área amplia (WAMs, por sus siglas en inglés) tienen importantes limitaciones debido a su escasa resolución temporal y su alta latencia. Esta escasa resolución temporal dificulta, entonces, estimar las frecuencias y el amortiguamiento de las oscilaciones eléctricas que se presentan en el sistema.

Luego de varios años sin ampliaciones significativas, el SADI ha experimentado $\mathrm{y}$ experimentará numerosos cambios, entre los que se puede destacar la incorporación de nuevas líneas de $500 \mathrm{kV}$ junto a la incorporación de fuentes de energía renovables. La denominada Interconexión NOA-NEA vinculó las áreas noroeste y noreste del SADI así como la denominada Interconexión Comahue - Cuyo conectó las áreas Comahue y Cuyo. En la Figura 1 se muestra un esquema topológico del SADI (sector Norte) incorporando las mencionadas interconexiones. Se observa como la estructura radial del SADI se ha transformado en una estructura que empieza a ser mallada. 


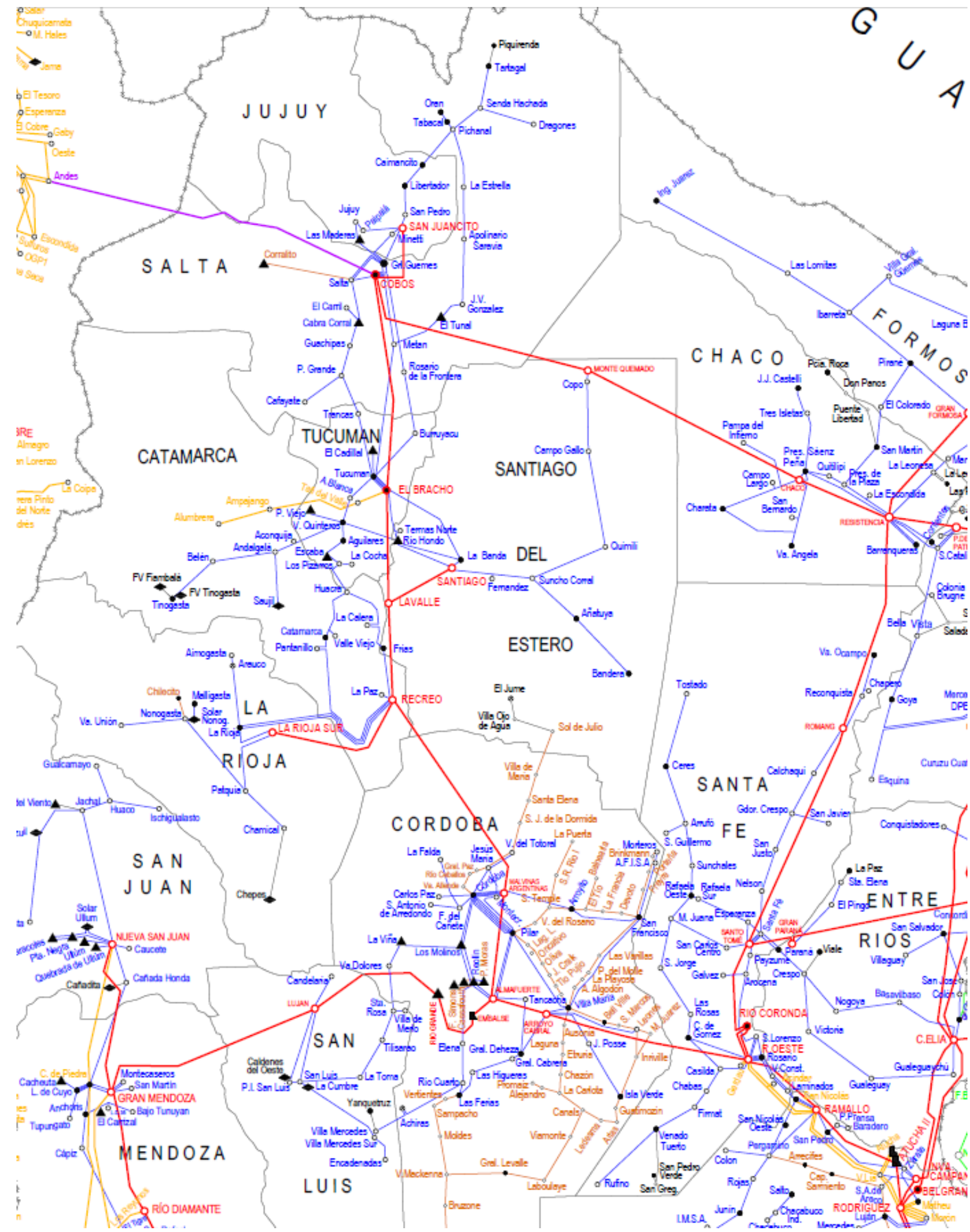

Figura 1. Vista general de la topología del SADI (Sector Norte). 


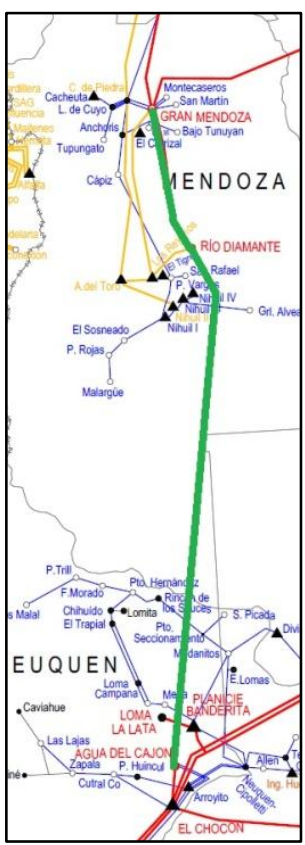

Figura 1-b.

Interconexión

Comahue-Cuyo.

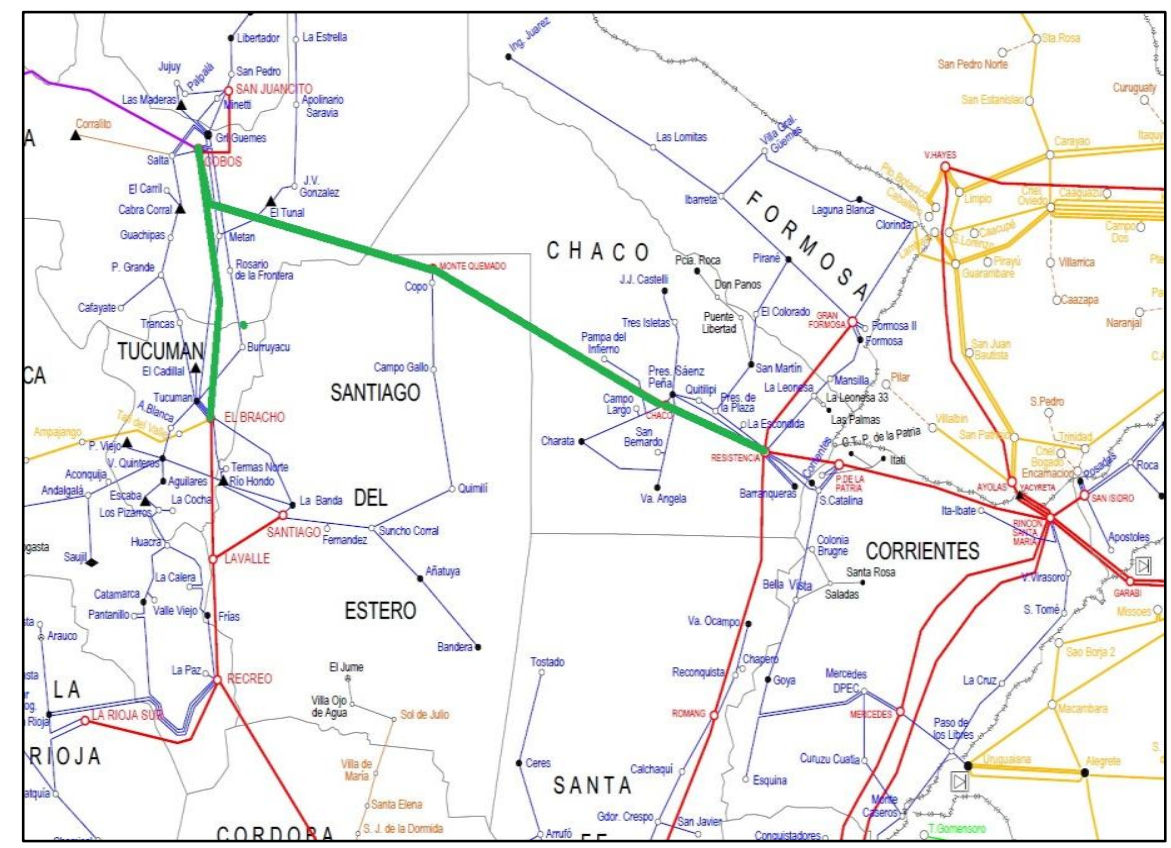

Figura 1-c. Interconexión NOA-NEA.

La Interconexión Comahue-Cuyo, indicada en verde en la Figura 1-b, está conformada por los tramos de líneas entre las EETT Agua del Cajón -Río Diamante Gran Mendoza. La Interconexión NOA-NEA, indicada en verde en la Figura 1-c, está conformada por los tramos de líneas entre las EETT Resistencia - Roque Sáenz Peña Monte Quemado - Cobos - Bracho, y dos vínculos radiales, uno entre las EETT Resistencia y Formosa, y el otro entre las EETT Cobos y Sanjuancito.

Asimismo, en la actualidad se están realizando numerosas obras asociadas a la generación eólica y solar. En el marco del programa gubernamental RENOVAR se adjudicaron hasta Noviembre de 2018 contratos de abastecimiento de energía por 4466 MW tendientes a incrementar la capacidad instalada del sistema. Estas importantes obras, principalmente en el sector sur del SADI, en conjunto con proyectos de grandes centrales hidroeléctricas, requerirán del correspondiente refuerzo del sistema de transmisión para transportar la energía a los centros de consumo.

Dicho cambio estructural del SADI produce una modificación en su comportamiento dinámico, ya que varían los modos dominantes de oscilaciones electromecánicas, es decir, los modos de oscilación entre máquinas sincrónicas con más bajos amortiguamientos. Esto hace que sea necesario profundizar el análisis de la estabilidad de los sistemas de potencia, con herramientas capaces de estimar su estado de operación, prácticamente en tiempo real [4][5][6][7].

Una de las principales variables a considerar es la diferencia entre los ángulos de fase de las tensiones en nodos críticos del sistema. Cuando dicho ángulo aumenta, se corre el riesgo de alcanzar las condiciones que deriven en la inestabilidad del sistema y el eventual colapso de tensión. Asimismo, la frecuencia y el patrón de amortiguamiento de 
las oscilaciones pueden ser utilizados como indicadores de la proximidad de condiciones de inestabilidad.

Por tal razón, resulta de suma importancia disponer de un sistema de medición de alta resolución. El estado actual de la técnica de monitoreo y supervisión en los principales sistemas eléctricos del mundo se basa esencialmente en el empleo de Sincrofasores [8]. Los Sincrofasores son representaciones de variables de los sistemas eléctricos con una referencia temporal precisa y exacta. Dichas mediciones se realizan a través de ciertos dispositivos denominados PMUs (Phasor Measurement Units, por sus siglas en inglés).

Las PMUs realizan mediciones con una velocidad máxima típica de 1 fasor por ciclo, es decir 1 fasor cada $20 \mathrm{~ms}$ en sistemas de $50 \mathrm{~Hz}$ y 1 fasor cada 16,66 ms en sistemas de $60 \mathrm{~Hz}$. Esta velocidad supera notablemente a las velocidades obtenidas con sistemas SCADA, que son del orden de 1 dato cada 2 o 4 segundos.

Como resultado de las mediciones fasoriales, el operador del Centro de Control tiene a la vista varios diagramas fasoriales con las variables de todos los nodos de la red geográficamente dispersa, como si todas las variables fueran locales.

Tal como se mencionó anteriormente, en sistemas similares existentes en diferentes lugares del mundo, se ha ido adoptando para la obtención de las mediciones de alta resoluciones sistemas basados en Unidades de Medición Fasorial (PMU, por sus siglas en inglés).

Como ejemplo, en la Figura 2 se presenta la interfaz de un sistema de medición fasorial piloto, realizado por la Universidad de Florianópolis y la empresa GE/Reason en Brasil.

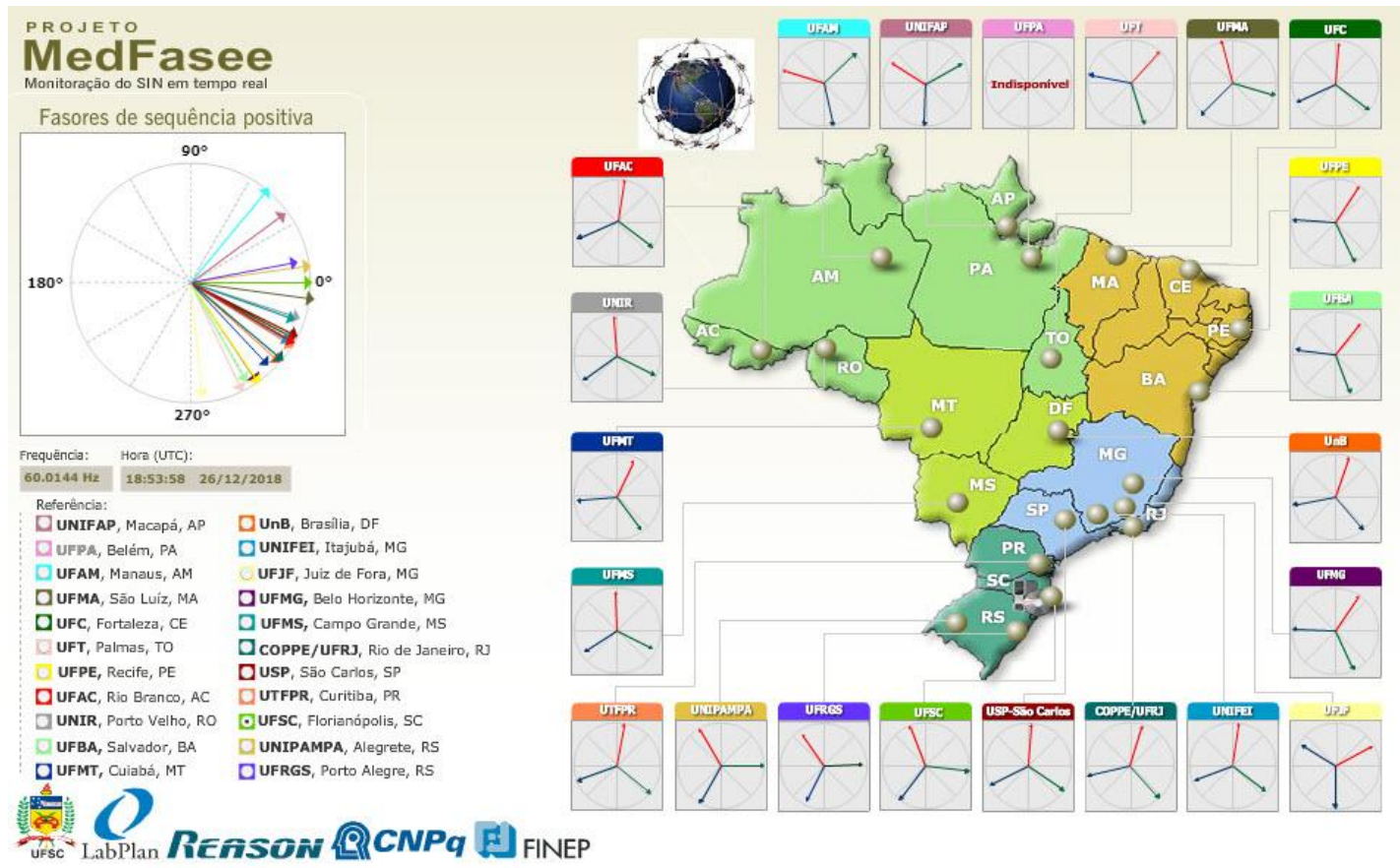

Figura 2. Interfaz sistema de medición fasorial piloto en Brasil. 
El gráfico presenta un diagrama fasorial (módulo y fase) de las tensiones en diferentes nodos del Sistema eléctrico de Brasil, y un diagrama fasorial con la composición de las mediciones de las tres fases de cada nodo, en el cual es relativamente simple estimar la diferencia de fase o diferencia angular.

La información obtenida, entonces, con este sistema de medición fasorial podrá alcanzar una resolución máxima de un dato cada $20 \mathrm{~ms}$ (y con una única base de tiempos) en comparación con los datos obtenidos cada 2 o 4 segundos (y sin sincronismo temporal) de un sistema SCADA tradicional. Esta elevada frecuencia de muestreo permite obtener información de fenómenos oscilatorios de frecuencias del orden de $10 \mathrm{~Hz}$, permitiendo analizar modos de oscilación electromecánica (interárea, locales e intraplanta) y oscilaciones subsincrónicas de baja frecuencia, como las que podrían ocurrir debido a la interacción entre turbinas de vapor que se encuentran vinculadas a largas líneas de transmisión con compensación serie (condición frecuente en el sector sur del SADI).

\subsection{Objetivos}

En esta Tesis de Doctorado se tiene por objetivo estudiar, desarrollar e implementar un sistema de medición fasorial completo, cubriendo todos los componentes básicos que conforman un sistema de medición de sincrofasores. Dichos componentes son:

Unidad de Medición Fasorial (PMU): Calcula los fasores de tensiones y corrientes de señales muestreadas con una base de tiempos universal provista por un reloj GPS según [9]. El paquete de datos de salida de una PMU está estandarizado en [10].

Comunicaciones: La transmisión de información de una PMU hacia un destino específico resulta primordial en los sistemas sincrofasoriales. La comunicación es provista típicamente a través de una red de área amplia privada (WAN por sus siglas en inglés), pero puede ser otro medio que ofrezca una seguridad y disponibilidad aceptables.

Concentradores (PDC): Reciben y sincronizan temporalmente los fasores de múltiples PMUs, de forma tal de producir un conjunto de datos sincronizados en el tiempo y en tiempo real. Los PDCs pueden intercambiar datos con otro PDC en otra zona geográfica.

Almacenamiento de Información: Para pode realizar procesamientos offline, es necesario almacenar los sincrofasores obtenidos. Los sistemas para el almacenamiento de la información pueden o no estar integrados con los PDCs.

Procesamiento de la Información: La obtención de información útil a partir del postprocesamiento de los sincrofasores representa una de las grandes ventajas de las mediciones sincrofasoriales. Para ello, se requiere de herramientas informáticas dedicadas, que permiten procesar la información de los sincrofasores en forma online y adicionalmente pueden contar con la capacidad de hacer procesamiento offline. 
De forma complementaria a la investigación teórica y aplicada, necesaria para la comprensión y el manejo de cada uno de los diversos componentes descriptos, en esta Tesis de Doctorado se presenta el desarrollo y la implementación de un sistema de medición fasorial completo, incluyendo tanto los componentes de hardware (PMU y comunicaciones) como de software (PDC, almacenamiento de la información y procesamiento de la información).

Dentro de los componentes de software se desarrollan los siguientes componentes:

- Un software de concentración de fasores (PDC), capaz de ser instalado en cualquier computadora personal con sistema operativo Windows, lo que lo hace completamente portable e independiente de un hardware específico.

- Un software de almacenamiento de fasores, capaz de ser instalado en cualquier computadora personal con sistema operativo Windows, para disponer de un registro de todos los sincrofasores procesados por el sistema y garantizar su disponibilidad para llevar a cabo procesamientos offline.

- Un software de procesamiento de la información, capaz de procesar la información suministrada por los fasores en tiempo real y detectar oscilaciones y situaciones de inestabilidad del sistema eléctrico. Dicho software de procesamiento se divide en dos partes fundamentales:

- Un módulo de procesamiento Online, en el cual se visualizan en forma gráfica los fasores utilizando diagramas fasoriales y de tendencias (gráficos con la evolución temporal de las variables registradas, como ser tensiones, corrientes, potencia y frecuencia). Este módulo es capaz de procesar en tiempo real los fasores y, en el caso de existir eventos que ameriten un análisis detallado, estima la amplitud, la frecuencia y el amortiguamiento de las oscilaciones presentes en la potencia mediante herramientas como el análisis Prony [11] [12].

- Un módulo de procesamiento Offline, en el cual se realiza un procesamiento de los fasores en una dada ventana de tiempo (seleccionable por el usuario) para extraer información asociada a los modos de oscilación presentes. Adicionalmente, este módulo cuenta con la capacidad de analizar archivos de datos COMTRADE, típicos de registradores rápidos de eventos, comúnmente empleados en los sistemas eléctricos de potencia.

Dentro de los componentes de hardware se desarrolla un prototipo de una PMU. Dicho equipamiento estará provisto con las herramientas de comunicaciones necesarias para establecer las comunicaciones entre la PMU y la unidad de concentración de fasores (PDC).

El trabajo de investigación y aplicación presentado en esta Tesis, a su vez, se enmarca dentro del Proyecto FONARSEC UREE No 004: "Sistema de Medición 
Fasorial para el Desarrollo de Redes Inteligentes". Dicho Proyecto es financiado por el Ministerio de Ciencia y Técnica de la Nación (MINCyT) y se encuentra conformado por el Instituto Nacional de Tecnología Industrial (INTI), el Centro de Simulación Computacional (CSC Conicet-UBA), el IITREE-FI-UNLP y la empresa Computec SRL.

En ese marco, y para cumplimentar con las tareas correspondientes al IITREE-FIUNLP, se diseñan e implementan todas las herramientas de software mencionadas anteriormente como primera etapa del desarrollo previsto. Dichas herramientas serán transferidas a la Compañía Administradora del Mercado Mayorista Eléctrico Sociedad Anónima (CAMMESA) para supervisar en tiempo real el estado de operación del Sistema Argentino de Interconexión (SADI).

En la Figura 3 se presenta un diagrama esquemático del sistema de medición fasorial completo.

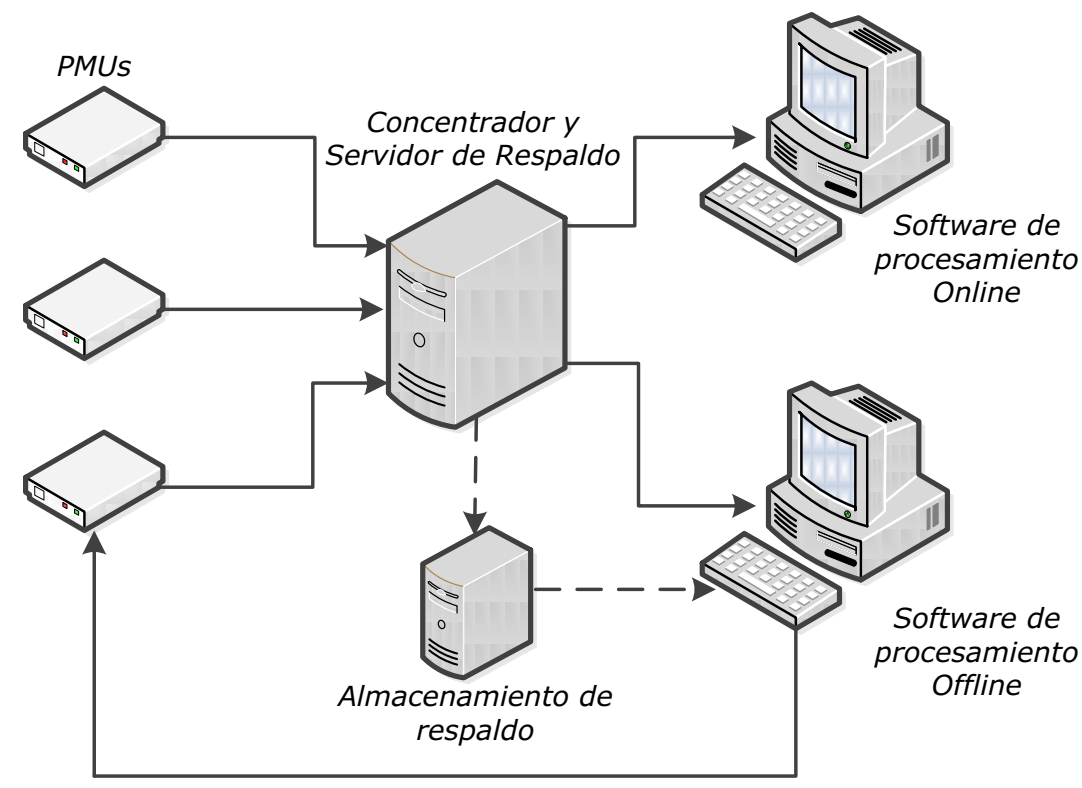

Figura 3. Diagrama esquemático del sistema de medición fasorial.

\subsection{Estructura de la Tesis}

La tesis está estructurada en doce capítulos, de los cuales el primero corresponde a la presente introducción. Los restantes capítulos se estructuran de la siguiente manera:

Capítulo 2: Se realiza una descripción detallada de los fenómenos de oscilaciones subsincrónicas que pueden afectar a un sistema eléctrico. Se presenta también una descripción de los fenómenos oscilatorios en términos de sus frecuencias y la clasificación típicamente utilizada. 
Capítulo 3: Se realiza una descripción detallada de cada componente de un sistema de medición fasorial, analizando sus funciones y características. Se presenta también una descripción de sistemas implementados comerciales y de código abierto.

Capítulo 4: Se desarrolla un análisis y descripción de los requerimientos y métodos de transmisión necesarios para las comunicaciones dentro del sistema. Dicha descripción presenta las características de los métodos de transmisión más utilizados en la tecnología actual junto con ensayos realizados para su evaluación. De esta manera se selecciona el método a utilizar en los diferentes componentes abarcados por la presente tesis.

Capítulo 5: Se describen las características e implementación del software Concentrador de Sincrofasores, describiendo la estrategia seguida para el procesamiento rápido y en tiempo real de los sincrofasores recibidos desde múltiples PMU para su ordenamiento y sincronización temporal.

Capítulo 6: Se presenta y caracteriza la estructura del Software de almacenamiento de Sincrofasores y Servidor de Respaldo implementado. Se describen las funciones de cada bloque, la estructura de la Base de Datos y la interfaz de usuario correspondiente.

Capítulo 7: Se desarrolla un análisis y descripción de la estructura general del Módulo de Procesamiento Online implementado en la presente tesis. Dicha descripción presenta las funciones de cada bloque de dicho módulo así como de las características del procesamiento Prony implementado para la detección automática de modos de oscilación. Se detallan también las pruebas realizadas al software para la validación de sus resultados.

Capítulo 8: Se presenta y caracteriza la estructura general del Módulo de Procesamiento Offline implementado. Se incluyen las funciones de cada bloque de este módulo así como de las características del procesamiento FFT (Transformada Rápida de Fourier, por sus siglas en inglés) y Prony implementado.

Capítulo 9: Se presenta la PMU. Dicha descripción incluye la comparación y evaluación de los algoritmos de procesamiento analizados e implementados junto con la arquitectura de hardware implementada y los resultados obtenidos.

Capítulo 10: Se presentan los ensayos realizados a la Unidad de Medición Fasorial y al sistema en su conjunto, describiendo las pruebas y los resultados obtenidos.

Capítulo 11: Se presentan las conclusiones del trabajo realizado y las líneas de investigación futuras.

\subsection{Publicaciones realizadas sobre el tema de tesis}

- "Comparison of Synchrophasor Estimation Methods in Simulation Environment and Real Hardware Implementation". P. Leibovich, F. Issouribehere, J. Barbero. 2018 IEEE Power Engineering Society (PES). Portland, Oregon, Estados 
Unidos. 5 al 9 de Agosto de 2018. Trabajo 18PESGM0550. ISBN 978-1-53867703-2.

- "Sistema de Medición Fasorial para Redes Inteligentes". Dr. H. Laiz, Ing. F. Issouribehere, Dra. C. Galarza, Ing. G. Estivariz, Lic. L. Di Lillo, Dr. L. Rey Vega, Ing. L. Domínguez Posse, Ing. O. Jalon, Ing. P. Leibovich, Ing. J. Barbero, Ing. G. Barbera, Ing. F. Messina, Ing. P. Marchi, Ing. J. Zuloaga, Ing. G. Alessandrini. Congreso Internacional de Distribución Eléctrica (CIDEL). Ciudad de Buenos Aires, Argentina. 24 al 26 de Agosto de 2018.

- "Métodos de estimación de Sincrofasores. Análisis, evaluación e implementación en entorno de simulación y en hardware". Autores: P. Leibovich, F. Issouribehere, J. Barbero. Articulo aceptado para su publicación en el XVIII Encuentro Regional Iberoamericano de CIGRÉ (XVIII ERIAC). Foz de Iguazú, Brasil, 19 al 23 de mayo de 2019. ISBN 978-85-906780-1-4.

- "Ensayo y comparación de métodos de transmisión de Sincrofasores sobre redes Ethernet". Autores: P. Leibovich, F. Issouribehere, J. Barbero. Articulo aceptado para su publicación en el XVIII Encuentro Regional Iberoamericano de CIGRÉ (XVIII ERIAC). Foz de Iguazú, Brasil, 19 al 23 de mayo de 2019. ISBN 97885-906780-1-4.

- "Synchrophasor communication over Internet: performance analysis of different methods based on real experiences". P. Leibovich, F. Issouribehere, J. Barbero. Artículo aceptado para su presentación en el Congreso 2019 IEEE Power Engineering Society (PES). Atlanta, Georgia, Estados Unidos. 4 al 8 de Agosto de 2019. Trabajo 19PESGM0341. ISBN pendiente. 


\section{Oscilaciones subsincrónicas en sistemas eléctricos de potencia}

\subsection{Introducción}

En un sistema de potencia tradicional, los generadores que lo componen se encuentran interconectados y en sincronismo operando a la misma frecuencia. En dicha condición, la potencia del sistema es provista por los generadores, generalmente de manera proporcional a la capacidad de cada uno de ellos, excepto que el operador del sistema modifique dicha condición.

En el caso de sistemas que operan a frecuencias diferentes, la interconexión también es posible empleando conversores de frecuencia o mediante enlaces de corriente continua. Éstos últimos también se pueden emplear en la interconexión de sistemas que operan con la misma frecuencia, pero presentan dificultades para mantener el sincronismo cuando son interconectados [2].

Los generadores de un sistema de potencia interconectado se mantienen en sincronismo mediante mecanismos de regulación propios de la interconexión. En pocas palabras, cuando una máquina pierde su velocidad de sincronismo, los restantes generadores transfieren potencia al sistema de manera tal de reducir dicha desviación en la velocidad de rotación.

Tal como se mencionó en el Capítulo 1, los sistemas interconectados de potencia requieren de un control para su operación. Dicho control se lleva a cabo de manera conjunta entre un operador manual y un control automático. El operador manual establece la potencia que deben suministrar los generadores en condiciones de estado estacionario del sistema, mientras que el control automático tiene como función principal la ejecución de ajustes en forma rápida para mantener la tensión y frecuencia del sistema dentro de los límites permitidos frente a cambios abruptos de la condición de operación del sistema.

Para llevar a cabo el control automático del sistema, los generadores cuentan con sistemas de control (comúnmente denominados Governor) que permiten mantener constante la velocidad de rotación del generador, así como sistemas para regular la tensión generada (AVR, por sus siglas en inglés).

En el marco de la búsqueda de confiabilidad del sistema y la calidad del servicio eléctrico, en todo sistema de potencia interconectado existen requerimientos respecto a la recuperación que deben tener los generadores frente a fallas en el sistema que son relevadas automáticamente. Históricamente, se utilizaron sistemas de control de tensión para prevenir la pérdida de sincronismo en los generadores frente a las fallas 
intempestivas. Actualmente, y con el objetivo de lograr una reducción de las oscilaciones de potencia en el sistema, se utilizan Sistemas de Estabilización de Potencia (PSS, por sus siglas en inglés).

La estabilidad de los sistemas de potencia, entonces, puede definirse como la capacidad de dichos sistemas para mantenerse en un estado de operación equilibrado bajo condiciones de operación normales así como la capacidad de recuperar dicho estado de equilibrio luego de ser afectado el sistema por una perturbación [5].

Las oscilaciones en el sistema de potencia son propias de sus características de funcionamiento, iniciándose debido a pequeños cambios de la carga conectada al sistema. Esto se debe a que, por motivos funcionales y económicos, los sistemas de potencia son operados en condiciones cercanas a los límites de estabilidad transitoria y de estado estacionario.

Por su dinámica intempestiva, cada nueva condición de carga puede provocar oscilaciones en el sistema. Dichas oscilaciones son aceptables en la medida en que estén afectadas por un elevado amortiguamiento, dado que el operador manual no cuenta tradicionalmente, con herramientas para tomar una decisión y mucho menos para prevenirlas.

Por lo tanto, las oscilaciones de potencia pueden llevar al sistema a una condición de inestabilidad que puede manifestarse de diferentes formas según la configuración del sistema y su estado de operación.

Para poder evaluar la estabilidad de un sistema de potencia, debe evaluarse el comportamiento del mismo cuando es sometido a una perturbación transitoria, que puede ser pequeña o de gran importancia.

Las pequeñas perturbaciones se producen continuamente en un sistema, debido a cambios en la carga conectada. Ante ellas, el sistema responde ajustándose automáticamente a la nueva condición de operación. En estos casos, todo sistema de potencia debe ser capaz de operar satisfactoriamente alimentando las cargas con la potencia requerida.

A su vez, un sistema debe ser capaz de soportar diferentes perturbaciones de distinta naturaleza, como pueden ser cortocircuitos en las líneas de transmisión, desconexiones de grandes generadores o cargas, o incluso la pérdida de conexión entre dos subsistemas del mismo. Frente a cualquiera de estas perturbaciones, la respuesta del sistema implica la actuación de diferentes equipamientos que lo componen. Por ejemplo, un cortocircuito en un elemento crítico del sistema seguido de una desconexión de dicho elemento mediante las protecciones correspondientes puede provocar una variación en el flujo de potencia del sistema, modificaciones de las velocidades de las restantes máquinas y variaciones en la tensión del sistema. La variación de tensión provoca la actuación de reguladores de tensión tanto en los generadores como en el sistema de transmisión, la actuación de controles de los generadores, cambios transitorios en la tensión y frecuencia que pueden afectar las cargas, entre otras. 
Sin embargo, en todas las perturbaciones que puedan afectar al sistema, la actuación de solo una parte de los equipamientos es significativa para la respuesta del sistema. Por lo tanto, en el análisis de la estabilidad del sistema, suelen realizarse suposiciones que tienden a simplificar el sistema destacando aquellos factores que tienen real influencia en el análisis de estabilidad.

\subsection{Estabilidad del ángulo de rotación de las máquinas generadoras}

Puede definirse a la estabilidad del ángulo de rotación de las maquinas sincrónicas de un sistema de potencia como la capacidad de las mismas de mantenerse en sincronismo [5]. Dicha capacidad está íntimamente relacionada con las oscilaciones electromecánicas de las máquinas generadoras. Para analizar dichas oscilaciones, es necesario realizar una breve descripción general del fenómeno electromagnético que da lugar a la generación eléctrica mediante máquinas sincrónicas.

En términos generales, la máquina sincrónica cuenta con dos elementos principales: el rotor y el estator. El rotor, que dispone de un devanado (el devanado rotórico) alimentado por corriente continua provista por un generador externo denominado excitatriz, es puesto en movimiento mediante una turbina. El movimiento del rotor con su devanado alimentado genera un campo magnético rotatorio que induce tensiones sinusoidales en los devanados del estator. La disposición geométrica de los devanados estatóricos permite obtener las tensiones trifásicas con el desfasaje correspondiente, mientras que la frecuencia de las tensiones generadas depende directamente de la velocidad de rotación del rotor.

Cuando un conjunto de máquinas sincrónicas son interconectadas en un sistema de potencia, las tensiones inducidas en los estatores de cada generador, y sus correspondientes corrientes en las cargas conectadas, deben tener la misma frecuencia. Este requerimiento implica que las velocidades de los rotores deben estar sincronizadas.

Una vez inducidas las tensiones en los devanados estatóricos, las corrientes de dichos devanados que alimentan una carga generan un campo, denominado estatórico. Los campos rotóricos y estatóricos reaccionan entre sí, tendiendo a alinearse dichos campos, para lo cual se produce un torque que se opone al movimiento del rotor. Dicho torque provoca, entonces, que la turbina vinculada al rotor deba aplicar un torque mecánico para mantener la rotación. Por lo tanto, la potencia de salida del generador solo puede modificarse mediante un cambio en el torque de la turbina.

El incremento del torque mecánico produce un aumento de la velocidad de rotación del rotor que permite ubicarlo en una nueva posición relativa al campo estatórico opuesto y, por lo tanto, una variación de la potencia de salida del generador. De la misma manera, una reducción del torque mecánico genera un retardo en la posición del rotor y una variación de la potencia generada. 
En condiciones de estado estacionario, los campos rotóricos y estatóricos tienen la misma velocidad de rotación pero con una diferencia angular dependiente de la potencia generada.

Para modelar la relación existente entre los ángulos de las distintas máquinas del sistema y el flujo de potencia existente, puede considerarse el diagrama de la Figura 4. El modelo consiste en dos máquinas sincrónicas (un generador y un motor) vinculadas mediante una línea de transmisión puramente inductiva, con su correspondiente reactancia $X_{L}$.

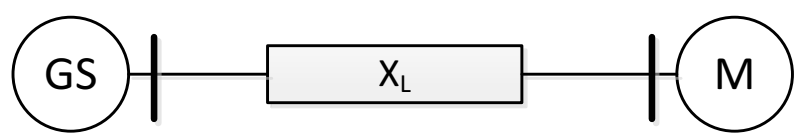

Figura 4. Modelo lineal de conexión entre máquinas sincrónicas.

Si se consideran los ángulos internos existentes entre los campos rotóricos y estatóricos existentes en cada una de las máquinas, el esquema de la Figura 4 puede modelarse mediante el circuito eléctrico de la Figura 5 y el diagrama fasorial de la Figura 6.

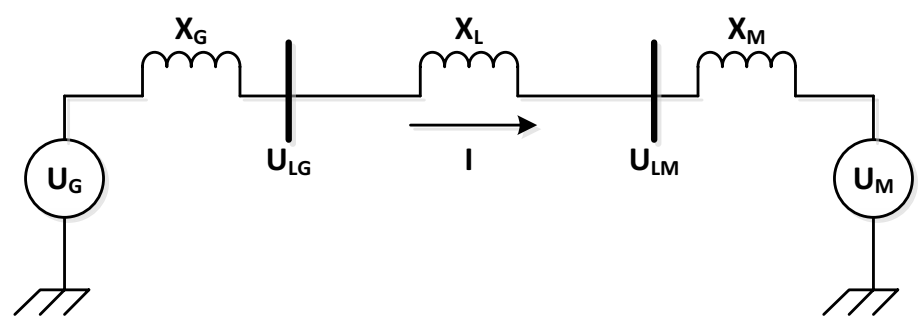

Figura 5. Esquema circuital de conexión entre máquinas sincrónicas.

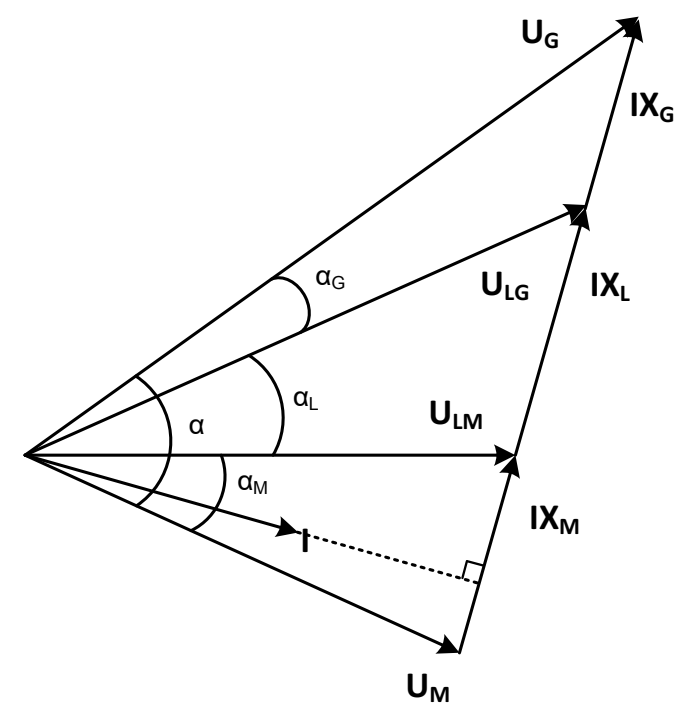

Figura 6. Diagrama fasorial de conexión entre máquinas sincrónicas.

En base al diagrama fasorial obtenido, puede calcularse la potencia transferida desde el generador al motor mediante la Ec. 2.1. 


$$
\mathrm{P}=\frac{\mathrm{U}_{\mathrm{G}} \mathrm{U}_{\mathrm{M}}}{\mathrm{X}_{\mathrm{TOT}}} \operatorname{sen}(\alpha) ; \mathrm{X}_{\mathrm{TOT}}=\mathrm{X}_{\mathrm{G}}+\mathrm{X}_{\mathrm{L}}+\mathrm{X}_{\mathrm{M}}
$$

De la Ec. 2.1 puede concluirse que la transferencia de potencia entre dos máquinas sincrónicas conectadas a un mismo sistema de potencia depende del ángulo existente entre ellas, siendo dicha relación no-lineal.

El modelo lineal considerado anteriormente muestra los efectos del ángulo de las máquinas sincrónicas cuando se consideran solo dos máquinas conectadas al sistema. Cuando se consideran múltiples generadores junto a los efectos de reguladores de tensión y otros sistemas de control, el análisis se vuelve más complejo pero, en todos los casos, el ángulo entre máquinas mantiene su influencia sobre el flujo de potencia existente.

\subsection{Análisis de la estabilidad de pequeña señal}

Tal como se describió en la sección 2.2, la estabilidad del sistema de potencia se define por su dinámica cuando se produce una perturbación mientras se encuentra funcionando en régimen estacionario. Dichas perturbaciones pueden ser clasificadas en perturbaciones de pequeña señal y perturbaciones de gran señal.

Las perturbaciones de pequeña señal se refieren a cambios en la carga conectada al sistema y son las perturbaciones típicas a las que se encuentra sometido el sistema durante su operación normal.

Las perturbaciones de gran señal se refieren a fallas en el sistema de potencia, provocadas, por ej., por cortocircuitos en las líneas de transmisión o pérdidas de conexión entre diferentes subsistemas.

La clasificación de las perturbaciones da lugar, entonces, a una clasificación de los problemas de estabilidad del sistema, que puede observarse en la Figura 7. 


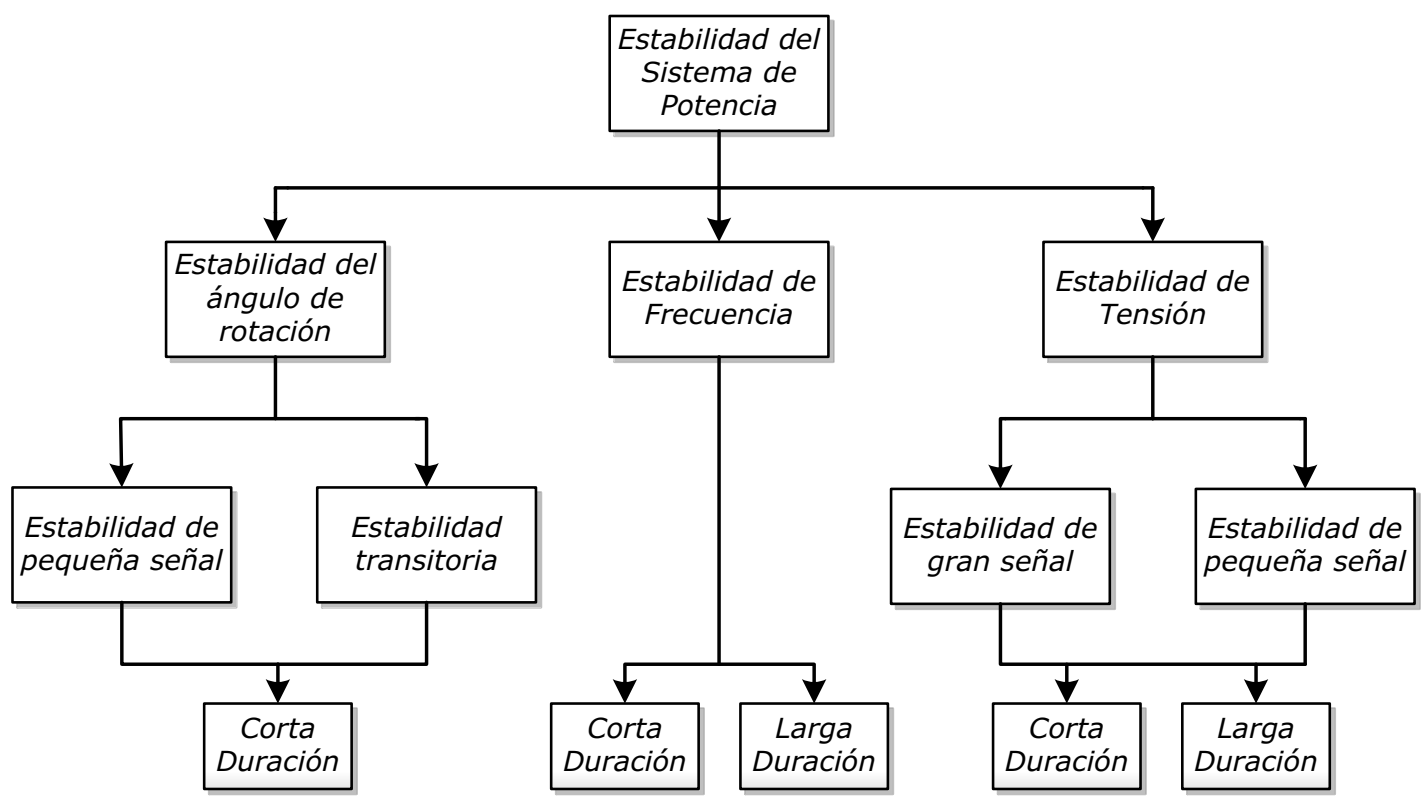

Figura 7. Clasificación de análisis de estabilidad.

La estabilidad transitoria se refiere a la capacidad del sistema de mantener el sincronismo cuando se producen perturbaciones transitorias severas. En ese caso, la respuesta del sistema incluye grandes variaciones del ángulo de rotación de las máquinas generadoras, siendo influencias por las no-linealidades de la relación ángulopotencia. Por lo tanto, la estabilidad depende tanto del estado inicial del sistema al momento de la perturbación como de la perturbación propiamente dicha. Usualmente, el estado estacionario del sistema una vez finalizada la perturbación es diferente del estado en que se encontraba antes del fenómeno analizado.

La estabilidad de pequeña señal se refiere, entonces, a la capacidad que tiene el sistema de mantener el sincronismo cuando se producen perturbaciones de pequeña magnitud. Esta característica de las perturbaciones permite analizar al sistema realizando simplificaciones y linealizando las ecuaciones de respuesta frente a los transitorios estudiados.

En el marco de la estabilidad de pequeña señal, la estabilidad del ángulo de rotación de las máquinas generadoras se convierte en la principal variable a considerar. Esto se debe a que, para mantener el sincronismo, es necesario mantener, y recuperar tras una perturbación, el equilibrio entre el torque electromagnético y el torque mecánico en cada máquina del sistema. La inestabilidad del sistema se traduce, entonces, en oscilaciones angulares crecientes entre generadores que conducen a pérdidas del sincronismo con respecto al resto de los generadores [13].

Las oscilaciones electromecánicas son analizadas como parte de la estabilidad del ángulo de rotación. En este caso, la oscilación se produce debido al comportamiento de los generadores frente a variaciones del ángulo de rotación.

Si el torque electromagnético de los generadores es constante e igual a su torque mecánico y se produce una perturbación que provoca un cambio abrupto en el torque 
electromagnético (por ejemplo, debido a una falla en una línea), el sistema experimentará una perturbación que promoverá o debilitará el movimiento del rotor de las maquinas interconectadas. Dicha situación podría llevar a una pérdida de sincronismo en algunos generadores.

Los generadores que sufren una reducción en su velocidad transfieren, de manera transitoria, la potencia que deben generar hacia otros generadores del sistema. Esta situación, entonces, puede resultar en dos tipos de oscilaciones.

Una de ellas corresponde a un sincronismo insuficiente, relacionado con la desviación del ángulo del rotor. La restante corresponde a una amortiguación insuficiente relacionada con la desviación de la velocidad del rotor.

La falta de amortiguación es el principal problema que existe en la estabilidad de pequeña señal y da como resultado una oscilación no amortiguada en el sistema de potencia que lo puede llevar al colapso.

Las oscilaciones electromecánicas generadas, entonces, adquieren gran importancia para la estabilidad del sistema. Dichas oscilaciones pueden ser muy bien diferenciadas en base a su frecuencia, adquiriendo entonces diferentes características [14].

- Modo de oscilación Intraplanta: Las máquinas que conforman una misma estación generadora oscilan unas contra otras. En este caso, la frecuencia de oscilación se ubica entre 2 y $3 \mathrm{~Hz}$ dependiendo de las potencias de las unidades y de la reactancia existente entre ellas. Se las denomina oscilaciones Intraplanta debido a que se manifiestan dentro de la estación, sin afectar al resto del sistema de potencia.

- Modo de oscilación Local: Un generador oscila contra el resto del sistema. En este caso, la frecuencia de oscilación se ubica entre 1 y $2 \mathrm{~Hz}$. Si al resto del sistema se lo modela como de potencia de cortocircuito infinita, la frecuencia y amortiguamiento de la oscilación varían según características propias de la maquina y su impedancia de conexión al sistema.

- Modo de oscilación Inter-Área: Este fenómeno se observa a lo largo de toda la red. En este caso, un grupo de generadores oscila contra otro grupo de generadores, con una frecuencia menor a $1 \mathrm{~Hz}$. El amortiguamiento de este modo de oscilación depende de las características de interconexión entre los grupos oscilantes, de la naturaleza de las cargas conectadas y su influencia sobre la dinámica de los controles de las maquinas oscilantes y del flujo de potencia existente en la interconexión. La oscilación inter-área es la principal causa de colapsos en el sistema de potencia.

- Modo de oscilación de Control: Las oscilaciones están asociadas a interacciones de los mecanismos de control de las máquinas con los sistemas de excitación y carga, debido a ajustes incorrectos en dichos mecanismos. La frecuencia de las oscilaciones varía entre 3 y $10 \mathrm{~Hz}$. 
- Modo de oscilación Torsional: La oscilación está asociada a los sistemas de control del eje de la turbina del generador y tiene una frecuencia que varía entre los 10 y los $46 \mathrm{~Hz}$.

\subsection{Modos de Oscilación en el SADI}

Tal como se analizó en la sección 2.3, gran parte de los elementos que componen los sistemas de potencia como ser generadores, sistemas de excitación, controles de velocidad-potencia y cargas, tienen una característica altamente no-lineal. Para poder llevar a cabo análisis de estos sistemas, se puede aplicar la teoría de sistemas no lineales. Sin embargo, la aplicación está restringida a sistemas simples y pequeños.

Para el análisis de la estabilidad de pequeña señal, puede utilizarse una descripción lineal, ya que no se alcanzan a poner de manifiesto las no linealidades para pequeñas variaciones en torno al punto de funcionamiento. En este caso, para poder analizar el comportamiento de un gran sistema y poder así determinar la naturaleza de las oscilaciones, la operación del sistema debe ser linealizada. En un sistema lineal, la dinámica puede ser descrita por una colección de modos. Un modo está caracterizado por su frecuencia y su amortiguamiento.

Existen diversos métodos que permiten llevar a cabo la linealización de sistemas y análisis de pequeña señal $[7][14][15][16]$. El método de análisis modal involucra un análisis de la matriz de estados del sistema, desacoplando las complejas relaciones existentes entre los distintos componentes y determinando los modos característicos de oscilación [5][6][13][14].

El análisis modal utiliza técnicas de autovalores para determinar la estabilidad ante pequeñas perturbaciones. Este método es de gran utilidad para determinar la necesidad de un sistema de control suplementario a los ya existentes ó determinar la sintonización adecuada de los controles existentes.

Existen diferentes herramientas informáticas que pueden ser aplicadas para realizar este tipo de análisis. Entre ellas puede mencionarse el módulo LSYSAN del programa PSS/E y un programa desarrollado por el IITREE-FI-UNLP en MATLAB denominado SIAM [17].

El Análisis Modal realizado mediante el software SIAM determina los Autovalores de la matriz de estados o modos de oscilación del sistema, expresados como partes real e imaginaria, o como frecuencia y amortiguamiento. Entre otros resultados, también es posible obtener los Factores de Participación, que corresponden a una medida de la participación de las distintas variables de estado del sistema en la conformación de un dado modo de oscilación.

En el estudio realizado en [17] con la herramienta SIAM, se obtienen los modos de oscilación presentes en el SADI con las interconexiones NOA-NEA y Comahue - Cuyo en operación. Dicho estudio se realizó en base a la Base de Datos de Modelos no 
lineales del SADI, que es proporcionada por CAMMESA. Algunos de los modos detectados son:

- Modo Local: Se detectó un modo de oscilación con una frecuencia de 0,976 $\mathrm{Hz}$ y que es inestable porque tiene amortiguamiento negativo. Este Modo Local corresponde al generador de la barra $\mathrm{N}^{\circ} 1634$ de Filo Morado.

- Modo Inter-Área: Se detectó un modo de oscilación de frecuencia 1,08 Hz con amortiguamiento del orden del 9,3\%. Este modo de oscilación corresponde a generadores que se encuentran en las áreas GBA (barras $\mathrm{N}^{\mathrm{o}}$ 3641 y No 3642) y Uruguay (barras $\mathrm{N}^{\circ} 98730$ y No 98121 ).

Las oscilaciones antes mencionadas corresponden a los modos de oscilación que típicamente pueden encontrarse en el SADI.

\subsection{Oscilaciones y PMUs}

Las Unidades de Medición Sincrofasorial permiten obtener, típicamente, una medición de las tensiones y corrientes del sistema cada $20 \mathrm{~ms}$, disponiéndose entonces de una frecuencia de muestreo de dichas magnitudes de $50 \mathrm{~Hz}$. A partir de ello, es posible afirmar que con las PMUs se cuenta con una frecuencia de muestreo lo suficientemente alta, según el criterio de Nyquist, para poder observar y detectar las oscilaciones de modo Intraplanta, Local o Inter-Área que pueden producirse en un sistema de potencia [18][19][20].

A modo de ejemplo, es posible analizar lo sucedido durante el colapso o "blackout" de la región occidental del sistema de potencia interconectado de EEUU y Canadá, producida el día 10 de Agosto de 1996, afectando a más de 7 millones de usuarios [2].

La sucesión de eventos que llevaron al colapso del sistema pudo ser registrada por equipamiento conectado para tal fin, independiente del sistema de control SCADA disponible al momento como método de operación y control del sistema de potencia.

En la Figura 8 puede observarse el flujo de potencia registrado en una de las principales líneas de transmisión del sistema. 


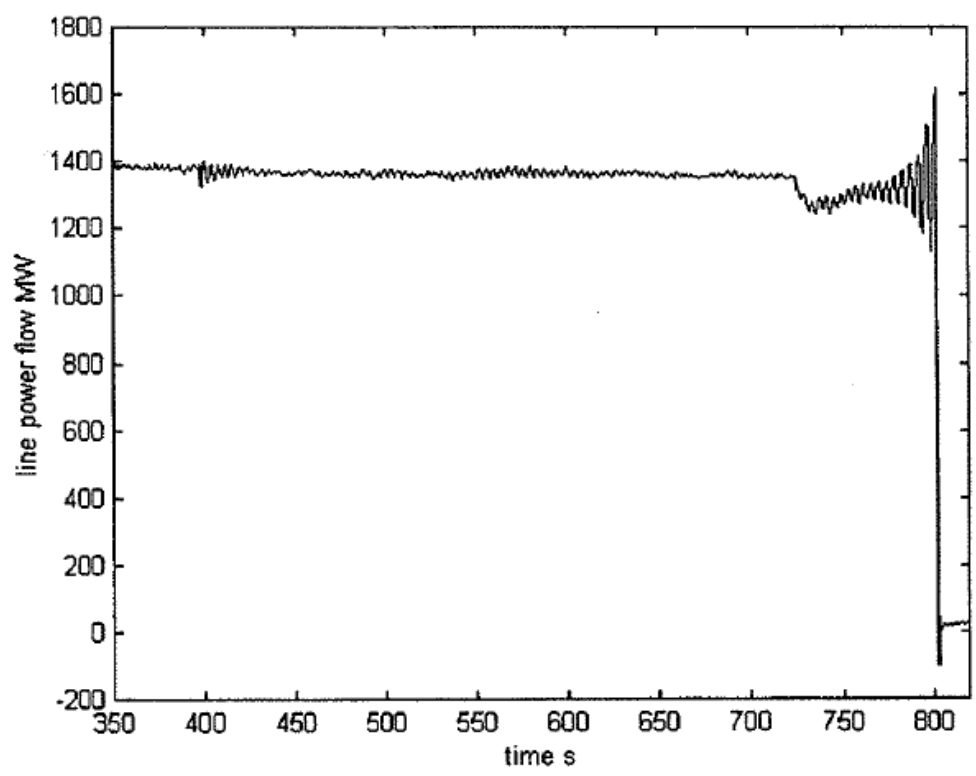

Figura 8. Flujo de Potencia durante la falla [2].

El registro comienza con el sistema en condiciones normales, observándose la evolución de la potencia hasta la desconexión total de la línea. En las Figuras 9 y 10 pueden observarse en detalle las respuestas del sistema frente a la falla inicial y a perturbaciones posteriores de menor amplitud.

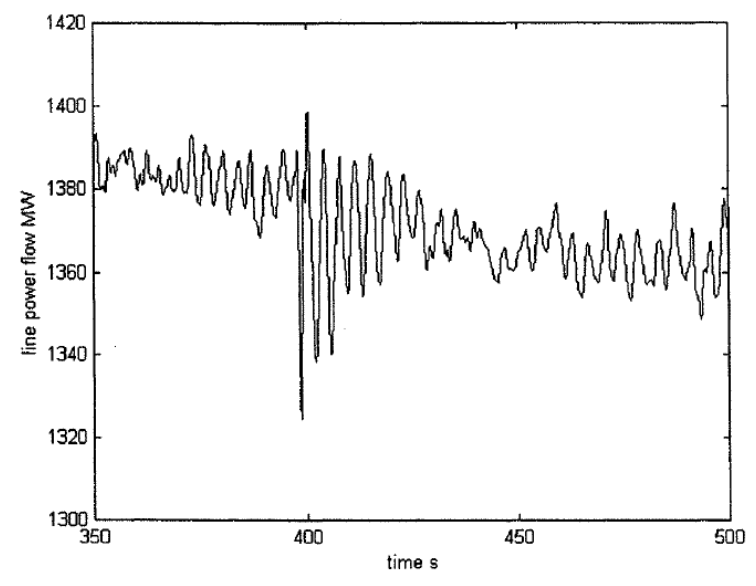

Figura 9. Oscilación durante la falla inicial [2].

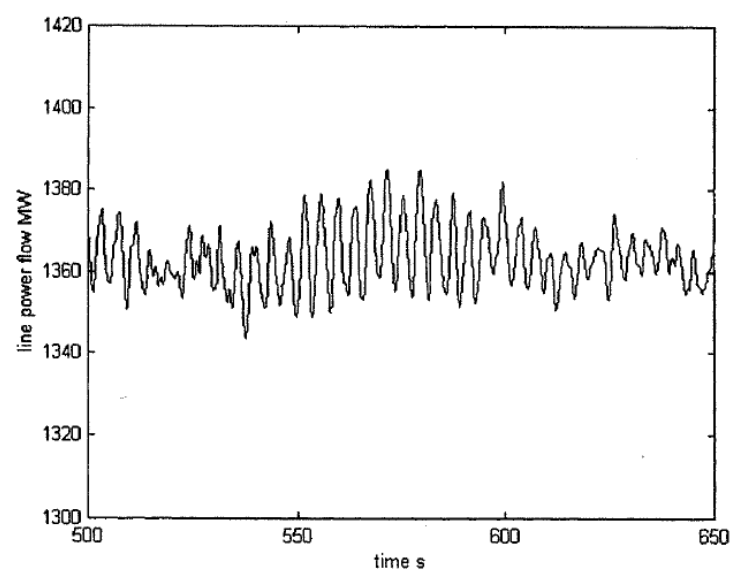

Figura 10. Oscilaciones durante fallas secundarias posteriores [2].

La potencia del sistema experimentó una oscilación amortiguada con una frecuencia de $0,26 \mathrm{~Hz}$ y una duración de $30 \mathrm{~s}$, aproximadamente. Dichas oscilaciones, no pudieron ser observadas por el operador del sistema de potencia debido a que el sistema SCADA provee una medición cada 2 a 4 segundos (lo que implica una frecuencia máxima observable de 0,5 a $0,25 \mathrm{~Hz}$ ).

En la Figura 11 puede observarse el colapso final del sistema, debido a oscilaciones no amortiguadas. 


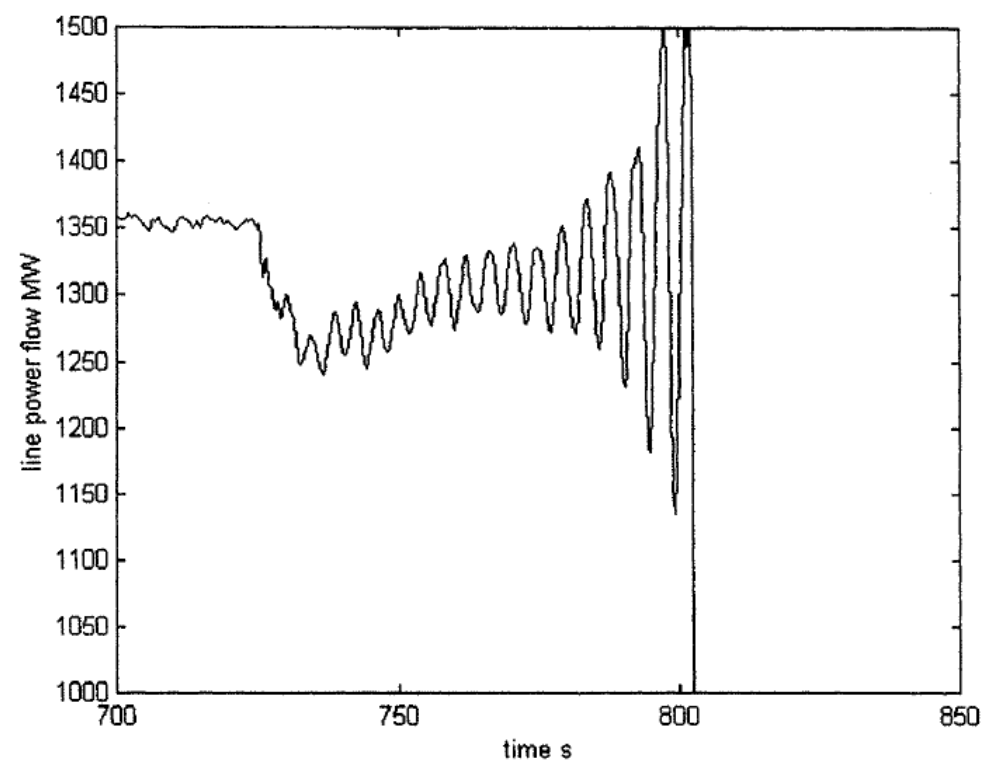

Figura 11. Oscilación final y colapso del sistema [2].

Análisis posteriores del fenómeno concluyeron que las oscilaciones amortiguadas iniciales derivaron en oscilaciones no amortiguadas debido a la sucesión de fallas y actuaciones automáticas de relés de protección que condujeron al colapso del sistema [21][22].

Antes de producirse la falla, algunas líneas de transmisión de $500 \mathrm{kV}$ se encontraban fuera de servicio debido a mantenimiento programado $\mathrm{y}$, dada la estación del año (verano), las tensiones del sistema se encontraban en sus límites inferiores debido al alto consumo energético.

El fenómeno comenzó con una falla en la línea de $230 \mathrm{kV}$ denominada RossLexington, en una zona próxima a Portland, Oregon. Los relés de protección procedieron a la apertura de la línea, desconectando también la línea LexingtonWoodland y la estación generadora denominada Swift. Luego, cuando la estación generadora MacNary se encontraba inyectando 480 Mvar a la red para mitigar el efecto de la desconexión anterior, las protecciones (debido a fallas en su operación) efectuaron la desconexión de dicha estación.

Por lo tanto, ante la pérdida de la inyección de potencia reactiva, las oscilaciones inter-área en la interconexión entre los estados de California y Oregon incrementaron su magnitud, teniendo un amortiguamiento negativo. Dicha situación derivó, finalmente, en la desconexión de la interconexión, causando la separación del sistema y el colapso definitivo.

Como consecuencia, se conformaron 4 islas con la pérdida de más de $30 \mathrm{GW}$ de carga. Las regiones desconectadas pueden observarse en la Figura 12. 


\section{Sequence of Significant Events}

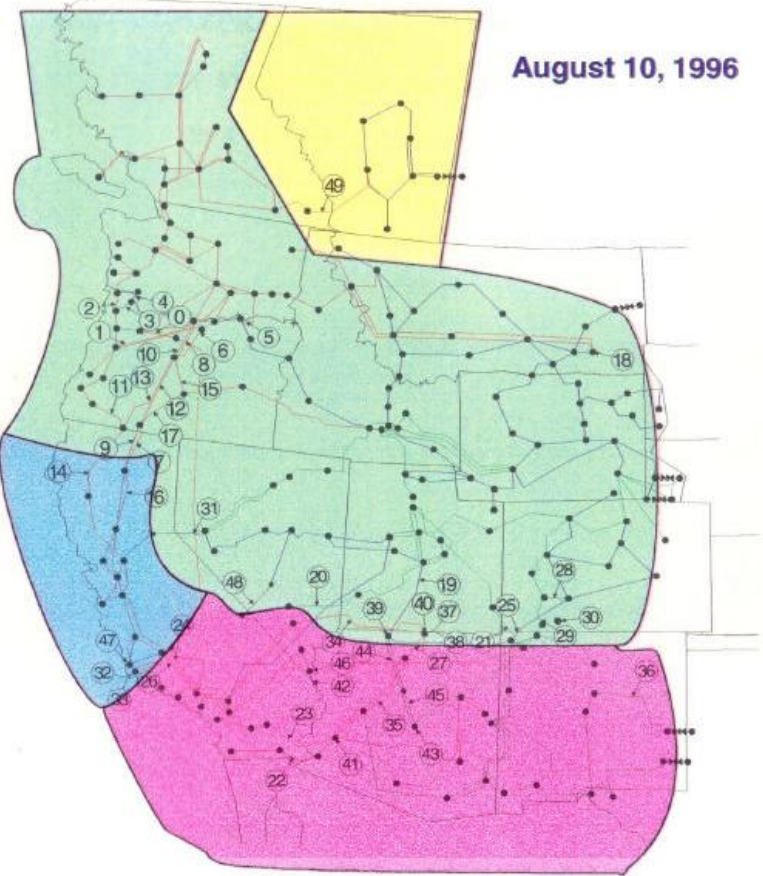

Islands Formed August 10, 1996

Figura 12. Islas conformadas como consecuencia de la falla [21]

Durante el fenómeno descripto anteriormente, el sistema de control disponible se basaba en el sistema SCADA. Dicho sistema provee, tal como se describió en el Capítulo 1, una medición cada 2 a 4 s. Por lo tanto, la perturbación no pudo ser observable por el operador del Sistema de Potencia.

Con la utilización de las mediciones sincrofasoriales, los operadores de sistemas de control cuentan con mediciones, típicamente, cada $20 \mathrm{~ms}$ lo que permite tener una observabilidad de fenómenos de hasta $25 \mathrm{~Hz}$. De esta manera, es posible afirmar que el uso de sincrofasores permite detectar, analizar y tomar acciones de control para actuar frente a perturbaciones similares [23][24][25]. 


\section{Sistema de medición sincrofasorial}

\subsection{Sincrofasor: Concepto y definición}

El concepto de fasor, y su definición clásica, fue introducido en el año 1893 [26] a partir de una señal sinusoidal de frecuencia $\mathrm{f}_{0}$, valor eficaz A y fase $\varphi$ constantes, tal como se muestra en la Ec. 3.1.

$$
x(t)=\sqrt{2} A \cos \left(2 \pi f_{0} t+\varphi\right)
$$

Con el objeto de poder representar dicha señal mediante un número complejo compuesto por su valor eficaz y fase, se define el correspondiente fasor según la Ec. 3.2, donde se muestra también la relación existente entre la señal original y el fasor.

$$
\overline{\mathrm{X}}=\mathrm{A} \mathrm{e}^{\mathrm{j} \varphi} \longrightarrow \mathrm{x}(\mathrm{t})=\mathbb{R}\left(\sqrt{2} \overline{\mathrm{X}} \mathrm{e}^{\mathrm{j} 2 \pi \mathrm{f}_{0} \mathrm{t}}\right)
$$

La representación fasorial de la señal permitió, históricamente, analizar el sistema de potencia considerando su estado estacionario, con frecuencia constante $(50 \mathrm{o} 60 \mathrm{~Hz}) \mathrm{y}$ fase inicial correspondiente a un instante de referencia temporal fijo y único para todo el sistema.

Con el crecimiento de las redes interconectadas y malladas, los ángulos de fase entre puntos de la red resultaron de suma importancia para el análisis de estabilidad de las mismas. En base a dichas necesidades, en la década de 1980 fue introducido el concepto de sincrofasor [27], posteriormente estandarizado mediante la norma IEEE 1344 [28] para finalmente ser formalizado mediante el estándar IEEE C37.118.1 en su versión actual IEEE 60255-118-1-2018 [9] e IEEE C37.118.2 [10] y sus modificaciones.

El sincrofasor se define en base a la medición de la señal de la Ec. 3.1, pero utilizando como referencia temporal el Tiempo Universal Coordinado (UTC, por sus siglas en inglés). De esta manera, se obtiene una única referencia temporal para todas las señales medidas en diferentes puntos de la red. Puede definirse, entonces, al sincrofasor como la representación de la señal $\mathrm{x}(\mathrm{t})$ de la Ec. 3.1 mediante la Ec. 3.2, pero donde la fase $\varphi$ corresponde al ángulo de fase instantáneo entre la señal $x(t)$ y una señal cosenoidal cuya frecuencia es la nominal del sistema y que se encuentra sincronizada con el tiempo UTC. Por lo tanto, la convención, establecida en [9], puede observarse en la Figura 13. 


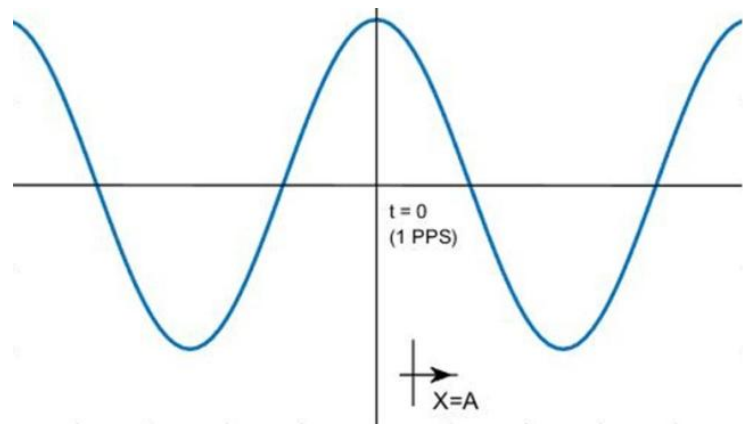

(a)

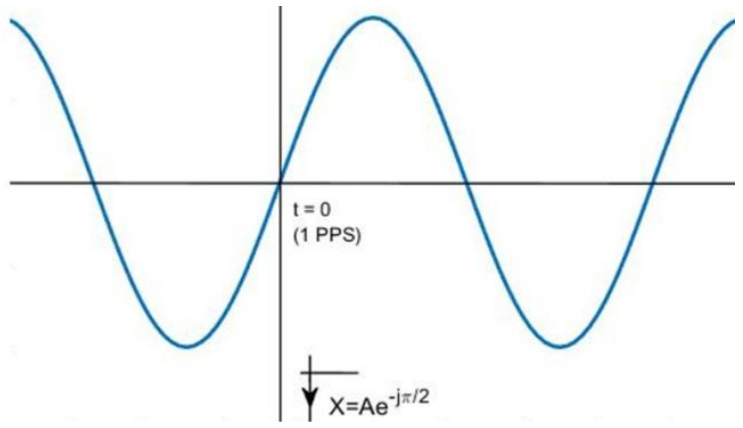

(b)

Figura 13. Convención de referencia temporal.

Se establece que, cuando el máximo de la señal medida ocurre coincidentemente con el instante de cambio del segundo del tiempo UTC, la fase del sincrofasor es cero (Figura 13-a). De la misma manera, si la señal es cero con pendiente positiva en el instante del cambio de segundo, la fase del sincrofasor resulta $-90^{\circ}$ (Figura 13-b).

Tal como se describió previamente, en estado estacionario se puede considerar constante la frecuencia, amplitud y fase de la señal a lo largo de la ventana de medición utilizada. Sin embargo, en condiciones más generales, tanto la amplitud como la fase pueden variar debido a, por ej., oscilaciones de potencia. Es por ello que para analizar el comportamiento del sistema de potencia tanto en condiciones estáticas como dinámicas, es necesario generalizar el modelo de señal tal como se muestra en la Ec. 3.3.

$$
x(t)=\sqrt{2} A(t) \cos \left(2 \pi \int f(t) d t+\varphi\right)
$$

En este caso, la amplitud A de la señal podría ser variable y, de forma similar, la frecuencia de la señal podría modificar su valor en el tiempo.

En el caso de considerar una frecuencia variable en el tiempo, es posible definir una función $\mathrm{p}(\mathrm{t})=\mathrm{f}(\mathrm{t})-\mathrm{f}_{0}$, resultando entonces que $\mathrm{p}(\mathrm{t})$ es la desviación instantánea de frecuencia respecto a la nominal. La representación generalizada de la señal resulta, entonces:

$$
x(t)=\sqrt{2} A(t) \cos \left(2 \pi \int f_{0}+p(t) d t+\varphi\right)=\sqrt{2} A(t) \cos \left(2 \pi f_{0} t+2 \pi \int p(t) d t+\varphi\right)
$$

En base al modelo de la Ec. 3.4, el sincrofasor en su forma más general se puede analizar según la Ec. 3.5.

$$
\bar{X}(t)=A(t) e^{j\left(2 \pi \int p(t) d t+\varphi\right)}
$$

En el caso de poder considerar amplitud constante y una desviación de frecuencia constante, tal que $\mathrm{p}(\mathrm{t})=\Delta \mathrm{f}$, el sincrofasor resulta

$$
\bar{X}(t)=A e^{j(2 \pi \Delta f t+\varphi)}
$$

Puede observarse, entonces, que en el caso de analizar una señal con desviación de frecuencia $\Delta \mathrm{f}$ constante medida a intervalos de tiempo constante, el sincrofasor rota uniformemente con una velocidad de giro $\Delta \mathrm{f}$ tal como se muestra en la Figura 14. 


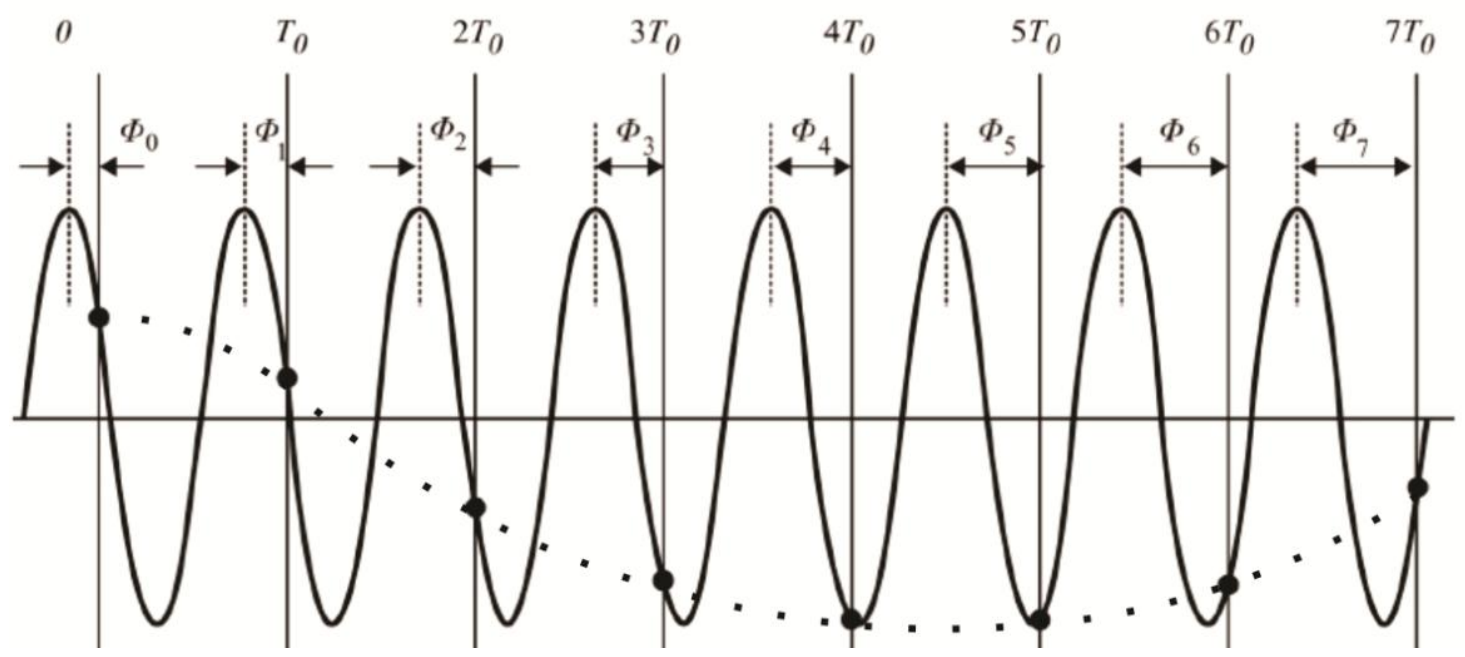

Figura 14. Medición periódica de señal con desviación de frecuencia constante [10].

\subsubsection{Frecuencia y Tasa de Variación de Frecuencia (ROCOF)}

La norma [9], que define el concepto y medición de sincrofasores, establece también la medición de la frecuencia y la tasa de variación de frecuencia. Para ello, puede escribirse a la Ec. 3.4 según la Ec. 3.7

$$
\begin{aligned}
& \mathrm{x}(\mathrm{t})=\sqrt{2} \mathrm{~A}(\mathrm{t}) \cos (\Phi(\mathrm{t})) \\
& \Phi(\mathrm{t})=2 \pi \mathrm{f}_{0} \mathrm{t}+2 \pi \int \mathrm{p}(\mathrm{t}) \mathrm{dt}+\varphi
\end{aligned}
$$

A partir de la definición de $\Phi(\mathrm{t})$, se define la frecuencia según la Ec. 3.8.

$$
\mathrm{f}(\mathrm{t})=\frac{1}{2 \pi} \frac{\mathrm{d} \Phi(\mathrm{t})}{\mathrm{dt}}=\mathrm{f}_{0}+\mathrm{p}(\mathrm{t})
$$

A su vez, el estándar define también el parámetro Tasa de Variación de Frecuencia (ROCOF, por sus siglas en inglés). En la Ec. 3.9 se puede observar la definición del mismo

$$
\operatorname{ROCOF}(\mathrm{t})=\frac{\mathrm{df}(\mathrm{t})}{\mathrm{dt}}=\frac{1}{2 \pi} \frac{\mathrm{d}^{2} \Phi(\mathrm{t})}{\mathrm{dt}^{2}}=\frac{\mathrm{dp}(\mathrm{t})}{\mathrm{dt}}
$$

\subsubsection{Medición de errores}

\section{Error Vectorial Total}

En términos generales, para medir la exactitud de la medición, la norma [9] define el Error Vectorial Total (TVE, por sus siglas en inglés) según la Ec. 3.10 donde $\hat{X}_{\mathrm{r}}$ y $\hat{\mathrm{X}}_{\mathrm{i}}$ corresponden a la parte real e imaginaria del sincrofasor medido mientras que $\mathrm{X}_{\mathrm{r}} \mathrm{y} \mathrm{X}_{\mathrm{i}}$ corresponden al sincrofasor real. 


$$
\mathrm{TVE}=\sqrt{\frac{\left(\hat{\mathrm{X}}_{\mathrm{r}}-\mathrm{X}_{\mathrm{r}}\right)^{2}+\left(\hat{\mathrm{X}}_{\mathrm{i}}-\mathrm{X}_{\mathrm{i}}\right)^{2}}{\mathrm{X}_{\mathrm{r}}^{2}+\mathrm{X}_{\mathrm{i}}^{2}}}
$$

En la Figura 15 se observa una representación gráfica del error. Un valor de TVE de $1 \%$ puede ser consecuencia tanto de un error de amplitud del $1 \%$ con un error de fase cero, como de una medición sin error de amplitud pero con un error de fase de $0,573^{\circ}$. En términos generales, un valor de TVE de 1\% puede deberse a cualquier combinación de valores intermedios de errores de amplitud y fase que determinen que el fasor $\hat{\mathrm{X}}$ se ubique sobre una circunferencia de radio 1 centrada en el extremo del fasor X.

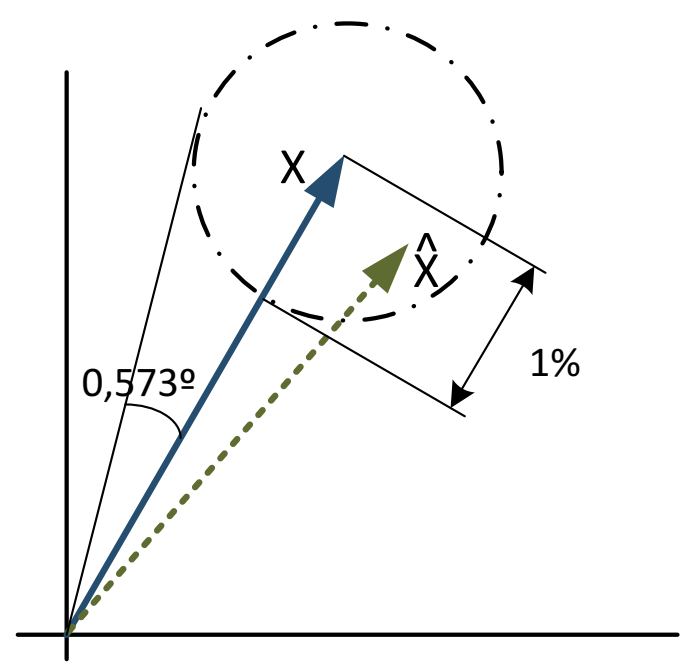

Figura 15. Diagrama Esquemático - Error Vectorial Total.

Tal como se puede concluir de la Ec. 3.10 y del análisis realizado anteriormente, el TVE tiene en cuenta diversos errores, incluyendo tanto errores de amplitud como de fase. En la Figura 16 puede observarse la variación de TVE para diferentes valores de error de fase cuando el error de magnitud se mantiene constante. Análogamente, en la Figura 17, se muestra la variación de TVE para diferentes valores de error de amplitud cuando el error de fase resulta constante. 


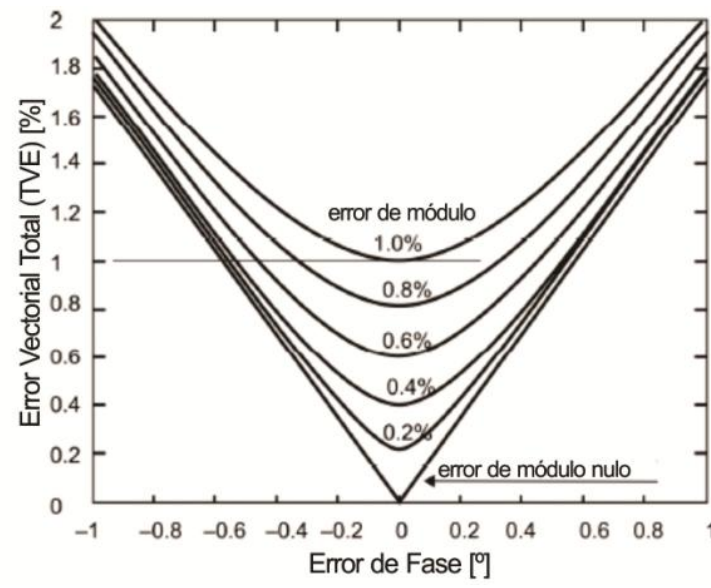

Figura 16. TVE en función del error en módulo [10].

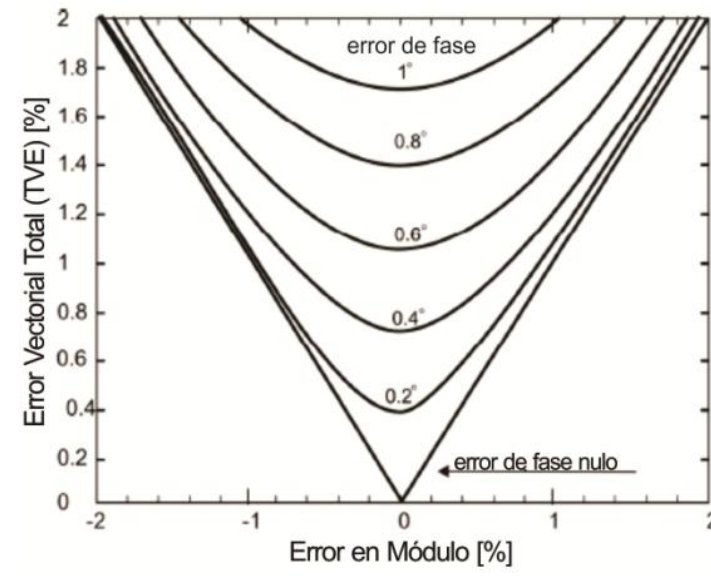

Figura 17. TVE en función del error en fase [10].

A su vez, el TVE tiene en cuenta errores de sincronización de la medición con el tiempo UTC. Para una señal de frecuencia $50 \mathrm{~Hz}$ (período de $20 \mathrm{~ms}$ ), un error de fase de $1^{\circ}$ corresponde a un error de sincronismo de 55,6 $\mu \mathrm{s}$. Por lo tanto, para no superar el límite de $0,573^{\circ}$ debe tenerse un error de sincronismo menor a $\pm 31,8 \mu \mathrm{s}$.

\section{Error de Frecuencia y ROCOF}

Así como la norma establece el TVE para evaluar la calidad de la medición del sincrofasor, también define parámetros que permiten evaluar la medición de frecuencia y ROCOF.

En ambos casos, se define al error como el valor absoluto de la diferencia existente entre el valor medido y el valor real. En las Ecs. 3.11 y 3.12, se observa la expresión del error de medición de frecuencia (FE, por sus siglas en inglés), y del error de medición de ROCOF (RFE, por sus siglas en inglés).

$$
\begin{aligned}
F E & =|\hat{f}(t)-f(t)| \\
R F E & =\left|\frac{d \hat{f}(t)}{d t}-\frac{d f(t)}{d t}\right|
\end{aligned}
$$

\subsection{Estructura general de un Sistema de medición sincrofasorial}

Tal como se describió anteriormente, las PMUs, encargadas de medir tensión, corriente y frecuencia para la obtención de los fasores, son dispuestas en diferentes zonas geográficas y de diferentes propietarios. El conjunto de fasores medidos por las distintas PMUs, son sincronizados mediante la misma base de tiempos obtenida a partir de un reloj GPS.

Habitualmente, las PMUs realizan mediciones con una velocidad máxima de 1 fasor por ciclo, es decir 1 fasor cada $20 \mathrm{~ms}$. Cada medición es transmitida mediante el correspondiente paquete de datos, estandarizado en la Norma IEEE C37.118.2 [10]. 
Los paquetes de datos son enviados a un Concentrador de Sincrofasores (PDC, por sus siglas en inglés). Los PDCs reciben y sincronizan temporalmente los fasores de múltiples PMUs, de forma tal de producir un conjunto de datos sincronizados en el tiempo y en tiempo real. Los PDCs pueden intercambiar datos con otro PDC en otra zona geográfica. El uso de múltiples PDCs permite la implementación de múltiples capas de concentración de datos.

Una vez sincronizados y combinados los sincrofasores provenientes de distintas PMUs, el PDC envía los datos a diferentes aplicaciones de Software, que utilizan el conjunto completo de datos, un muestreo de ellos o los datos históricos en conjunto con los modelos de simulación, a los efectos de proveer funciones de operación, control y supervisión del sistema. De esta manera, el Operador del Centro de Control tiene a su disposición las variables de todos los nodos de la red para realizar las operaciones que sean necesarias.

Las aplicaciones de Software se componen, comúnmente, de dos módulos independientes, tal como se observa en la Figura 18.

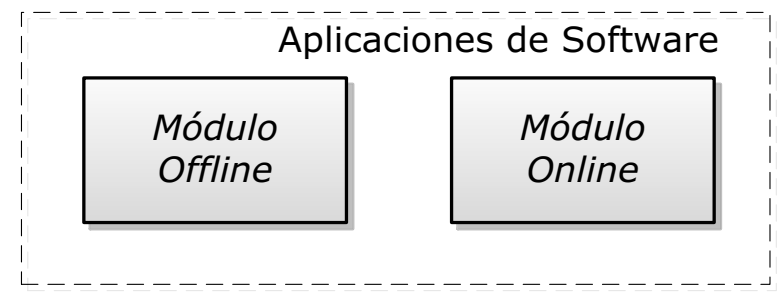

Figura 18. Diagrama en bloques - Software de procesamiento.

El módulo de procesamiento Online es el encargado de la graficación de los fasores mediante diagramas fasoriales, junto con los diagramas de tendencias o trazas donde se puede observar la evolución temporal de las variables registradas (tensiones, corrientes, potencia, frecuencia, entre otras). A su vez, es el encargado de realizar el procesamiento en tiempo real de los parámetros anteriormente mencionados, con el objetivo de obtener información aproximada en lo que se refiere a modos de oscilación presentes en la red, su frecuencia, amplitud y amortiguamiento. En la sección 3.2.1 se realiza una descripción más detallada de éste módulo.

El módulo de procesamiento Offline es el encargado de realizar un procesamiento pormenorizado de una dada ventana temporal, pudiendo obtener diversos parámetros de ella (modos de oscilación, su frecuencia, su amortiguamiento) calculados a través de diferentes procesamientos matemáticos. En la sección 3.2.2 se realiza una descripción más detallada de éste módulo.

A su vez, en algunos esquemas de medición se dispone también de sistemas de almacenamiento de información. Éstos son sistemas para almacenar los sincrofasores a los efectos de realizar procesamientos offline, y que pueden o no estar integrados con los PDCs. 
La estructura general del sistema de medición sincrofasorial puede observarse en la Figura 19.

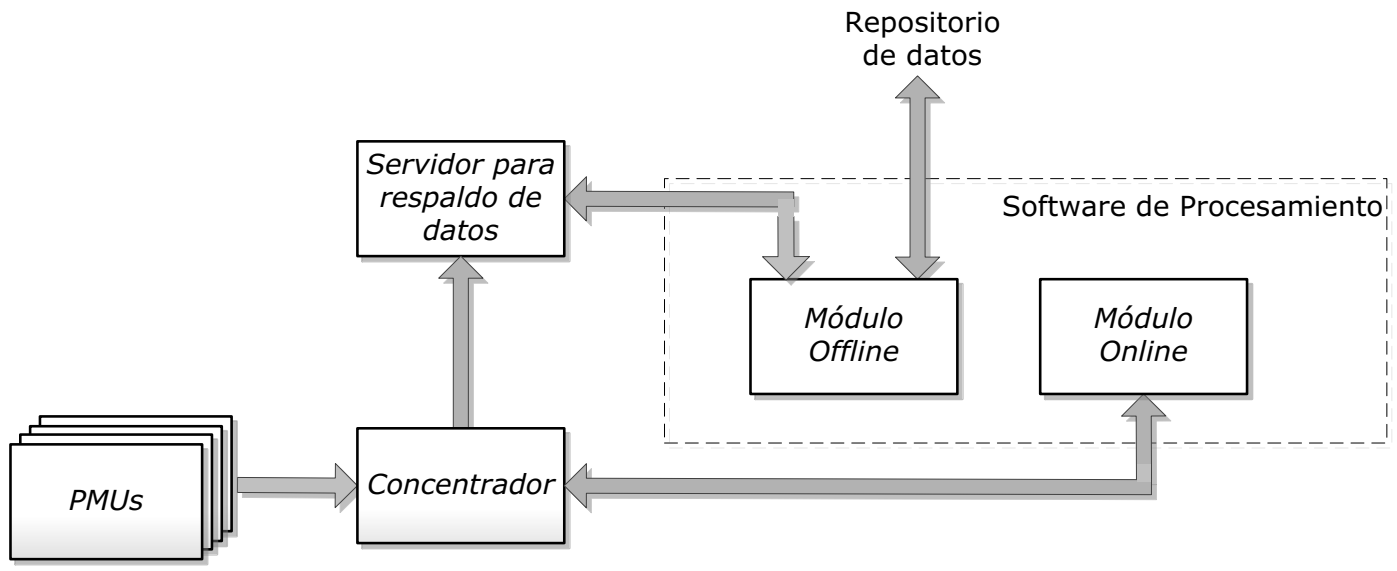

Figura 19. Diagrama en bloques - Sistema de medición sincrofasorial.

Dependiendo de las prestaciones requeridas para el sistema de monitoreo de fasores es posible elegir casi cualquier medio de comunicación entre los equipos de medición y el concentrador. Algunos ejemplos son:

- Fibra óptica

- $\quad$ Líneas telefónicas

- $\quad$ Satélite

- $\quad$ PLC (Power Line Carrier)

- $\quad$ Enlaces de microondas

- $\mathrm{GSM} / \mathrm{GPRS}$

La tecnología sincrofasorial es, actualmente, la más aplicada en sistemas de monitoreo de área amplia, (WAMS, por sus siglas en inglés), sistemas de monitoreo y control de área amplia (WAMC, por sus siglas en inglés) y sistemas de monitoreo, control y protección de área amplia (WAMPAC, por sus siglas en inglés). Estos sistemas se basan en una arquitectura que incluye cuatro componentes principales: PMUs, PDCs, software de procesamiento de sincrofasores y la red de comunicaciones para la transferencia de datos entre capas.

Las conexiones de las PMUs a las barras de las estaciones o subestaciones del sistema de potencia conforman la capa de Adquisición de Datos. La siguiente capa se denomina Organización de Datos, y corresponde al procesamiento de los datos de las PMUs por parte de los PDCs, generando las transmisiones de sincrofasores de múltiples PMUs ordenados temporalmente. Finalmente, la tercera capa se denomina Capa de Aplicación, donde los datos de las PMUs son procesados y monitoreados por las diferentes aplicaciones de visualización y control. 


\subsubsection{Software de procesamiento - Modulo Online}

El módulo de procesamiento Online tiene como objetivo brindar las visualizaciones de las variables medidas con el menor tiempo de latencia posible. En base a este principio, se presenta en la Figura 20 un diagrama en bloques del módulo en cuestión.

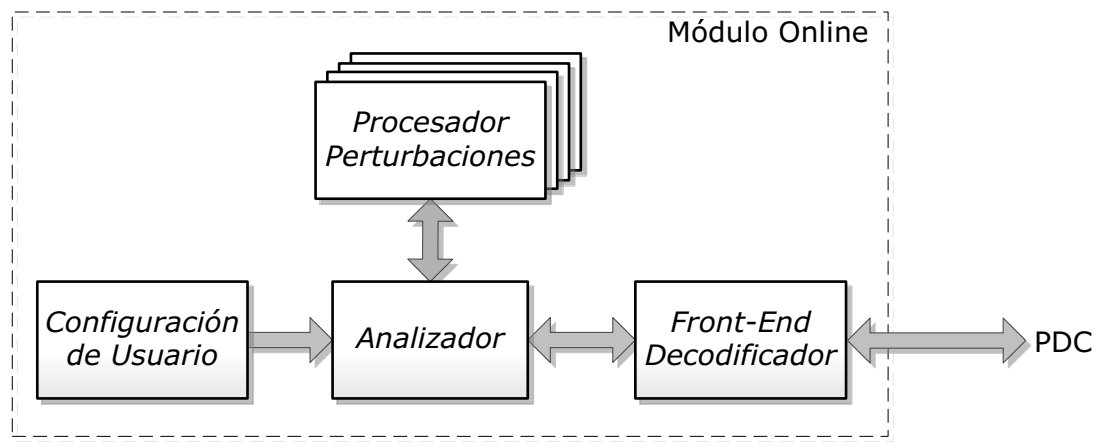

Figura 20. Diagrama en bloques - Módulo online.

El componente Configuración de Usuario es la interfaz de usuario para la configuración del módulo. Mediante esta interfaz, el usuario establece diversos parámetros relacionados al Concentrador o PDC, a las PMUs a analizar, frecuencias de actualización de datos, parámetros de visualización y factores para el procesamiento matemático, entre otros.

El componente denominado Analizador es el componente principal del módulo online. Dicho componente es el encargado de la administración temporal del procesamiento en tiempo real, de la visualización de los datos en sus gráfícos correspondientes (fasoriales y diagramas de tendencia) y del análisis para la detección de perturbaciones que ameriten su evaluación en forma automática.

El componente Procesador Perturbaciones tiene como función principal el cálculo optimizado de diferentes parámetros para la ventana de datos asignada que permitan caracterizar la perturbación analizada.

El componente Front End y Decodificador es la interfaz entre el presente módulo y el PDC. Este componente implementa las interfaces de comunicaciones correspondientes para la transferencia de datos con el concentrador junto con los buffers de datos necesarios. A su vez, es quien se encarga de la decodificación y control de la integridad de los datos, a partir de las especificaciones establecidas por la norma [10].

\subsubsection{Software de procesamiento - Modulo Offline}

El módulo de procesamiento Offline tiene como premisa brindar al usuario la mayor cantidad de herramientas de análisis de la ventana temporal seleccionada. En base a este principio, el modulo en cuestión puede esquematizarse con el diagrama en bloques de la Figura 21. 


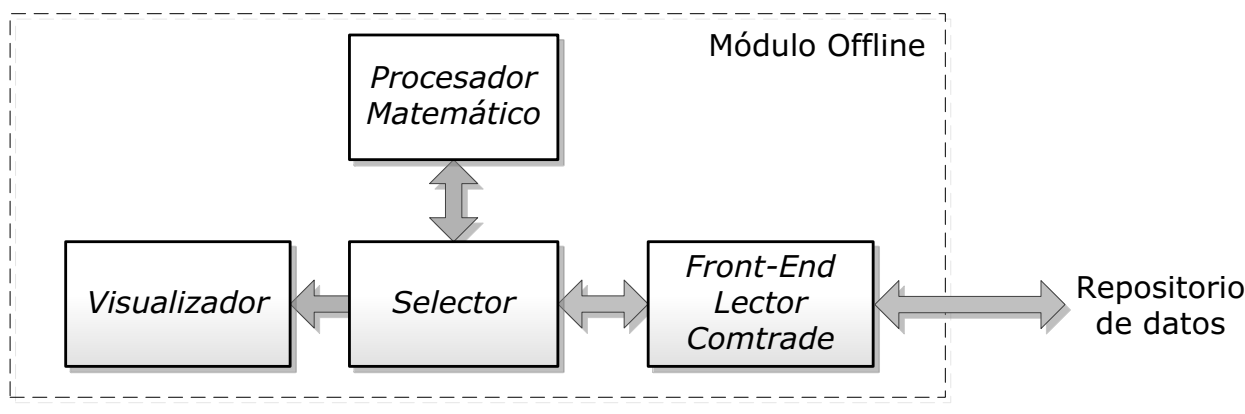

Figura 21. Diagrama en bloques - Módulo offline.

El componente Selector es la interfaz de usuario del presente módulo. Mediante la interfaz, es posible seleccionar la ventana temporal a analizar, configurar diversos parámetros relacionados a la visualización de la ventana y factores para el procesamiento matemático, entre otros.

El componente denominado Visualizador es el encargado de realizar los gráficos correspondientes (fasoriales y diagramas de tendencia, entre otros) en base a las configuraciones establecidas en el componente Selector.

El componente Procesador Matemático tiene como función principal el análisis mediante diferentes procesamientos de la ventana temporal seleccionada. Entre ellos pueden mencionarse métodos para la evaluación de los modos de oscilación presentes. Los resultados obtenidos se visualizan y grafican con el Visualizador.

El componente Front End y Lector Comtrade es la interfaz entre el presente módulo y el Repositorio de Datos. Para ello, este componente implementa las interfaces de comunicaciones correspondientes para la transferencia de datos $\mathrm{y}$, a su vez, se encarga de la decodificación y obtención de los datos de la ventana temporal seleccionada que se encuentran almacenados en archivos con formato COMTRADE [29]. COMTRADE (Common format for Transient Data Exchange for power systems) es un formato altamente difundido, que se utiliza para el almacenamiento de oscilogramas y otros datos relacionados a perturbaciones en sistemas de potencia.

\subsection{Sistema de medición sincrofasorial brasileño - Proyecto MedFasee y MedFasee Conosur}

El proyecto MedFasee es una iniciativa iniciada en el año 2003 por la Universidad Federal de Santa Catarina, Brasil (UFSC) mediante su Laboratorio de Planeamiento de Sistemas de Energía Eléctrica (LabPlan) destinado a la implementación de una red de medición de la tensión trifásica en la red de distribución de baja tensión para ser utilizada como un instrumento de desarrollo, difusión y uso académico de la tecnología.

El proyecto cuenta actualmente con PMUs instaladas en 25 universidades de Brasil, cubriendo las 5 regiones geográficas del territorio. Mediante dicho sistema, se han obtenido mediciones de diferentes fenómenos de la red [30] a través del análisis, 
principalmente, de la frecuencia del sistema y su comportamiento en dichas perturbaciones.

A partir de los resultados favorables obtenidos, el proyecto inició en el año 2009 un programa de colaboración con el operador brasileño del sistema eléctrico (ONS) con el objetivo de registrar y analizar las perturbaciones del Sistema Interconectado Nacional (SIN) brasileño para brindarle herramientas de diagnostico adicionales al ONS.

Con el objetivo de ampliar el alcance del proyecto para sistemas eléctricos diferentes al sistema brasileño, la UFSC se unió al INESC P\&D Brasil, creando un Observatorio de la Dinámica de los Sistemas Eléctricos de América del Sur. En este contexto, el proyecto extendió el MedFasee de Brasil hacia Chile y Argentina, conformando el proyecto MedFasee Conosur. Actualmente, el sistema cuenta, en Argentina, con PMUs instaladas en la Universidad Nacional de San Juan (UNSJ), la Universidad Nacional de Tucumán (UNT), la Universidad Nacional del Comahue (UNCO) y la Universidad Nacional de La Plata (UNLP). En la Figura 22 pueden observarse las mediciones sincrofasoriales recibidas de cada una de las universidades argentinas y chilenas.

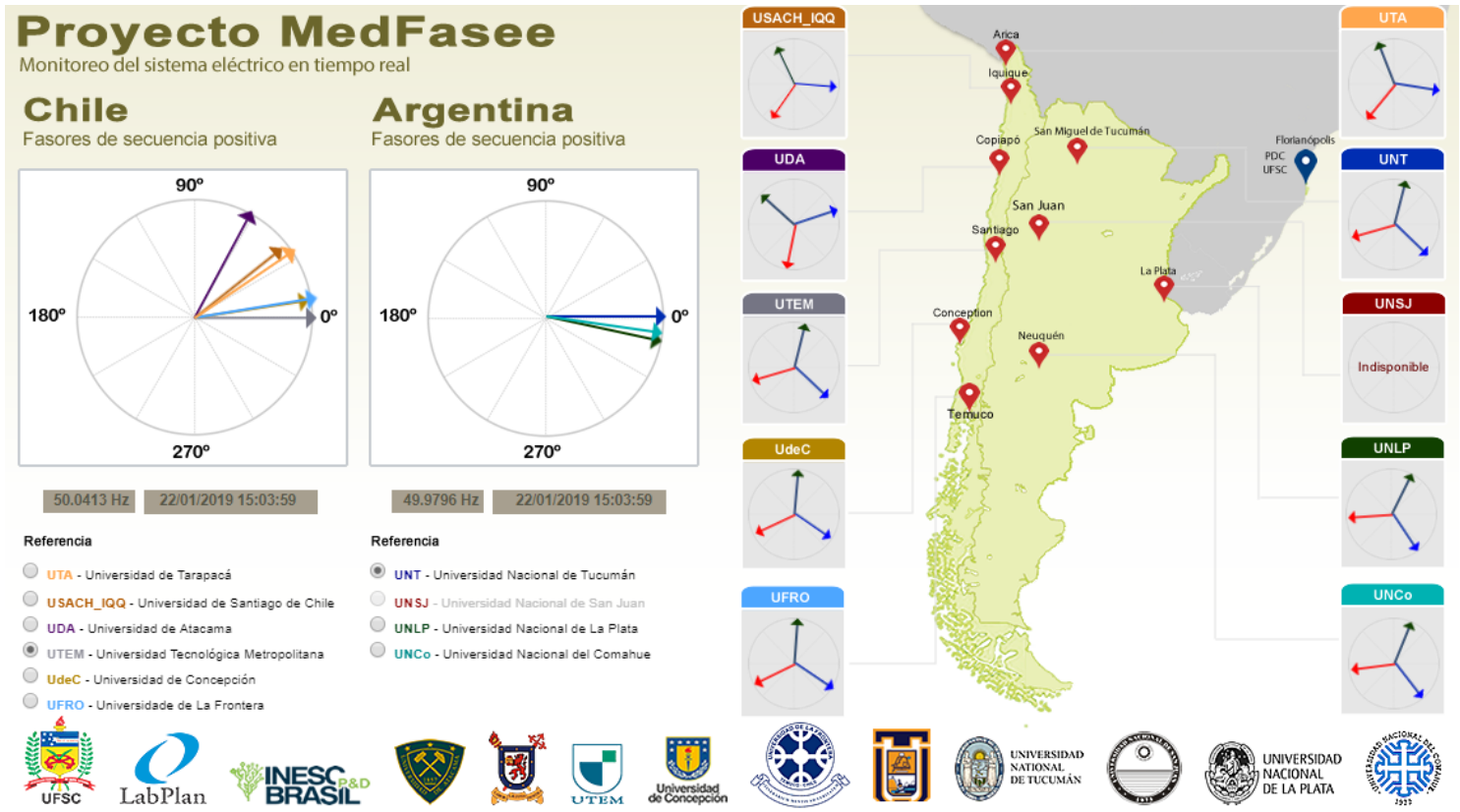

Figura 22. Interfaz sistema de medición MedFasee Conosur.

\subsubsection{Corte de Suministro Eléctrico - La Plata - 19 de Enero de 2019}

A modo de ejemplo, el día 19 de enero de 2019 a las 11:40 hs aproximadamente se produjo en la ciudad de La Plata un corte del suministro eléctrico [31] que fue registrado mediante la PMU instalada en el IITREE -UNLP conectada al sistema MedFasee. En la Figura 23 puede observarse la amplitud de la tensión de secuencia directa del sistema trifásico obtenida a partir del post-procesamiento de los sincrofasores medidos en la UNLP, UNT y UNCO. La PMU instalada en la UNSJ se encontraba fuera de servicio. 


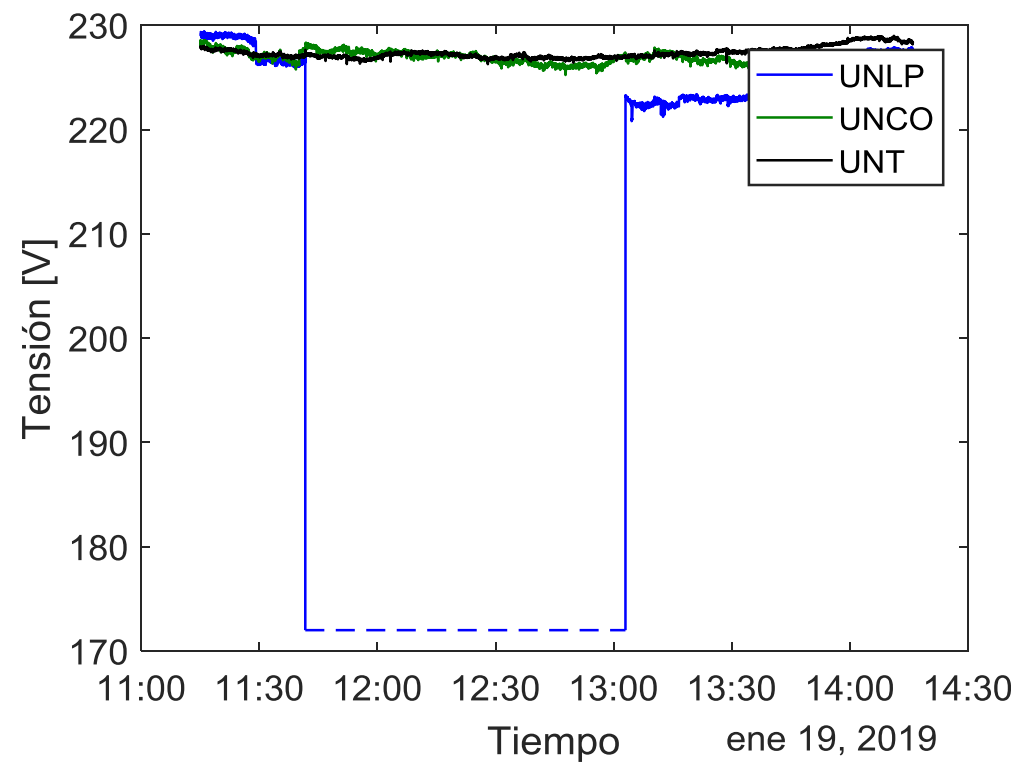

Figura 23. Tensión de Secuencia Directa - MedFasee.

Es importante mencionar que las líneas punteadas en el caso de la UNLP hacen referencia a la faltante de datos existente en ese período de tiempo, producto de la pérdida de alimentación en la PMU debida al corte de suministro. En la Figura 24 puede observarse el registro de la frecuencia en las mismas unidades de medición.

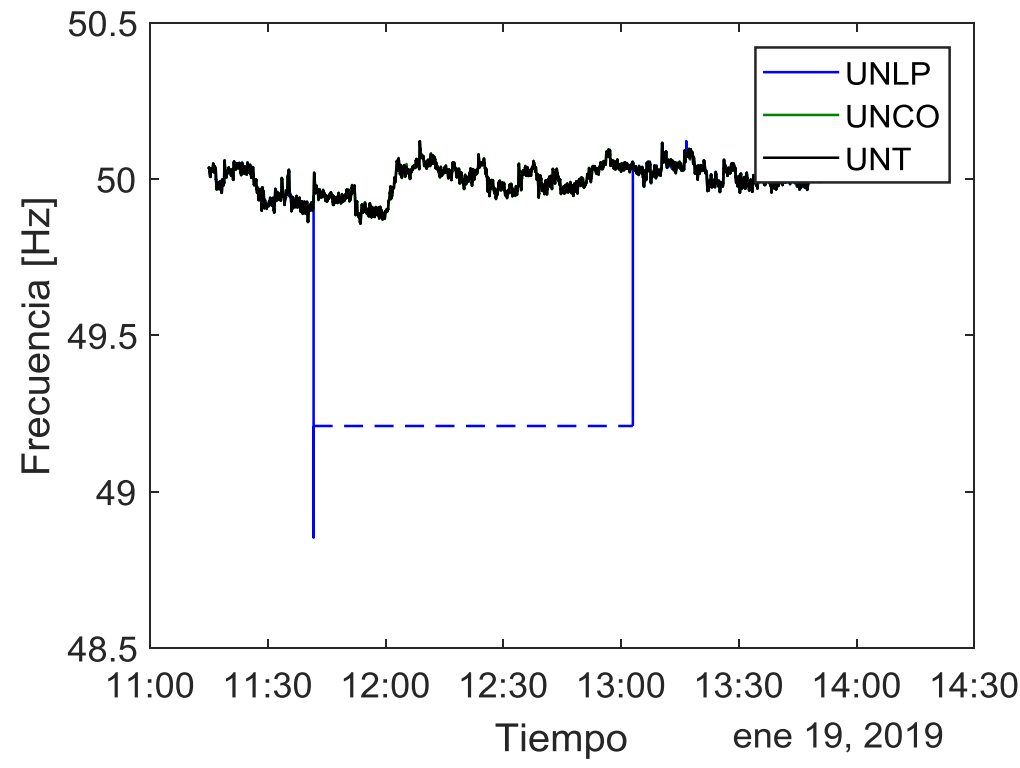

Figura 24. Frecuencia - MedFasee.

En la Figura 25 puede observarse el registro de amplitud de tensión de secuencia directa y frecuencia en la UNLP. 


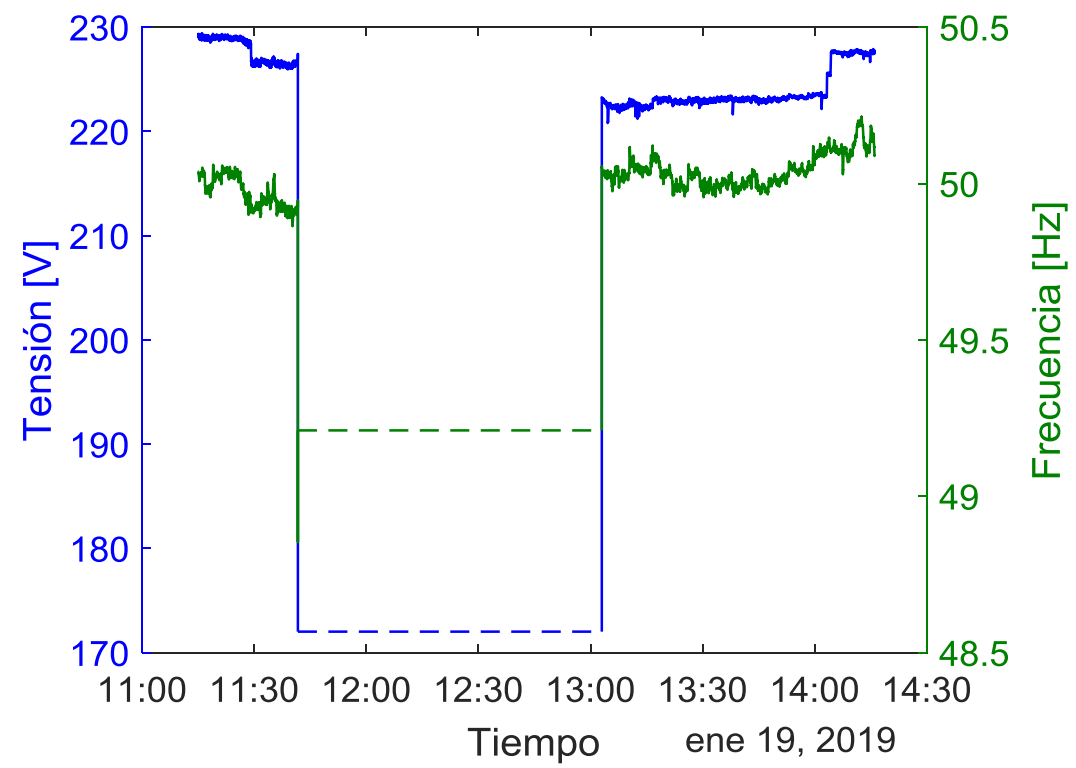

Figura 25. Tensión y frecuencia en UNLP - MedFasee.

En la Figura 26 se observa el detalle del registro de tensión de secuencia directa y frecuencia en la UNLP obtenido instantes antes del corte de suministro. Puede notarse en la traza de la frecuencia una caída súbita y posterior recuperación instantes antes de producirse el corte de suministro.

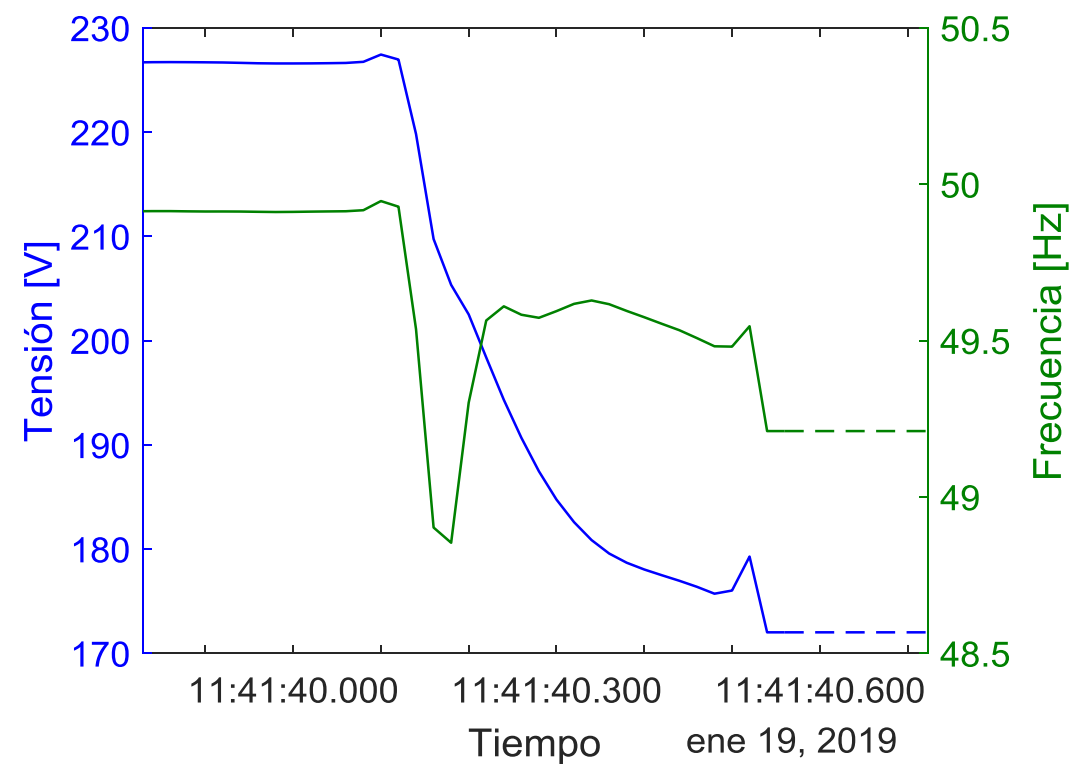

Figura 26. Detalle de Tensión y Frecuencia en UNLP - MedFasee.

Finalmente, en la Figura 27 puede observarse, en detalle, la recuperación de la tensión una vez restaurado el suministro eléctrico, observándose escalones de tensión debidos, normalmente, a la variación de taps de los transformadores de distribución. 


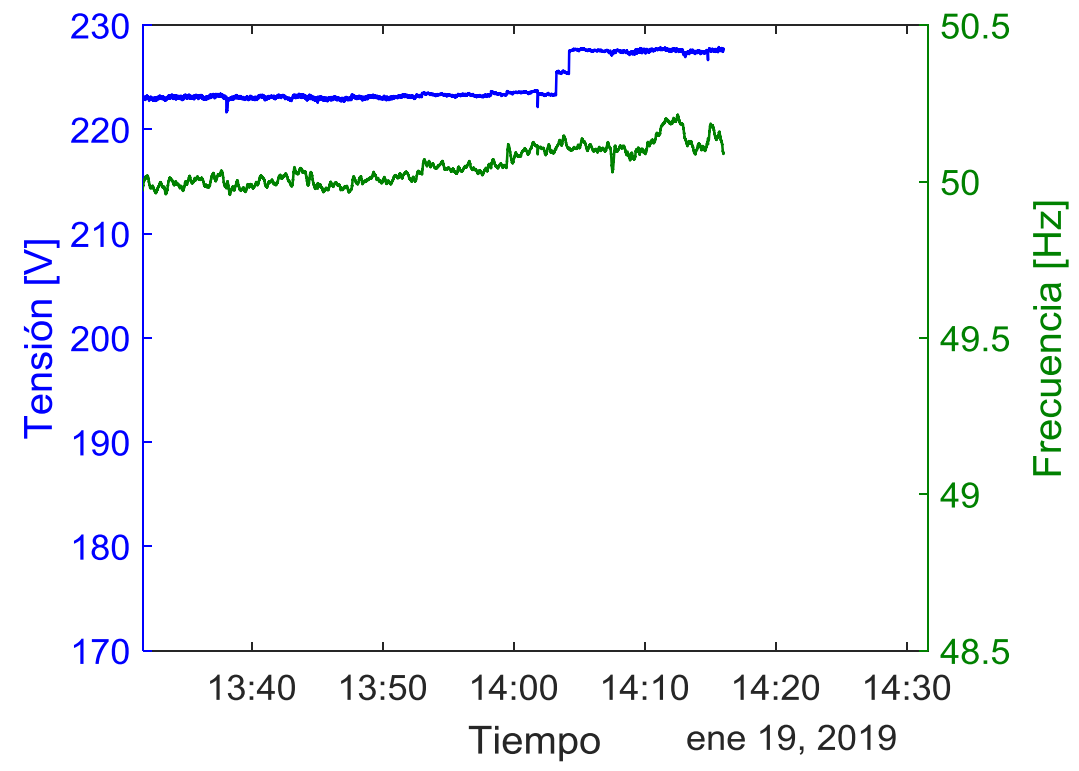

Figura 27. Detalle de Tensión y Frecuencia durante restauración de suministro en UNLP - MedFasee.

\subsubsection{Corte de Suministro Eléctrico - Ciudad Autónoma de Buenos Aires- 22 de}

\section{Enero de 2019}

El día 22 de enero de 2019 a las 18:05 hs aproximadamente se produjo en la Ciudad Autónoma de Buenos Aires un corte del suministro eléctrico [32] debido a un incendio ocurrido en la subestación Morón de la distribuidora EDENOR, que fue registrado mediante la PMU instalada en el IITREE -UNLP conectada al sistema MedFasee. En la Figura 28 puede observarse la amplitud de la tensión de secuencia directa del sistema trifásico obtenida a partir del post-procesamiento de los sincrofasores medidos en la UNLP, UNT y UNCO.

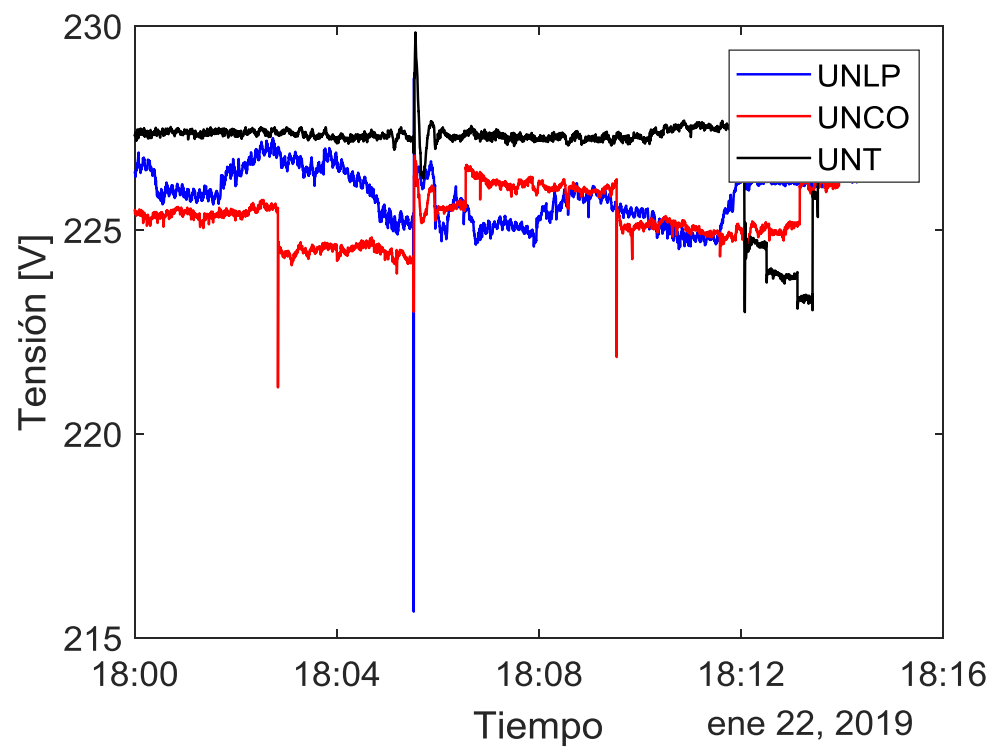

Figura 28. Tensión de Secuencia Directa - MedFasee. 
En la Figura 29 se observa el registro de la frecuencia en las mismas locaciones.

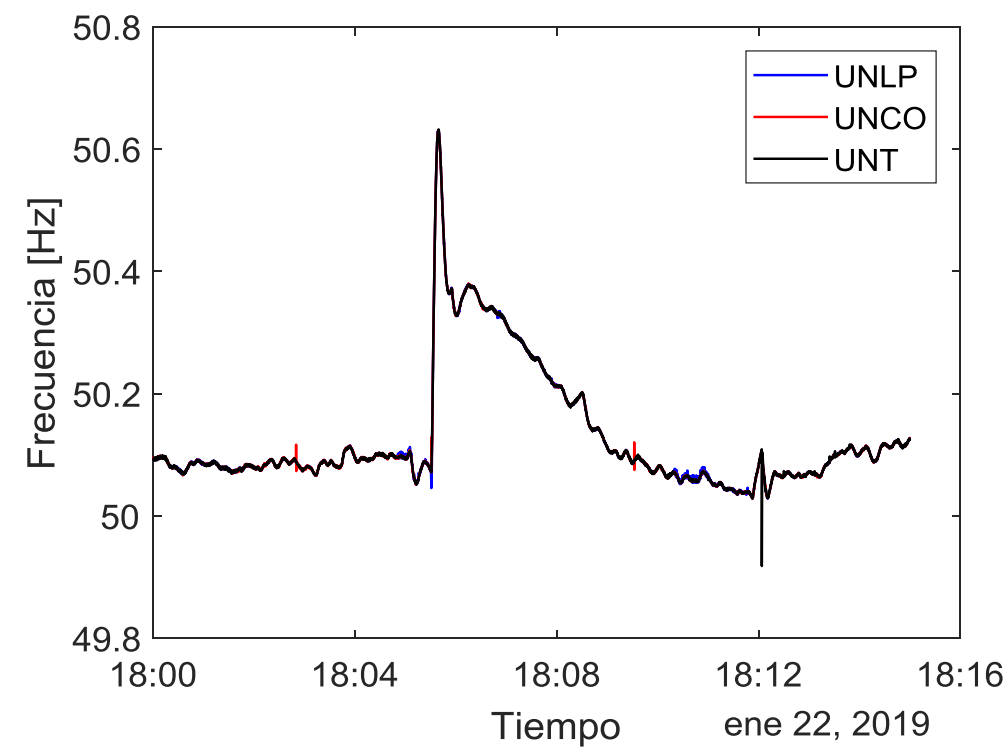

Figura 29. Frecuencia - MedFasee.

En la Figura 30 puede observarse el registro de amplitud de tensión de secuencia directa y frecuencia en la UNLP.

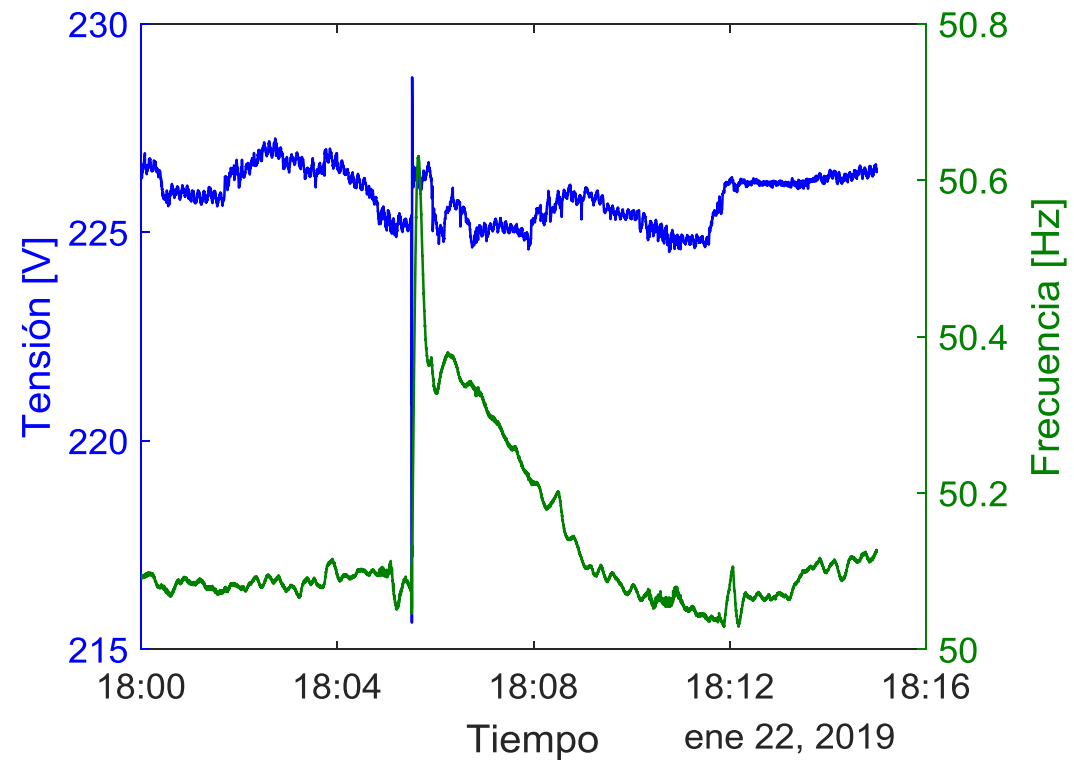

Figura 30. Tensión y frecuencia en UNLP - MedFasee.

En la Figura 31 se observa el detalle del registro de tensión de secuencia directa y frecuencia en la UNLP obtenido durante el corte de suministro. Puede notarse una oscilación de la frecuencia junto a una posterior recuperación de su condición nominal, instantes posteriores a producirse el corte de suministro. 


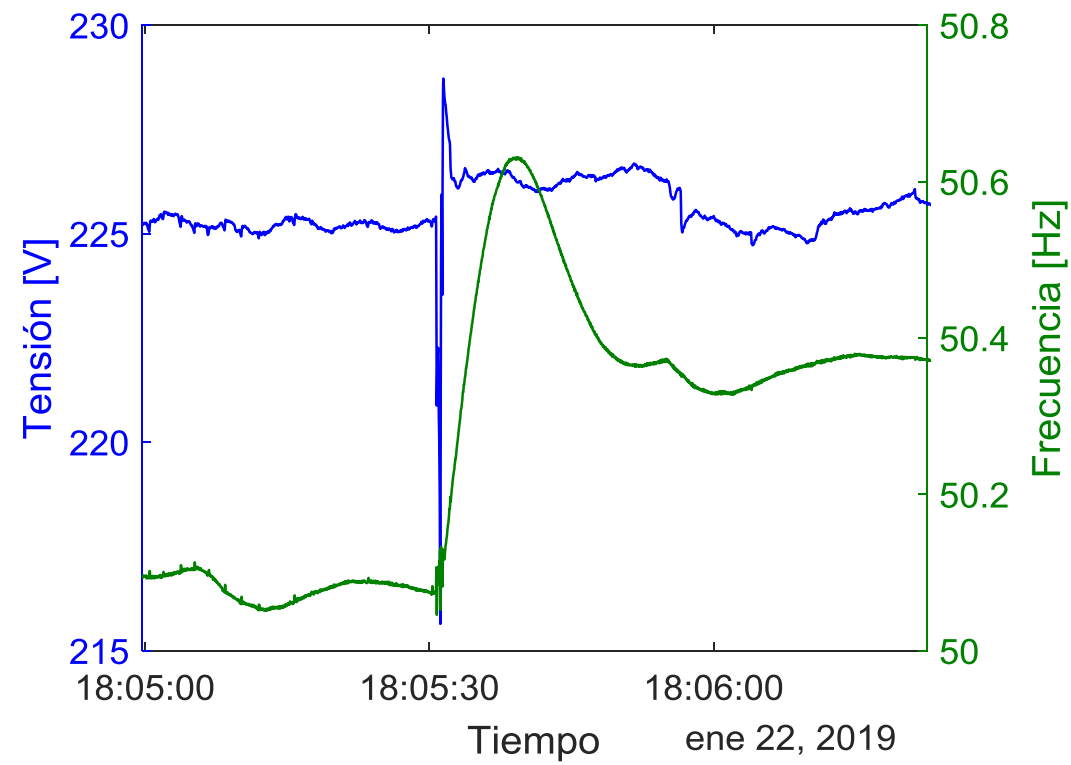

Figura 31. Detalle de Tensión y Frecuencia en UNLP - MedFasee.

\subsubsection{Blackout Argentino - 16 de Junio de 2019}

El día 16 de junio de 2019 a las 07:06 hs aproximadamente se produjo en el Sistema Argentino de Interconexión un corte de servicio general, afectando el suministro eléctrico de todo el territorio nacional y las interconexiones con Brasil y Uruguay [33]. Al momento de desarrollar la presente sección de la tesis, existen importantes conjeturas en cuanto a las causas del evento, pero aún no se dispone de documentación oficial que permita explicar lo sucedido.

Mediante las PMUs del sistema MedFasee Conosur, se registró la dinámica de la red, en baja tensión, durante los instantes previos al apagón tanto en el IITREE - UNLP como en UNT, UNSJ y UNCO. En la Figura 32 puede observarse la amplitud de la tensión de secuencia directa del sistema trifásico obtenida a partir del postprocesamiento de los sincrofasores medidos en las PMUs de dichas universidades. 


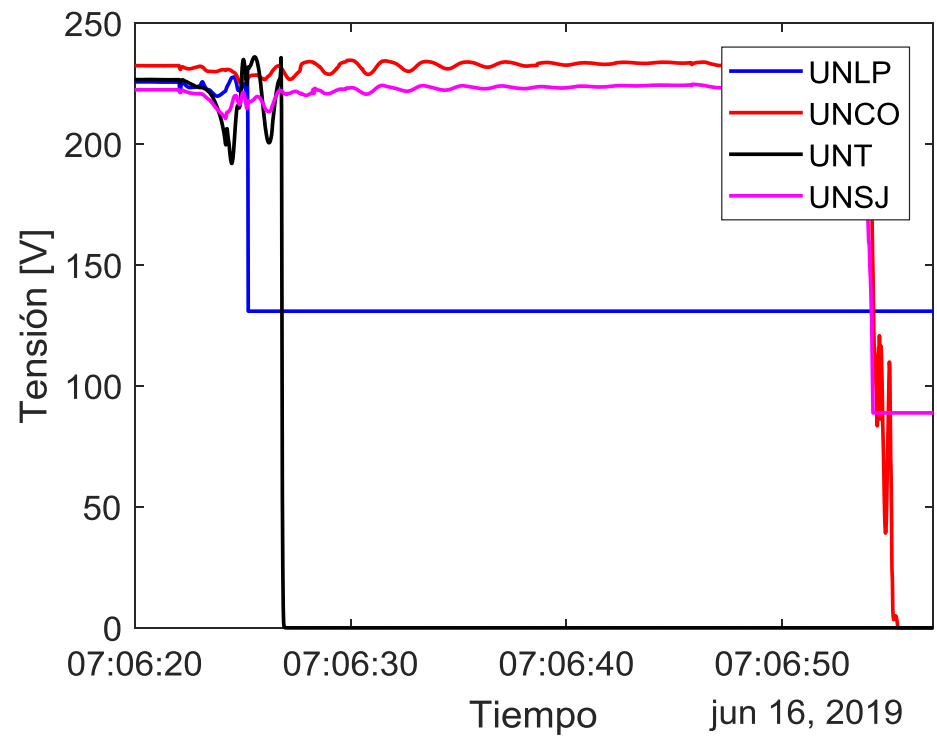

Figura 32. Tensión de Secuencia Directa - MedFasee Argentina.

En la Figura 33 se observa el registro de la frecuencia en las mismas locaciones.

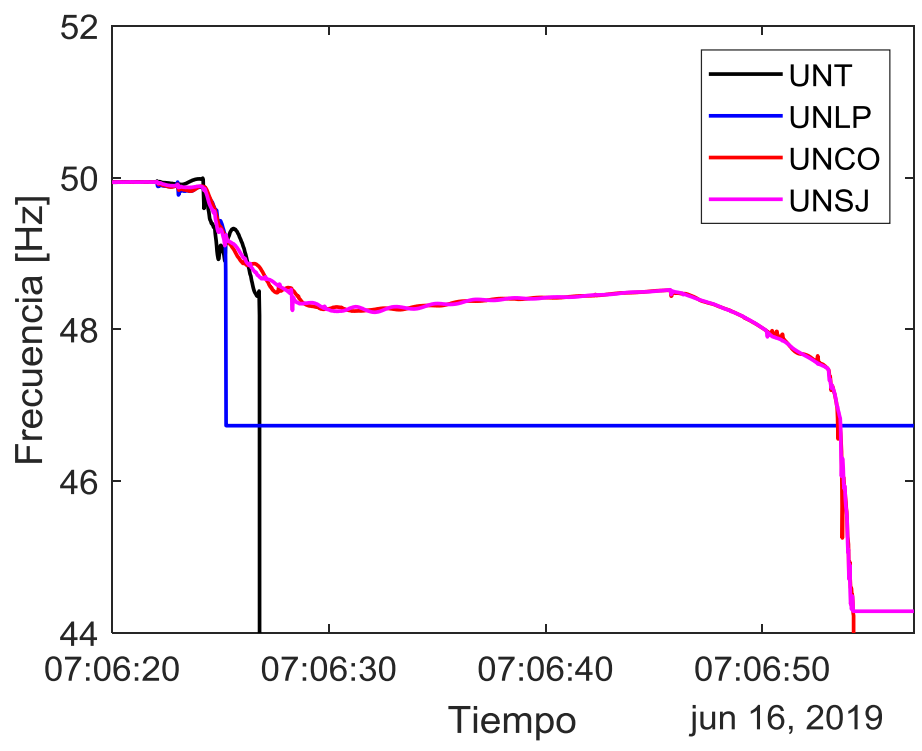

Figura 33. Frecuencia - MedFasee Argentina.

En la Figura 34 es posible analizar la variación de la diferencia angular de la tensión entre UNLP, UNCO y UNT respecto a la PMU ubicada en UNSJ. La elección de la UNSJ como referencia se debe a que la PMU instalada allí fue la que permaneció mayor tiempo transmitiendo sincrofasores. 


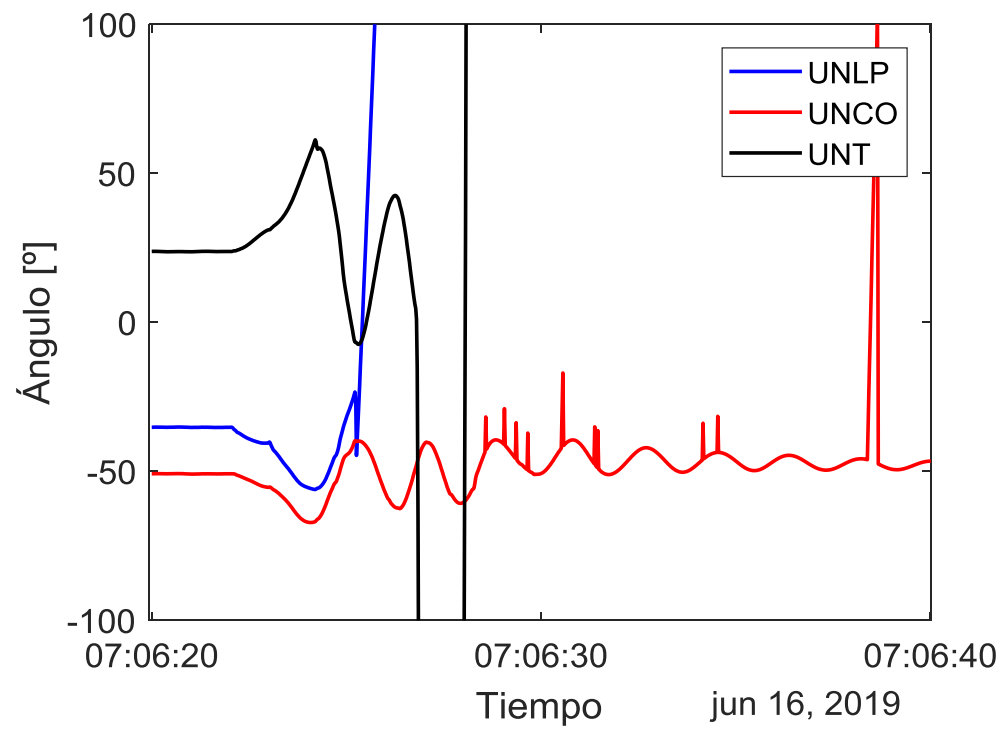

Figura 34. Diferencia Angular. Ref.: UNSJ - MedFasee Argentina.

En la Figura 35 puede observarse el registro de ROCOF medido con las mismas PMUs.

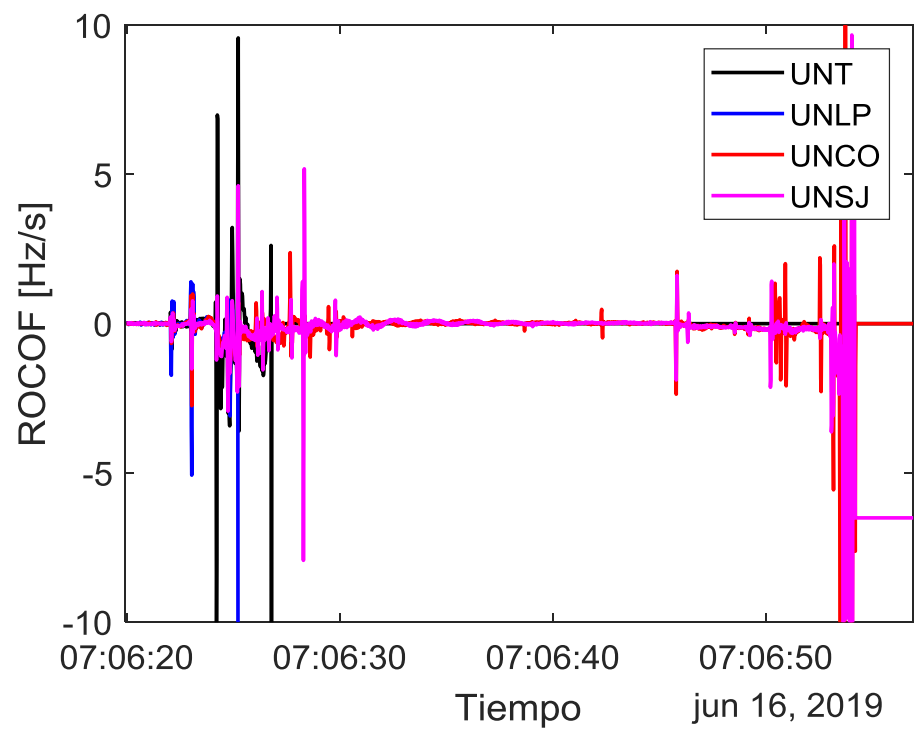

Figura 35. ROCOF - MedFasee Argentina.

De los registros disponibles, es posible concluir que la región de Cuyo y Comahue (UNSJ y UNCO) experimentaron el corte de suministro eléctrico 30 segundos después que lo sucedido en Tucumán y La Plata.

A su vez, tanto en el registro de amplitud de las tensiones como en el de diferencia angular, puede notarse una oscilación entre la PMU de UNCO y la de UNSJ con una frecuencia de $0,54 \mathrm{~Hz}$ y un amortiguamiento de aproximadamente $7 \%$, correspondiente a un modo de oscilación Inter-Área. 
Finalmente, resulta importante mencionar también la detección de valores de ROCOF superiores a $-1 \mathrm{~Hz} / \mathrm{s}$, que suele ser el límite típicamente utilizado en los relés de protección por subfrecuencia.

Los registros del proyecto MedFasee no solo incluyen las mediciones realizadas por PMUs instaladas en Argentina, sino también se dispone de las mediciones realizadas por las PMUs ubicadas en diferentes puntos de Brasil. En la Figura 36 puede observarse la amplitud de la tensión de secuencia directa del sistema trifásico obtenida a partir del post-procesamiento de los sincrofasores medidos en las PMUs localizadas en la UTFPR (en el estado de Paraná), UNIPAMPA (en el estado de Rio Grande del Sur) y UFSC (en el estado de Santa Catarina). Dichas ubicaciones corresponden a los puntos de medición disponibles más cercanos a la Interconexión Rincón-Garabi entre Argentina y Brasil.

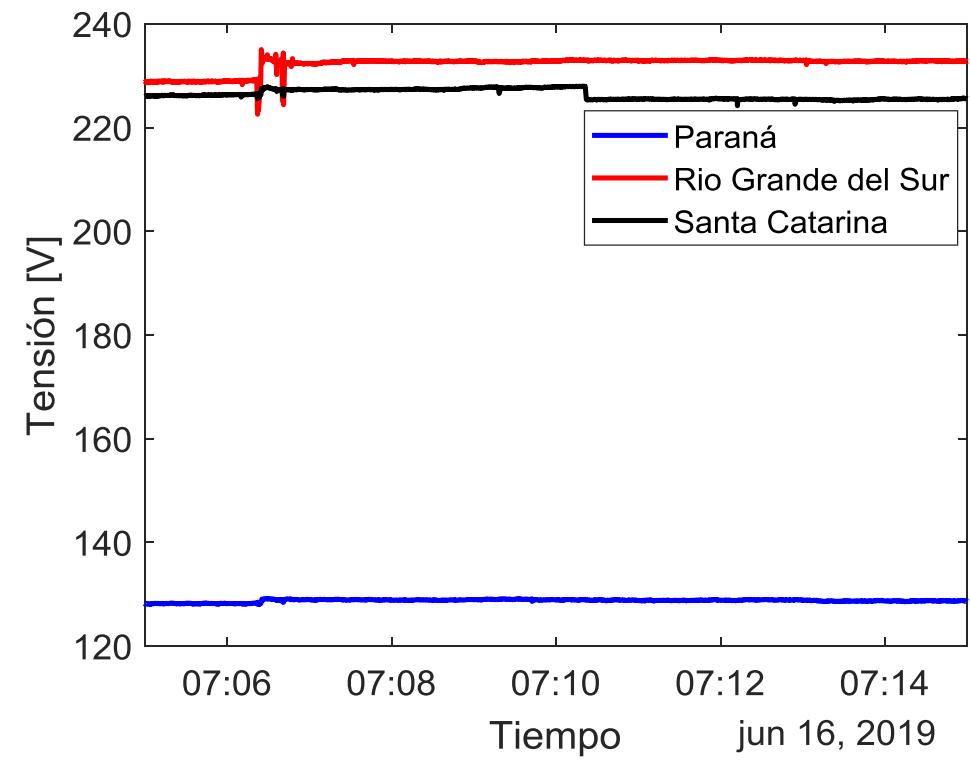

Figura 36. Tensión de Secuencia Directa - MedFasee Brasil.

En la Figura 37 se observa el registro de la frecuencia en las mismas locaciones. 


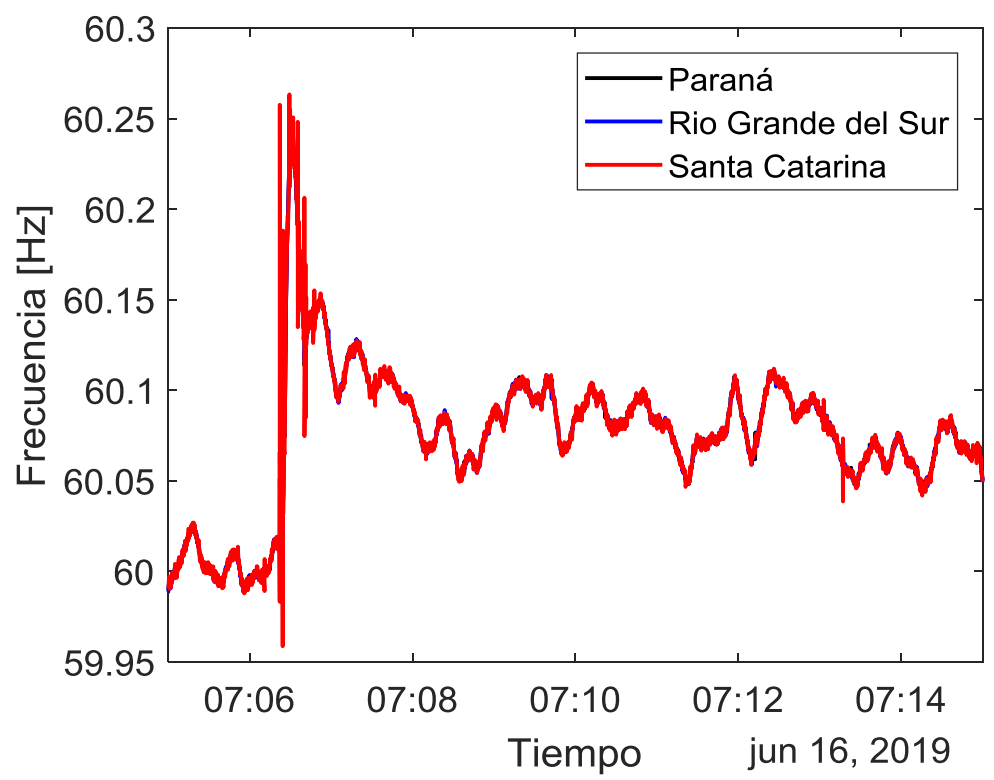

Figura 37. Frecuencia - MedFasee Brasil.

En la Figura 38 es posible analizar la variación de la diferencia angular de la tensión entre la PMU del estado de Paraná y Rio Grande del Sur respecto a la PMU ubicada en Santa Catarina.

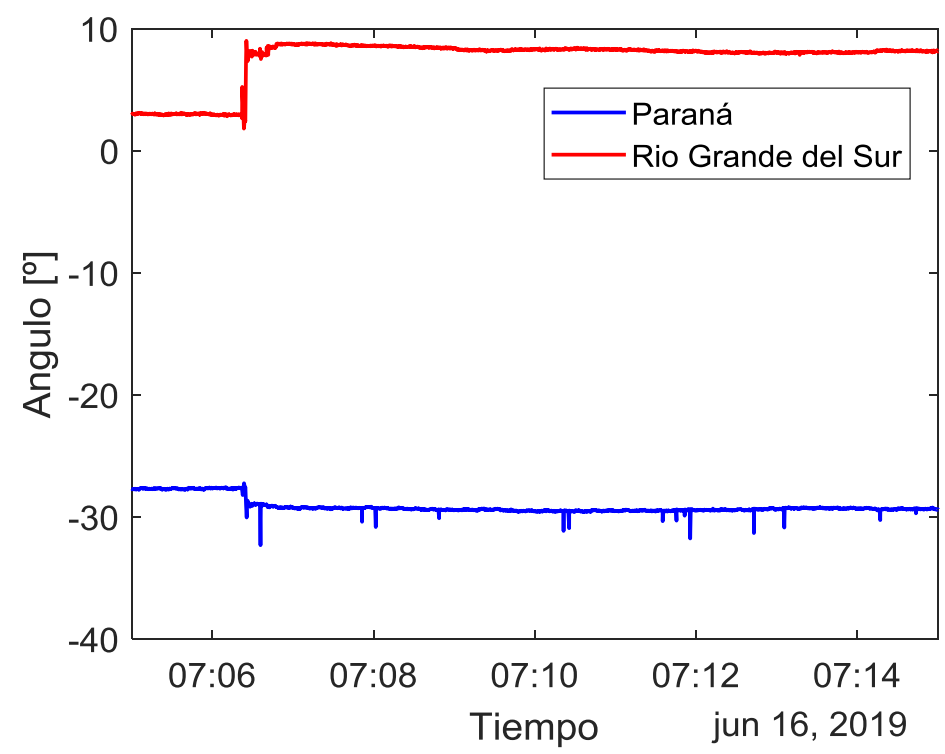

Figura 38. Diferencia Angular. Ref.: Santa Catarina - MedFasee Brasil.

En la Figura 39 puede observarse el registro de ROCOF medido con las mismas PMUs. 


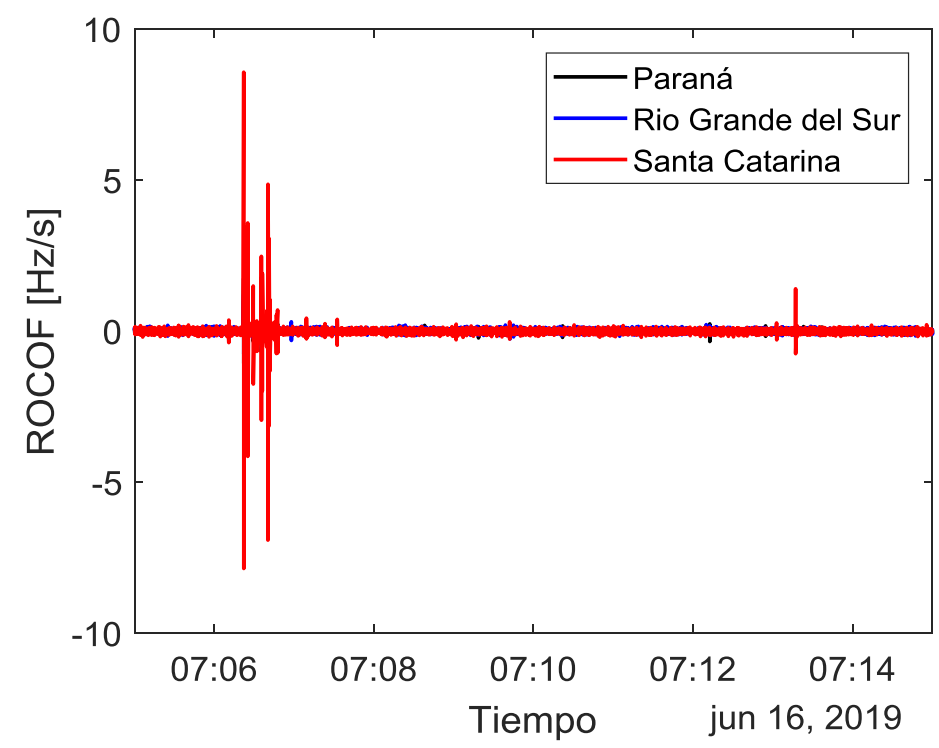

Figura 39. ROCOF - MedFasee Brasil

De los registros disponibles, es posible analizar la perturbación experimentada en Brasil durante los instantes previos a la salida de servicio del SADI, hasta la apertura de la interconexión entre Argentina y Brasil. Pueden notarse las variaciones de la tensión producidas por los sistemas de regulación del sistema brasileño tras la apertura de la interconexión así como las variaciones de la frecuencia hasta lograr su regulación. Esta situación queda documentada, a su vez, en la medición de valores de ROCOF que superaron, instantáneamente, los $5 \mathrm{~Hz} / \mathrm{s}$.

\subsection{Iniciativa Norteamericana de Sincrofasores (NASPI) - Estados Unidos}

La Iniciativa Norteamericana Sincrofasorial (NASPI, por sus siglas en inglés) [34] es un proyecto colaborativo llevado adelante por el Departamento de Energía y el Instituto de Investigación de Energía Eléctrico, ambos de los Estados Unidos, cuyo objetivo es aumentar la confiabilidad y observabilidad del sistema eléctrico estadounidense mediante la tecnología de medición sincrofasorial [35].

La NASPI está conformada por representantes de la industria privada, fabricantes y comercializadores de equipamiento eléctrico, universidades, laboratorios y expertos del gobierno federal estadounidense que se reúnen periódicamente para el análisis y la resolución de inconvenientes técnicos, operacionales e institucionales relativos al sistema eléctrico así como para elaborar normas y planes estratégicos.

Para el año 2017, contaba con más de 2500 PMUs instaladas en distintos puntos del territorio junto con 65 concentradores de datos, tal como se observa en la Figura 40 


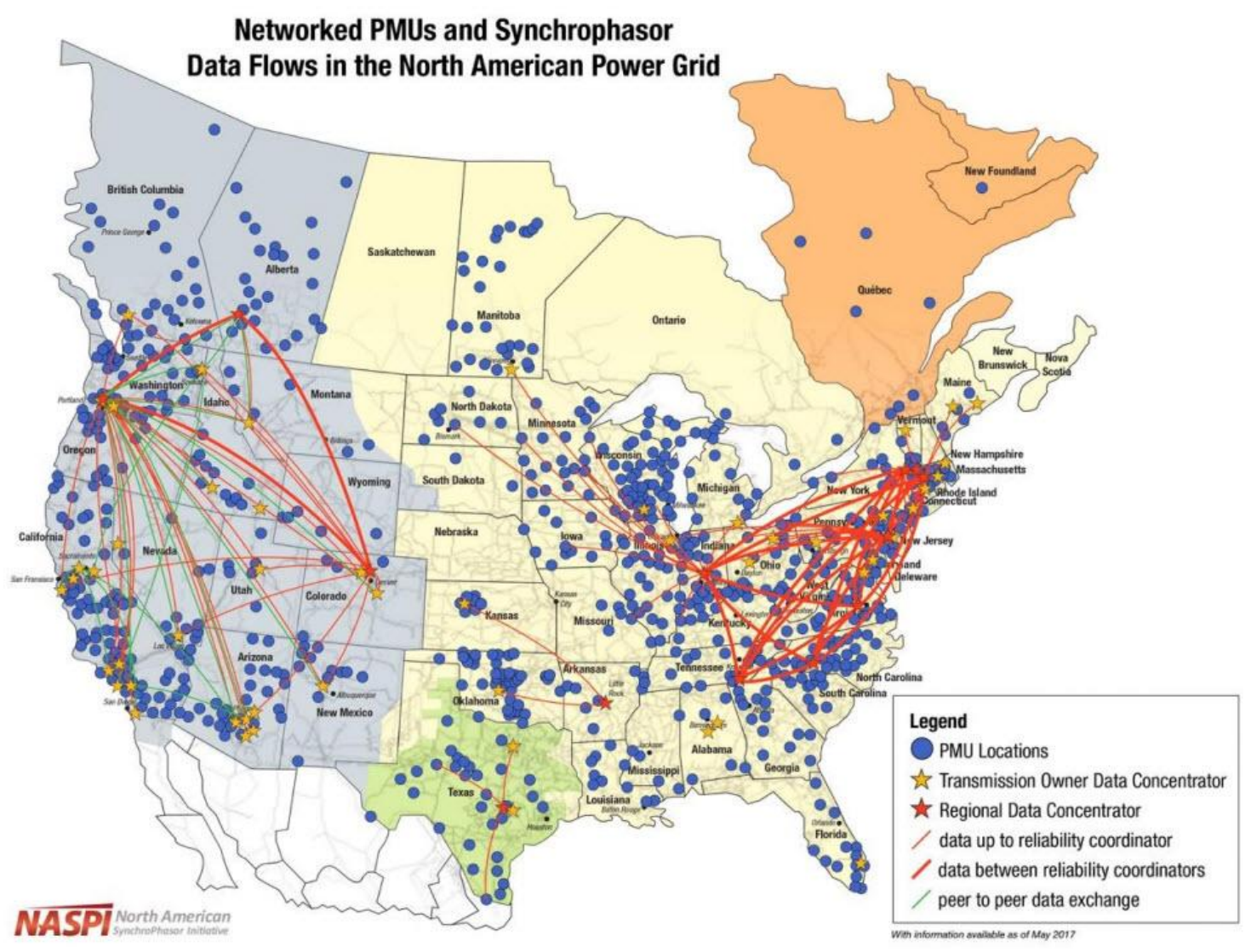

Figura 40. Red de medición sincrofasorial de EEUU.

\subsection{Sistema de medición sincrofasorial - China}

A partir del año 1995, China comenzó un plan de transformación de su red eléctrica tradicional hacia una red eléctrica de tipo smart grid para brindar soporte a técnicas de subestaciones inteligentes y asegurar mediciones de alta precisión basadas en las normas correspondientes [36].

Para ello, inició la instalación de PMUs a lo largo de la red, incorporando entre el año 1995 y 200240 PMUs en diversos subsistemas. Los objetivos estratégicos planteados fueron:

- Visualización de la dinámica del sistema eléctrico y de la carga de líneas de transmisión.

- Identificación de parámetros de generadores.

- Señalización de eventos para grabación y análisis.

- Monitoreo de las oscilaciones electromecánicas.

- Validación de modelos de simulación.

- Estimación de estados. 
Para el año 2013, China llevaba instaladas más de 2,400 PMUs a lo largo de su territorio, cubriendo todas las subestaciones de $500 \mathrm{kV}$ y una gran parte de las plantas de generación y subestaciones de $220 / 110 \mathrm{kV}$. A su vez, contaban con más de 30 centros de control de la red procesando los sincrofasores en tiempo real. En la Figura 41 puede observarse un mapa de la instalación de PMUs correspondiente al año 2012.

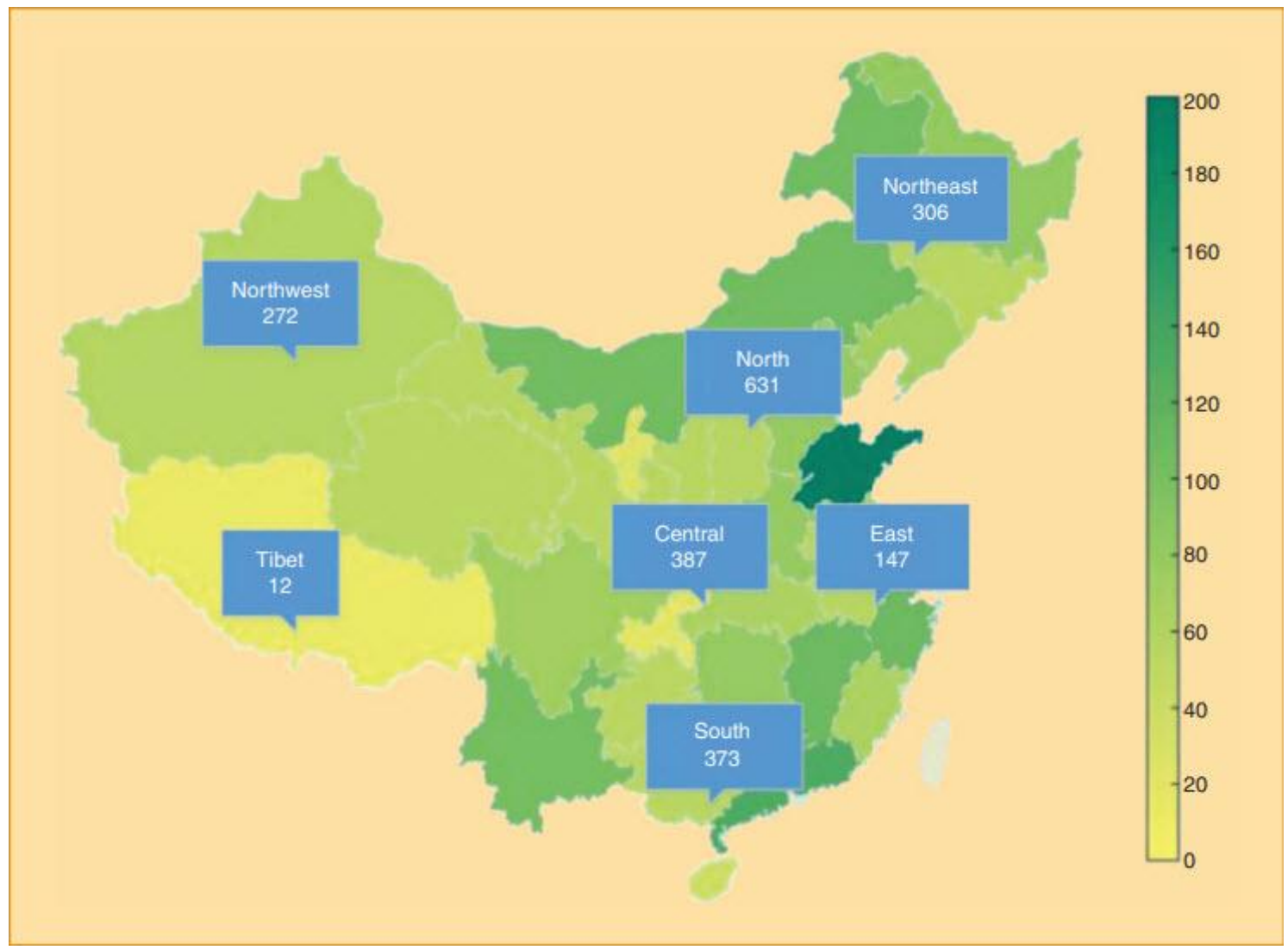

Figura 41. Mapa de cobertura con PMUs - China

El sistema implementado no solo ha permitido visualizar e identificar perturbaciones de la red, sino que también se han implementado sistemas de control y protección. China cuenta con sistemas de control de oscilaciones de área amplia así como sistemas automáticos de protección frente a perturbaciones de la red basados en las mediciones sincrofasoriales.

\subsection{Software de Código Abierto - Grid Protection Alliance}

La corporación Grid Protection Alliance [37] (GPA) es una organización sin fines de lucro especializada en desarrollar y brindar soporte a soluciones de software diseñadas para la industria eléctrica. Todas sus tareas y software desarrollados se basan en la utilización de código abierto y de distribución gratuita.

Desde el año 2010, esta corporación se encuentra desarrollando soluciones de software gratuitas diseñadas para la aplicación de sincrofasores al sistema eléctrico en relación directa con entidades federales de los Estados Unidos. 
A partir de estos fundamentos, la organización ha desarrollado un concentrador de código abierto y distribución gratuita denominado openPDC.

El concentrador openPDC está diseñado para manipular datos provenientes de diferentes protocolos, entre ellos IEEE C37.118. Permite obtener sincrofasores enviados por PMUs que implementan diferentes métodos de transmisión y, de la misma manera, es capaz de enviar los datos concentrados a concentradores de orden superior o software de procesamiento.

En la Figura 42 puede observarse la pantalla principal del openPDC Manager, la herramienta grafica que permite configurar el openPDC.

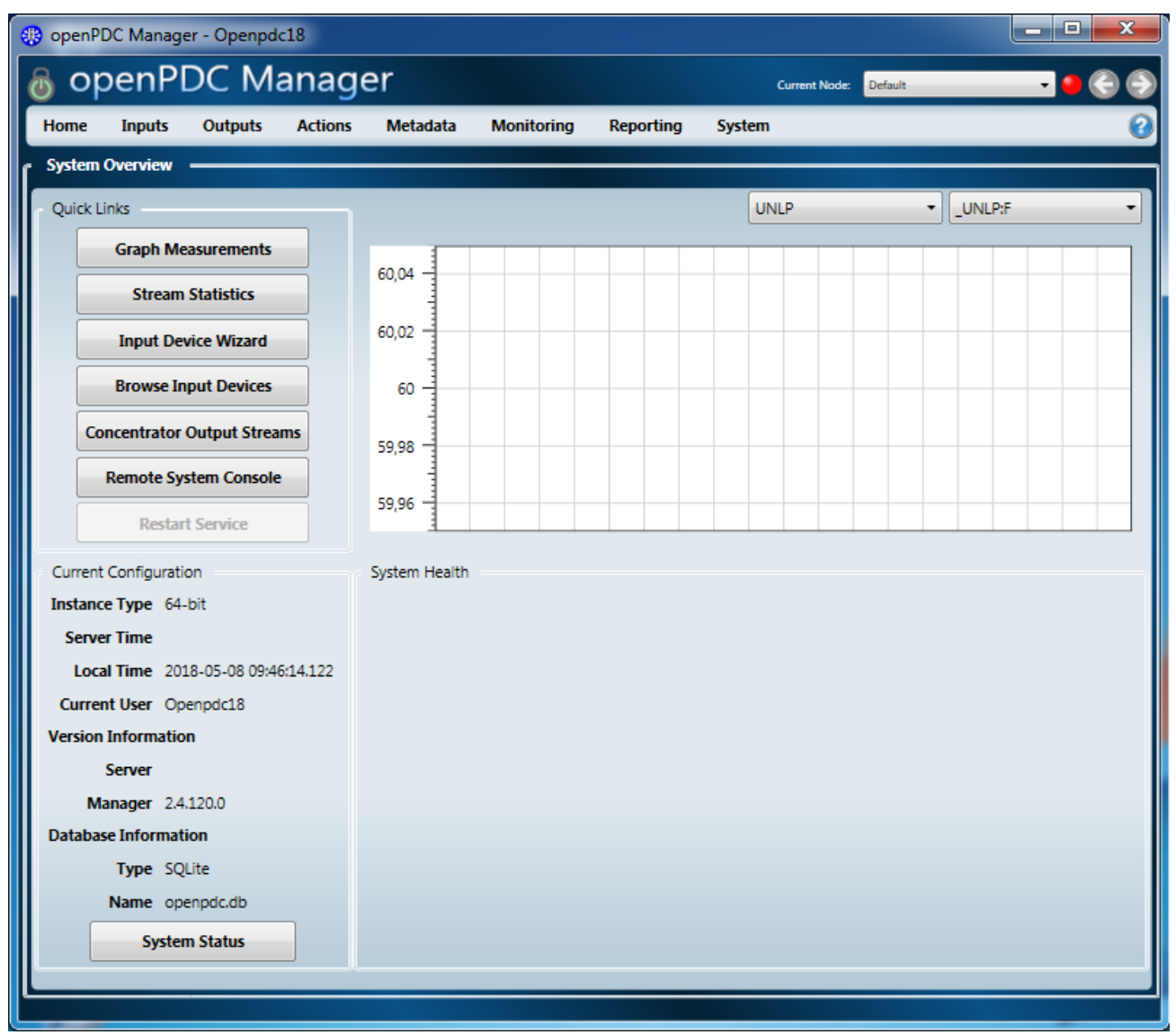

Figura 42. Interfaz de openPDC Manager.

Para incluir PMUs de donde concentrar datos, el concentrador cuenta con un asistente y una herramienta que permiten verificar la correcta conexión con la PMU para posteriormente incluirla en el concentrador.

Dicha herramienta, denominada PMU Connection Tester, brinda al usuario la posibilidad de configurar el método de conexión con la PMU y observar los datos recibidos para verificar la correcta comunicación con la PMU.

A su vez, el openPDC permite configurar diversos destinos, denominadas salidas, para los datos concentrados. 
Cada salida del concentrador cuenta con una denominación configurable por el usuario y un método de envío de los datos. Adicionalmente, para cada salida del concentrador pueden seleccionarse entre la lista de PMUs conectadas, a las PMUs cuyos datos se envían a esa salida.

Por otro lado, la GPA ha desarrollado también un sistema de almacenamiento y búsqueda de registros de sincrofasores de código abierto y distribución gratuita denominado openHistorian.

El sistema openHistorian está optimizado para almacenar y realizar búsquedas sobre grandes volúmenes de datos ordenados temporalmente en forma rápida y eficiente, logrando un sistema de almacenamiento de alta velocidad de inserción y extracción de datos, con confiabilidad en la integridad de los datos y compatible con fuentes de información de alta velocidad.

El openHistorian es compatible con diversas fuentes de datos y protocolos, entre ellos IEEE C37.118. En el caso de datos provenientes de PMUs o concentradores de orden inferior, permite obtener sincrofasores enviados mediante diferentes métodos de transmisión. En la Figura 43 puede observarse la pantalla principal del openHistorian Manager, la interfaz gráfica que permite configurar el openHistorian.

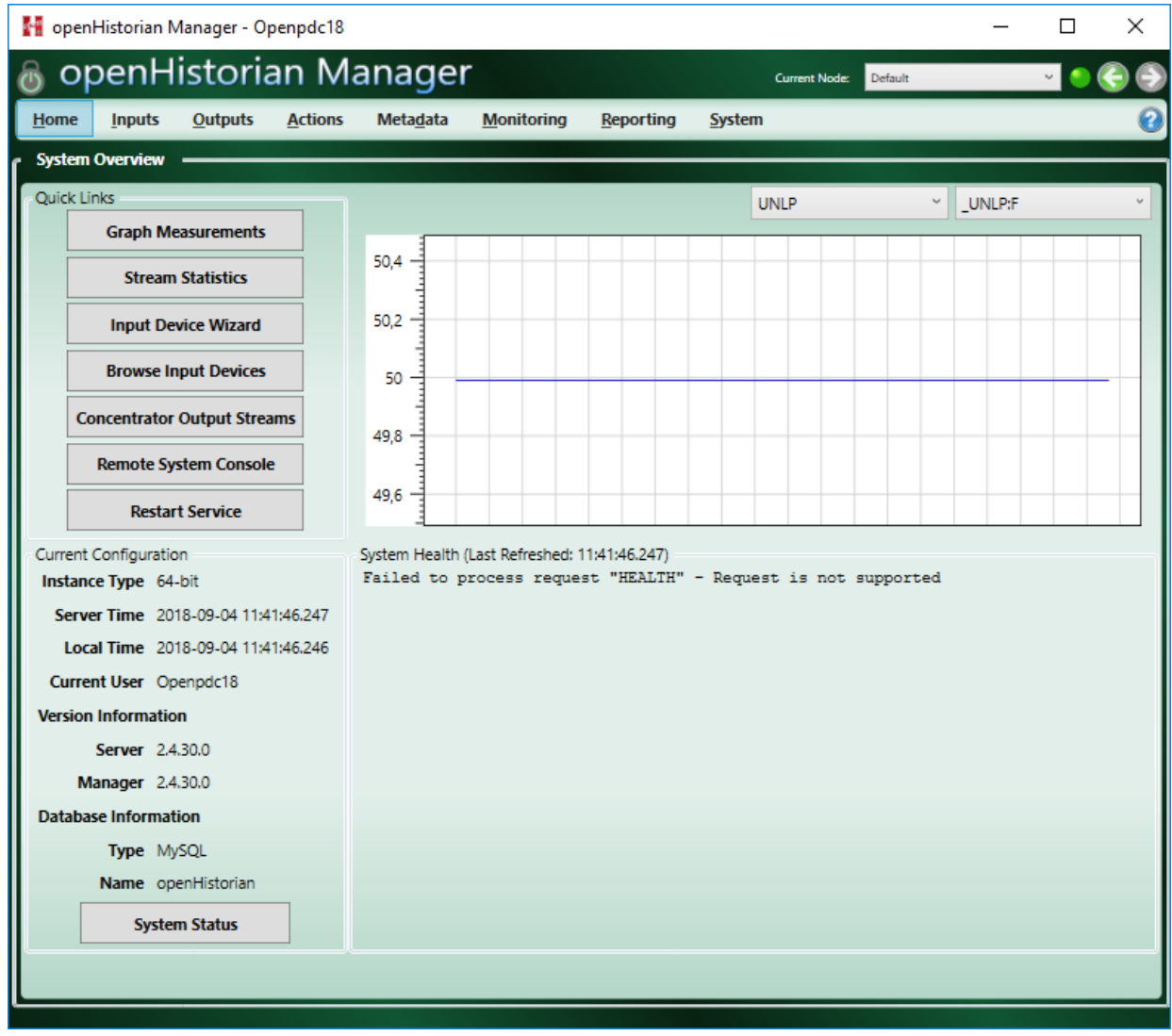

Figura 43. Interfaz de openHistorian Manager.

Al igual que el openPDC, el open Historian permite configurar las PMUs de donde recibir sincrofasores mediante la utilidad PMU Connection Tester. 
Una de las grandes virtudes del sistema de respaldo de archivos implementado por el software openHistorian es la capacidad de acceso remoto que brinda. Mediante un navegador convencional a través de la web es posible acceder a la PC donde se ejecuta el sistema y se almacenan los archivos, con los requisitos de identificación de usuario y contraseña preestablecidos para tal fin.

Una vez que el usuario ingresa, es posible realizar una recuperación de datos según diferentes criterios de búsqueda, lo que permite obtener dicha información sin necesidad de tener acceso físico a la PC servidora, dotando al sistema de mayor seguridad. 


\section{Comunicaciones y transmisión de sincrofasores}

\subsection{Características generales}

Con el surgimiento y la difusión de los sistemas de medición sincrofasoriales, la tasa de transmisión de datos desde cada punto de medición al centro de Operación y Control aumentó considerablemente, desde una tasa de transmisión de 1 medición cada 2 - $4 \mathrm{~s}$ en el caso de SCADA hasta una medición cada $20 \mathrm{~ms}$ en el caso de los sincrofasores. Este aumento de tasa transmisión implicó también una redefinición de los requerimientos en la infraestructura de comunicaciones necesaria para la comunicación y transmisión de los datos.

Para definir las resoluciones temporales y latencias, la norma IEEE 60255-118-12018 [9] y sus modificaciones establecen la máxima latencia de transmisión de datos aceptable desde una PMU. Para definir los requerimientos de latencia de los PDCs, la norma IEEE C37.244 [38] especifica diferentes límites referidos a los retardos entre la entrada y salida de datos de los concentradores.

Sin embargo, ninguna de las normas antes mencionadas define una única infraestructura de red que deba emplearse para sistemas de medición sincrofasorial. En la tecnología de vanguardia de PMUs y PDCs, los enlaces seriales y Ethernet son los más utilizados, siendo estos últimos los más aplicados en sistemas de monitoreo de área amplia (WAMS, entre otros). En el caso de Ethernet, el Protocolo de Control de Transmisión (TCP, por sus siglas en inglés) y el Protocolo de Datagramas de Usuario (UDP, por sus siglas en inglés) son los protocolos de transferencia de datos comúnmente aplicados.

A medida que las redes de PMUs crecen o se instalan en sistemas de potencia o redes de distribución más antiguas, la disponibilidad de enlaces dedicados Ethernet o de fibra óptica se reduce, de manera tal que redes compartidas, como conexiones a internet cableadas o redes móviles GSM/GPRS, se convierten en la principal alternativa. A su vez, en países en vías de desarrollo como la Argentina, donde las estaciones del sistema de potencia se encuentran ubicadas en lugares remotos y con disponibilidad limitada de enlaces exclusivos aptos para esta aplicación, las redes compartidas, alámbricas o inalámbricas, se convierten en la opción más aplicable.

Todas estas características confluyen en la necesidad de evaluar, para la presente tesis, de dos métodos típicamente utilizados para la transmisión de sincrofasores. Los mismos fueron ensayados en condiciones reales utilizando tanto conexiones a internet cableadas como conexiones inalámbricas GSM/GPRS. 


\subsection{Métodos de transmisión}

\subsubsection{Método de transmisión TCP}

El protocolo TCP se basa en una arquitectura orientada a la conexión entre transmisores y receptores. Esto implica que se requiere de negociaciones entre ellos para establecer y mantener la conexión punto a punto. Este método establece una conexión para transferir comandos del PDC a la PMU y datos en el sentido opuesto. En este caso, la PMU se comporta como un servidor de manera tal que el cliente (el PDC) debe conocer la dirección IP del servidor (la PMU) para poder establecer la conexión y transferencia de datos. Dicho método se denomina método comandado de transmisión de datos

Las conexiones a internet cableadas comerciales y las conexiones móviles GSM/GPRS utilizan, usualmente, el direccionamiento IP dinámico. Este tipo de administración de direcciones provoca que las direcciones IP de las PMUs instaladas en locaciones remotas sean, típicamente, desconocidas. Esta es la principal causa por la cual las PMUs publican sus direcciones mediante diferentes métodos como, por ejemplo, sistemas dinámicos de nombres de dominio (DDNS, por sus siglas en inglés).

Al igual que una típica transferencia de datos TCP, la transferencia de datos desde una PMU mediante TCP cuenta con diferentes métodos de control y seguridad de la comunicación, detectando pérdidas de paquetes y reorganizando paquetes desordenados. Estas capacidades de administración de la conexión requieren, como consecuencia, un mayor ancho de banda y tasa de transferencia de datos.

Para obtener un mejor desempeño y mejorar el uso del ancho de banda, el protocolo TCP cuenta con diferentes métodos para reducir la transferencia de datos. Uno de los métodos más utilizados es el denominado Algoritmo de Nagle [39]. Este algoritmo establece que si una pequeña cantidad de bytes debe ser transmitida (menor a la cantidad total de un paquete de datos) y aún hay algunos datos en tránsito de los cuales no se recibió confirmación de su recepción, el transmisor puede esperar hasta recibir más datos a enviar (los suficientes como para completar un paquete de datos TCP) o hasta recibir las confirmaciones de recepción faltantes, de manera que no haya más datos en tránsito.

Típicamente, éste es un método eficiente para reducir el uso del ancho de banda en transmisiones a través de internet. Sin embargo, en aplicaciones de tiempo real donde los datos deben ser transmitidos inmediatamente, el Algoritmo de Nagle puede generar problemas de disponibilidad de datos debido a los tiempos de espera para la transmisión descriptos anteriormente. Las transmisiones de PMUs a través de internet pueden verse afectadas por la aplicación de estos métodos de reducción de uso de ancho de banda en diferentes nodos de la red. 


\subsubsection{Método de transmisión UDP}

El protocolo UDP se basa en un modelo de intercambio de datagramas, sin la existencia de negociaciones. Esto implica que ambos extremos del enlace transmiten datos sin mecanismos de negociación ni control entre ellos. Si se lo compara con el protocolo TCP, no existen en este caso métodos de control y seguridad de la comunicación. El protocolo UDP solo provee control de errores en los datos para detectar transmisiones erróneas. Como consecuencia, con respecto al método TCP, se requieren tanto menor ancho de banda como menor tasa de transferencia de datos.

Las PMUs implementan, habitualmente, dos tipos de comunicaciones UDP. El primero de ellos, al igual que el método TCP, se basa en una arquitectura clienteservidor donde la PMU funciona como servidor y es controlada por el PDC (el cliente) con los correspondientes comandos. El segundo tipo se denomina método espontáneo de transmisión de datos [10].

El método espontáneo de transmisión de datos se basa en un enlace de datos unidireccional. En este caso, los datos son transmitidos desde la PMU a PDCs predefinidos sin la existencia de comandos u otro tipo de mensajes enviados en el sentido opuesto. Esto implica, entonces, que sólo deben conocerse las direcciones IP de los PDCs que son configurados en la PMU. Este requerimiento es más simple de cumplir para sistemas de monitoreo y control donde las PMUs son instaladas en lugares remotos y conectadas a través de conexiones a internet cableadas mientras que los PDCs son instalados en lugares donde diferentes proveedores de conexiones a internet están disponibles, incluyendo servicios de direccionamiento IP fijo.

En este caso, la PMU envía automáticamente los datos a las direcciones IP predefinidas. Los PDCs no pueden enviar comandos o pedidos de configuración a las PMUs. Por esta razón, la PMU transmite periódicamente su configuración, generalmente una vez por minuto. Éste método se encuentra disponible en diversas PMUs comerciales [40][41][42].

El método espontáneo no solo reduce el ancho de banda requerido. Dado que no es posible enviar comandos a las PMUs, las mismas pueden ser instaladas con protecciones cibernéticas por cortafuegos u otros sistemas de seguridad, bloqueando cualquier tráfico de datos entrante. Esta característica le brinda al sistema de medición mayor seguridad, obteniendo por ejemplo inmunidad a ataques de denegación de servicio (DoS, por sus siglas en inglés).

\subsubsection{Estudio comparativo del ancho de banda entre ambos métodos}

A partir de lo descripto en las secciones 4.2.1 y 4.2.2, una de las principales diferencias que puede notarse entre el método comandado y el método espontáneo corresponde al ancho de banda requerido por cada uno de ellos cuando se lo utiliza para transmitir datos en forma continua. 
Debido a los mecanismos de control que tienen por objetivo asegurar la correcta transferencia de datos entre el cliente y el servidor, el método comandado basado en el protocolo TCP transmite obligatoriamente un conjunto de datos de control en cada transmisión, junto a los datos que conforman la información útil de la transmisión. Un esquema de un paquete de datos, con la mínima cantidad de datos de control, enviado mediante el protocolo TCP puede observarse en la Figura 44.

\begin{tabular}{|c|c|c|c|}
\hline \multicolumn{3}{|c|}{$\begin{array}{l}\text { PUERTO ORIGEN } \\
2 \text { bytes }\end{array}$} & $\begin{array}{c}\text { PUERTO DESTINO } \\
2 \text { bytes }\end{array}$ \\
\hline \multicolumn{4}{|c|}{$\begin{array}{c}\text { NÚMERO DE SECUENCIA } \\
4 \text { bytes }\end{array}$} \\
\hline \multicolumn{4}{|c|}{$\begin{array}{c}\text { NÚMERO DE ACUSE DE RECIBO } \\
4 \text { bytes }\end{array}$} \\
\hline $\begin{array}{l}\text { OFFSET } \\
4 \text { bits }\end{array}$ & $\begin{array}{l}\text { RESERVADO } \\
3 \text { bits }\end{array}$ & $\begin{array}{l}\text { INDICACIONES } \\
9 \text { bits }\end{array}$ & $\begin{array}{l}\text { TAMAÑO DE VENTANA RECEPTORA } \\
2 \text { bytes }\end{array}$ \\
\hline \multicolumn{3}{|c|}{$\begin{array}{c}\text { CHECKSUM } \\
2 \text { bytes }\end{array}$} & $\begin{array}{l}\text { ID DATO URGENTE } \\
2 \text { bytes }\end{array}$ \\
\hline \multicolumn{4}{|c|}{ DATOS DE USUARIO } \\
\hline
\end{tabular}

Figura 44. Esquema de paquete de datos TCP.

A diferencia de los datos transmitidos mediante protocolo TCP, el método espontáneo basado en transmisiones UDP carece de los mecanismos de control antes mencionados, lo que provoca una reducción de la cantidad de datos de control que se envían en cada transmisión. Un esquema correspondiente a un paquete de transmisión UDP con la mínima cantidad de datos de control puede observase en la Figura 45.

\begin{tabular}{|c|c|}
\hline PUERTO ORIGEN & PUERTO DESTINO \\
2 bytes & 2 bytes \\
\hline LONGITUD & CHECKSUM \\
2 bytes & 2 bytes \\
\hline \multicolumn{2}{|c|}{ DATOS DE USUARIO } \\
\hline
\end{tabular}

Figura 45. Esquema de paquete de datos UDP.

A partir de las Figuras 44 y 45, es posible observar que los paquetes mínimos de datos que se pueden enviar mediante protocolo TCP y UDP difieren en la cantidad de bytes que requieren. Esta característica implica que el método TCP requiere un ancho de banda superior que el método UDP para la misma cantidad de datos útiles enviados.

A modo de comparación, en la Tabla I se muestra la cantidad de datos transmitidos por la PMU, el tamaño mínimo del conjunto de datos y el ancho de banda requerido para una PMU midiendo 6 sincrofasores con una tasa de 50 mediciones/s utilizando tanto el protocolo TCP como el protocolo UDP. Las mediciones realizadas se supone son transmitidas con la precisión de coma flotante, estableciendo entonces que cada sincrofasor requiere de 8 bytes para ser representado y enviado [10]. 
Tabla I. Cantidad de datos y ancho de banda - TCP y UDP.

\begin{tabular}{|c|c|c|}
\hline Descripción & TCP & UDP \\
\hline Sincrofasores desde PMU & 74 bytes & 74 bytes \\
\hline Encabezado mínimo & 20 bytes & 8 bytes \\
\hline Paquete de red mínimo & 94 bytes & 82 bytes \\
\hline Ancho de banda mínimo & $59,6 \mathrm{kbps}$ & $54,4 \mathrm{kbps}$ \\
\hline
\end{tabular}

Es importante mencionar que para el cálculo del ancho de banda mínimo requerido se tuvo en cuenta también el conjunto de datos de control que requieren las transmisiones IP y Ethernet que corresponden a las capas de Enlace y Red del Modelo OSI [43]. Dichas capas se utilizan de la misma manera, y con los mismos datos, tanto para las transmisiones TCP como para las transmisiones UDP.

\subsection{Ensayos de transmisión}

\subsubsection{Descripción}

Con el objetivo de obtener resultados basados en experiencias reales de transmisión de sincrofasores que permitieran seleccionar el método a utilizar en la PMU implementada para la presente tesis, los métodos de comunicaciones fueron probados en un hardware de PMU real y en un PDC funcionando en una computadora personal.

La PMU fue instalada en Concordia, Argentina, a $370 \mathrm{~km}$ del PDC. La conexión comercial cableada a internet cuenta con 12 nodos de red entre la PMU y el PDC mientras que la conexión GSM/GPRS cuenta con 9 nodos de red.

Los enlaces de comunicaciones fueron analizados mediante dos ensayos distintos diseñados para evidenciar los diferentes fenómenos que se suceden durante la transferencia de datos entre la PMU y el PDC. Cabe mencionar que la comunicación entre la PMU y el PDC fue previamente verificada a través de una conexión de área local, obteniendo una transmisión de datos sin errores.

\subsubsection{Análisis del orden de los conjuntos de datos recibido}

El orden de recepción de los paquetes transmitidos mediante protocolos TCP y UDP se encuentra íntimamente relacionado con las características propias de transmisión de dichos métodos.

Tal como se mencionó en la sección 4.2.1, la transferencia de datos mediante TCP cuenta con diferentes métodos de control que permiten detectar pérdidas de paquetes $y$, principalmente, reorganizar paquetes que arriban en forma desordenada al receptor de los datos. En forma opuesta, la transferencia de datos mediante UDP carece de métodos similares, obteniendo entonces un menor requerimiento de ancho de banda pero una mayor sensibilidad a inconvenientes en la red que afecten el orden de los paquetes.

Dado que el orden en la recepción de los sincrofasores resulta de gran importancia para el análisis y control del sistema de potencia que esté bajo estudio mediante la 
tecnología sincrofasorial, se realizó un ensayo que permitiera caracterizar a ambos métodos de transmisión según la capacidad de reordenamiento de paquetes de datos.

Este ensayo tuvo como propósito registrar los fasores, en el extremo del PDC del enlace de comunicaciones, a medida que arribaban al concentrador.

A tal fin, se desarrolló un registrador de datos de red para funcionar en paralelo con el PDC, actuando como espía de los datos recibidos. El registrador almacena en un archivo dedicado para tal fin, todos los sincrofasores recibidos en el PDC, junto con la estampa temporal correspondiente. En la Figura 46 puede observarse un esquema del registrador de sincrofasores.

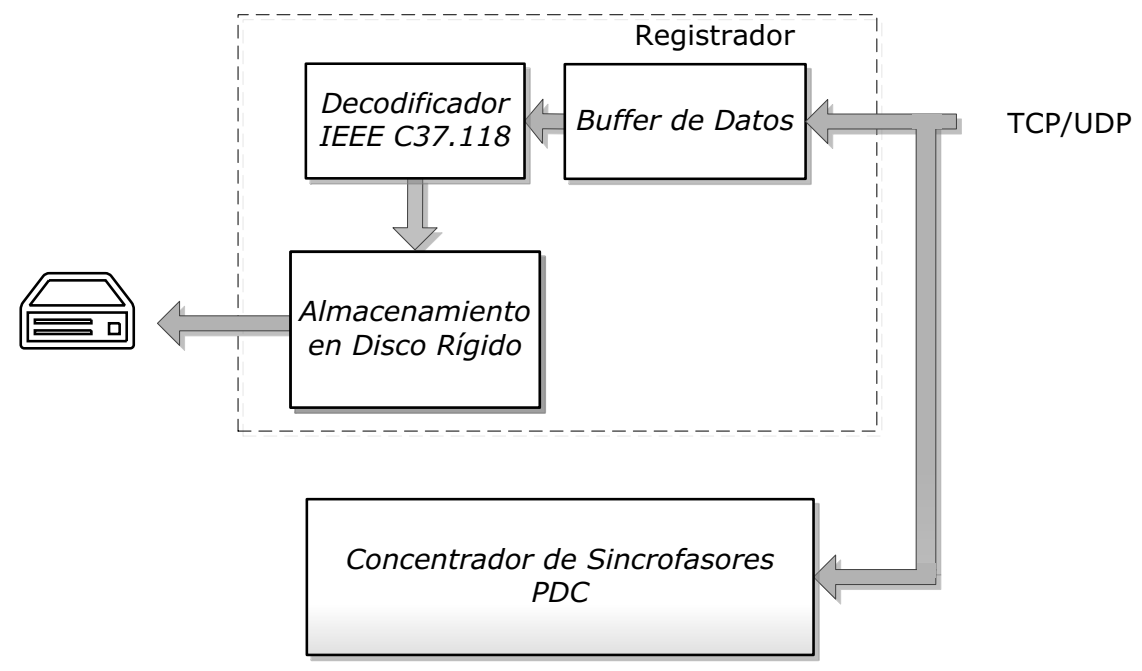

Figura 46. Diagrama en bloques - Registrador de Datos.

El buffer de datos almacena en un buffer de tipo FIFO los paquetes de datos TCP o UDP recibidos para que los mismos sean posteriormente decodificados según la norma [10] mediante el Decodificador diseñado para tal fin. Dichos sincrofasores son, finalmente, almacenados en el archivo correspondiente en el disco rígido de la PC donde se ejecuta el registrador, mediante el administrador para el almacenamiento que incluye en el software de prueba.

Una vez que los datos fueron registrados, se analiza en forma offline la estampa de tiempo de los sincrofasores recibidos. Para realizar este análisis, se realizan gráficos donde se presenta cada sincrofasor con su correspondiente estampa, en el orden en que los fasores fueron recibidos.

De esta manera, si las estampas temporales son recibidas en el orden correcto, se observaría una sucesión temporal lineal, es decir, mediciones que fueron recibidas en el mismo orden en que fueron realizadas.

En el caso opuesto, si los paquetes arriban al concentrador en forma desordenada, se observaría una sucesión temporal "caótica", es decir, mediciones que arriban al concentrador antes que otras que se realizaron anteriormente. 
Este ensayo fue realizado tanto con el método comandado (TCP) como el método espontáneo (UDP) durante períodos de 10 minutos repetidas veces.

\subsubsection{Análisis de los sincrofasores recibidos en paquetes de red}

El desempeño de los métodos de transmisión es un parámetro importante en los sistemas WAMS, WAMC o WAMPAC para poder cuantificar la latencia total de datos. Dado que todos los datos son transmitidos a través de la red de dichos sistemas, es necesario que ésta sea compatible en términos de ancho de banda y latencia para obtener los datos necesarios en el instante y el lugar que se los requiera.

Por todo ello, se consideró de suma importancia controlar la calidad de los paquetes transferidos a través de la red. El ensayo propuesto permite analizar las características de los paquetes recibidos para cada método de transmisión utilizado. El análisis incluye el estudio del efecto de los algoritmos para un uso eficiente del ancho de banda y su influencia en la latencia de datos.

Para implementar la prueba, se desarrollo un software de PDC específico el cual, toda vez que se recibe un paquete de red, decodifica la información para detectar el número de transmisiones de PMUs que incluye ese paquete. Una vez que se separan las transmisiones, el algoritmo analiza si cada una de ellas contiene todos los datos, si contiene datos erróneos o si está incompleta. Esta función se realiza mediante múltiples procesadores de datos funcionando en paralelo, uno por medición de PMU recibida.

Finalmente, el software genera un reporte mostrando el número de transmisiones de datos recibidas en cada paquete, la calidad de las transmisiones y el número de errores o datos incompletos registrados. En la Figura 47, se observa un diagrama en bloques del software de procesamiento.

Este ensayo fue realizado durante períodos de 10 minutos repetidas veces, utilizando tanto el método comandado (TCP) como el método espontáneo (UDP) a través de una conexión cableada a internet comercial y a través de una conexión inalámbrica GSM/GPRS

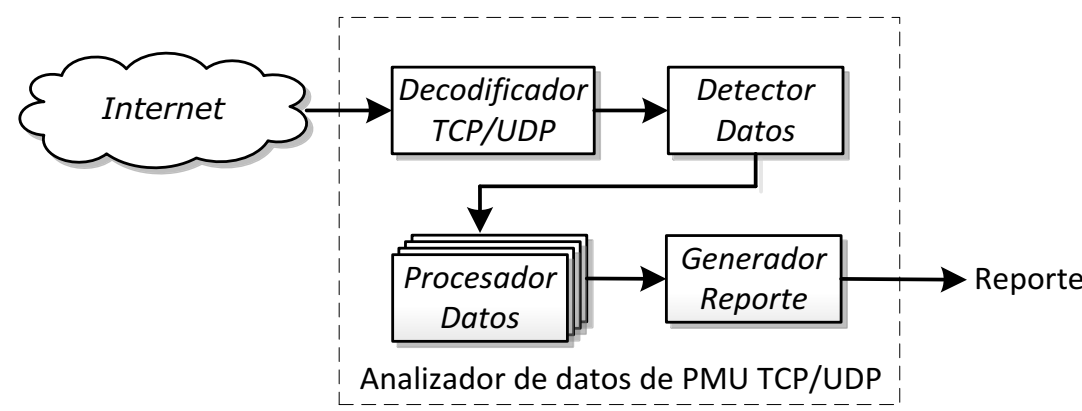

Figura 47. Diagrama en bloques - Software analizador de datos. 


\subsubsection{Resultados}

El análisis del orden de los paquetes de red recibidos fue realizado tanto para el método comandado como para el método espontáneo, y los resultados obtenidos pueden observarse en las Figuras 48 y 49. Cada caso fue ensayado para una tasa de transmisión de sincrofasores de 25 mediciones/s y de 50 mediciones/s.

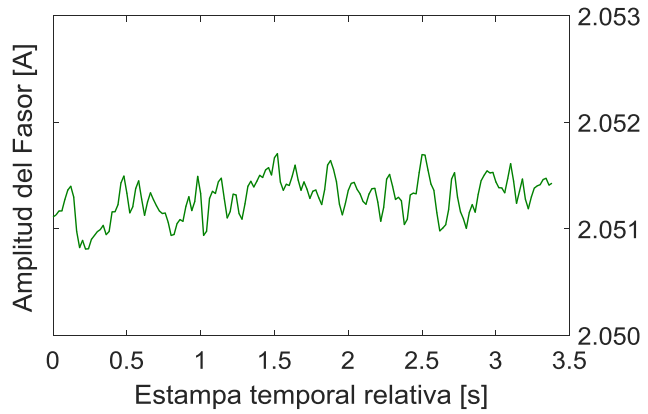

Figura 48-a. Orden de paquetes Método comandado - 25 mediciones/s.

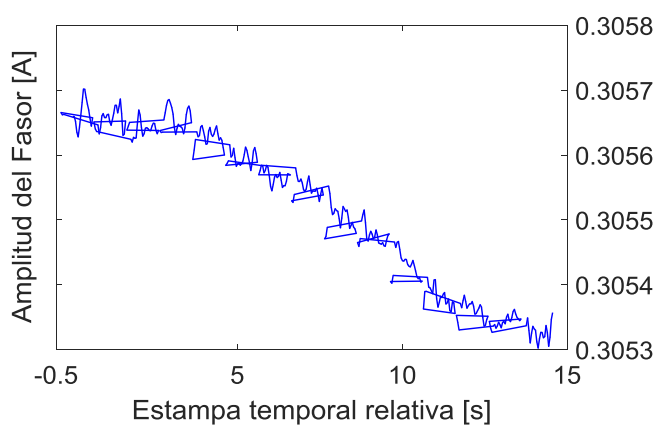

Figura 49-a. Orden de paquetes Método espontáneo - 25 mediciones/s.

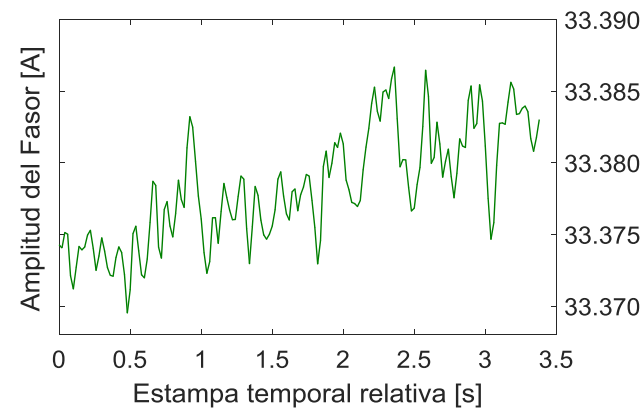

Figura 48-b. Orden de paquetes Método comandado - 50 mediciones/s.

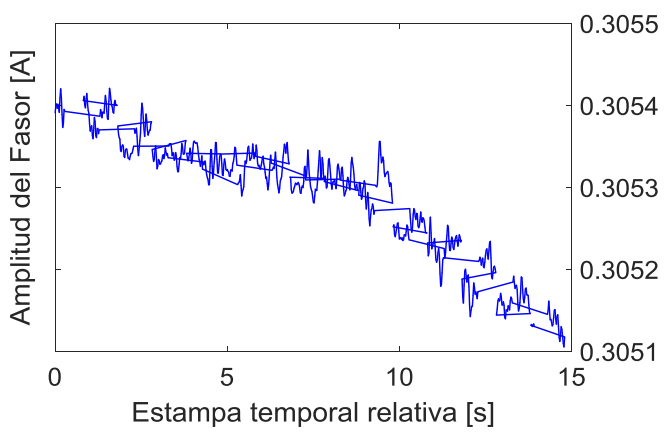

Figura 49-b. Orden de paquetes Método espontáneo - 50 mediciones/s.

En dichas Figuras se observa la amplitud del primer fasor recibido desde la PMU en función de su correspondiente estampa temporal relativa, con el objetivo de analizar el orden cronológico de los paquetes de red. La estampa temporal relativa significa que el primer paquete de red recibido (que no es necesariamente el primer paquete enviado por la PMU) se corresponde con el tiempo cero, de manera tal que las estampas temporales recibidas a continuación son procesadas en forma relativa a ella. Por ejemplo, el valor 1 en el eje temporal se corresponde con la estampa temporal generada 1 segundo después de la primera estampa recibida. Un valor negativo en el eje temporal significa que la primera estampa temporal recibida no fue la primera estampa enviada. Es decir, en el extremo del PDC del sistema, algunos paquetes de red recibidos con posterioridad son anteriores a la primera estampa temporal recibida.

La Figura 48 muestra una amplitud continua del fasor, sin cruces en el trazo, indicando de esta manera una correcta recepción de los datos. La Figura 49, en cambio, muestra una amplitud discontinua del sincrofasor incluyendo cruces en el trazo, lo que demuestra una recepción errónea de los datos. Como consecuencia, puede afirmarse que el método comandado no evidenció ningún error en el orden de recepción de los datos, 
mientras que el método espontáneo sí lo hizo. Este fenómeno se debe a la capacidad de retransmisión y reordenamiento de datos que posee el protocolo TCP a diferencia del protocolo UDP.

Al igual que en el ensayo descripto anteriormente, el análisis de los sincrofasores recibidos en cada paquete de red se realizó tanto para el método comandado como para el método espontáneo utilizando los dos enlaces de comunicaciones estudiados. Se registraron los paquetes de red recibidos en cada caso durante un período de aproximadamente 10 minutos repetidas veces. Para cada registro, se procesó el número de datos sincrofasoriales recibidos en cada paquete con el objetivo de realizar un análisis estadístico.

En la Tabla II, se muestran los resultados obtenidos en una de las pruebas realizadas para cada método. Es posible observar el número de paquetes de red TCP/UDP recibidos, el número de conjuntos de datos recibidos y una clasificación de los paquetes según la cantidad de datos recibidos incluidos en ellos.

Tabla II. Registro de paquetes y datos recibidos.

\begin{tabular}{|c|c|c|c|c|}
\hline & \multicolumn{2}{|c|}{ Comandado } & \multicolumn{2}{c|}{ Espontáneo } \\
\cline { 2 - 5 } & Cableado & GSM/GPRS & Cableado & GSM/GPRS \\
\hline Total de conjunto de datos recibidos & 26406 & 28680 & 26894 & 33263 \\
\hline Paquetes recibidos & 24971 & 27661 & 26894 & 33263 \\
\hline 1 conjunto/paquete & 24475 & 27226 & 26894 & 33263 \\
\hline 2 conjunto/paquete & 147 & 232 & 0 & 0 \\
\hline 3 conjunto/paquete & 66 & 41 & 0 & 0 \\
\hline 4 conjunto/paquete & 55 & 39 & 0 & 0 \\
\hline 5 conjunto/paquete & 48 & 55 & 0 & 0 \\
\hline 6 conjunto/paquete & 48 & 6 & 0 & 0 \\
\hline 7 conjunto/paquete & 23 & 21 & 0 & 0 \\
\hline 8 conjunto/paquete & 7 & 9 & 0 & 0 \\
\hline 9 conjunto/paquete & 6 & 9 & 0 & 0 \\
\hline 10 conjunto/paquete & 42 & 10 & 0 & 0 \\
\hline Conjuntos con errores & 54 & 13 & 0 & 0 \\
\hline
\end{tabular}

A partir de un análisis estadístico realizado sobre los resultados obtenidos en cada prueba, en la Figura 50 se observa el porcentaje de paquetes recibidos conteniendo un único conjunto de datos en cada caso analizado.

La Tabla II y la Figura 50 demuestran que la combinación de conjuntos de datos en un único paquete de red no se produce para el caso de transmisiones UDP mediante el 
método espontáneo, mientras que sí se produce en el caso del método comandado aplicando TCP. Por lo tanto, es posible concluir que los algoritmos diseñados para realizar un uso eficiente del ancho de banda afectan solo al método comandado, dado que se basa en el protocolo TCP.

Basada en los resultados estadísticos, es posible observar en la Figura 51 el porcentual de paquetes de red que contienen entre 2 y 10 conjuntos de datos respecto al número total de paquetes de red recibidos. Es posible concluir, entonces, que el efecto más importante de los algoritmos para el uso eficiente del ancho de banda consiste en generar paquetes que contienen, en la mayoría de los casos, 2 conjuntos de datos combinados en su interior.

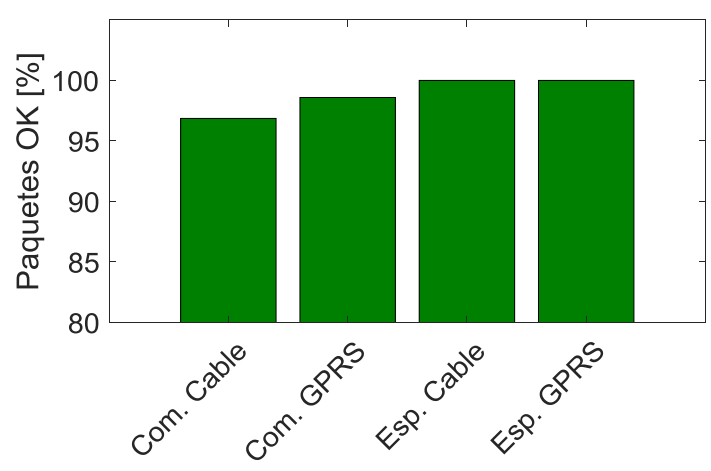

Figura 50. Paquetes de red con un único conjunto de datos.

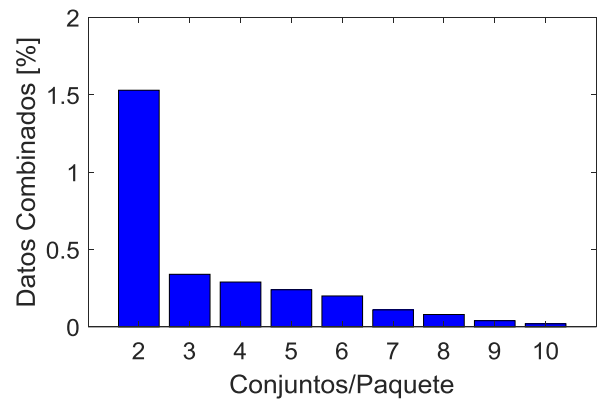

Figura 51. Cantidad de paquetes con múltiples conjuntos.

\subsection{Elección del método transmisión}

Tal como se describe en [44][45][46][47], la latencia de datos es crítica y tiene diferentes requerimientos según la aplicación analizada. Los resultados obtenidos de los ensayos realizados muestran cómo se deben considerar, en una transmisión de sincrofasores basada en TCP e internet, el efecto de los diferentes nodos de la red y los algoritmos que en los nodos se ejecutan. La combinación de los conjuntos de datos de las PMUs en un único paquete de red TCP genera indisponibilidad de datos durante ciertos intervalos de tiempo, que puede ser analizado como latencia de datos para los conjuntos más antiguos que fueron combinados en dicho paquete. Por ejemplo, si 2 conjuntos de datos son combinados en un paquete de red, se obtiene una latencia mínima de $20 \mathrm{~ms}$ (para el caso de una transmisión de 50 mediciones/s) que puede aumentar debido a latencias propias de la red y el procesamiento de la medición; 6 conjuntos combinados producen una latencia mínima de $100 \mathrm{~ms}$.

Los fenómenos rápidos y peligrosos que pueden producirse en los sistemas de potencia definen requerimientos temporales muy estrictos en aplicaciones de tipo WAMC o WAMPAC. Estos requerimientos establecen límites a los retardos en la transmisión de datos, en el procesamiento del PDC, en la toma de decisiones y en la acción de control. El retardo en la transmisión de datos, o latencia, es provocado por 
diferentes factores como el almacenamiento en memoria de mediciones, la distancia entre nodos y el tiempo de procesamiento. Esta latencia en sistemas WAMC/WAMPAC puede ser estimada mediante la Ec. 4.1.

$$
\mathrm{T}_{\mathrm{T}}=\mathrm{T}_{\mathrm{P}}+\mathrm{T}_{\mathrm{C}}+\frac{\mathrm{P}}{\mathrm{R}}+\frac{\mathrm{n}-1}{\mathrm{~S}}
$$

donde $\mathrm{T}_{\mathrm{T}}$ es el retardo total, $\mathrm{T}_{\mathrm{P}}$ es el retardo asociado a la medición y procesamiento de señal (30-100 ms), $\mathrm{T}_{\mathrm{C}}$ es el retardo en la transmisión de datos a través del enlace de comunicaciones (15-150 ms), $\mathrm{P}$ es la cantidad de datos enviados (6 fasores con formato coma flotante utilizan 384 bits), $R$ es la tasa de transmisión del enlace (100 kbps), $n$ es el número de conjuntos de datos combinados (habitualmente 2) y $\mathrm{S}$ es la tasa de transmisión de sincrofasores (50 mediciones/s). A modo de ejemplo, la estimación de retardo total resulta de $185 \mathrm{~ms}$ aproximadamente para un enlace de comunicaciones dedicado basado en una red de fibra óptica sin combinaciones de datos [48]. Naturalmente, este retardo aumenta cuando se utiliza una conexión a internet.

En un caso límite, para la estabilidad transitoria o estabilidad de primera oscilación del sistema, la acción de control completa (desde la detección de la perturbación hasta la actuación) debe producirse antes que la variación pico del ángulo de fase del modo inter-área (habitualmente 1 a 1,5 s) [49]. Si se considera también el tiempo de apertura o cierre del interruptor, la acción de control basada en mediciones sincrofasoriales debe realizarse en 0,3 segundos, incluyendo la transmisión y procesamiento de los sincrofasores.

Estos límites temporales pueden ser utilizados como requerimientos para evaluar cada método de transmisión a través de internet según la aplicación de sincrofasores que se analice. El método comandado provee siempre datos ordenados. Sin embargo, los datos presentan indisponibilidad temporal, debido al Algoritmo de Nagle. El método espontáneo provee alta disponibilidad de datos, pero desordenados.

En el caso de sistemas WAMS, ambos métodos pueden ser utilizados aplicando diferentes algoritmos para el procesamiento de datos. En el caso del método comandado, los datos recibidos más antiguos en un paquete de red combinado pueden ser visualizados en simultáneo con el dato más reciente o descartados. En el caso del método espontáneo, los datos desordenados pueden ser almacenados y ordenados o descartados.

Para sistemas WAMC o WAMPAC, la disponibilidad de datos es crítica para detectar condiciones peligrosas del sistema y realizar las acciones de control correspondientes. Los algoritmos de detección y control requieren alta disponibilidad de datos y cuentan con diferentes métodos para procesar información desordenada.

Tal como se mencionó en la sección 4.1, las normas que rigen los sistemas sincrofasoriales de medición no definen una única infraestructura de red que deba ser empleada. En las normas correspondientes se describen algunos de los métodos posibles 
a utilizar, incluyendo los métodos comandado y espontáneo que en esta tesis se analizan y que son ampliamente utilizados en la tecnología actual.

La falta de definición sobre un único método de transmisión da lugar, entonces, a la elección de uno u otro método según las necesidades particulares de cada aplicación, siendo realizada dicha elección tanto por el fabricante de la PMU como por el administrador del sistema de medición en cuestión. Por lo tanto, no es posible encontrar en la literatura afín análisis muy acabados que demuestren las ventajas y desventajas de un método frente al otro ni la viabilidad de aplicación de dichos métodos para aplicaciones específicas.

Ante la falta de parámetros para elegir un método u otro, en la presente tesis se desarrollaron las pruebas antes descriptas que permitieran evaluar el desempeño de los métodos de transmisión propuestos. Por lo tanto, a partir de las conclusiones obtenidas de los ensayos y las características de los diferentes sistemas de medición (WAMS, WAMC, WAMPAC, etc.), en la Tabla III se muestra la máxima latencia aceptable [46] y los métodos de transmisión sugeridos para las diferentes aplicaciones, donde $\mathrm{S}$ denota método sugerido y NS método no sugerido.

Tabla III. Requisitos de latencia y compatibilidad de métodos de transmisión.

\begin{tabular}{|c|c|c|c|c|c|c|}
\hline \multirow{2}{*}{ Fenómeno } & \multirow{2}{*}{ Aplicaciones } & \multirow{2}{*}{$\begin{array}{c}\text { Latencia } \\
\text { [s] }\end{array}$} & \multicolumn{2}{|c|}{ Cableado } & \multicolumn{2}{|c|}{ GSM/GPRS } \\
\hline & & & TCP & UDP & TCP & UDP \\
\hline $\begin{array}{l}\text { Estimación de } \\
\text { estados }\end{array}$ & $\begin{array}{l}\text { Análisis de contingencias } \\
\text { Flujo de potencia }\end{array}$ & 1 & $S$ & $S$ & $S$ & $S$ \\
\hline $\begin{array}{l}\text { Estabilidad } \\
\text { transitoria }\end{array}$ & $\begin{array}{c}\text { Protección de carga } \\
\text { Disparo automático de carga } \\
\text { (DAC) } \\
\text { Protección de generación } \\
\text { Disparo automático de } \\
\text { generación (DAG) } \\
\text { Formación de Islas }\end{array}$ & 0,3 & $N S$ & $S$ & $N S$ & $S$ \\
\hline $\begin{array}{l}\text { Estabilidad de } \\
\text { pequeña señal }\end{array}$ & $\begin{array}{c}\text { Modos de oscilación } \\
\text { Forma de los modos } \\
\text { Amortiguamiento } \\
\text { Actualización de parámetros de } \\
\text { Estabilizadores de Potencia } \\
\text { (PSS) en línea y actualización } \\
\text { de parámetros de lazos de } \\
\text { control (POD) de dispositivos } \\
\text { FACTS. }\end{array}$ & 1 & $S$ & $S$ & $S$ & $S$ \\
\hline $\begin{array}{l}\text { Estabilidad de } \\
\text { tensión }\end{array}$ & $\begin{array}{c}\text { Conmutación de capacitores } \\
\text { Liberación de cargas } \\
\text { Formación de Islas }\end{array}$ & $1-5$ & $S$ & $S$ & $S$ & $S$ \\
\hline
\end{tabular}

En conclusión, en base a los resultados obtenidos tanto en conexiones cableadas como GSM/GPRS y su evaluación respecto a los requerimientos de latencias de las diferentes aplicaciones, se detectó la obtención de un mejor desempeño cuando el método utilizado es el espontáneo. Es por ello que el método espontáneo fue 
seleccionado para la implementación del sistema de medición sincrofasorial de la presente tesis. 


\section{Concentrador de Datos}

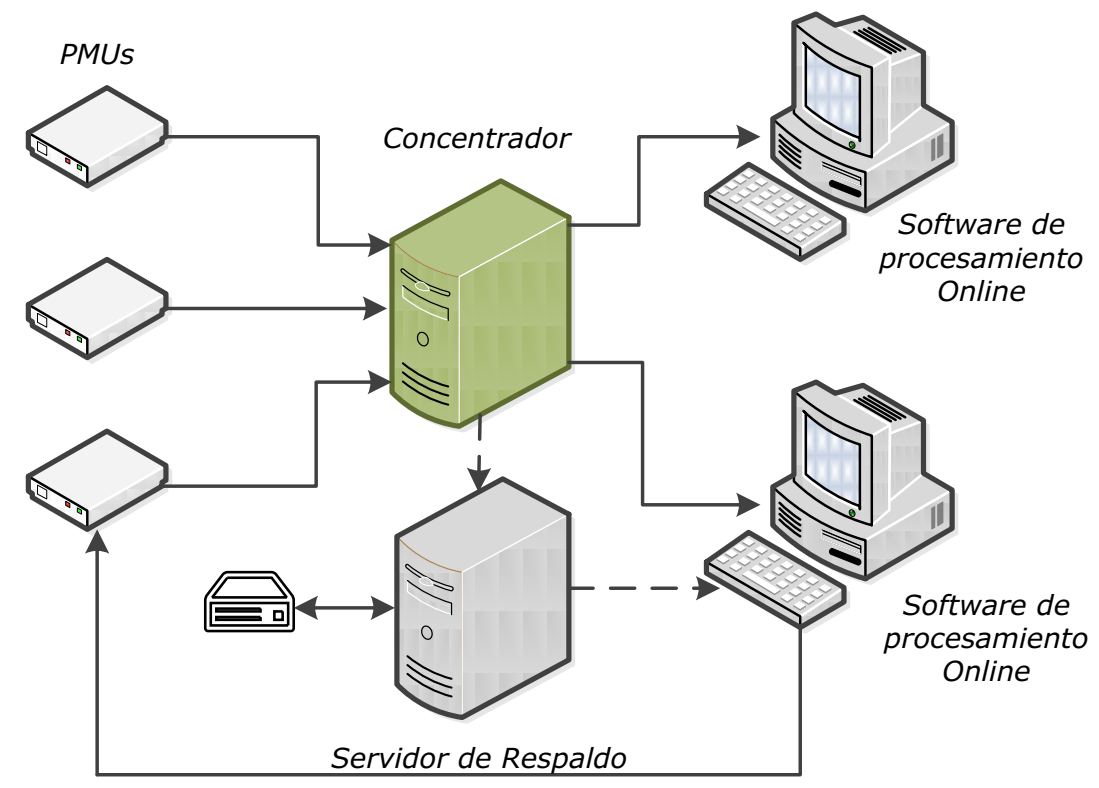

Figura 52. Concentrador de Datos en el sistema de medición sincrofasorial

\subsection{Descripción General}

El Concentrador de Datos tiene como función principal la recepción y sincronización temporal de los fasores recibidos de múltiples PMUs, de forma tal de producir un conjunto de datos sincronizados en el tiempo y en tiempo real. Los PDCs pueden intercambiar datos con otros PDCs en otra zona geográfica. El uso de múltiples PDCs permite la implementación de múltiples capas de concentración de datos.

En la Figura 53 puede observarse un diagrama en bloques del diseño realizado, teniendo en cuenta las especificaciones establecidas en [38].

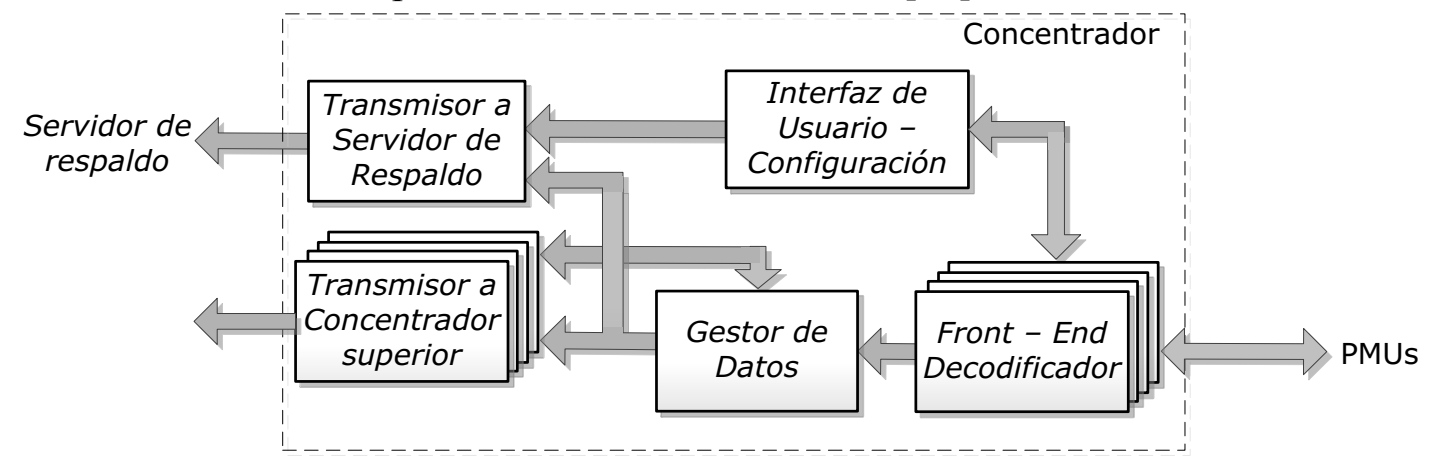

Figura 53. Diagrama en Bloques - Concentrador.

El Front - End tiene como objetivo la recepción y decodificación de los datos provenientes de las PMUs, obteniendo los fasores y las etiquetas temporales entre otros. 
El concentrador dispone de un Front-End por cada PMU conectada, de manera tal de recibir en simultáneo datos de cada una de ellas.

El Gestor de Datos es el encargado de realizar el alineamiento temporal de los sincrofasores recibidos de las distintas PMUs, generando los paquetes de datos necesarios para ser transmitidos al Servidor de Respaldo en el caso que sea necesario y a concentradores de jerarquía superior o directamente al software de procesamiento. Esto se realiza mediante los Transmisores correspondientes.

El Concentrador es un software diseñado para ser utilizado bajo sistema operativo Windows, tanto de 32 como de 64 bits.

\subsection{Comunicaciones}

La transmisión de los sincrofasores medidos por las PMUs hacia el concentrador se realiza, tal como se detalló en el capítulo 4, mediante comunicaciones UDP o TCP. Dichas comunicaciones requieren la existencia de un receptor compatible con la topología cliente-servidor propia de las comunicaciones de red LAN/WAN para el caso del método comandado aplicando TCP o UDP, y de un receptor de datos provenientes de una multidifusión UDP para el caso del método espontáneo. Un esquema de la topología de conexión puede observarse en la Figura 54.

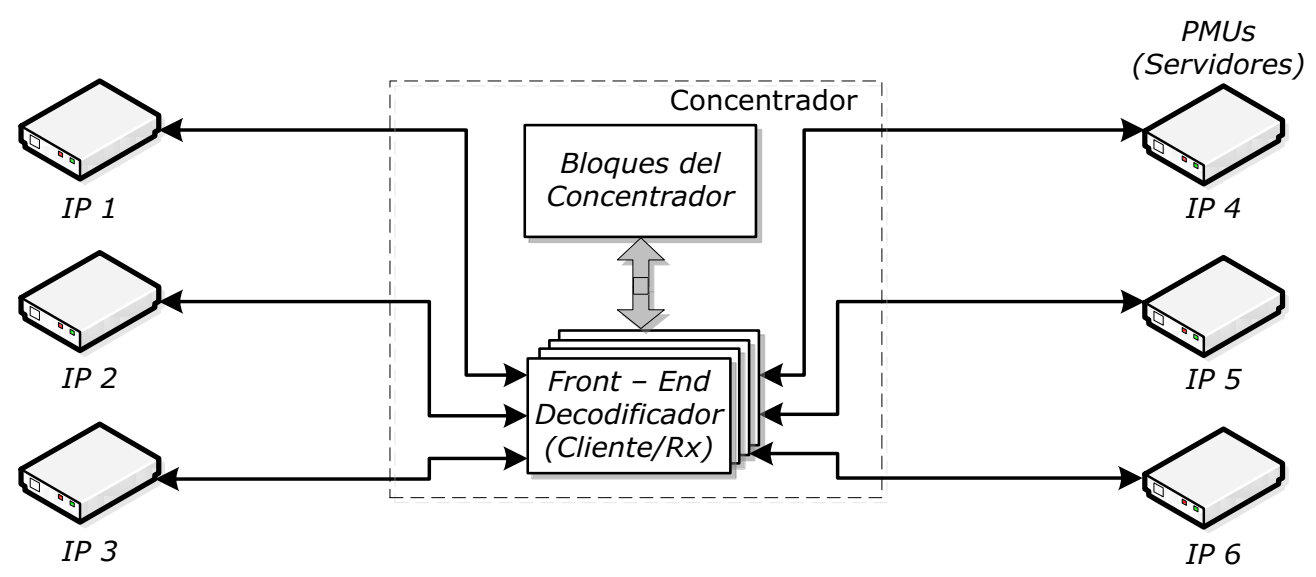

Figura 54. Topología de comunicaciones - Concentrador.

\subsection{Identificación de cada PMU}

Según lo analizado en el capítulo 4, las PMUs instaladas en el sistema cuentan, generalmente, con una dirección IP variable y que sufre modificaciones en instantes desconocidos para el concentrador. Esto provoca que dicha dirección no pueda ser utilizada como identificador unívoco de cada una de las PMUs conectadas al sistema. 
Con el objetivo de disponer de un método para identificar la PMU con independencia de la dirección IP asignada, se utiliza comúnmente el Sistema Dinámico de Nombres de Dominio (DDNS).

El DDNS es un sistema de nomenclatura jerárquico descentralizado para dispositivos conectados a redes IP como Internet o una red privada. Este sistema basa su funcionamiento en asociar a un nombre de dominio fijo y único información que puede ser variable como por ejemplo la dirección IP. De esta manera, dicho sistema permite realizar una traducción entre el nombre de dominio del dispositivo y su identificador IP.

Para poder hacer uso de dicho sistema, existen servicios brindados de forma gratuita o arancelada cuya función principal es realizar un seguimiento de la dirección IP de un dispositivo (a través de software específico) de manera tal de poder acceder al dispositivo a través de su nombre de dominio al cual se le actualiza constantemente la dirección IP que le corresponde.

De esta manera, cada PMU es identificada con un nombre de dominio, que no sufre modificaciones a lo largo del tiempo, y los servicios descriptos anteriormente son los encargados de actualizar la dirección IP asignada según las variaciones que vaya sufriendo.

Cuando la PMU es configurada para transmitir sus sincrofasores mediante el método comandado, es necesario establecer la conexión desde el PDC a la PMU. Para ello, el PDC debe conectarse, entonces, a la dirección IP obtenida mediante el nombre de dominio que la PMU disponga.

\subsection{Front-End}

El Front-End/Decodificador puede esquematizarse con un diagrama en bloques como el que se observa en la Figura 55.

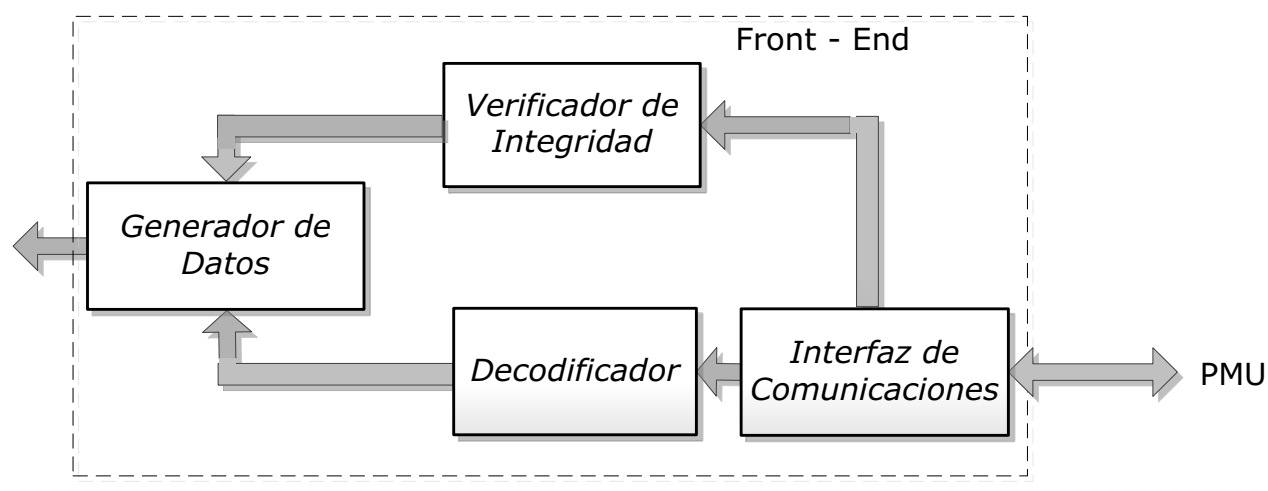

Figura 55. Front-End/Decodificador - Concentrador.

La comunicación con la PMU se lleva a cabo mediante la Interfaz de Comunicaciones. Este enlace se realiza mediante una comunicación TCP o UDP con la topología correspondiente. En la Figura 56 se observa un esquema de dicha interfaz. 


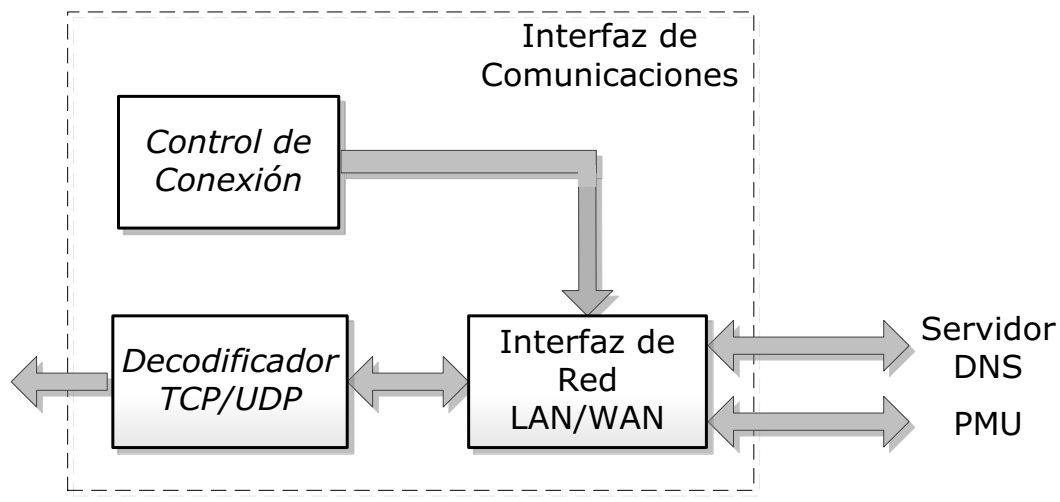

Figura 56. Interfaz de Comunicaciones - Decodificador.

La Interfaz de Comunicaciones tiene dos funciones principales. La primera de ellas es la recepción y decodificación de los paquetes TCP/UDP transmitidos por las PMUs para su análisis posterior. La segunda función de este bloque, necesaria en el caso de una conexión cliente-servidor, es el mantenimiento de la conexión con la PMU. Para ello, lleva adelante un control de la disponibilidad del enlace entre el Front-End y la PMU con el objetivo de detectar un eventual corte de la conexión para, en ese caso, intentar una reconexión de manera automática. Dicha función puede denominarse, entonces, Control de Conexión.

En el caso del método espontáneo de transmisión de sincrofasores, la Interfaz establece el canal de comunicaciones correspondiente y comienza la espera de datos transmitidos por la PMU realizando la apertura del puerto UDP asignado a la PMU, que debe ser establecido previamente por el Administrador del sistema de medición.

En el caso del método comandado de transmisión de sincrofasores, para establecer el canal de comunicaciones correspondiente, la Interfaz realiza en primer lugar una consulta al Sistema de Nombres de Dominio a través de la interfaz de red. Dicha consulta consiste en obtener la dirección IP que le corresponde al nombre de dominio ingresado por el usuario. De esta manera, se obtiene la dirección IP actual de la PMU a la que se desea conectar el Concentrador.

Una vez obtenidos los datos del Sistema DNS, la Interfaz establece la comunicación con el servidor que dispone la PMU para inicializar el canal de comunicaciones y comenzar a recibir los sincrofasores correspondientes.

Los datos obtenidos por la interfaz son recibidos por el Decodificador y el Verificador de Integridad.

El Decodificador es el encargado de recuperar la información útil que se recibe de la PMU. Para ello, implementa un analizador de datos que realiza la búsqueda de cada uno de los campos de datos previstos en la norma IEEE C37.118.2 [10].

Como primer paso, el Decodificador determina el tipo de paquete recibido (Paquete de configuración o Paquete de Datos). En función del tipo recibido, se realiza la decodificación correspondiente. 
Para el caso de la recepción de un Paquete de Configuración, el Decodificador obtiene del paquete las características de la PMU conectada. Entre ellas, puede mencionarse el identificador de la PMU (ID), el Nombre de la PMU, la cantidad de fasores medidos, el tipo y unidad de conversión de cada fasor, la frecuencia nominal de la red medida y la tasa de transmisión de datos, entre otros. Todos estos datos son almacenados en la memoria del concentrador para poder realizar la decodificación de los Paquetes de Datos.

Para el caso de la recepción de un Paquete de Datos, el Decodificador obtiene los valores medidos por la PMU. En base a la configuración almacenada de la PMU, se extraen del paquete recibido las mediciones de todos los fasores, los canales analógicos, los canales digitales y la etiqueta temporal a la que corresponde el paquete. A su vez, se realiza la verificación del campo de validez de datos emitido por la propia PMU, con el objetivo de marcar la fiabilidad de las mediciones que se hayan efectuado

El Verificador de Integridad tiene como función la verificación de errores en el paquete recibido. Para ello, realiza la comparación entre el código de Verificación de Redundancia Cíclica (CRC - CCITT) recibido con el calculado localmente. Si ambos códigos no coinciden, el paquete recibido es finalmente descartado.

El Generador de Datos, finalmente, es el encargado de producir los paquetes de datos necesarios para su procesamiento por los demás bloques del concentrador. En dichos paquetes se incluyen las mediciones de la PMU, la etiqueta temporal y el campo de validez de datos.

Es importante mencionar que este módulo incluye también, en la Interfaz de Comunicaciones, la posibilidad de transmitir datos hacia la PMU cuando el método de transmisión lo permite. Dichas transmisiones permiten enviarle comandos a la PMU para solicitarle su configuración o para habilitar/deshabilitar la transmisión de paquetes de datos.

\subsubsection{Control de Conexión}

El control de conexión de la Interfaz de Comunicaciones del Concentrador tiene como función, tal como se mencionó anteriormente, supervisar el estado del enlace de comunicaciones existente entre el Concentrador (que cumple las funciones de cliente en la topología cliente-servidor del protocolo TCP) y la PMU (que cumple las funciones de servidor).

La función de control de este componente se aplica a la actividad del enlace TCP o UDP existente, verificando la integridad de los datos y la integridad de la conexión propiamente dicha. De esta manera, cuando se detecta la pérdida del enlace, el concentrador realiza intentos de reconexión con la PMU correspondiente hasta tanto lograr restablecer la comunicación. 


\subsection{Gestor de Datos}

El Gestor de Datos es el encargado de alinear temporalmente todos los datos provenientes de las PMUs y generar el paquete de datos. El diagrama en bloques del gestor se puede observar en la Figura 57.

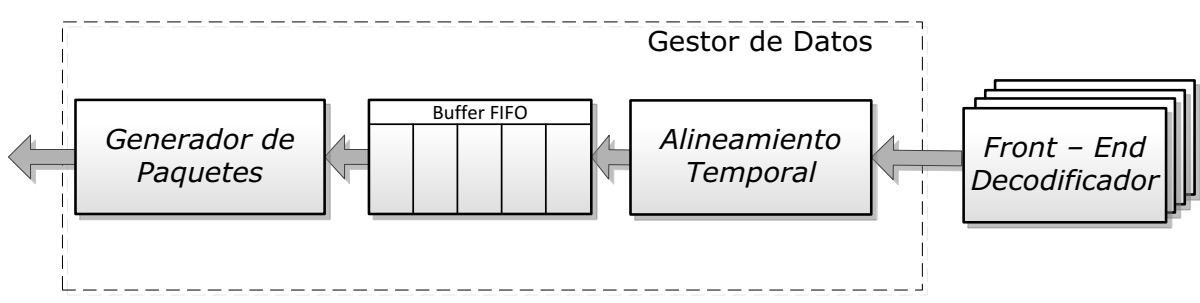

Figura 57. Gestor de Datos - Concentrador.

El principal componente de este bloque es el buffer FIFO. En cada posición de este buffer se almacenan todos los datos que tengan la misma etiqueta temporal. De esta manera, se agregan datos a medida que se reciben y se extraen datos a medida que son transmitidos por el concentrador.

Los datos provenientes de cada uno de los front-end son recibidos por el bloque de alineamiento temporal. Este bloque realiza una búsqueda en el buffer FIFO de una posición que tenga la misma etiqueta temporal que los datos recibidos. Si se encuentra, los datos recibidos son agregados a los ya existentes en el buffer para esa misma etiqueta. Si no se encuentra, y la etiqueta temporal recibida es más nueva que la última almacenada, se genera una nueva posición en el buffer con dicha etiqueta y se agregarán allí todos los datos recibidos que correspondan. Caso contrario, los datos recibidos son descartados.

Para brindar mayor flexibilidad en lo que se refiere a retardos en las transmisiones de datos provenientes de una PMU, la profundidad del buffer FIFO es configurable por el usuario. De esta manera, el usuario puede establecer cuánto tiempo el concentrador esperará la llegada de un dato retardado de la PMU. Por ejemplo, si se configura un retardo de $1 \mathrm{~s}$, la profundidad del buffer será de 50 frames de datos. De esta manera, el Concentrador será capaz de aceptar datos retrasados hasta $1 \mathrm{~s}$ sin descartarlos.

Dado que el buffer tiene un tamaño fijo una vez configurado, cuando se necesita generar una nueva posición se verifica que exista memoria disponible. Si no la hay, la posición más antigua es extraída, liberando una posición para realizar el desplazamiento del buffer y el almacenamiento de la nueva posición.

La posición extraída del buffer es utilizada por el Generador de Paquetes para formar un paquete de datos compatible con [10] que incluya todas las mediciones y la etiqueta temporal que le corresponde.

Para realizar la administración del buffer FIFO descripto anteriormente, el PDC dispone de un gestor de memoria. Dicho gestor se encarga de solicitar al sistema operativo de la PC donde el concentrador se encuentra corriendo, un espacio de memoria donde almacenar los datos recibidos con la etiqueta temporal correspondiente. 
De la misma manera, cada vez que una posición del buffer es extraída y procesada por el Generador de Paquetes, el gestor de memoria informa y habilita al sistema operativo para reutilizar las posiciones de memoria ocupadas por esa posición del buffer.

De esta manera, se realiza un uso dinámico de la memoria de la PC.

\subsection{Transmisores}

Los transmisores, tanto para el Servidor de Respaldo como para los Concentradores de orden superior o software, emplean el método de transmisión espontáneo. Para ello, el usuario del PDC debe configurar las direcciones IP y los puertos UDP de los Concentradores de orden superior, Servidores de Respaldo o Software de procesamiento.

\subsection{Interfaz de Usuario}

La interfaz de usuario al iniciarse el Concentrador de Datos se muestra en la Figura 58. Es posible observar en dicha figura las opciones que el usuario posee para interactuar con las PMUs cuando el concentrador comience la transferencia de datos con cada una de ellas.

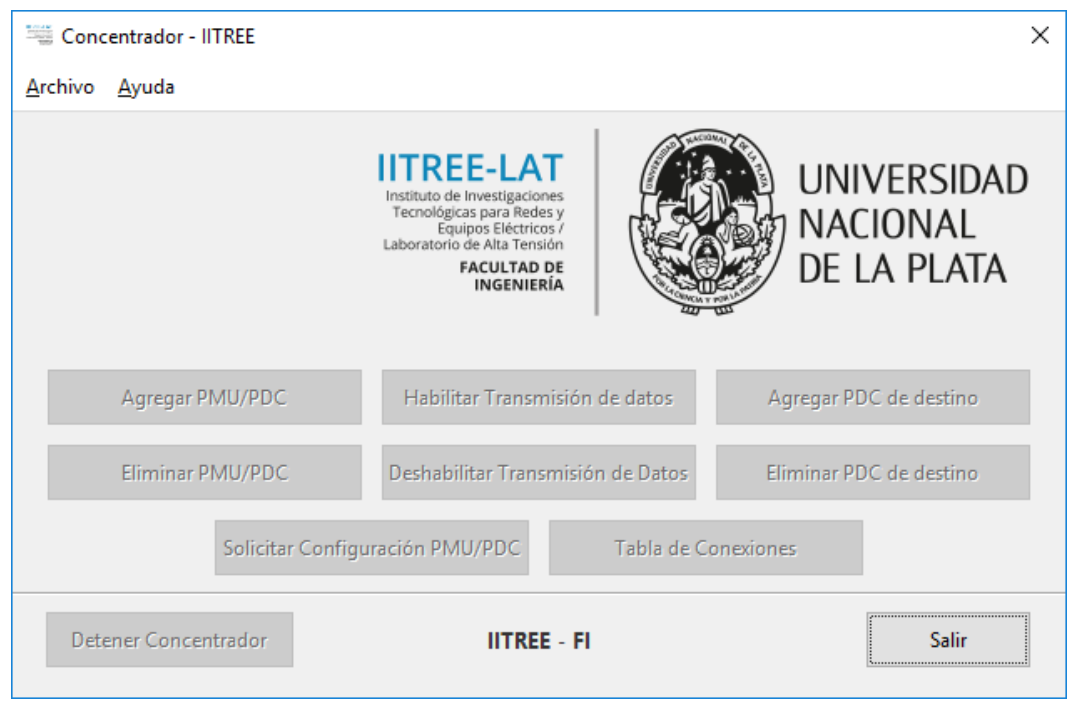

Figura 58. Interfaz de Usuario - Concentrador.

El usuario tiene la posibilidad, mediante el menú correspondiente, de generar una nueva configuración de concentrador (Archivo - Nueva Configuración) o cargar una generada previamente (Archivo - Cargar Configuración).

En la Figura 59, puede observarse el menú de generación de una nueva configuración. 


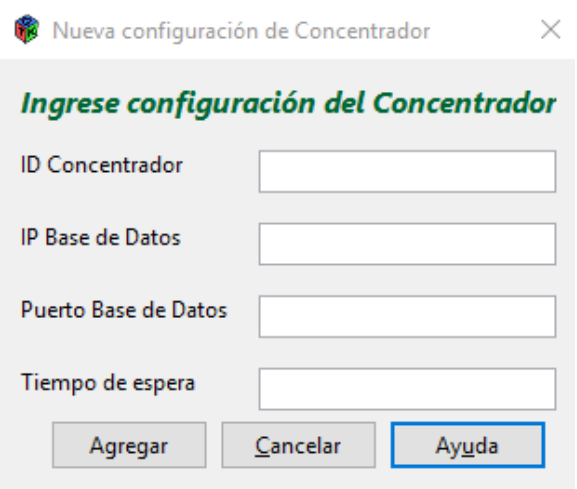

Figura 59. Configuración del Concentrador de Datos.

Los datos requeridos para configurar el concentrador son el ID que tendrá el concentrador en el sistema y el Tiempo de espera. Este último se refiere a la profundidad del buffer FIFO descripto en la sección 5.5. A su vez, se requiere la dirección IP y puerto UDP del Servidor de Respaldo (Base de Datos) a donde se realizará, de ser necesario, el respaldo de cada uno de los sincrofasores procesados.

Una vez que el Concentrador se configura, es posible utilizar todas las opciones que se observan en la Figura 58 deshabilitadas.

En la Figura 60 se puede observar la pantalla de configuración para incorporar una nueva PMU o concentrador de jerarquía inferior desde donde recibir datos (función Agregar PMU/PDC).

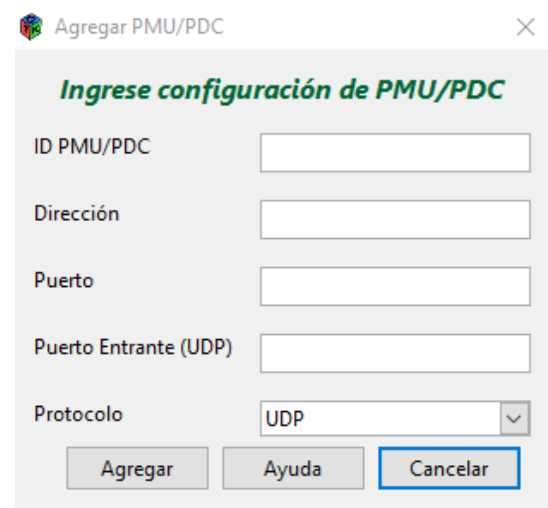

Figura 60. Configuración de PMU o PDC inferior.

Los parámetros de la PMU o PDC de orden inferior que deben configurarse son aquellos que se requieren para establecer la comunicación, según el método de transmisión utilizado.

En el caso de utilización del método comandado, debe seleccionarse como Protocolo TCP o UDP según corresponda. Una vez seleccionado, debe configurarse la ID de la PMU, su dirección DNS y el Puerto TCP o UDP.

En el caso de utilización del método espontáneo, debe seleccionarse como Protocolo SUDP (Spontaneous UDP, por sus siglas en inglés). Una vez seleccionado, debe configurarse sólo el Puerto Entrante (UDP) provisto por el administrador del sistema. 
De la misma manera, puede incorporarse un concentrador de orden superior o software de procesamiento a donde transmitir datos (función Agregar PDC de destino), tal como se ve en la Figura 61.

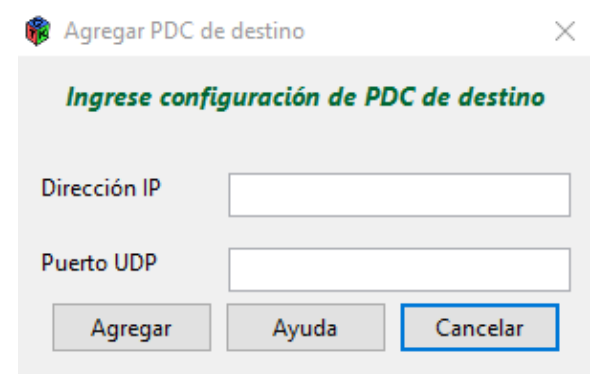

Figura 61. Configuración de PDC superior o Software de procesamiento.

En este caso, solo debe establecerse la dirección IP y puerto UDP del destino a donde enviar los datos mediante el método de transmisión espontáneo.

Finalmente, es importante mencionar las demás posibilidades que brinda el concentrador al usuario, incluyendo aquellas útiles cuando se utiliza el método de transmisión comandado con una PMU. Es posible habilitar o deshabilitar la transmisión de datos de una PMU en particular, eliminar una PMU de la que se estén recibiendo datos, solicitar la configuración de una PMU. A su vez, para cualquier método es posible eliminar un concentrador de orden superior a donde se envían los datos del concentrador.

\subsection{Ensayos de evaluación}

Con el objetivo de comprobar la compatibilidad del Front-End con la norma IEEE C37.118.2 [10], se llevaron a cabo pruebas con software específico de simulación de una PMU, ejecutable en una PC. Dicho software emula todos los paquetes de datos que emite una PMU.

Para poder simular el canal de comunicaciones, se utilizó un módem GSM/GPRS marca Digi modelo DC-WAN-P501 [50]. Dicho módem le provee a la PC una conexión de red de manera tal que actúa de interfaz con la red móvil correspondiente. De esta manera, la conexión de la PC a la red tiene las mismas características que la que disponen las PMUs del sistema de medición sincrofasorial conectadas a una red de este tipo. Es decir, se utilizan direcciones IP dinámicas y una red móvil.

En el caso del ensayo para el método comandado de transmisión, en la PC de emulación de la PMU se ejecutó también el software específico de los servicios de nombre de dominio, que permiten mantener actualizada la dirección IP relacionada al nombre de dominio de la PMU. Es importante mencionar en este caso que la actualización en el servidor DNS de la dirección IP se realiza una vez por minuto. Esto implica que, en el caso de una variación de la dirección IP de la PMU debido a disposiciones de la red móvil, puede producirse una pérdida de la conexión entre la 
PMU y el Concentrador cuya duración en el tiempo puede ser, como máximo, 1 minuto. Esto es causado directamente por la tasa de actualización del servidor DNS.

Las pruebas consistieron en establecer todas las comunicaciones necesarias para poner en funcionamiento el sistema completo, para ambos métodos de transmisión. De esta manera, se ejecutó en una PC el Concentrador, estableciendo comunicaciones con una PMU a través de la red móvil, y se ejecutó en otra PC el Software de Procesamiento Online (ver capítulo 7) que recibió los sincrofasores ordenados por el Concentrador para su visualización.

A lo largo de las pruebas realizadas, no se observaron inconvenientes en la administración de los datos por parte del concentrador.

El mantenimiento de las conexiones con las PMU frente a cortes de la red móvil o cambios en las direcciones IP fue satisfactorio, observándose el buen funcionamiento de la detección de la disponibilidad del enlace por parte del Concentrador y su restablecimiento en caso de corte, para el método comandado de transmisión.

Con estos resultados, pudo validarse el funcionamiento del Concentrador y, además, su compatibilidad con una red móvil con la tasa de datos que requiere una PMU para transmitir 50 paquetes de sincrofasores por segundo. 


\section{Servidor de Respaldo}

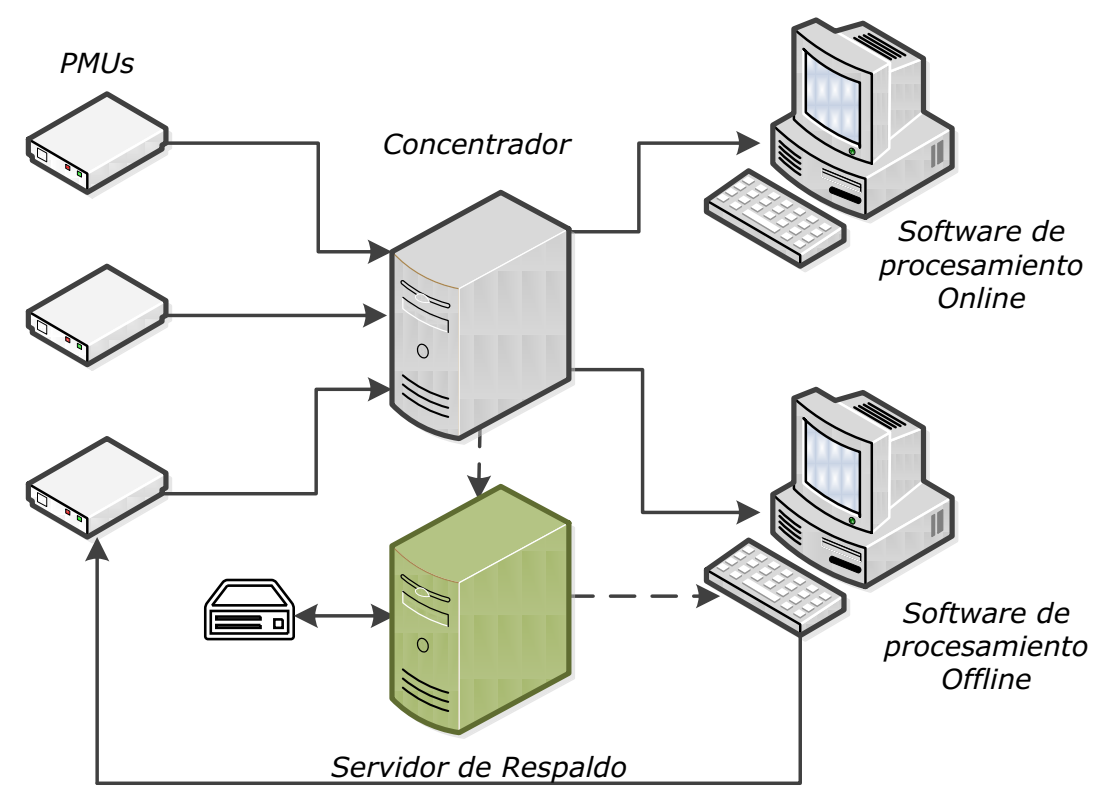

Figura 62. Servidor de Respaldo en el sistema de medición sincrofasorial.

\subsection{Descripción General}

El Servidor de Respaldo tiene por objetivo realizar un almacenamiento en un medio alternativo de todas las mediciones y configuraciones recibidas desde las PMUs. El objetivo es tener disponibles cada uno de los datos obtenidos y permitir una posterior búsqueda y análisis de eventos pasados.

En la Figura 63 se puede observar un diagrama en bloques general del Sistema de Respaldo.

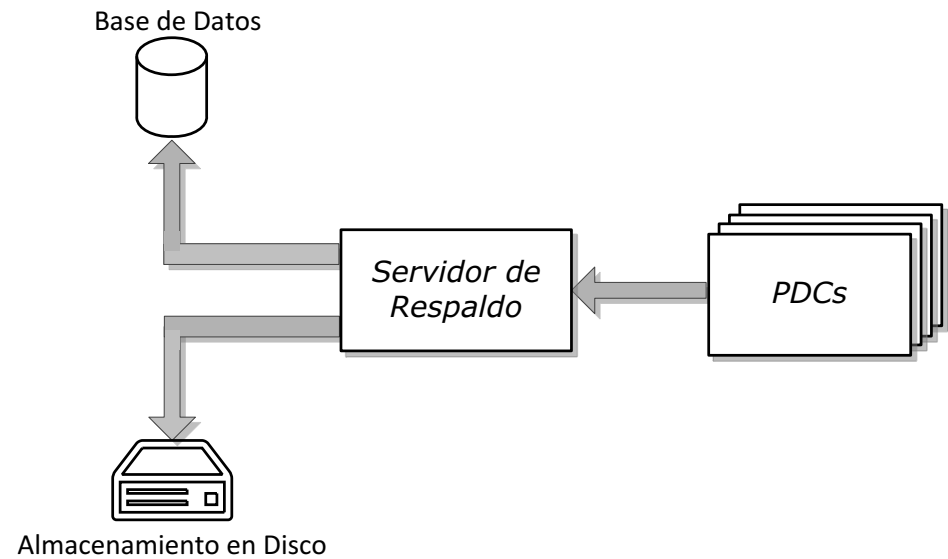

Almacenamiento en Disco

Figura 63. Diagrama en bloques - Sistema de Respaldo. 
El Sistema recibe todos los datos provenientes de los Concentradores mediante una comunicación UDP aplicando el método espontáneo. Cada uno de ellos es almacenado en la Base de Datos dispuesta para tal fin.

De manera periódica y también manual (a pedido del usuario), el servidor realiza un almacenamiento en una unidad intercambiable (prevista para tal fin) de todos los datos organizados en la Base de Datos. De esta forma, se lleva a cabo un control del espacio requerido por la Base de Datos ya que, una vez realizado el respaldo de los datos en la unidad, la Base de Datos es vaciada para comenzar un nuevo período de almacenamiento.

El Agente de Respaldo, dentro del Servidor que compone, se encarga de mantener las comunicaciones con los concentradores, procesar la información recibida y conformar los datos necesarios para su almacenamiento en la Base de Datos. También, tiene como tarea realizar el respaldo de la base de datos en la unidad correspondiente.

En la Figura 64 puede observarse un diagrama en bloques del Agente.

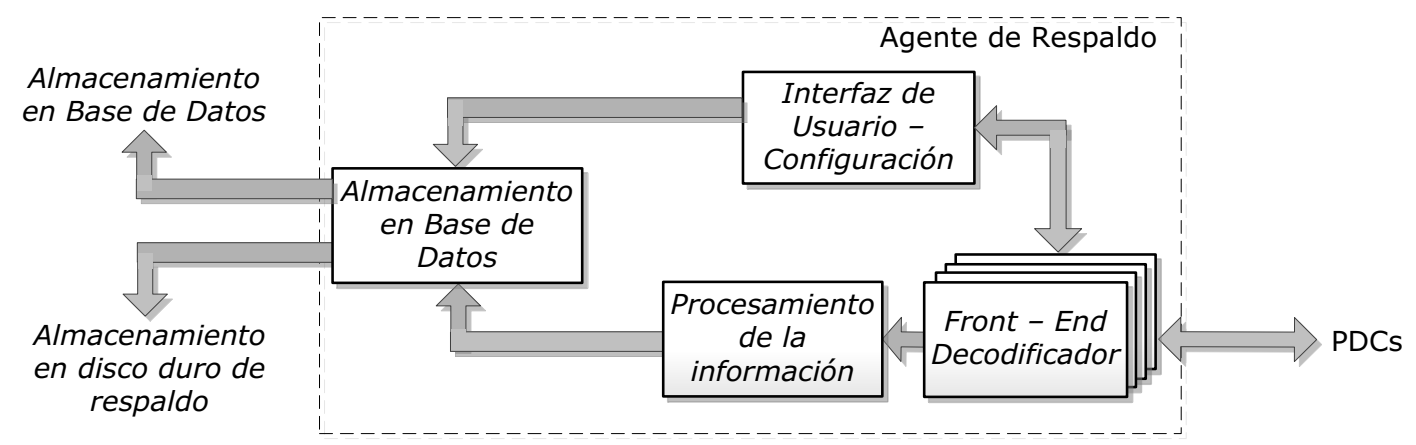

Figura 64. Diagrama en bloques - Servidor de Respaldo.

El Front-End tiene como objetivo la decodificación de los datos provenientes de los PDCs, obteniendo las mediciones y etiquetas temporales. El Agente dispone de un Front-End por cada PDC conectado, de manera tal de recibir en simultáneo datos de cada uno de ellos.

El bloque de Procesamiento de la Información es el encargado de realizar todos los cálculos necesarios para obtener los fasores y demás mediciones en un formato útil para el usuario y listo para su almacenamiento.

El bloque de Almacenamiento tiene dos objetivos principales. El primero de ellos es ser la interfaz entre el Servidor y la Base de Datos propiamente dicha, llevando a cabo todas las tareas necesarias para realizar el almacenamiento de los datos en ella. El segundo objetivo, y no menor, es realizar el almacenamiento de respaldo (back-up) de los datos de la Base en la unidad de almacenamiento que se configure.

El Servidor de Respaldo es un software diseñado para ser utilizado bajo sistema operativo Windows, tanto de 32 como de 64 bits. 


\subsection{Componentes del Servidor de Respaldo}

\subsubsection{Front-End/Decodificador}

El Front-End/Decodificador puede esquematizarse con un diagrama en bloques como el que se observa en la Figura 65.

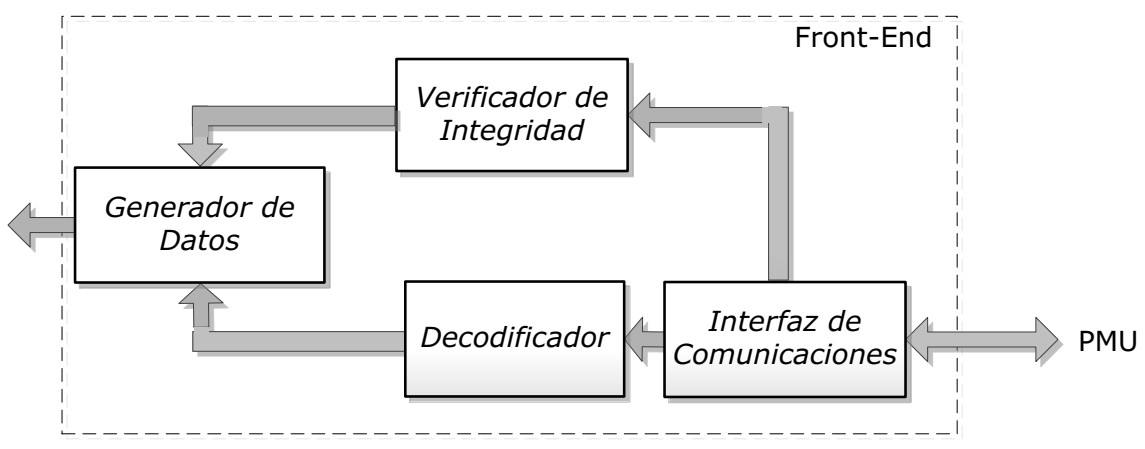

Figura 65. Diagrama en bloques Front-End - Servidor de Respaldo.

La comunicación con el concentrador se realiza mediante la Interfaz de Comunicaciones y Control. Este enlace se realiza mediante una comunicación UDP, aplicando el método espontáneo. Para ello, el sistema de respaldo procesa los datos del PDC recibidos en el puerto UDP asignado por el Administrador del sistema.

Al igual que en toda comunicación compatible con lo establecido por la norma [10], la Interfaz recibe la configuración del PDC. La configuración contiene las características del concentrador conectado. Entre ellas, puede mencionarse el identificador del PDC, su descripción, la cantidad de PMUs concentradas, la cantidad de fasores de cada PMU, el tipo y unidad de conversión de cada fasor, la frecuencia nominal de la red medida por cada PMU y la tasa de transmisión de datos, entre otros. Todos estos datos son almacenados luego en la Base de Datos y en la memoria del Servidor para poder realizar la decodificación y procesamiento de los Paquetes de Datos.

Los datos obtenidos por la interfaz son recibidos por el Decodificador y el Verificador de Integridad.

El Decodificador es el encargado de recuperar la información útil recibida. Para ello, implementa un analizador de datos que realiza la búsqueda de cada uno de los campos de datos previstos en [10] y que son enviados por el concentrador.

De cada paquete recibido, en base a la configuración almacenada del PDC, se obtiene: las mediciones de todos los fasores, los canales analógicos, los canales digitales y la etiqueta temporal a la que corresponde el paquete. A su vez, se realiza la verificación del campo de validez de datos emitido por cada PMU concentrada, con el objetivo de marcar la fiabilidad de las mediciones que se hayan efectuado.

El Verificador de Integridad tiene como función la verificación de errores en el paquete recibido. Para ello, realiza la comparación entre el código de Verificación de 
Redundancia Cíclica (CRC-CCITT) recibido con el calculado localmente. Si ambos códigos no coinciden, el paquete recibido es finalmente descartado.

El Generador de Datos, finalmente, es el encargado de producir los paquetes de datos necesarios para el procesamiento. En dichos paquetes se incluyen las mediciones, la etiqueta temporal y el campo de validez de datos.

\subsubsection{Procesamiento}

El bloque de Procesamiento del Servidor de Respaldo es el encargado de realizar la conversión de los datos a un formato útil para el usuario y listo para su almacenamiento en la Base de Datos.

Un diagrama del bloque de Procesamiento puede observarse en la Figura 66.

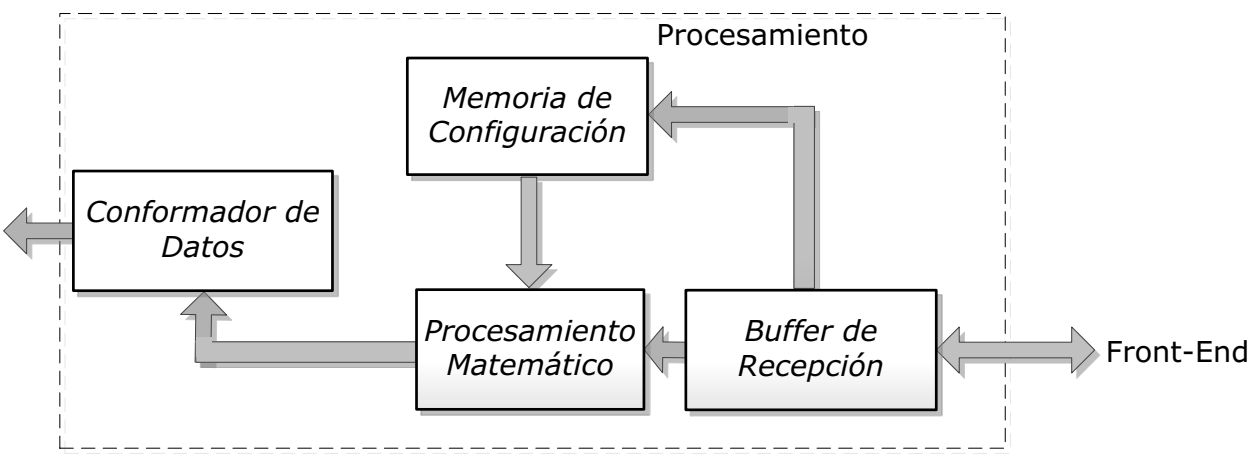

Figura 66. Diagrama en bloques del Procesamiento - Servidor de Respaldo.

Los datos recibidos del Front-End son almacenados temporalmente en el Buffer de recepción para su procesamiento.

Cada uno de los datos recibidos es procesado por el bloque de Procesamiento Matemático en base a la configuración almacenada en la Memoria de configuración. De esta manera, en función de los factores de conversión configurados, el tipo de dato recibido (coma flotante o entero de 16 bits), formato del número complejo, base de tiempo, etc., se obtienen las mediciones en su formato puro listas para ser utilizadas por el usuario si se requiere un análisis offline.

Todos los datos obtenidos, finalmente, son organizados por el Conformador de Datos para su almacenamiento.

\subsubsection{Almacenamiento}

El bloque de almacenamiento es uno de los principales bloques del Servidor de Respaldo. Este bloque tiene por objetivo realizar el almacenamiento en la Base de Datos de los datos procesados y realizar el back-up de la misma en la unidad de almacenamiento. Su diagrama en bloques puede observarse en la Figura 67. 


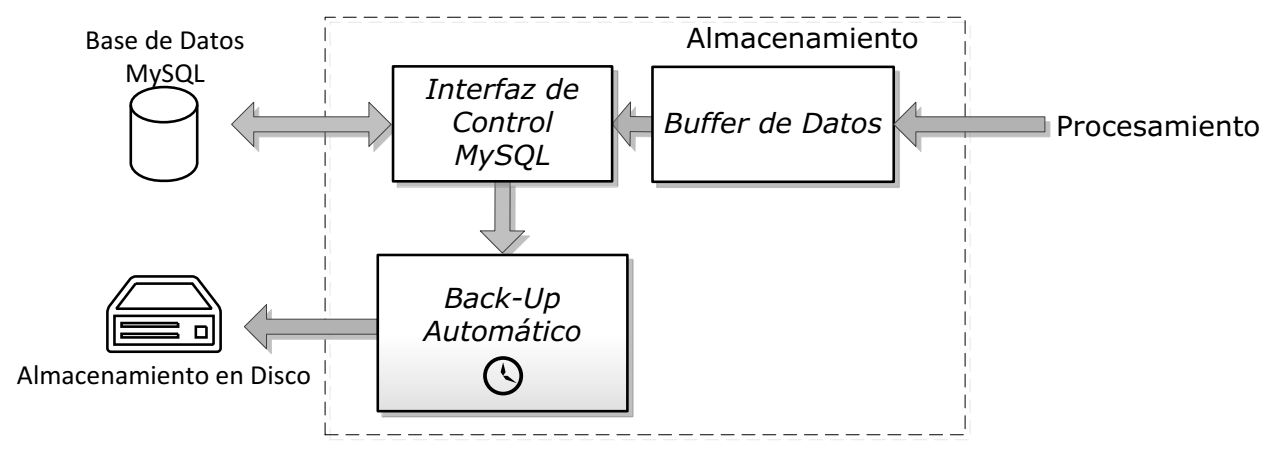

Figura 67. Diagrama en bloques Almacenamiento de Datos - Servidor de Respaldo.

Para realizar el almacenamiento en una Base de Datos, el Servidor utiliza el sistema de gestión MySQL. El sistema MySQL fue elegido por su gratuidad, su simpleza en el control y su velocidad para el almacenamiento masivo de datos. Para ello, la PC donde se instala el Servidor debe contar con la instalación de MySQL Server, porque es a través de él que se realiza la interacción con la base de datos.

Para incorporar datos a la base de datos, el sistema emplea la utilidad mysqlimport del sistema de gestión de base de datos MySQL [51]. Esto se debe a que de esta manera se pueden obtener velocidades de escritura hasta 20 veces mayores que utilizando los comandos tradicionales de MySQL.

Para emplear la utilidad mysqlimport, el bloque de almacenamiento administra un archivo por cada tabla de la base de datos que se desea actualizar (ver sección 6.2.4). Cada archivo contiene todos los datos recibidos correspondientes a la tabla, que serán incorporados a la base mediante la herramienta mencionada. Una vez incorporados los datos, el contenido de los archivos es eliminado para almacenar los nuevos datos recibidos.

Por otro lado, este módulo se encarga también de realizar el back-up de la base de datos. Para ello, en forma periódica (con un periodo configurable por el usuario) se realiza un volcado de todos los datos de la base mediante la utilidad mysqldump [52] a archivos de tipo CSV. Esto se realiza de esta manera para lograr la mayor velocidad posible en la descarga de datos. Cada respaldo es almacenado en una carpeta dentro de la unidad configurada, cuyo nombre contiene la fecha y hora en que se realizó el backup.

\subsubsection{Esquema de la Base de Datos}

En función de lo mencionado en la sección 6.2.3, la base de datos se utiliza mediante el sistema MySQL. En la Figura 68 puede observarse un diagrama de las tablas y campos que conforman la estructura de la Base de Datos. 


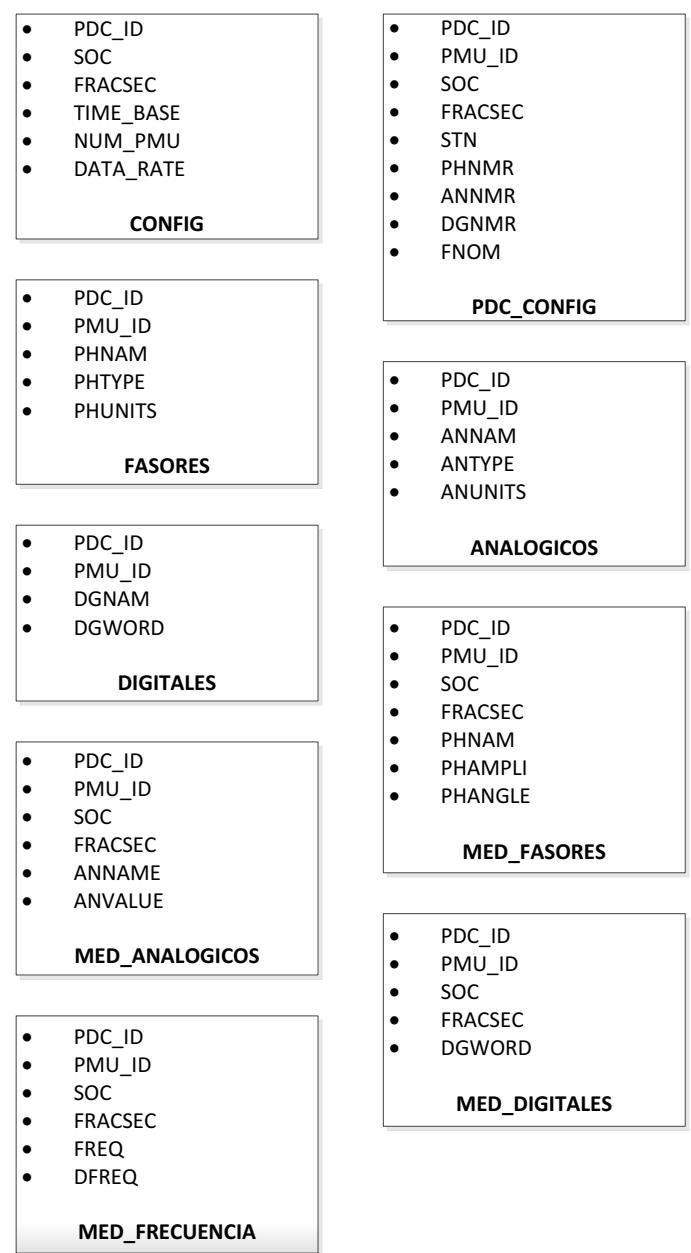

Figura 68. Tablas de Base de Datos.

La tabla CONFIG almacena los datos correspondientes a la configuración general de cada PDC, es decir, ID del PDC, base de tiempo, cantidad de PMUs concentradas y frecuencia de transmisión de datos.

La tabla PDC_CONFIG almacena la configuración de cada PMU concentrada por cada PDC. De esta manera, se almacena el ID de cada PMU, su nombre, la cantidad de fasores, canales analógicos y canales digitales y la frecuencia nominal de la red a la que se encuentra conectada.

La tabla FASORES contiene las características de cada fasor medido por cada PMU. Por lo tanto, sus campos son el nombre de cada fasor, el tipo y la unidad de conversión. Este mismo esquema es el utilizado para la tabla ANALOGICOS, correspondiente a cada canal de medición analógica.

La tabla DIGITALES contiene las características de conversión para la palabra de medición digital.

Finalmente, las tablas MED_FASORES, MED_ANALOGICOS, MED_DIGITALES y MED_FRECUENCIA contienen las mediciones obtenidas de cada PMU, con la etiqueta temporal que les corresponde. 
Los nombres de los campos fueron elegidos en función de la denominación establecida en la norma [9].

\subsection{Interfaz de Usuario}

La interfaz de usuario del Servidor de respaldo puede observarse en la Figura 69.

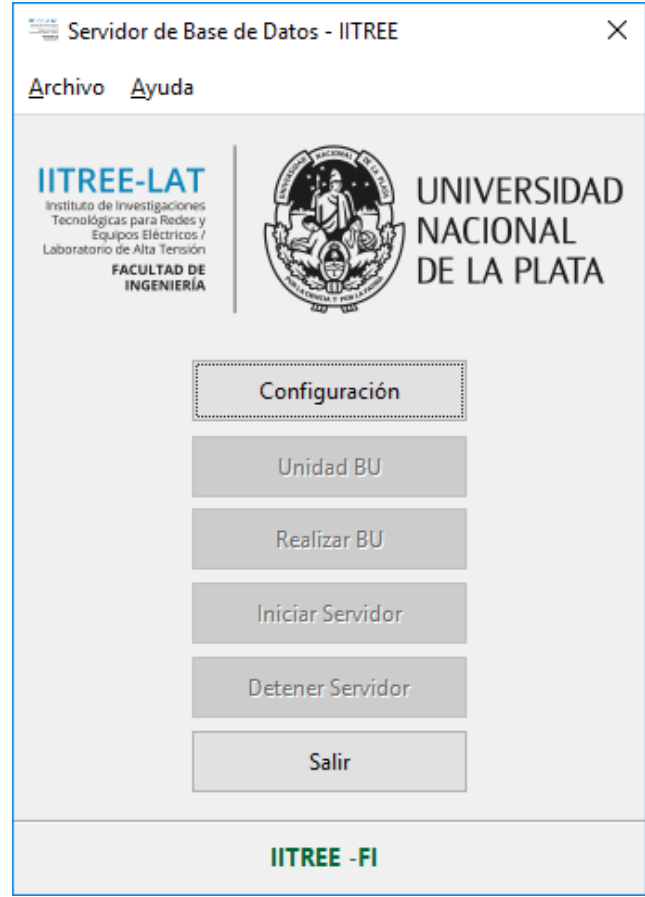

Figura 69. Interfaz de Usuario del Servidor de Respaldo.

El usuario tiene la posibilidad, mediante el menú correspondiente, de generar una nueva configuración del Servidor o cargar una generada previamente.

En la Figura 70, puede observarse el menú de configuración.

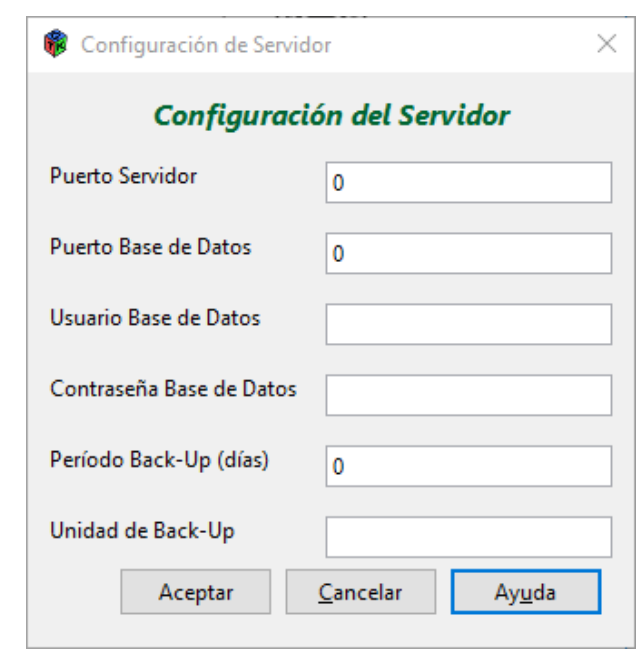

Figura 70. Configuración del Servidor. 
Los datos requeridos para configurar el Servidor son el puerto por el que se recibirán los datos del concentrador, el puerto de comunicaciones con el servidor MySQL, el usuario y contraseña configurado en MySQL, el período (en días) para realizar automáticamente el back-up y la unidad de disco donde se realizará el respaldo.

Una vez que el Servidor se configura correctamente, es posible iniciarlo mediante el botón Iniciar Servidor.

Una vez iniciado el Servidor, el usuario podrá detenerlo o realizar, también, back-ups de manera manual presionando el botón Realizar BU. 


\section{Software de procesamiento - Módulo Online}

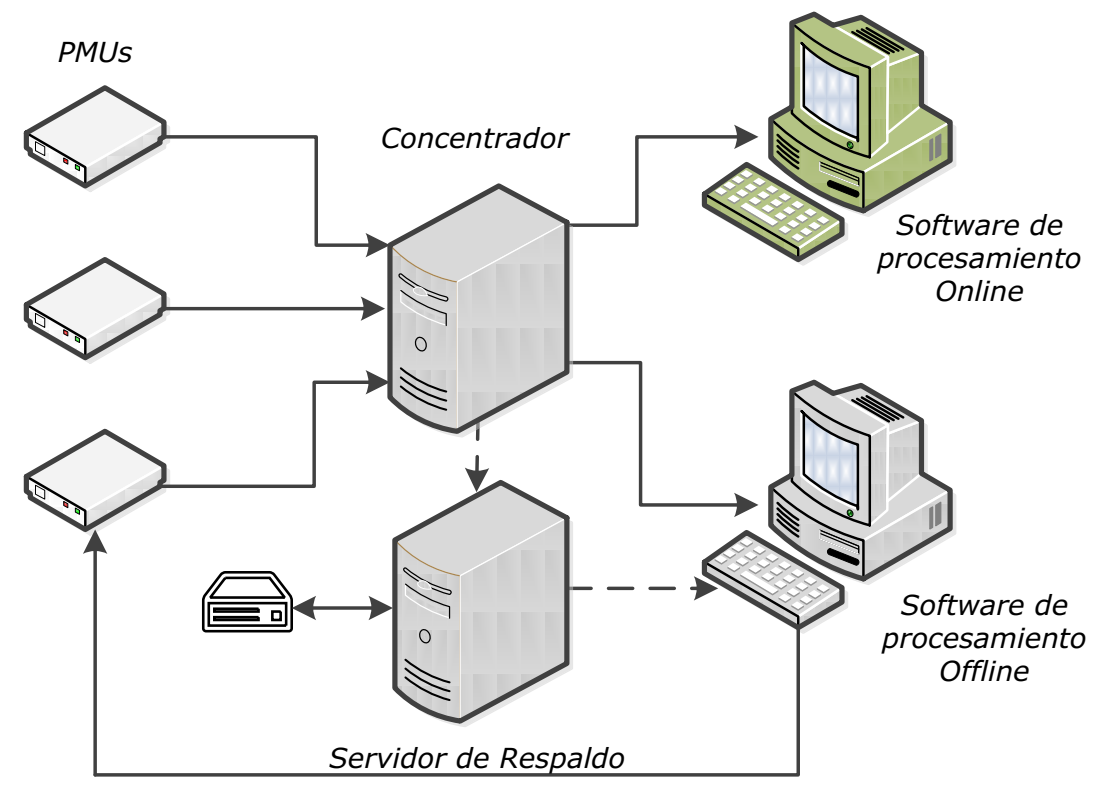

Figura 71. Software de Procesamiento Online en el sistema de medición sincrofasorial.

\subsection{Descripción General}

El software de procesamiento de sincrofasores se compone, tal como se describió en el Capítulo 3 de dos grandes módulos, siendo uno de ellos el Módulo Online.

El módulo de procesamiento Online es el encargado de la graficación de los sincrofasores mediante diagramas fasoriales, junto con los diagramas de tendencias o trazas donde se puede observar la evolución temporal de las variables registradas (tensiones, corrientes, potencia, frecuencia, entre otras). A su vez, es el encargado de realizar el procesamiento en tiempo real de los parámetros anteriormente mencionados, con el objetivo de obtener información aproximada en lo que se refiere a modos de oscilación presentes en la red, su frecuencia, amplitud y amortiguamiento. En la Figura 72 puede observarse un diagrama en bloques de éste módulo. 


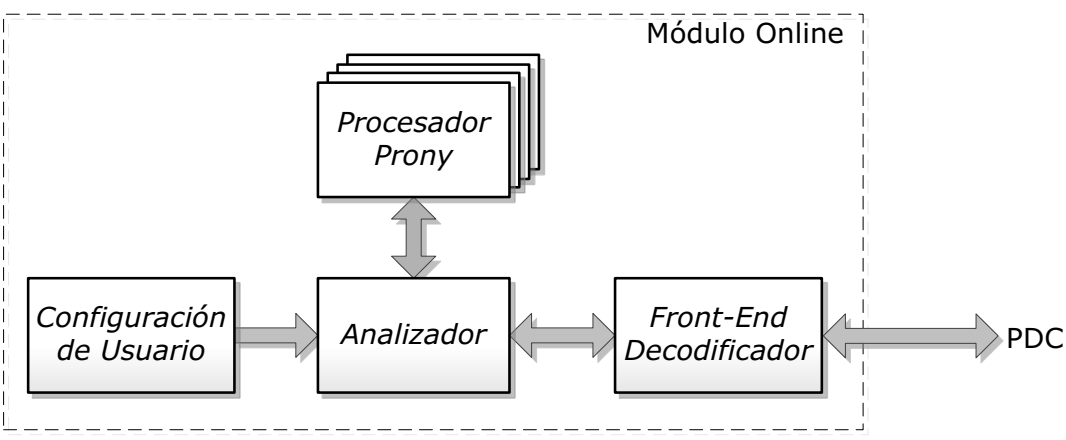

Figura 72. Diagrama en Bloques - Módulo Online.

El Analizador es el principal bloque del módulo online. Este bloque se encarga de la administración temporal del procesamiento, de la visualización de los datos y del análisis para la detección de perturbaciones que ameriten su evaluación con respecto a los modos de oscilación presentes. En el caso en que se requiera el análisis mencionado, este componente activa el correspondiente Procesador Prony (ver sección 7.2).

El componente Procesador Prony tiene como función principal el cálculo optimizado del método de Prony para la ventana de datos asignada. Se incluyen tantos componentes ejecutándose en paralelo con las demás tareas como número de PMUs a analizar se hayan configurado, optimizando de esta manera la latencia de los resultados.

El componente Front End y Decodificador es la interfaz con el concentrador. Se encarga de la decodificación y control de la integridad de los datos, a partir de las especificaciones establecidas por la norma [10].

En este módulo, la ejecución de tareas en forma paralela es esencial para el cumplimiento de su función. Es por ello que el Analizador incluye también rutinas de gestión de los recursos disponibles, con el objetivo de permitir el funcionamiento sincronizado del Front-End, los Procesadores Prony y el Analizador propiamente dicho.

El módulo online del Software de Procesamiento está diseñado para ser utilizado bajo sistema operativo Windows de 64 bits y su diseño se realizó utilizando el entorno de programación y simulación MATLAB.

\subsection{Selección del método de procesamiento online de sincrofasores}

La herramienta apropiada para el estudio de los modos de oscilación predominantes en un sistema eléctrico de potencia, debería proporcionar información exacta y precisa de la frecuencia, la amplitud y el amortiguamiento de dichos modos. Luego de una extensa revisión bibliográfica sobre el tema, se encontraron diferentes herramientas que permitirían estimar las variables de interés. Dichas herramientas son las Transformada Rápida de Fourier (FFT) [53][54], el método de Prony [11][12][55][56][57] y la Transformada Wavelet [58][59].

La Transformada Rápida de Fourier o FFT es una herramienta bien conocida y desarrollada en la actualidad, con una comprobada eficacia para el análisis del 
contenido espectral de señales sostenidas en el tiempo, es decir, de fenómenos de estado estacionario.

El método de Prony es una técnica para la extracción de sinusoides o exponenciales complejas de un conjunto de datos, basada en la resolución de un conjunto de ecuaciones lineales. Es decir, el análisis de Prony permite modelar señales muestreadas como una combinación de sinusoides amortiguadas, minimizando el error cuadrático medio entre la señal real y la señal estimada. A partir de dichas ecuaciones, es posible determinar entonces todos los parámetros de cada componente presente en las variables registradas: amplitud, frecuencia y amortiguamiento.

La Transformada Wavelet es eficiente para el análisis local de señales no estacionarias y de rápida transitoriedad $\mathrm{y}$, al igual que la Transformada de Fourier aplicada a una cierta ventana temporal, mapea la señal en una representación de tiempofrecuencia. La diferencia radica en que la Transformada Wavelet provee un análisis multirresolución. El análisis multirresolución está previsto para proporcionar una buena resolución temporal y una pobre resolución en frecuencia para altas frecuencias y una buena resolución en frecuencia y una pobre resolución en el tiempo para señales de baja frecuencia. Este tratamiento adquiere un sentido especial cuando las señales a manejar tienen componentes de alta frecuencia de corta duración y componentes de baja frecuencia de larga duración.

\subsubsection{Descripción matemática del método de Prony}

El método de Prony es una técnica para la extracción de sinusoides o exponenciales complejas de un conjunto de datos, a partir de resolver un conjunto de ecuaciones lineales.

Asumiendo un conjunto de datos de longitud $N, \mathrm{x}[1] \ldots \ldots . \mathrm{x}[\mathrm{N}]$, la señal investigada puede ser aproximada por $\mathrm{M}$ funciones exponenciales, tal como se expresa en la Ec. 5.1.

$$
y[n]=\sum_{k=1}^{M} A_{k} e^{\left(\alpha_{k}+j \omega_{k}\right)(n-1) T_{p}+j \psi_{k}}
$$

Siendo $\mathrm{n}=1,2 \ldots \ldots \mathrm{N}, \mathrm{T}_{\mathrm{P}}$ el período de muestreo, $\mathrm{A}_{\mathrm{k}}$ la amplitud, $\alpha_{\mathrm{k}}$ el factor de amortiguamiento, $\omega_{\mathrm{k}}$ la velocidad angular y $\psi_{\mathrm{k}}$ la fase inicial.

La función de tiempo discreto puede ser expresada en forma concisa según la Ec. 5.2.

$$
\mathrm{y}[\mathrm{n}]=\sum_{\mathrm{k}=1}^{\mathrm{M}} \mathrm{h}_{\mathrm{k}} \mathrm{z}_{\mathrm{k}}^{\mathrm{n}-1}
$$

Donde

$$
\begin{array}{r}
h_{k}=A_{k} e^{j \psi_{k}} \\
z_{k}=e^{\left(\alpha_{k}+j \omega_{k}\right) T_{p}}
\end{array}
$$


El problema de la estimación se basa en minimizar el error cuadrático medio sobre el conjunto de los $\mathrm{N}$ datos.

$$
\begin{gathered}
\delta=\sum_{\mathrm{n}=1}^{\mathrm{N}}|\varepsilon[\mathrm{n}]|^{2} \\
\varepsilon[\mathrm{n}]=\mathrm{x}[\mathrm{n}]-\mathrm{y}[\mathrm{n}]=\mathrm{x}[\mathrm{n}]-\sum_{\mathrm{k}=1}^{\mathrm{M}} \mathrm{h}_{\mathrm{k}} \mathrm{z}_{\mathrm{k}}^{\mathrm{n}-1}
\end{gathered}
$$

Esto resulta en un conjunto de ecuaciones no lineales, de complicada resolución exacta. Dado que muchos conjuntos de datos están basados en funciones exponenciales, es posible en estos casos lograr un ajuste perfecto utilizando exponenciales complejas.

Si se considera la señal exponencial de tiempo discreto de la Ec. 5.7

$$
\mathrm{x}[\mathrm{n}]=\sum_{\mathrm{k}=1}^{\mathrm{M}} \mathrm{h}_{\mathrm{k}} \mathrm{z}_{\mathrm{k}}^{\mathrm{n}-1}
$$

Las $\mathrm{M}$ ecuaciones de la señal $\mathrm{x}[\mathrm{n}]$ pueden expresarse en forma matricial según la Ec. 5.8 .

$$
\left[\begin{array}{cccc}
\mathrm{z}_{1}^{0} & \mathrm{z}_{2}^{0} & \ldots & \mathrm{z}_{\mathrm{M}}^{0} \\
\mathrm{z}_{1}^{1} & \mathrm{z}_{2}^{1} & \ldots & \mathrm{z}_{\mathrm{M}}^{1} \\
\vdots & \vdots & \ldots & \vdots \\
\mathrm{z}_{1}^{\mathrm{M}-1} & \mathrm{z}_{2}^{\mathrm{M}-1} & \ldots & \mathrm{z}_{\mathrm{M}}^{\mathrm{M}-1}
\end{array}\right]\left[\begin{array}{c}
\mathrm{h}_{1} \\
\mathrm{~h}_{2} \\
\vdots \\
\mathrm{h}_{\mathrm{M}}
\end{array}\right]=\left[\begin{array}{c}
\mathrm{x}[1] \\
\mathrm{x}[2] \\
\vdots \\
\mathrm{x}[\mathrm{M}]
\end{array}\right]
$$

La Ec. 5.8 corresponde a una ecuación matricial que representa un conjunto de ecuaciones lineales que puede resolverse para el vector de amplitudes incógnita.

El método de Prony propone definir un polinomio que tiene a sus $z_{k}$ exponentes como raíces:

$$
\mathrm{F}[\mathrm{z}]=\prod_{\mathrm{k}=1}^{\mathrm{M}}\left(\mathrm{z}-\mathrm{z}_{\mathrm{k}}\right)=\left(\mathrm{z}-\mathrm{z}_{1}\right)\left(\mathrm{z}-\mathrm{z}_{2}\right) \ldots .\left(\mathrm{z}-\mathrm{z}_{\mathrm{M}}\right)
$$

El polinomio puede ser representado por la suma de la Ec. 5.10

$$
\mathrm{F}[\mathrm{z}]=\sum_{\mathrm{m}=0}^{\mathrm{M}} \mathrm{a}[\mathrm{m}] \mathrm{z}^{\mathrm{M}-\mathrm{m}}=\mathrm{a}[0] \mathrm{z}^{\mathrm{M}}+\mathrm{a}[1] \mathrm{z}^{\mathrm{M}-1}+\ldots+\mathrm{a}[\mathrm{m}-1] \mathrm{z}+\mathrm{a}[\mathrm{M}]
$$

Si se realiza un cambio de variables en la Ec. 5.7 de n a n-m y se multiplica por el parámetro $\mathrm{a}[\mathrm{m}]$, se obtiene la expresión 5.11

$$
\mathrm{a}[\mathrm{m}] \mathrm{x}[\mathrm{n}-\mathrm{m}]=\mathrm{a}[\mathrm{m}] \sum_{\mathrm{k}=1}^{\mathrm{M}} \mathrm{h}_{\mathrm{k}} \mathrm{z}_{\mathrm{k}}^{\mathrm{n}-\mathrm{m}-1}
$$

La Ec. 5.11 puede modificarse, obteniendo

$$
\sum_{m=0}^{M} a[m] x[n-m]=\sum_{k=1}^{M} h_{k} z_{k}^{n-M}\left\{\sum_{m=0}^{M} a[m] z_{k}^{M-n-1}\right\}
$$


El lado derecho de la Ec. 5.12 se reconoce como el polinomio definido en 5.10, evaluado en cada una de sus raíces $\mathrm{z}_{\mathrm{k}}$ lo que da como resultado un valor nulo.

$$
\sum_{\mathrm{m}=0}^{\mathrm{M}} \mathrm{a}[\mathrm{m}] \mathrm{x}[\mathrm{n}-\mathrm{m}]=0
$$

Esta ecuación puede ser resuelta para los coeficientes del polinomio. En un segundo paso, las raíces del polinomio definido en 5.10 pueden ser calculadas. El factor de amortiguamiento y las frecuencias se obtienen a partir de las raíces $\mathrm{z}_{\mathrm{k}}$.

En situaciones prácticas, el número de datos $\mathrm{N}$ excede normalmente el mínimo número necesario para aproximar las exponenciales, es decir $\mathrm{N}>2 \mathrm{M}$. En este caso sobredeterminado, la Ec. 5.13 puede modificarse, obteniendo la expresión 5.14.

$$
\sum_{m=0}^{M} a[m] x[n-m]=e[n]
$$

El problema de estimación, entonces, se basa en minimizar el error cuadrático medio, dado por:

$$
\mathrm{E}=\sum_{\mathrm{n}=\mathrm{M}+1}^{\mathrm{N}}|\mathrm{e}[\mathrm{n}]|^{2}
$$

\section{Ejemplo de aplicación del método de Prony}

Dadas las muestras de una señal $\mathrm{u}[1]=526,6403$; $\mathrm{u}[2]=534,7375$; $\mathrm{u}[3]=539,6529$; $\mathrm{u}[4]=541,2862 ; \mathrm{u}[5]=539,5659 ; \mathrm{u}[6]=534,4505 ; \mathrm{u}[7]=525,9285 ; \mathrm{u}[8]=514,0191 ; \mathrm{se}$ tiene por objetivo encontrar señales de segundo orden de la forma $x(t)=A e^{-\sigma t} \operatorname{sen}(\omega t+$ $\phi)$ que coincidan con las muestras.

Las muestras corresponden a la señal de la Ec. 5.16, generadas con una frecuencia de muestreo $\mathrm{f}_{\mathrm{s}}=50 * 64=3200$ muestras $/ \mathrm{s}$.

$$
\begin{gathered}
u(t)=230 \sqrt{2} \operatorname{sen}(2 \pi 50 t+\pi / 3)+200 \sqrt{2} e^{-10 t} \cos (2 \pi 20 t+\pi / 6) \\
u[n]=230 \sqrt{2} \operatorname{sen}\left(\frac{2 \pi 50 n}{3200}+\pi / 3\right)+200 \sqrt{2} e^{-\frac{10 n}{3200}} \cos \left(\frac{2 \pi 20 n}{3200}+\pi / 6\right) \\
u[n]=230 \sqrt{2} \operatorname{sen}\left(\frac{\pi n}{32}+\pi / 3\right)+200 \sqrt{2} e^{-\frac{n}{320}} \cos \left(\frac{\pi n}{80}+\pi / 6\right)
\end{gathered}
$$




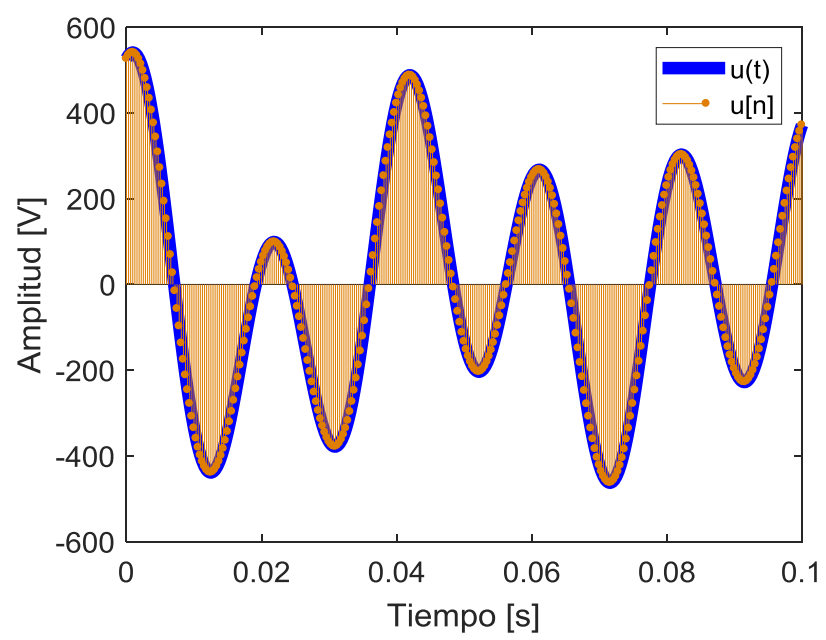

Figura 73. Señal original $u(t)$ y señal muestreada $u[n]$

Teniendo en cuenta que cada sinusoide es modelada por un par de polos y que la cantidad de muestras necesarias por sinusoide amortiguada son 4 , entonces en este caso se requieren 8 muestras de la señal para la resolución del método.

Las ecuaciones que surgen de las 8 muestras analizadas no tienen una resolución analítica dado que las ecuaciones son no lineales. Es por ello que es necesario transformar el problema al tiempo discreto y obtener la solución del sistema de ecuaciones a partir de un sistema de ecuaciones en diferencias.

Si se modelan los datos con una ecuación en diferencias, se obtiene

$$
\mathrm{u}[\mathrm{n}]=\mathrm{A}_{4} \mathrm{u}[\mathrm{n}-1]+\mathrm{A}_{3} \mathrm{u}[\mathrm{n}-2]+\mathrm{A}_{2} \mathrm{u}[\mathrm{n}-3]+\mathrm{A}_{1} \mathrm{u}[\mathrm{n}-4]
$$

Cuya estructura se muestra en la Figura 74.

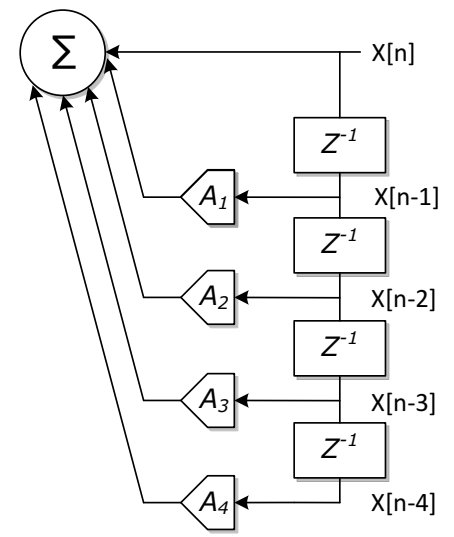

Figura 74. Estructura de la ecuación en diferencias.

Es posible escribir entonces las siguientes relaciones:

$$
\begin{aligned}
& u[5]=A_{1} u[4]+A_{2} u[3]+A_{3} u[2]+A_{4} u[1] \\
& u[6]=A_{1} u[5]+A_{2} u[4]+A_{3} u[3]+A_{4} u[2] \\
& u[7]=A_{1} u[6]+A_{2} u[5]+A_{3} u[4]+A_{4} u[3] \\
& u[8]=A_{1} u[7]+A_{2} u[6]+A_{3} u[5]+A_{4} u[4]
\end{aligned}
$$


Si a las Ecs. 5.20 a 5.23 se las escribe matricialmente, se obtiene

$$
\left[\begin{array}{l}
u[5] \\
u[6] \\
u[7] \\
u[8]
\end{array}\right]=\left[\begin{array}{llll}
u[1] & u[2] & u[3] & u[4] \\
u[2] & u[3] & u[4] & u[5] \\
u[3] & u[4] & u[5] & u[6] \\
u[4] & u[5] & u[6] & u[7]
\end{array}\right] *\left[\begin{array}{c}
A_{4} \\
A_{3} \\
A_{2} \\
A_{1}
\end{array}\right]
$$

Por lo tanto, los coeficientes de la Ec. 5.24 resultan

$$
\begin{gathered}
A=\operatorname{inv}\left(\left[\begin{array}{llll}
u[1] & u[2] & u[3] & u[4] \\
u[2] & u[3] & u[4] & u[5] \\
u[3] & u[4] & u[5] & u[6] \\
u[4] & u[5] & u[6] & u[7]
\end{array}\right]\right) *\left[\begin{array}{l}
u[5] \\
u[6] \\
u[7] \\
u[8]
\end{array}\right] \\
A=\operatorname{inv}\left(\left[\begin{array}{llll}
526,6403 & 534,7375 & 539,6529 & 541,2862 \\
534,7375 & 539,6529 & 541,2862 & 539,5659 \\
539,6529 & 541,2862 & 539,5659 & 534,4505 \\
541,2862 & 539,5659 & 534,4505 & 525,9285
\end{array}\right]\right) *\left[\begin{array}{l}
539,5659 \\
534,4505 \\
525,9285 \\
514,0191
\end{array}\right]=\left[\begin{array}{l}
-0,9938 \\
3,9702 \\
-5,9590 \\
3,9826
\end{array}\right]
\end{gathered}
$$

Si se calculan ahora las transformada $Z$ de las ecuaciones en diferencias, se obtiene la Ec. 5.26.

$$
\mathrm{U}(\mathrm{Z})=3,9826 \mathrm{U}(\mathrm{Z}) \mathrm{Z}^{-1}-5,9590 \mathrm{U}(\mathrm{Z}) \mathrm{Z}^{-2}+3,9702 \mathrm{U}(\mathrm{Z}) \mathrm{Z}^{-3}-0,9938 \mathrm{U}(\mathrm{Z}) \mathrm{Z}^{-4}(5.26)
$$

Esta ecuación puede expresarse poniendo en evidencia la "ecuación característica".

$$
\mathrm{U}(\mathrm{Z})\left[1-3,9826 \mathrm{Z}^{-1}+5,9590 \mathrm{Z}^{-2}-3,9702 \mathrm{Z}^{-3}+0,9938 \mathrm{Z}^{-4}\right]=0
$$

Los polos de la ecuación característica se calculan a partir de la Ec. 5.28.

$$
Z^{4}-3,9826 Z^{3}+5,9590 Z^{2}-3,9702 Z^{1}+0,9938=0
$$

Lo que da como resultado

$$
\mathrm{p}_{\mathrm{zl}, 2}=0,9952 \pm \mathrm{j} 0,098 \mathrm{p}_{\mathrm{z} 3,4}=0,9961 \pm \mathrm{j} 0,0392
$$

Los polos se encuentran dentro del circulo unitario $|Z|=1$, por lo tanto la señal es estable. Con la transformación bilineal, se pueden obtener los polos en el plano de Laplace.

$$
\begin{gathered}
\mathrm{p}_{\mathrm{s} 1,2}=\frac{2}{\mathrm{Ts}} \frac{\mathrm{p}_{\mathrm{z} 1,2}-1}{\mathrm{p}_{\mathrm{z} 1,2}+1}=-0,0023 \pm \mathrm{j} 314,37 \\
\mathrm{p}_{\mathrm{s} 3,4}=\frac{2}{\mathrm{Ts}} \frac{\mathrm{p}_{\mathrm{z} 3,4}-1}{\mathrm{p}_{\mathrm{z} 3,4}+1}=-10 \pm \mathrm{j} 125,78
\end{gathered}
$$


La parte real de los polos en el plano s proporciona el amortiguamiento y la parte imaginaria proporciona la frecuencia angular. En el caso de $\mathrm{p}_{1,2}$, resulta un amortiguamiento nulo y una frecuencia de $\omega=314,7 \mathrm{rad} / \mathrm{s}$ o $\mathrm{f}=50,03 \mathrm{~Hz}$. En el caso de $\mathrm{p}_{3,4}$ resulta un amortiguamiento de -10 y una frecuencia de $\omega=125,78 \mathrm{rad} / \mathrm{s}$ of $=20,02$ $\mathrm{Hz}$.

Es importante tener en cuenta que el error en la determinación de estos parámetros depende fuertemente de la frecuencia de muestreo utilizada. Como regla técnica, resulta conveniente utilizar una frecuencia de muestreo 100 veces superior que la mayor frecuencia que se desea sintetizar.

Resulta de interés, entonces, expresar a $\mathrm{u}[\mathrm{n}]$ como una suma de exponenciales complejas con parámetros $\mathrm{A}, \sigma, \omega \mathrm{y} \phi$. Para ello es necesario expresar los polos en el plano $\mathrm{z}$ en su forma polar.

$$
\begin{aligned}
& \mathrm{p}_{\mathrm{Z} 1}=\mathrm{r} \cdot \mathrm{e}^{\mathrm{j} \omega}= 1 \cdot \mathrm{e}^{\mathrm{j} 0,0982} \text { con: } \mathrm{r}=\left|\mathrm{p}_{\mathrm{Z1}}\right|=1 \quad \mathrm{y} \quad \omega=\tan ^{-1}\left[\frac{\operatorname{imag}\left(\mathrm{p}_{\mathrm{Z1}}\right)}{\operatorname{real}\left(\mathrm{p}_{\mathrm{Z} 1}\right)}\right] \\
& \mathrm{p}_{\mathrm{Z} 2}=1 \mathrm{e}^{-\mathrm{j} 0,0982} ; \mathrm{p}_{\mathrm{Z} 3}=0,9969 \mathrm{e}^{\mathrm{j} 0,0393} ; \mathrm{p}_{\mathrm{Z} 4}=0,9969 \mathrm{e}^{-\mathrm{j} 0,0393}
\end{aligned}
$$

Los amortiguamientos se pueden calcular según la Ec. 5.32.

$$
\mathrm{r}=\mathrm{e}^{-\sigma} \rightarrow \sigma=-\ln (\mathrm{r})
$$

Para $p_{\mathrm{Z} 1,2}$ resulta $\sigma=0$ y para $\mathrm{p}_{\mathrm{Z} 3,4}$ resulta $\sigma=0,0031$ (que coincide con el amortiguamiento que se observa en la expresión de $u[n]$ ). Por lo tanto la señal $u[n]$ puede expresarse según la Ec. 5.33.

$$
\begin{gathered}
u[n]=(a+j b) e^{-\sigma_{1} n} e^{j \omega_{1} n}+(a-j b) e^{-\sigma_{1} n} e^{-j \omega_{1} n}+(c+j d) e^{-\sigma_{2} n} e^{j \omega_{2} n}+(c-j d) e^{-\sigma_{2} n} e^{-j \omega_{2} n}(5.33) \\
u[n]=2 a e^{-\sigma_{1} n} \cos \left(\omega_{1} n\right)-2 b e^{-\sigma_{1} n} \operatorname{sen}\left(\omega_{1} n\right)+2 c e^{-\sigma_{2} n} \cos \left(\omega_{2} n\right)-2 d e^{-\sigma_{2} n} \operatorname{sen}\left(\omega_{2} n\right) \\
u[n]=2|(a+j b)| e^{-\sigma_{1} n}\left[\frac{a}{|(a+j b)|} \cos \left(\omega_{1} n\right)-\frac{b}{|(a+j b)|} \operatorname{sen}\left(\omega_{1} n\right)\right] \\
+2|(c+j d)| e^{-\sigma_{2} n}\left[\frac{c}{|(c+j d)|} \cos \left(\omega_{2} n\right)-\frac{d}{|(c+j d)|} \operatorname{sen}\left(\omega_{2} n\right)\right]
\end{gathered}
$$

Finalmente, su expresión resulta

$$
\mathrm{u}[\mathrm{n}]=2|(\mathrm{a}+\mathrm{jb})| \mathrm{e}^{-\sigma_{1} \mathrm{n}} \operatorname{sen}\left(\omega_{1} \mathrm{n}+\phi_{1}\right)+2|(\mathrm{c}+\mathrm{jd})| \mathrm{e}^{-\sigma_{2} \mathrm{n}} \operatorname{sen}\left(\omega_{2} \mathrm{n}+\phi_{2}\right)
$$

Donde

$$
\phi_{1}=\tan ^{-1}\left[\frac{a /|(a+j b)|}{-b /|(a+j b)|}\right] \text { y } \phi_{2}=\tan ^{-1}\left[\frac{c /|(c+j d)|}{-d /|(c+j d)|}\right]
$$


Reemplazando por valores resulta

$$
u[n]=325,318 \operatorname{sen}\left(\frac{\pi}{32} n+\pi / 6\right)+282,851 e^{-0,0031 n} \operatorname{sen}\left(\frac{\pi}{80} n-\pi / 6\right)
$$

$\mathrm{O}$, lo que es equivalente

$$
u[n]=325,318 \operatorname{sen}\left(\frac{\pi}{32} n+\pi / 3\right)+282,851 e^{-0,0031 n} \cos \left(\frac{\pi}{80} n+\pi / 6\right)
$$

La señal obtenida a partir de la reconstrucción coincide exactamente con la señal original muestreada, tal como se puede observar en la Figura 75, donde en rojo se indican las muestras utilizadas para la obtención de los parámetros, en azul las muestras reconstruidas y en verde las muestras de la señal original.

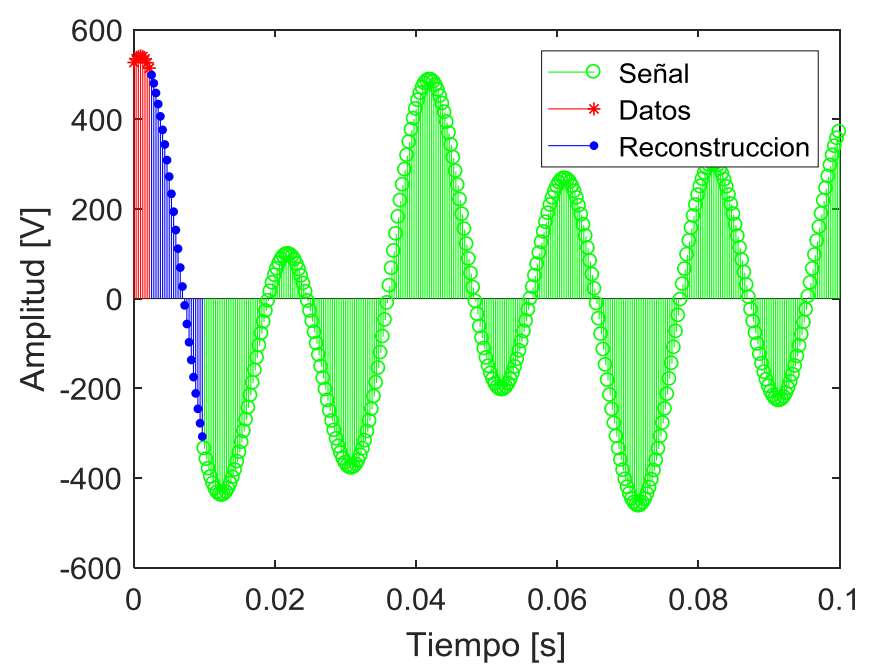

Figura 75. Señal original, datos y reconstrucción por el método de Prony.

Se pueden observar mayores detalles de la señal reconstruida en la Figura 76.

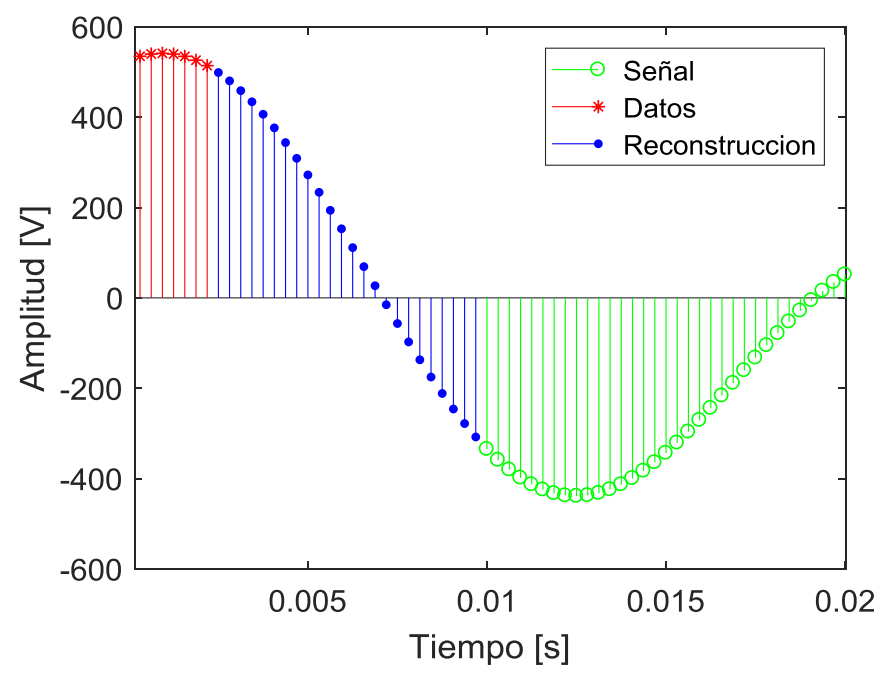

Figura 76. Detalles de la Figura 75. 


\subsubsection{Comparación entre el análisis de Prony y la Transformada de Fourier}

Tal como se mencionó en la sección 7.2, la Transformada de Fourier, y su versión numérica para variable discreta FFT, es una de los procesamientos matemáticos comúnmente utilizados para el análisis espectral de variables de un sistema de potencia. Sin embargo, por la propia definición de la FFT, las señales deben ser estacionarias y periódicas para que los resultados del análisis espectral sean válidos.

Una señal no estacionaria amortiguada puede expresarse según la Ec. 5.37.

$$
x(t)=A e^{\delta t} \cos \left(2 \pi f_{n} t\right)
$$

Para obtener un mejor resultado del análisis espectral, la ventana temporal procesada suele tener una duración T múltiplo del período de la componente periódica de la señal analizada.

Por lo tanto, si el instante de tiempo de inicio del análisis espectral es $\mathrm{t}_{0}$ y la ventana temporal procesada tiene una duración $\mathrm{T}$, el desarrollo de la componente espectral (con la escala correctamente aplicada) en la frecuencia $f_{n}$ obtenida mediante la Transformada de Fourier resulta según la Ec. 5.38.

$$
\begin{gathered}
X\left(f_{n}\right)=\frac{2}{T} \int_{t_{0}}^{t_{0}+T} A e^{\delta t} \cos \left(2 \pi f_{n} t\right) e^{-j 2 \pi f_{n} t} d t=\frac{2}{T} \int_{t_{0}}^{t_{0}+T} A e^{\delta t} \cos \left(2 \pi f_{n} t\right)\left[\cos \left(2 \pi f_{n} t\right)+j \operatorname{sen}\left(2 \pi f_{n} t\right)\right] d t= \\
=\frac{2}{T} \int_{t_{0}}^{t_{0}+T} A e^{\delta t} \cos ^{2}\left(2 \pi f_{n} t\right) d t+j \frac{2}{T} \int_{t_{0}}^{t_{0}+T} A e^{\delta t} \cos \left(2 \pi f_{n} t\right) \operatorname{sen}\left(2 \pi f_{n} t\right) d t= \\
=A \frac{2}{T} \int_{t_{0}}^{t_{0}+T} e^{\delta t} \frac{1+\cos \left(4 \pi f_{n} t\right)}{2} d t+j \frac{A}{T} \int_{t_{0}}^{t_{0}+T} e^{\delta t} \operatorname{sen}\left(4 \pi f_{n} t\right) d t \\
=\frac{A}{T} \int_{t_{0}}^{t_{0}+T} e^{\delta t} d t+\frac{A}{T} \int_{t_{0}}^{t_{0}+T} e^{\delta t} \cos \left(4 \pi f_{n} t\right) d t
\end{gathered}
$$

Si se desarrolla el segundo término de la Ec. 5.38, se obtiene finalmente la componente espectral que expresa la Ec. 5.39.

$$
X\left(f_{n}\right)=A e^{\delta t_{0}}\left(\frac{e^{\delta T}-1}{\delta T}\right)
$$

Por lo tanto, la relación entre la magnitud que se obtiene a partir de la Transformada de Fourier de dicha señal y la magnitud de la señal propiamente dicha en el instante $\mathrm{t}_{0} \mathrm{se}$ define según la Ec. 5.40

$$
k=\frac{e^{\delta \mathrm{T}}-1}{\delta \mathrm{T}}
$$


La Ec. 5.40 muestra que:

- Si el amortiguamiento es $\delta=-5(\tau=0,2 \mathrm{~s})$ y el ancho de la ventana temporal de la FFT es $\mathrm{T}=1 \mathrm{~s}$ (para lograr una resolución en frecuencia de $1 \mathrm{~Hz}$ ) la relación resulta $\mathrm{k}=0,1986$.

- Si el amortiguamiento es $\delta=-5(\tau=0,2 \mathrm{~s})$ y el ancho de la ventana temporal de la FFT es $\mathrm{T}=10 \mathrm{~s}$ (para lograr una resolución en frecuencia de $0,1 \mathrm{~Hz}$ ) la relación resulta $\mathrm{k}=0,02$.

Estos resultados indican que existe una relación de compromiso en el uso de la FFT como herramienta de análisis de señales amortiguadas. Si se desea aumentar la resolución en frecuencia se debe aumentar el ancho de la ventana temporal, lo que aumenta el error en la estimación de amplitud de las señales oscilatorias amortiguadas. Esta limitación no está presente en el método de Prony, ya que está inherentemente diseñado para estimar amplitud, amortiguamiento y frecuencia de señales oscilatorias amortiguadas.

En la Figura 77, puede observarse el resultado obtenido mediante el uso de la FFT cuando es aplicada a la señal analizada en la sección 7.2.1 con una ventana de procesamiento de $0,1 \mathrm{~s}$.

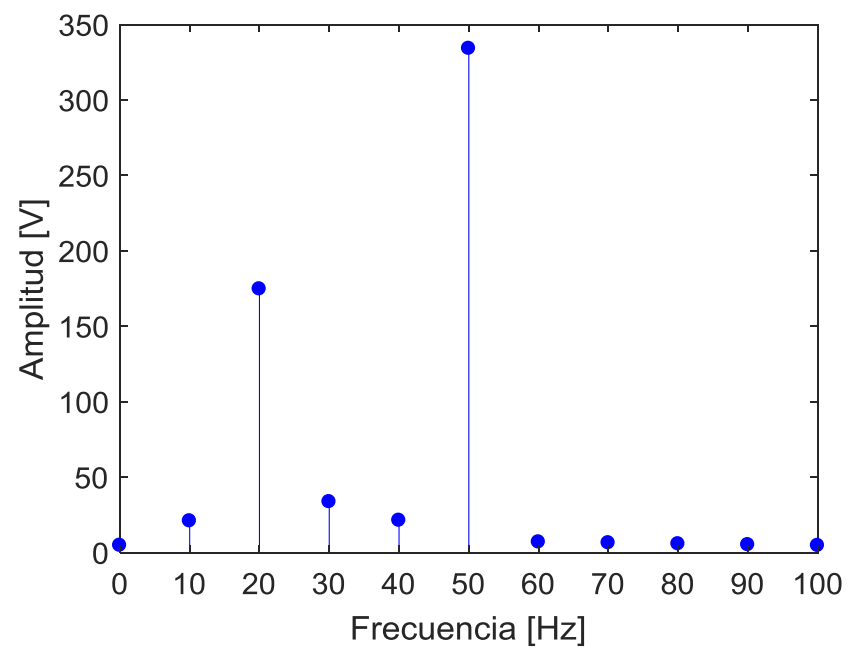

Figura 77. Análisis mediante FFT.

En la Figura, se puede observar que tanto la amplitud como la frecuencia de la componente de $20 \mathrm{~Hz}$ no se pueden determinar con exactitud.

Por otro lado, y a modo de ejemplo, en la Figura 78 se presenta el procesamiento de un oscilograma de corriente registrada en barras de un generador durante un evento ocurrido en el sistema eléctrico. Dicho procesamiento se efectúa utilizando [56] con la FFT y con el método de Prony. En ambos casos se realiza un análisis deslizante ciclo a ciclo, con un ancho de ventana temporal de $1 \mathrm{~s}$ para la FFT y de $0,2 \mathrm{~ms}$ para el Prony. 


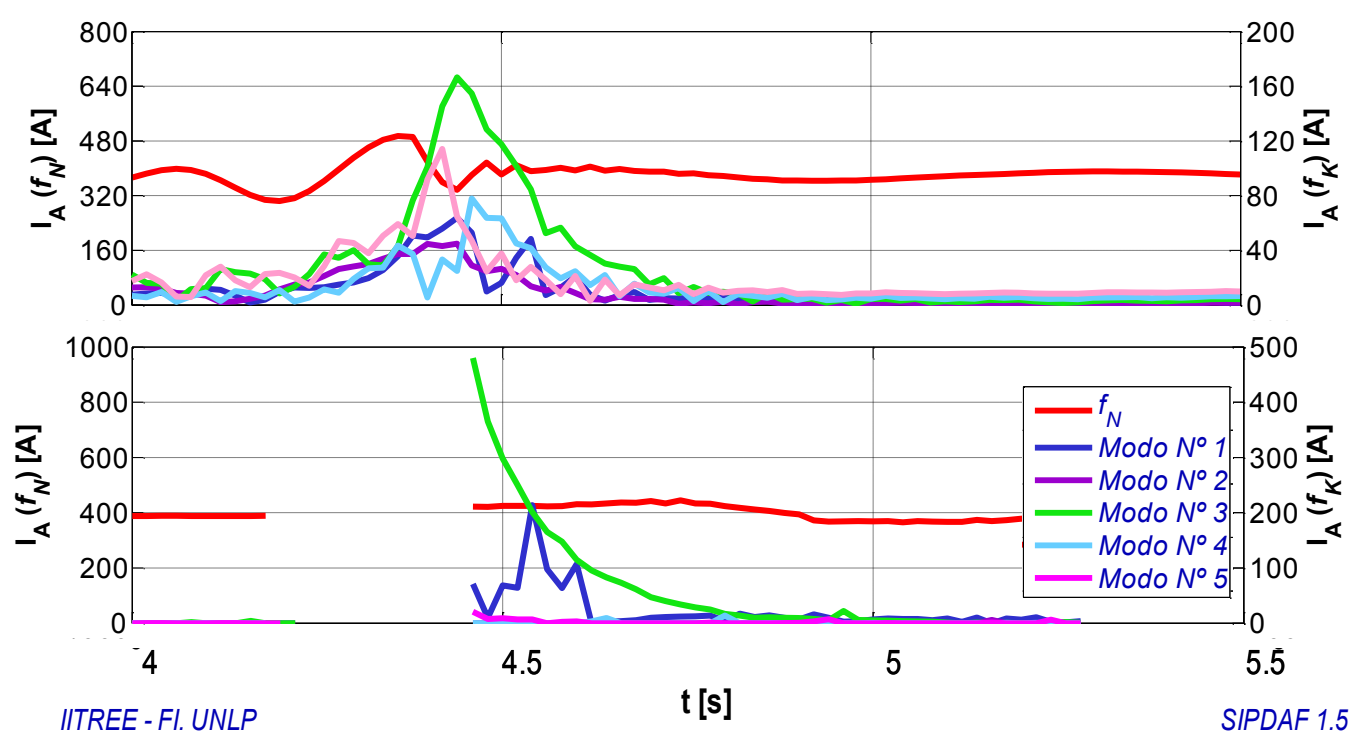

Figura 78. Comparación de resultados del análisis con FFT (gráfico superior) y con Prony (gráfico inferior).

En la componente de corriente del modo 3 (curva verde, de frecuencia 21,2 Hz) se observa una estimación muy similar de la frecuencia y del amortiguamiento con ambos métodos. Sin embargo, en la medición de la amplitud el método de la FFT estima un valor $(165 \mathrm{~A})$ que es aproximadamente 3 veces menor que el resultado que provee el método de Prony (480 A). Esto es debido a que, con la FFT, la magnitud de la señal está promediada por el ancho de la ventana temporal utilizada (1 s).

Consideraciones como la realizada previamente sugieren que una herramienta de análisis basada en el método de Prony proporciona información correcta sobre la amplitud, la frecuencia y el amortiguamiento de los modos de oscilación subsincrónicos a diferencia de lo que se obtiene aplicando la FFT.

\subsubsection{Comparación entre el análisis de Prony y la Transformada Wavelet}

Para llevar a cabo el análisis de señales no estacionarias, afectadas por distorsiones que varían en el tiempo, la Transformada de Fourier presenta diferentes limitaciones que dificultan su aplicación, según lo analizado en la sección 7.2.2.

El análisis espectral que la Transformada de Fourier brinda tiene como sustento teórico la condición que la señal a analizar sea periódica. En base a este concepto, el método tradicional de aplicación del análisis de Fourier propone descomponer la señal en un conjunto de señales sinusoidales de diferente frecuencia. Dada la periodicidad de la señal analizada, el conjunto de señales obtenidas permite contar con una buena resolución en frecuencia (logrando diferenciar las componentes de frecuencia que conforman la señal analizada), pero sin disponer de una buena resolución temporal, que permita establecer los instantes de tiempo en donde dichas componentes se presentan. 
Para lograr una mejor resolución temporal, el método de aplicación de la Transformada de Fourier se modifica levemente. Para ello, la señal a analizar es separada en un conjunto de segmentos temporales donde se puede considerar que la señal es estacionaria. Finalmente, se procesa cada una de esos segmentos mediante la Transformada de Fourier de Tiempo Reducido (STFT, por sus siglas en inglés). De esta manera, se puede establecer para cada segmento temporal las componentes de frecuencia presentes, pudiendo establecer los instantes temporales donde cada una de estas componentes afecta a la señal analizada.

Este último método presenta importantes dificultades cuando se aplica a señales de naturaleza compleja, con diferentes perturbaciones ocurriendo a lo largo del tiempo. Estas dificultades se deben a la existencia de una relación de compromiso entre la duración del segmento temporal analizado y la resolución en frecuencia obtenida. Cuando la duración del segmento es pequeña (para tener una buena resolución temporal de las perturbaciones), la perdida de resolución en frecuencia aumenta; cuando la duración del segmento es mayor (para tener una buena resolución en frecuencia), la resolución temporal se reduce.

Frente a los problemas citados, una de las alternativas propuestas en la literatura es la Transformada Wavelet [58][59].

La Transformada Wavelet presenta, como una de sus principales virtudes la utilización de segmentos temporales cortos para el análisis de altas frecuencias y segmentos temporales largos en el caso de bajas frecuencias. De esta manera, se logra una buena resolución en tiempo y en frecuencia.

La Transformada Wavelet de una señal x(t) se define según la Ec. 5.41.

$$
\mathrm{CW}_{\mathrm{f}}^{\psi}(\mathrm{a}, \mathrm{b})=\int_{-\infty}^{\infty} \mathrm{x}(\mathrm{t}) \psi_{\mathrm{ab}}^{*}(\mathrm{t}) \mathrm{dt}
$$

donde

$$
\psi_{\mathrm{ab}}(\mathrm{t})=\frac{1}{\sqrt{\mathrm{a}}} \psi\left(\frac{\mathrm{t}-\mathrm{b}}{\mathrm{a}}\right) ; \mathrm{a}, \mathrm{b} \in \mathbb{R} ; \mathrm{a} \neq 0
$$

La función $\psi$ se denomina wavelet madre, y tiene dos parámetros característicos: la dilatación $a$ y la traslación $b$.

Al igual que la Transformada de Fourier, la Transformada Wavelet Discreta puede ser aplicada a un conjunto de muestras de señal, tal como muestra la Ec. 5.43

$$
\operatorname{DW}_{\mathrm{f}}^{\psi}(\mathrm{j}, \mathrm{k})=\frac{1}{\sqrt{\mathrm{a}_{0}^{\mathrm{j}}}} \sum_{\mathrm{n}=-\infty}^{\infty} \mathrm{x}[\mathrm{n}] \psi\left[\frac{\mathrm{n}-\mathrm{a}_{0}^{\mathrm{j}} \mathrm{kb} \mathrm{b}_{0}}{\mathrm{a}_{0}^{\mathrm{j}}}\right] ; \mathrm{j}, \mathrm{k}, \mathrm{n} \in \mathbb{Z}, \mathrm{a}_{0}>1
$$

Típicamente, la Transformada Wavelet, y su versión discreta, se aplica estableciendo los parámetros $\mathrm{a}=2 \mathrm{y} \mathrm{b}=1$. Mediante dicha selección, se obtiene una transformada 
ortonormal, que da lugar al reconocido Análisis Multirresolución (AMR) aplicando la Transformada Wavelet [59] [60].

El AMR permite obtener una buena resolución temporal en altas frecuencias junto a una buena resolución en frecuencia en el caso de bajas frecuencias.

En forma simplificada, el AMR se lleva a cabo mediante la aplicación en forma recursiva de un filtro pasa-altos y un filtro pasa-bajos, cuyas respuestas impulsionales están relacionadas a la wavelet madre que se desee utilizar. En la Figura 79 puede observarse un diagrama del Análisis Multirresolución, ejemplificando los rangos de frecuencia obtenidos cuando se aplica este análisis a una señal muestreada a $2 \mathrm{kHz}$.

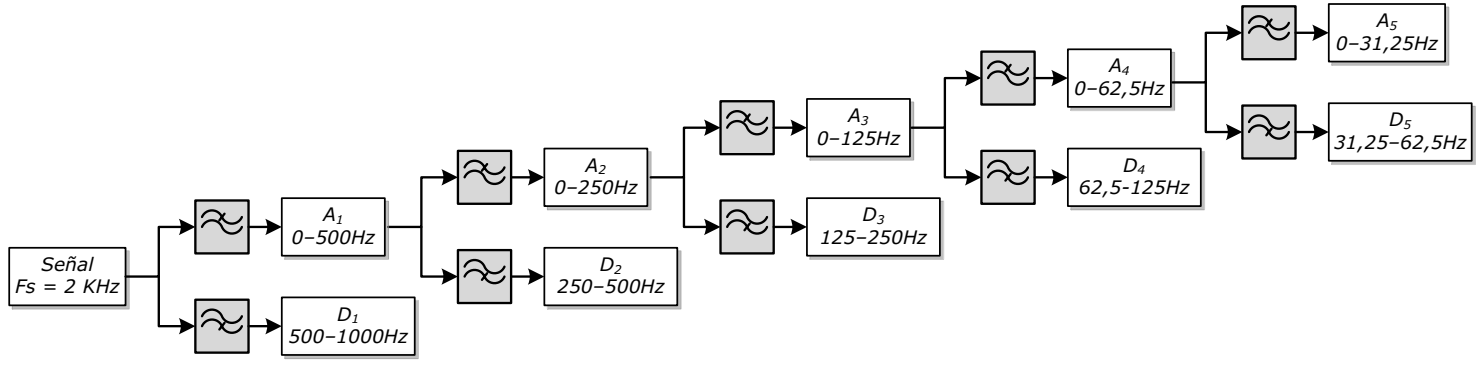

Figura 79 - Diagrama del Análisis Multirresolución mediante la Transformada Wavelet

Tal como muestra la Figura, el análisis consiste en aplicar repetidas veces el filtrado, obteniendo en cada caso la separación en mitades del espectro de señal.

Una característica muy importante de la Transformada Wavelet es que pueden obtenerse resultados muy disímiles según qué wavelet madre se utilice para procesar la transformada. Sin embargo, no todas las wavelet madres resultan apropiadas para llevar a cabo un análisis espectral de señales no estacionarias.

Una de las familias de wavelet madre más aplicada es la denominada Wavelet de Daubechie [58] [59]. Esto se debe a que dichas wavelet madre son ortogonales y tienen una duración temporal compacta. Sin embargo, presentan como desventaja que no poseen una expresión analítica cerrada $\mathrm{y}$, a su vez, las versiones de menor orden no tienen derivadas continuas. Por otro lado, las familias de wavelet madre basadas en funciones gaussianas moduladas como las wavelet de Morlet o Meyer resultan de gran utilidad para el análisis de armónicas debido a su suavidad. En las Figuras 80 y 81 pueden observarse las wavelet madre de Daubechie de orden 5 y Meyer, respectivamente. 


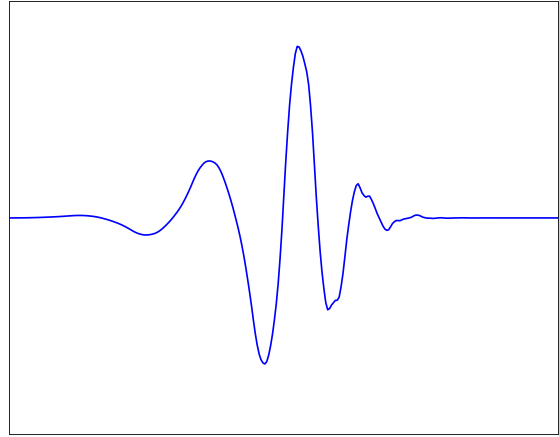

Figura 80. Wavelet madre Daubechie (orden 5).

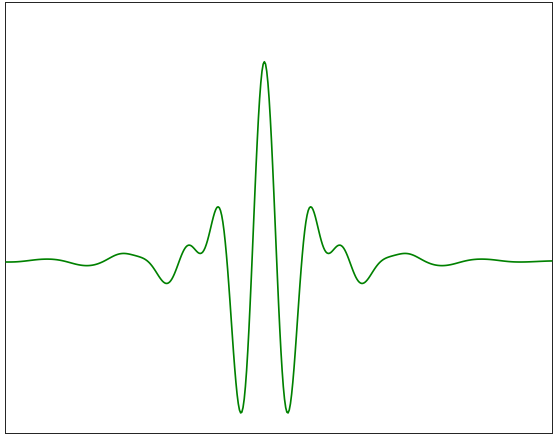

Figura 81. Wavelet madre Meyer.

Para el caso de análisis de señales de sistemas de potencia que se realizan en tiempo real, donde se requiere llevar a cabo un análisis espectral que a su vez se realice con una baja carga computacional, la wavelet madre de Meyer resulta de las más utilizadas [60].

\section{Ejemplo de aplicación de la Transformada Wavelet}

Dada la señal $\mathrm{x}(\mathrm{t})$ de la Ec. 5.16, se tiene por objetivo llevar a cabo la descomposición y AMR de la misma mediante la Transformada Wavelet. Para tal fin, se muestrea la señal con una frecuencia de muestreo de $2000 \mathrm{~Hz}$, obteniéndose las expresiones que se observan en la Ec. 5.44 y 5.45

$$
\begin{gathered}
u[n]=230 \sqrt{2} \operatorname{sen}\left(\frac{2 \pi 50 \mathrm{n}}{2000}+\pi / 3\right)+200 \sqrt{2} \mathrm{e}^{-\frac{10 \mathrm{n}}{3200}} \cos \left(\frac{2 \pi 20 \mathrm{n}}{2000}+\pi / 6\right) \\
\mathrm{u}[\mathrm{n}]=230 \sqrt{2} \operatorname{sen}\left(\frac{\pi \mathrm{n}}{20}+\pi / 3\right)+200 \sqrt{2} \mathrm{e}^{-\frac{\mathrm{n}}{320}} \cos \left(\frac{\pi \mathrm{n}}{50}+\pi / 6\right)
\end{gathered}
$$

Dicha señal es procesada mediante el AMR, aplicando la Transformada Wavelet. Para ello, se utiliza la wavelet madre de Meyer y se realizan 5 descomposiciones. De esta manera, se obtiene el mismo diagrama de descomposición que el que se observa en la Figura 79. El resultado del análisis puede observarse en la Figura 82. 


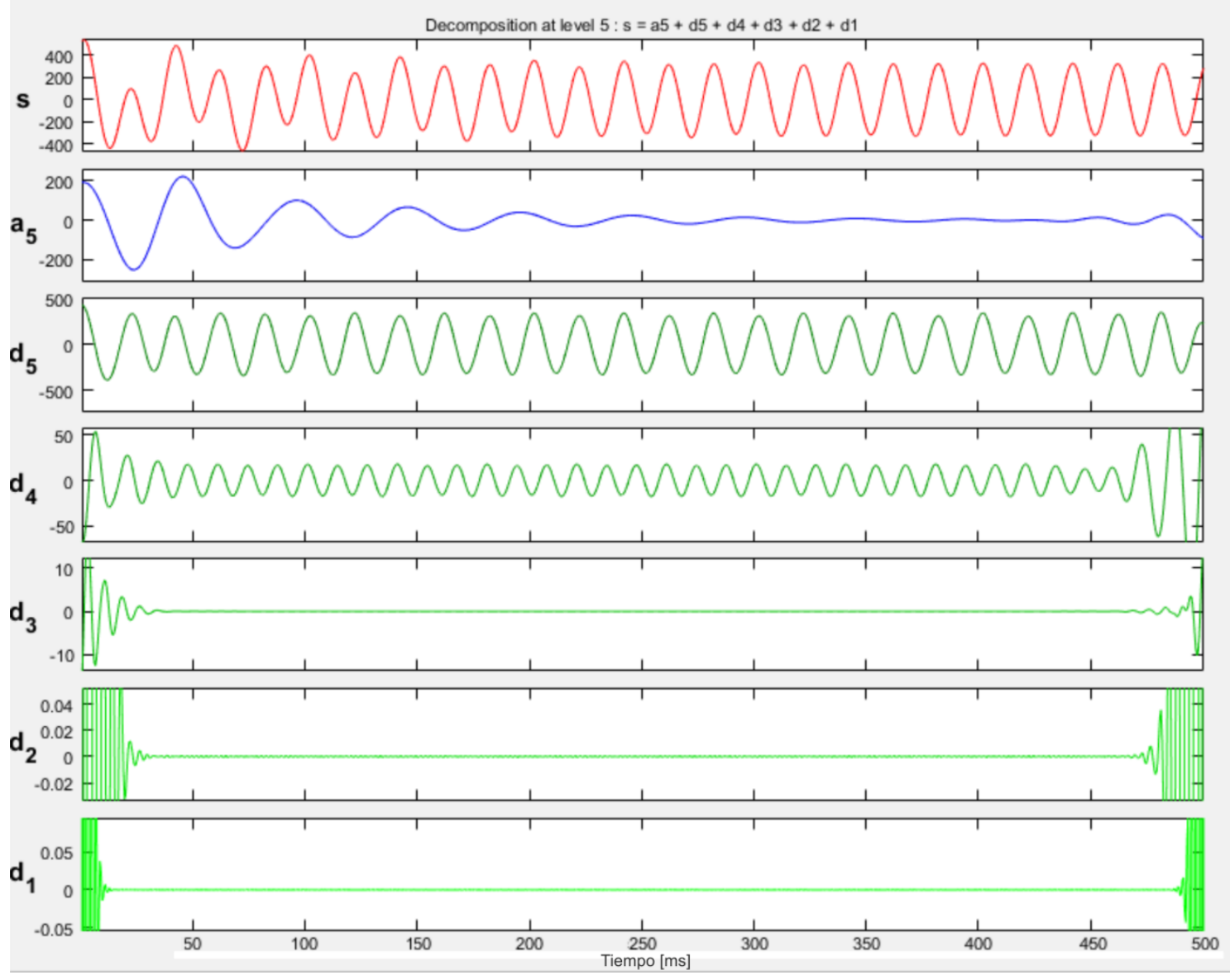

Figura 82. Análisis Multirresolución con 5 niveles de descomposición.

Tal como puede notarse en la Figura, las componentes de señal presentes se encuentran en el nivel de descomposición $\mathrm{d}_{5}$, correspondiente a un rango de frecuencias entre $31,25 \mathrm{~Hz}$ y $62,5 \mathrm{~Hz}$ y en el nivel $\mathrm{a}_{5}$ correspondiente a un rango de frecuencias entre 0 y $31,25 \mathrm{~Hz}$.

En esos niveles puede observarse la componente de $50 \mathrm{~Hz}$ (en el nivel $\mathrm{d}_{5}$ ), que se hace presente a lo largo de todo el registro, y la componente de $20 \mathrm{~Hz}$ (en el nivel $\mathrm{a}_{5}$ ) donde se puede notar también su comportamiento amortiguado.

Del análisis de los resultados obtenidos, es posible notar las siguientes características propias del procesamiento Wavelet de una señal oscilante amortiguada:

- La presencia de señal en los niveles $d_{1}$ a $d_{3}$ corresponde a ruido $y$ componentes oscilatorias propias de realizar el análisis de un segmento temporal de la señal sin aplicar pre-procesamientos que reduzcan la fuga espectral.

- La Transformada Wavelet permite obtener como resultados las componentes de señal presentes en cada banda de frecuencia, sin brindar en forma directa los parámetros necesarios para obtener una expresión cerrada de cada una de ellas. Es decir, no se obtiene en forma directa amplitud, frecuencia o amortiguamiento. 
- La separación de frecuencias en cada uno de los niveles presenta dificultades en los límites de cada una de las bandas a las que corresponden los niveles, tal como se observa para la componente de $50 \mathrm{~Hz}$ en los niveles $\mathrm{d}_{4} \mathrm{y} \mathrm{d}_{5}$. Dicho efecto se explica en detalle a continuación.

Tal como se describió anteriormente, el AMR aplicando Transformada Wavelet consiste en la aplicación de filtros pasa-bajos y pasa-altos a la señal en forma recursiva. Dado que este procesamiento se realiza sobre muestras discretas obtenidas mediante muestreo uniforme con una frecuencia fija, la respuesta y características de dichos filtros no solo dependen de la wavelet madre seleccionada sino también de la frecuencia de muestreo.

En el AMR, la capacidad de separación de frecuencias en los distintos niveles resultantes y la mezcla de frecuencias en los límites de las bandas dependen directamente de las características de dichos filtros. En la Figura 83 puede observarse la respuesta de cada uno de los filtros correspondientes a un AMR aplicando la wavelet de Mayer con 5 niveles de descomposición.

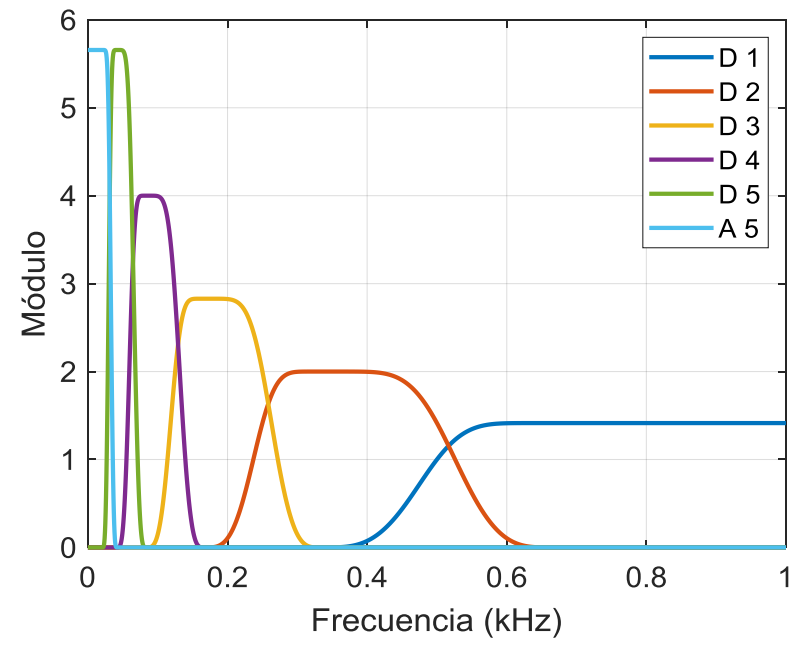

Figura 83. Respuesta en frecuencia del filtrado para Análisis Multirresolución.

La ubicación de los filtros pasa-banda se define mediante la frecuencia de muestreo utilizada ( $2 \mathrm{kHz}$ en el presente ejemplo) y la banda de frecuencia correspondiente a cada nivel en el AMR. Es posible notar que si una componente de frecuencia se ubica dentro de las regiones de transición entre filtros contiguos, dicha componente podrá ser observable en ambos filtros adyacentes. Por lo tanto, la componente se apreciará distorsionada y en ambos niveles de análisis.

Para reducir dicho efecto, es necesario realizar un post-procesamiento de los resultados obtenidos que permita diferenciar aquellas componentes presentes en múltiples niveles.

Las características del AMR demuestran, entonces, la necesidad de llevar a cabo tareas de pre-procesamiento y post-procesamiento para la obtención de resultados útiles 
para el análisis de señales físicas correspondientes a un sistema de potencia. A su vez, la dificultad para la diferenciación de componentes de frecuencia ubicadas en los límites de las bandas y la ausencia de métodos directos para la obtención de los parámetros de las señales oscilatorias amortiguadas analizadas sugieren que una herramienta de análisis basada en el método de Prony proporciona información correcta sobre la amplitud, la frecuencia y el amortiguamiento de los modos de oscilación subsincrónicos de manera más directa y simple que si se analizaran los mismos modos mediante el AMR aplicando la Transformada Wavelet.

Los resultados obtenidos de las comparaciones realizadas entre el análisis de Prony y la Transformada de Fourier y el análisis de Prony y la Transformada Wavelet permiten concluir que el análisis de Prony resulta la herramienta más adecuada para llevar a cabo el estudio de los modos subsincrónicos presentes en la potencia medida en un sistema eléctrico, más aún cuando dicho análisis debe llevarse a cabo en tiempo real.

\subsubsection{Implementación del método de Prony}

El método de Prony se implementó en MATLAB, utilizando como base el desarrollo ya realizado en [56] y según el procesamiento descripto en la sección 7.2.1.

El análisis de Prony se realiza sobre una ventana temporal de ancho configurable por el usuario, deslizante con un paso configurable, detectando la presencia de modos de oscilación dentro de bandas de exploración especificadas por el usuario. El ancho de la ventana de Prony queda determinado por la frecuencia del modo más bajo que se pretende detectar: debe abarcar no menos de medio ciclo de dicha frecuencia.

La robustez del algoritmo se logró dotándolo de la capacidad de identificar las componentes válidas resultantes del análisis de cada ventana de la forma de onda analizada. Para ello, en cada ventana temporal del análisis de Prony, con el paso de decimación considerado, se depuran las componentes resultantes con los siguientes criterios:

- La magnitud se determina efectuando la suma vectorial de todas las componentes detectadas dentro de dicha banda, afectadas por sus correspondientes amortiguamientos exponenciales para una unidad de tiempo, y dividida por el número de componentes detectadas en la banda. La magnitud resultante debe ser mayor que la Magnitud Mínima (configurada por el usuario) para que no sea considerada despreciable y descartada automáticamente.

- La frecuencia se determina promediando la frecuencia de todas las componentes detectadas dentro de dicha banda, pesadas por sus respectivas amplitudes y afectadas por sus correspondientes amortiguamientos exponenciales para una unidad de tiempo. 
- El amortiguamiento se determina promediando el amortiguamiento de todas las componentes detectadas dentro de dicha banda, pesados por sus respectivas amplitudes (afectadas por sus amortiguamientos exponenciales para una unidad de tiempo).

Tal como se describió anteriormente, y como se documenta en [55] y [61], el método de Prony resulta apropiado para la evaluación de oscilaciones subsincrónicas en sistemas de potencia.

\subsection{Componentes del módulo Online}

\subsubsection{Front-End/Decodificador}

El Front-End/Decodificador puede esquematizarse con un diagrama en bloques como el que se observa en la Figura 84.

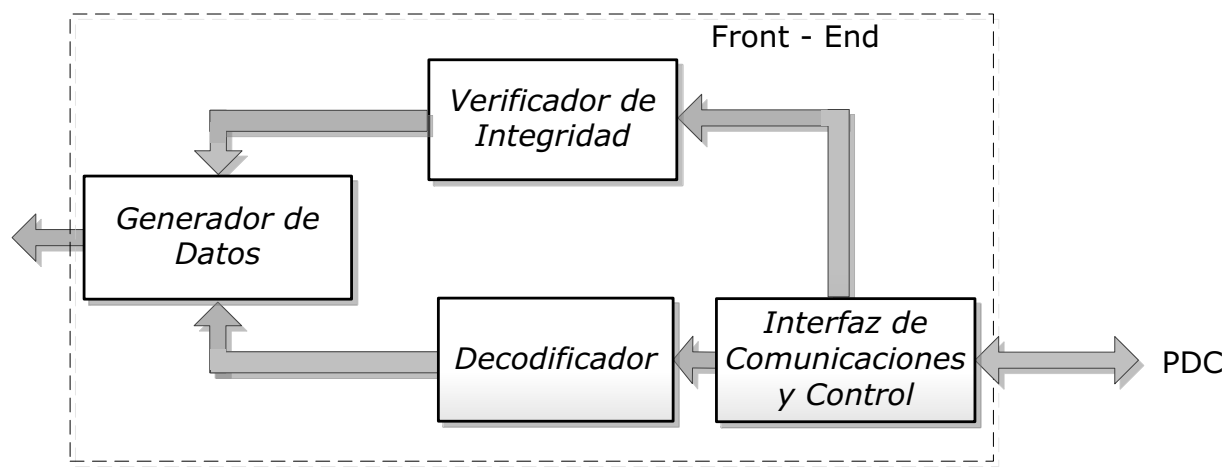

Figura 84. Diagrama en Bloques de Front-End - Módulo Online.

La comunicación con el concentrador se realiza mediante la Interfaz de Comunicaciones y Control. Este enlace se realiza mediante una comunicación UDP con el PDC.

Este bloque tiene dos funciones principales. La primera de ellas es la recepción y decodificación de los paquetes UDP transmitidos por el PDC mediante el método de transmisión espontáneo para su procesamiento posterior. La segunda función de este bloque es el control de la conexión con el PDC. Para ello, lleva adelante un seguimiento del enlace entre el Front-End y el PDC con el objetivo de detectar un eventual corte de la conexión para, en ese caso, brindar la información del estado del enlace al Analizador para que sea informada al usuario.

Tal como es esperable en cualquier comunicación regida por la norma [10], el FrontEnd recibe la configuración que envía el PDC con sus características y las de las PMUs conectadas. Entre ellas, puede mencionarse el identificador del PDC, su descripción, la cantidad de PMUs concentradas, la cantidad de fasores de cada PMU, el tipo y unidad de conversión de cada fasor, la frecuencia nominal de la red medida en cada PMU y la tasa de transmisión de datos, entre otros. Todos estos datos son almacenados por el 
Front-End para poder realizar la decodificación y procesamiento de los Paquetes de Datos.

Los datos obtenidos por la interfaz son recibidos por el Decodificador y el Verificador de Integridad.

El Decodificador es el encargado de recuperar la información útil recibida. Para ello, implementa un analizador de datos que realiza la búsqueda de cada uno de los campos de datos previstos en la norma y que son enviados por el concentrador.

De cada paquete de datos recibido, en base a la configuración almacenada del PDC, se obtienen las mediciones de todos los fasores, de la frecuencia, de la variación de frecuencia (ROCOF) y la etiqueta temporal a la que corresponde el paquete. A su vez, se realiza la verificación del campo de validez de datos emitido por cada PMU concentrada, con el objetivo de marcar la fiabilidad de las mediciones que se hayan efectuado.

El Verificador de Integridad tiene como función la verificación de errores en el paquete recibido. Para ello, realiza la comparación entre el código de Verificación de Redundancia Cíclica (CRC-CCITT) recibido con el calculado localmente. Si ambos códigos no coinciden, el paquete recibido es finalmente descartado.

El Generador de Datos, finalmente, es el encargado de producir los paquetes de datos necesarios para el Analizador. En dichos paquetes se incluyen las mediciones fasoriales, de frecuencia y de variación de frecuencia, la etiqueta temporal que corresponde a la medición y el campo de validez de datos. Para ello, este bloque realiza la conversión de la etiqueta temporal a un formato de horario comprensible por el usuario. A su vez, como el usuario selecciona las PMUs que se desean visualizar y procesar, este bloque realiza una búsqueda, en los datos recibidos, de las mediciones provenientes de las PMUs seleccionadas.

\subsubsection{Analizador}

El Analizador tiene como funciones principales la visualización de los datos y el análisis de los sincrofasores para la detección de perturbaciones que ameriten su evaluación con respecto a los modos de oscilación presentes. En el caso en que se requiera el análisis mencionado, este componente activa el correspondiente Procesador Prony. A su vez, también se encarga de la administración temporal del procesamiento online y de los recursos disponibles (procesadores y memoria). 


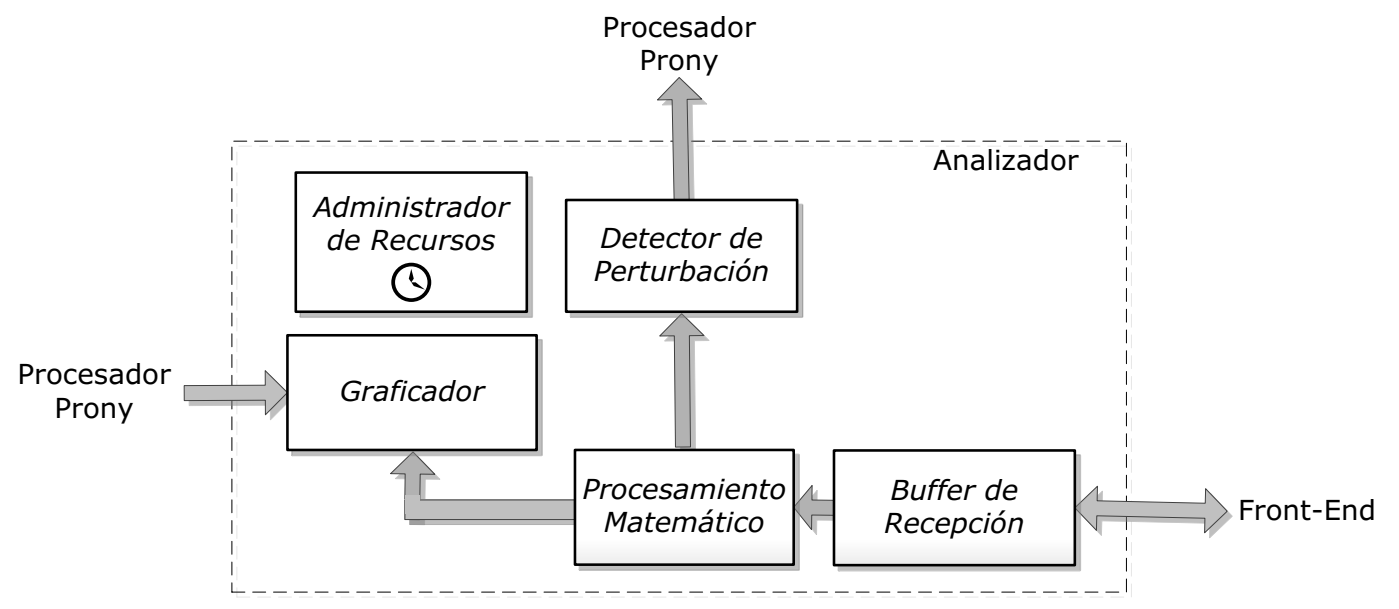

Figura 85. Diagrama en Bloques del Analizador - Módulo Online.

El buffer de recepción recibe los datos del front-end, almacenándolos en un buffer de tipo FIFO. Cada uno de los paquetes de datos recibidos es analizado por el bloque de Procesamiento Matemático.

Este bloque lleva a cabo todos los cálculos necesarios para la obtención, a partir de los valores medidos, de otras variables de interés como, por ejemplo, la potencia.

El Detector de Perturbación es el encargado de procesar, mediante el Algoritmo de Detección (que se describirá a continuación), la potencia medida en cada PMU con el objetivo de detectar condiciones anómalas que ameriten su evaluación por medio del Procesamiento Prony para la obtención de los modos de oscilación. Cuando esta situación sucede, este bloque activa el Procesador Prony que corresponde a la PMU en cuestión transfiriéndole, además, las mediciones que correspondan.

El Graficador es el bloque encargado de la visualización de datos. Para ello, en base a los fasores medidos y las variables calculadas, administra los gráficos de las variables que el usuario desea observar. De esta manera, es el encargado de realizar los gráficos fasoriales de tensiones y corrientes y las trazas de potencia, tensiones, corrientes, frecuencia y ROCOF.

Finalmente, el Administrador de Recursos es quien realiza todas las tareas relacionadas a la temporización, sincronización y administración de las tareas. Para ello, lleva adelante el control de la finalización de cada uno de los procesamientos en paralelo que se estén realizando para, de esa manera, administrar la carga de procesos.

\section{Algoritmo para la detección de perturbaciones}

El algoritmo de detección fue diseñado para llevar a cabo el análisis de las mediciones realizadas con el objetivo de localizar una perturbación en la señal.

En base a la configuración realizada por el usuario, se evalúa una ventana temporal de longitud $\mathrm{N}$ de la señal. Siendo $\mathrm{C}$ el conjunto de datos de dicha ventana, donde se almacenan las últimas $\mathrm{N}$ muestras de señal, 


$$
C=\{x[n-1], x[n-2], \ldots \ldots, x[n-N]\}
$$

la detección se realiza comparando la media de dicha ventana con la nueva muestra de señal. Para ello se calcula la diferencia entre la media y la nueva muestra, elevando el resultado a una potencia de exponente par. De esta manera, se magnifica el fenómeno (si es que existe), independizándose del signo de dicha diferencia.

$$
\mathrm{Z}=\left(\mathrm{x}[\mathrm{n}]-\frac{1}{\mathrm{~N}} \sum_{\mathrm{i}=1}^{\mathrm{N}} \mathrm{x}[\mathrm{n}-\mathrm{i}]\right)^{2 \mathrm{p}}
$$

El factor de mérito $\mathrm{Z}$ es comparado con un nivel de disparo o threshold, configurable por el usuario. Si el factor $\mathrm{Z}$ supera este nivel, se considera que una perturbación está presente.

En el caso del software de procesamiento, la potencia utilizada es $4(\mathrm{p}=2)$. Dicho valor fue seleccionado en base a diversas pruebas realizadas al algoritmo, que consistieron en evaluar su funcionamiento frente a perturbaciones de diversas características conocidas previamente.

\subsubsection{Procesador Prony}

El Procesador Prony, basado en la implementación descripta en 7.2.4, realiza todos los cálculos relacionados a la obtención de los modos de oscilación presentes durante una perturbación.

Este análisis se aplica a una ventana temporal de ancho fijo deslizante entre ciclos. El ancho y la cantidad de ciclos que se desliza la ventana entre análisis sucesivos son configurados por el usuario. El procesamiento detecta en cada ventana la presencia de modos de oscilación dentro de bandas de exploración especificadas por el usuario. A su vez, sobre cada ventana temporal es posible aplicar un submuestreo de las muestras, con un paso de decimación también configurable.

Cuando el usuario configura el ancho de la ventana de Prony, es importante que tenga en cuenta que la longitud de la ventana queda determinada por la frecuencia del modo más bajo que se pretende detectar: debe abarcar no menos de medio ciclo de dicha frecuencia.

El procesamiento tiene un retardo mínimo igual al largo de la ventana temporal configurada para realizar el procesamiento. Esto se debe a que, por las características propias del método de Prony, el fenómeno que se desea analizar debe encontrarse en el inicio de la ventana de procesamiento. Para ello, la conformación de la ventana comienza una vez que se detecta la perturbación y finaliza una vez transcurrido el tiempo correspondiente al largo de la ventana. Por lo tanto, el inicio real del cálculo del método de Prony comienza con un retardo respecto a la perturbación igual al largo de la ventana temporal. 
Es importante mencionar que cada PMU tiene un procesador Prony asignado, de manera tal que no exista interacción ni pérdida de datos cuando sea necesario procesar perturbaciones de distintas PMUs.

Una vez finalizado el análisis, el procesador informa al analizador los resultados para que estos sean visualizados por el usuario.

\subsection{Interfaz de Usuario}

En la Figura 86 puede observarse la ventana principal de la interfaz de usuario.

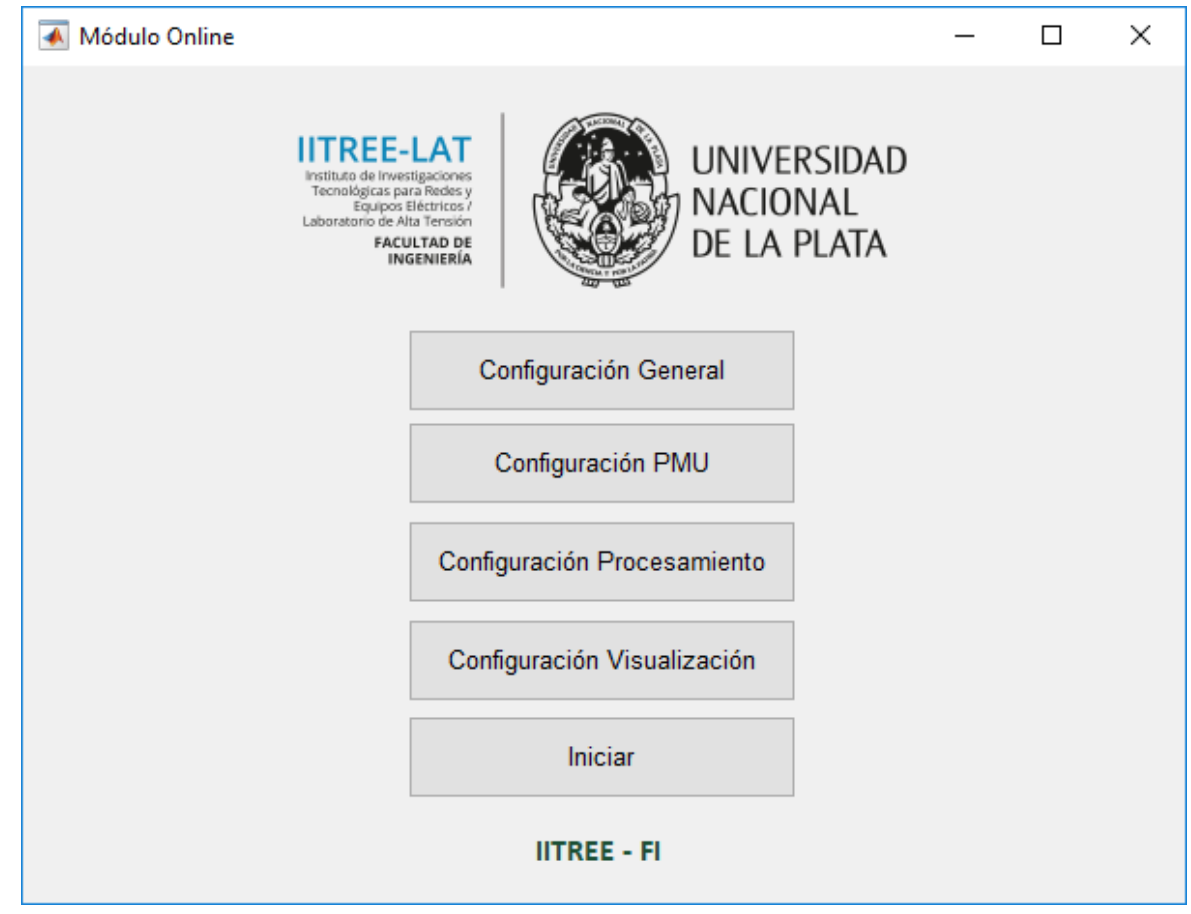

Figura 86. Interfaz de Usuario - Módulo Online.

El software inicia dando al usuario la posibilidad de configurar todos los parámetros necesarios para realizar la visualización que desea.

\subsubsection{Configuración General}

La configuración general se refiere a los parámetros de comunicación con el concentrador y la cantidad de PMUs a procesar. En la Figura 87 se muestra la ventana correspondiente. 


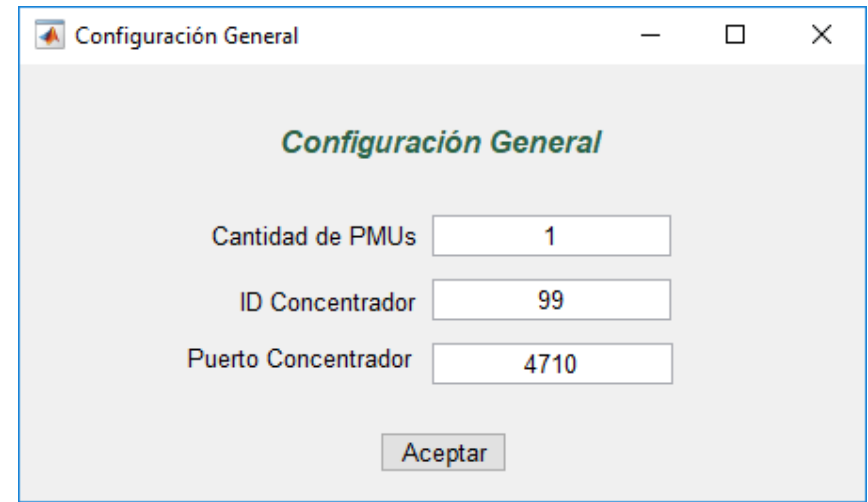

Figura 87. Configuración General - Módulo Online.

En este caso, los parámetros que deben configurarse son la cantidad de PMUs que se desea procesar, el ID del concentrador de donde se recibirán los datos y el puerto UDP a donde arribarán los sincrofasores transmitidos por el concentrador.

\subsubsection{Configuración PMU}

En el menú de configuración de PMU, el usuario debe establecer para cada una de las PMUs que desea procesar los parámetros que se observan en la Figura 88. Dichos parámetros permiten realizar el procesamiento que corresponda según la PMU analizada.

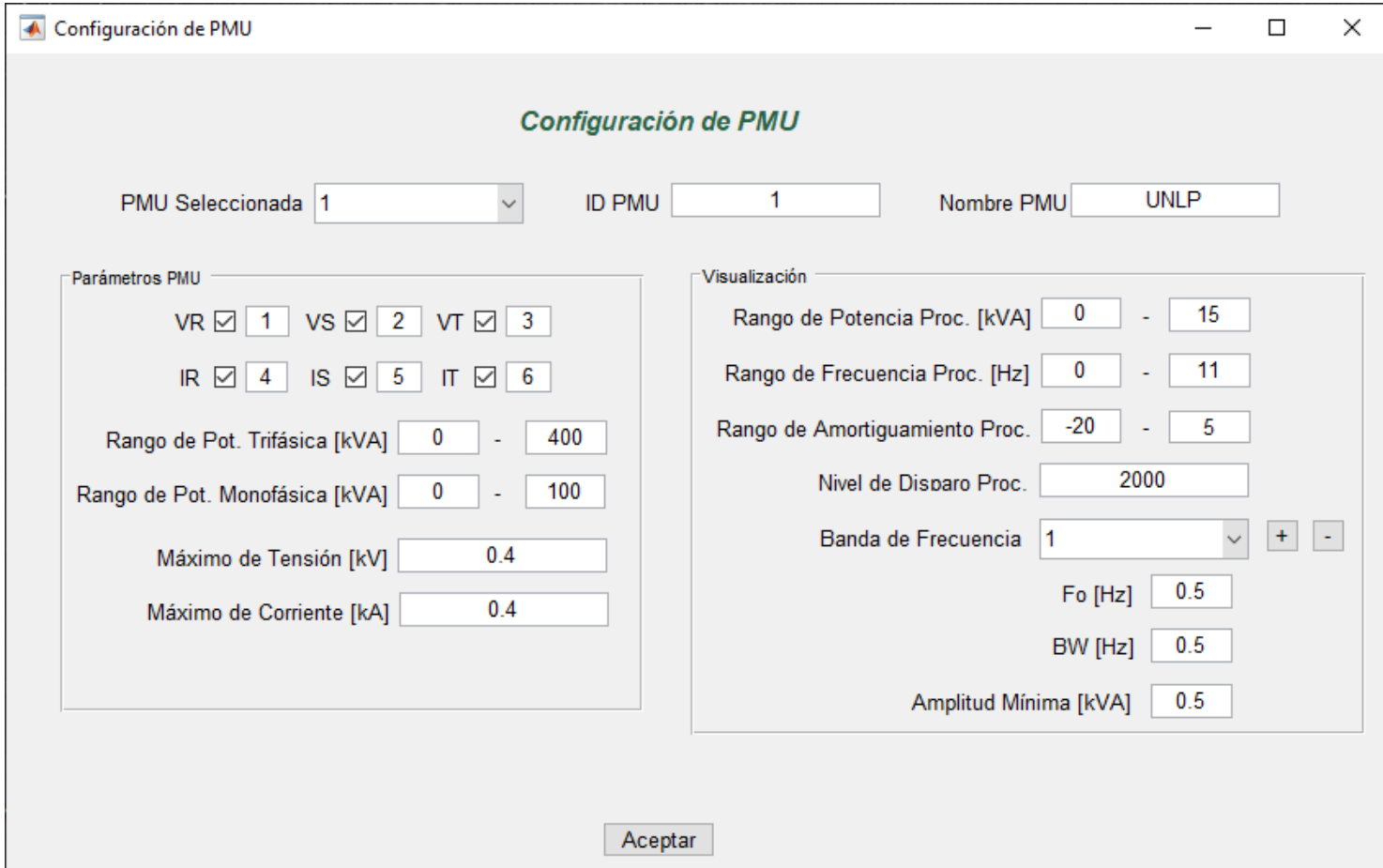

Figura 88. Configuración PMU - Módulo Online.

El usuario dispondrá de configuraciones independientes, una por cada PMUs siendo el número de PMUs el indicado en la Configuración General 
El ID PMU es el identificador de la PMU que desea procesar, establecido por el Administrador del Sistema.

El Nombre de la PMU es un campo alfanumérico que permite ingresar un título a la PMU seleccionada con el objetivo de facilitar la identificación y visualización de los sincrofasores que la PMU envía.

En el apartado Parámetros PMU, es posible realizar configuraciones relacionadas a los sincrofasores de la PMU en cuestión.

El usuario puede seleccionar cuáles variables del punto de conexión de la PMU desea analizar (tensiones y corrientes), debiendo indicar en cada caso el número de orden del sincrofasor enviado por la PMU al cual corresponde la variable correspondiente.

El rango de potencia es el valor mínimo y máximo esperable de potencia que se medirá en la PMU en cuestión, tanto en la opción monofásica como trifásica. También debe configurarse el máximo de tensión y corriente. Estos tres parámetros son necesarios para la graficación de las mediciones.

En el apartado Visualización, es posible realizar configuraciones relacionadas a la visualización y procesamiento de los sincrofasores de la PMU en cuestión.

El Rango de Potencia Proc. corresponde al rango de potencia esperable de cada modo de oscilación que pueda medirse cuando se realice un procesamiento Prony. Este mismo concepto es el que corresponde al Rango de Frecuencia Proc. para la frecuencia y el Rango de Amortiguamiento Proc. para el amortiguamiento.

El Nivel de Disparo Proc. es el valor límite en el Algoritmo de Detección de perturbaciones que define el inicio o no del procesamiento Prony para una condición de perturbación.

Las bandas de frecuencia corresponden a aquellas bandas donde se analizarán los modos de oscilación. Se pueden definir de manera independiente para cada PMU hasta un máximo de 15 bandas de exploración.

Cada banda tiene su frecuencia central (Fo), su semi-ancho de banda (BW) y la amplitud mínima que debe tener el modo resultante en esa banda para que no se lo considere despreciable. De esta manera, cada banda corresponde a las frecuencias [Fo$\mathrm{BW} ; \mathrm{Fo}+\mathrm{BW}]$.

\subsubsection{Configuración de procesamiento}

La configuración del procesamiento define parámetros del procesamiento Prony comunes a todas las PMUs. En la Figura 89 se muestra la ventana de configuración. 


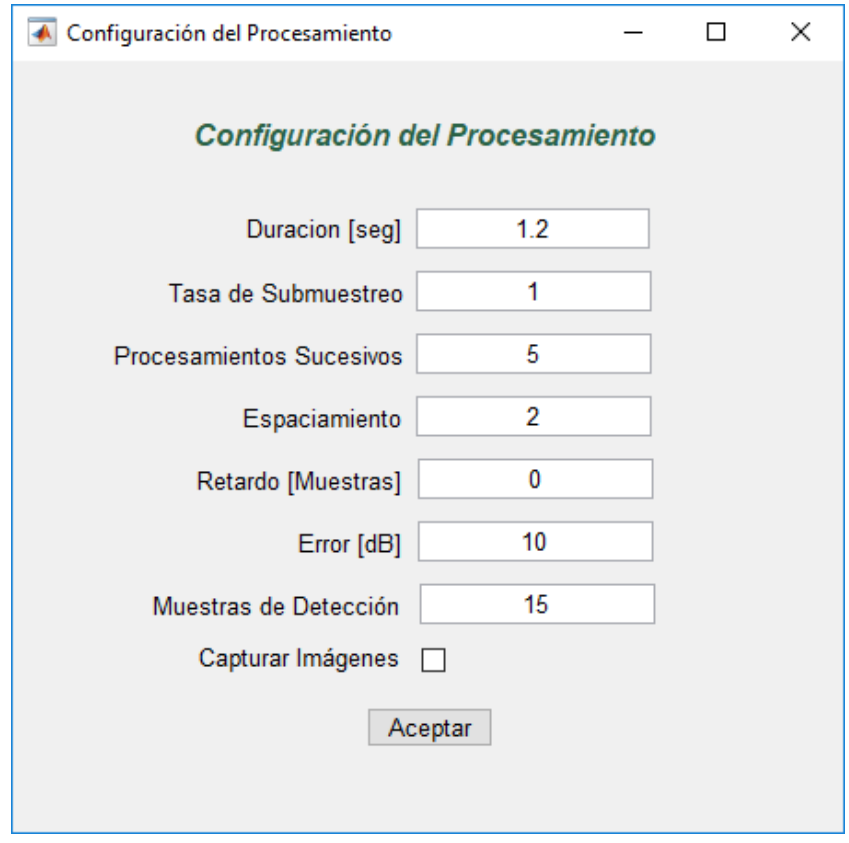

Figura 89. Configuración del Procesamiento - Módulo Online.

La duración del procesamiento establece el ancho de la ventana temporal sobre la que se realizará el procesamiento Prony.

La tasa de submuestreo o paso de decimación define la frecuencia de muestreo que desea emplearse para los datos utilizados por el Procesamiento Prony. Una tasa de submuestreo de valor 1 equivale a utilizar el muestreo original $(\mathrm{F})$ mientras que una tasa mayor (de valor $\mathrm{N}$ ) equivale a utilizar una tasa de muestreo $\mathrm{F} / \mathrm{N}$. Se sugiere utilizar tasas de submuestreo entre 1 y 3 .

Los procesamientos sucesivos establecen el número de ventanas del análisis de Prony a procesar una vez detectada la perturbación. Es recomendable realizar hasta 10 procesamientos sucesivos.

El espaciamiento define cada cuántos ciclos se realiza el nuevo procesamiento (es decir, el desplazamiento que se realiza sobre la ventana). Se recomienda utilizar un espaciamiento entre 1 y 3 .

El retardo define cuantas muestras de señal deben sucederse una vez detectada la perturbación para comenzar a muestrear para el procesamiento Prony. Se sugiere configurar el retardo entre 0 y 5.

El error, en decibeles, es el máximo error (definido como relación de potencias de señal) que desea tenerse en el procesamiento. Aquí es importante mencionar que este objetivo no siempre es posible. Se sugiere utilizar valores entre $5 \mathrm{~dB}$ y $15 \mathrm{~dB}$.

Finalmente, las muestras de detección definen el largo de la ventana temporal sobre la que se implementa el algoritmo de detección. Es recomendable utilizar entre 10 y 20 muestras. 
Capturar imágenes es una opción adicional que habilita el guardado en la carpeta de instalación del software de las trazas resultantes del procesamiento Prony. Esta opción puede provocar mayores tiempos de latencia en el procesamiento y la visualización.

\subsubsection{Configuración de Visualización}

La configuración de visualización define parámetros para la graficación y las variables que se desean visualizar.

En la Figura 90 se observa la pantalla de configuración. La grilla que presenta esta pantalla consta de tres ventanas con 13 celdas, cada una de las cuales representa una zona de graficación.

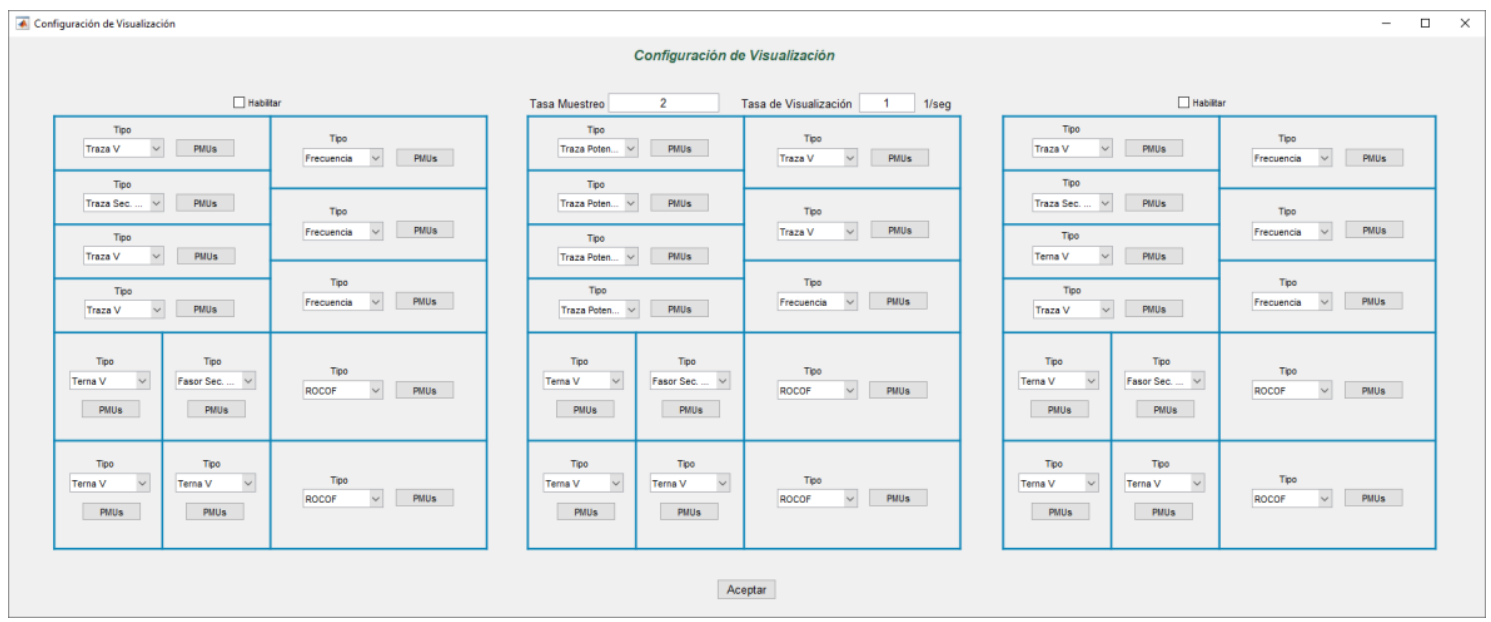

Figura 90. Configuración de Visualización - Módulo Online.

En la Figura 91 se brinda un detalle de la pantalla de configuración, pudiendo observarse la configuración de una de las ventanas disponibles. 


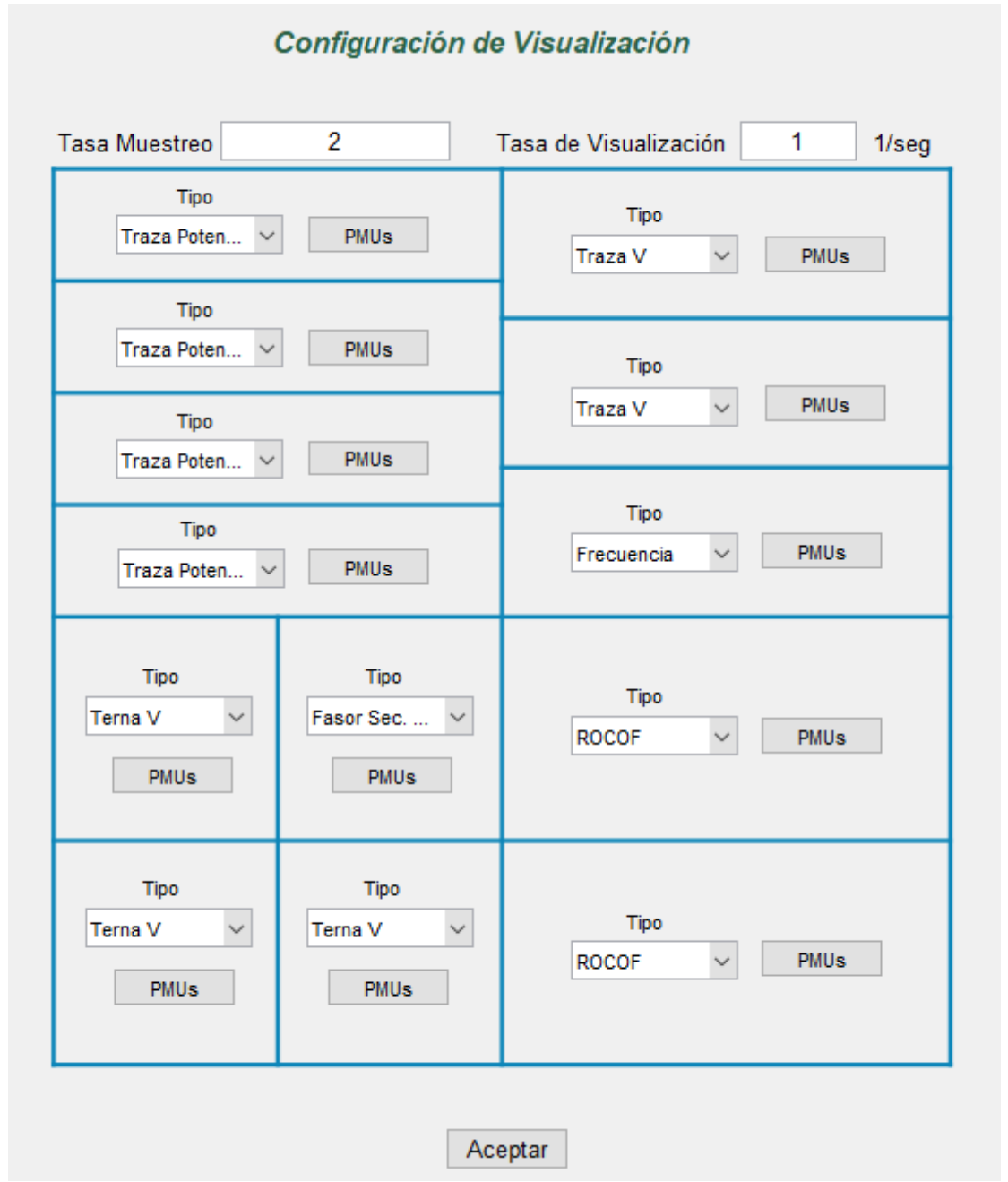

Figura 91. Detalle de configuración de Visualización - Módulo Online.

En el presente menú, es posible configurar el tipo de gráfico que se desplegará en cada zona de graficación y las PMUs de la cuales se quieren visualizar los datos correspondientes.

Las ventanas laterales adicionales pueden ser habilitadas o deshabilitadas con la correspondiente casilla en la parte superior de la configuración de cada una de ellas.

El parámetro Tasa de Muestreo define cada cuántas mediciones recibidas se evalúa una de ellas. Es decir, se divide a la tasa de transmisión del concentrador por el parámetro Tasa de muestreo. Es recomendable utilizar una tasa de muestreo entre 2 y 4.

El parámetro Tasa de Visualización establece la frecuencia con que se lleva a cabo una actualización de los gráficos realizados, completándolos con todas las mediciones obtenidas en ese intervalo de tiempo. Este parámetro es muy importante para reducir las posibilidades de sobrecarga del sistema. Se recomienda realizar una actualización de visualización por segundo. 
Finalmente, en esta ventana se muestra un esquema de la ventana de visualización de datos con el objetivo que el usuario defina qué tipo de variable desea observar en cada posición. Los tipos de variables observables son:

- Traza de potencia trifásica

- Traza de potencia monofásica $\mathrm{R}$

- Traza de potencia monofásica $\mathrm{S}$

- Traza de potencia monofásica T

- Traza de tensión (las tres tensiones de una PMU)

- Traza de corriente (las tres corrientes de una PMU)

- Terna de tensión (diagrama fasorial de una PMU)

- Terna de corriente (diagrama fasorial de una PMU)

- Frecuencia

- $\mathrm{ROCOF}$

- Traza de la componente de secuencia directa de tensión

- Traza de la componente de secuencia directa de corriente

- Fasorial de la componente de secuencia directa de tensión

- Fasorial de la componente de secuencia directa de corriente

Una vez definida la variable que se desea visualizar en la zona de graficación correspondiente, el usuario debe ingresar al menú PMUs para establecer de cuáles se quiere observar la variable seleccionada.

El usuario puede observar en pantalla una ventana como la que se muestra en la Figura 92. 


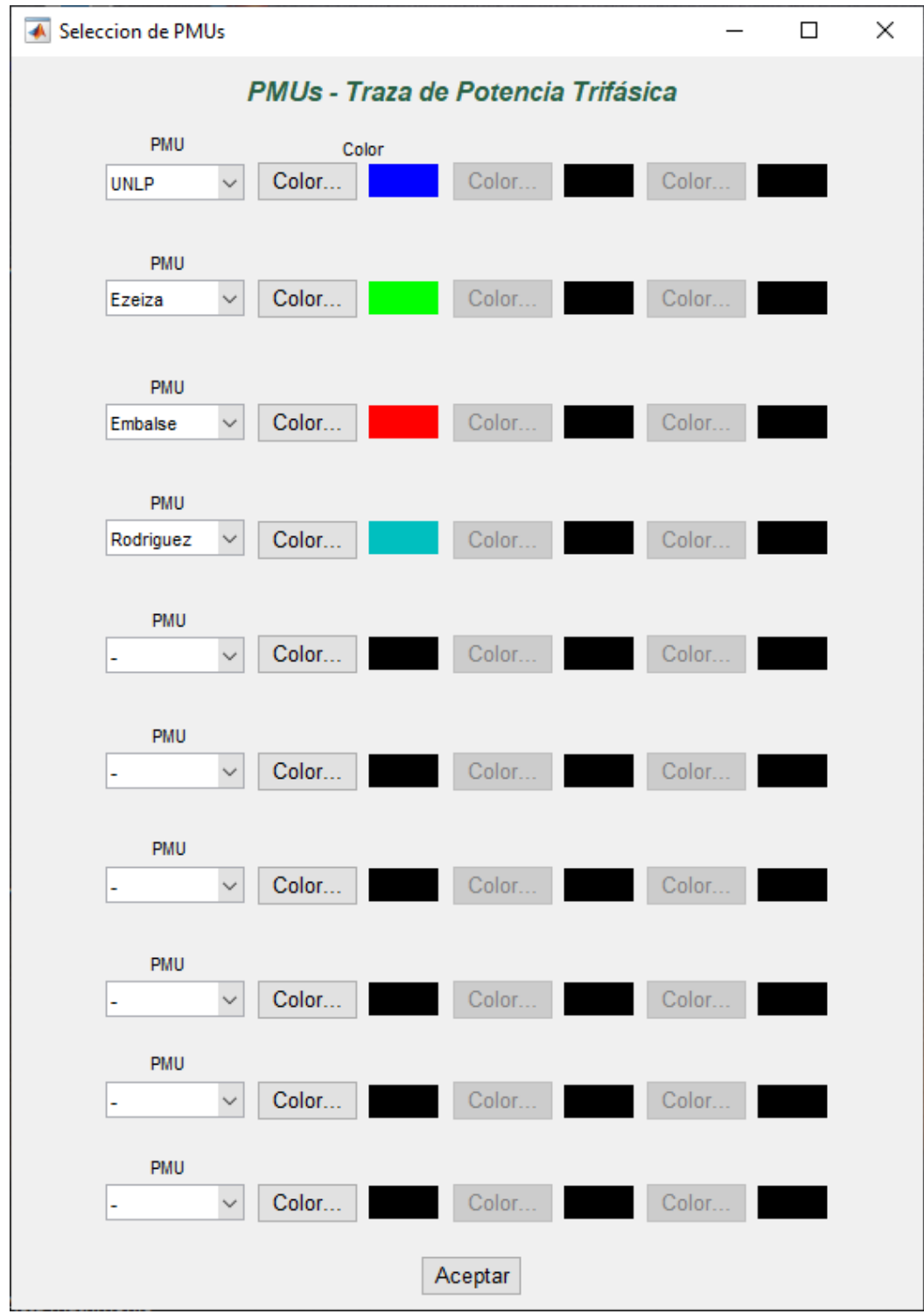

Figura 92. Configuración de Visualización - Módulo Online.

Como se puede observar en la Figura 92, el usuario dispondrá de la posibilidad de incluir hasta 10 PMUs en un mismo gráfico. Para ello, cuenta con un menú desplegable con la lista de las PMUs configuradas, indicadas cada una con el nombre provisto en la Configuración de PMU.

A su vez, el usuario podrá establecer los colores con los que desea graficar la variable correspondiente. En el caso de la graficación de trazas o ternas de tensión, donde se debe incluir las tres fases correspondientes, se deberán configurar los colores para cada una de ellas. Caso contrario, para gráficos de una única variable por PMU, se deberá configurar un único color por PMU. 


\subsubsection{Ventana de visualización}

Una vez que el usuario finaliza la configuración y presiona el botón Iniciar, el software realiza todas las conexiones y recepción de datos de configuración con el concentrador para comenzar con la visualización y procesamiento de los datos. La ventana de visualización puede observarse en la Figura 93, y cuenta con las 13 zonas de graficación configuradas en 7.4.4, cada una de las cuales contiene el gráfíco configurado por el usuario (variable y tipo de gráfico).

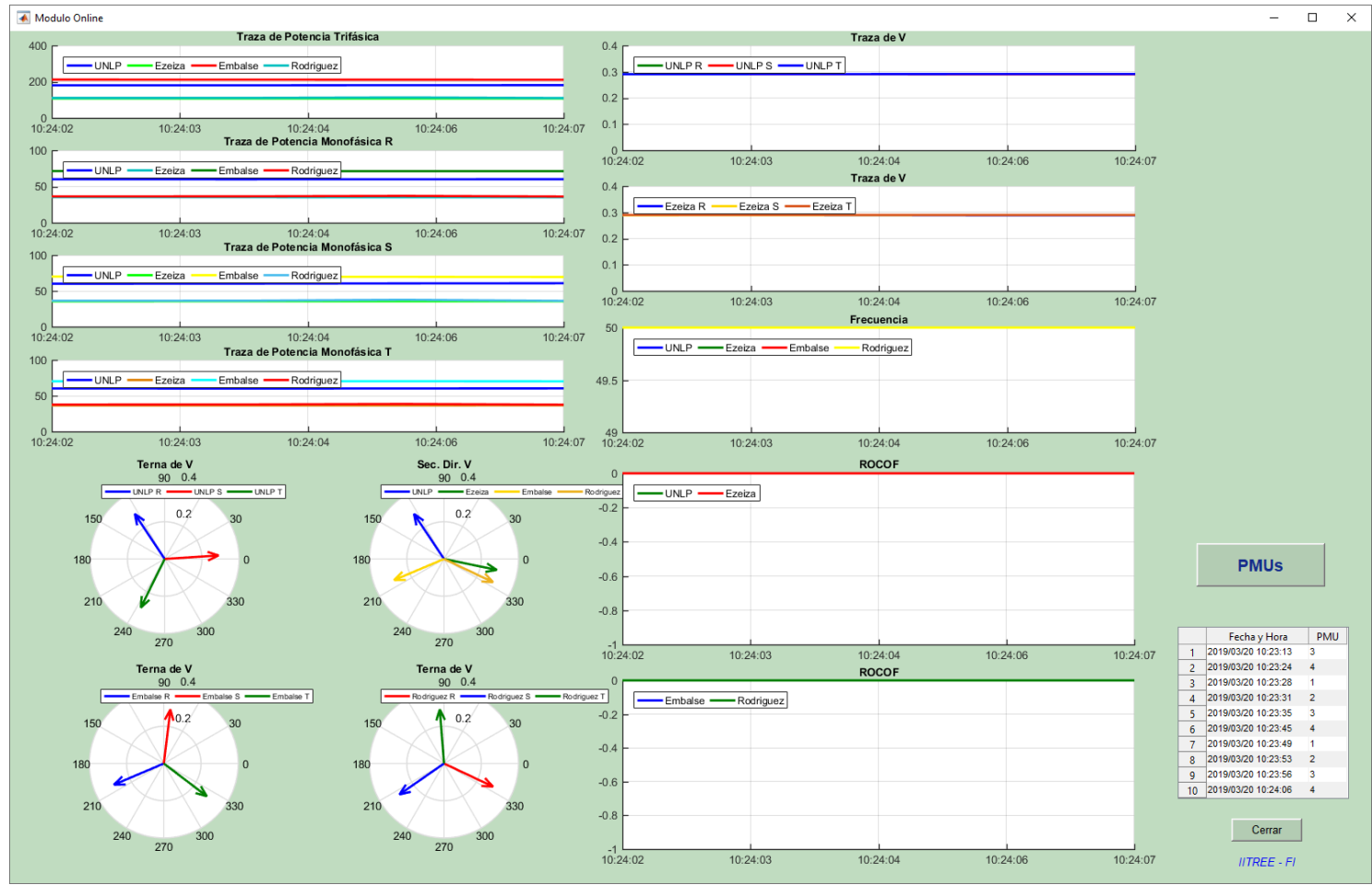

Figura 93. Ventana de Visualización- Módulo Online.

A su vez en la ventana principal se dispone, en la tabla que se observa a la derecha de la Figura 93, de un registro de las últimas 10 perturbaciones detectadas por el sistema (Fecha y Hora del evento y PMU afectada identificada por su ID). Si se selecciona una entrada de dicho registro, se abrirá una nueva ventana como la que se muestra en la Figura 94 con las trazas correspondientes a los modos de oscilación obtenidos para esa perturbación. De esta manera, el usuario dispone de un historial de los eventos sucedidos y sus respectivos modos de oscilación. 


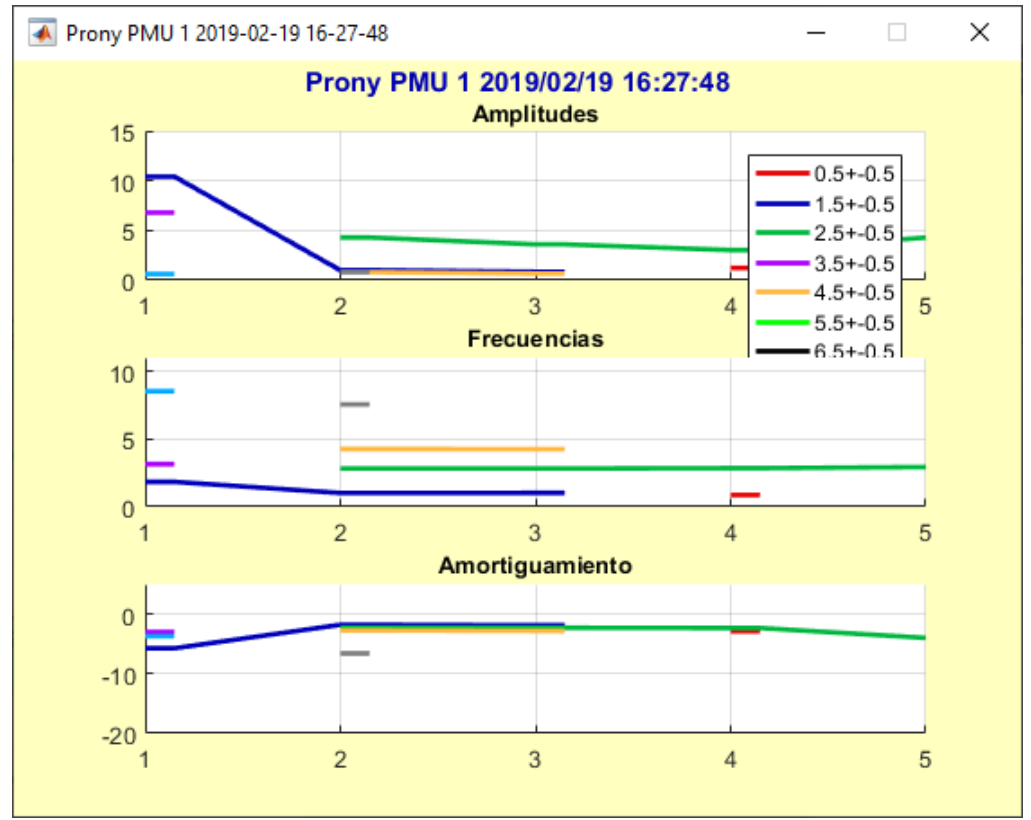

Figura 94. Procesamiento de modos de oscilación - Módulo Online.

Por otro lado, en la ventana principal también se dispone de un acceso, denominado "PMUs", que permite al usuario mostrar un listado de las PMUs configuradas en el sistema. Dicho listado, tal como se observa en la Figura 95, muestra el ID de la PMU junto al nombre provisto en la Configuración de PMU.

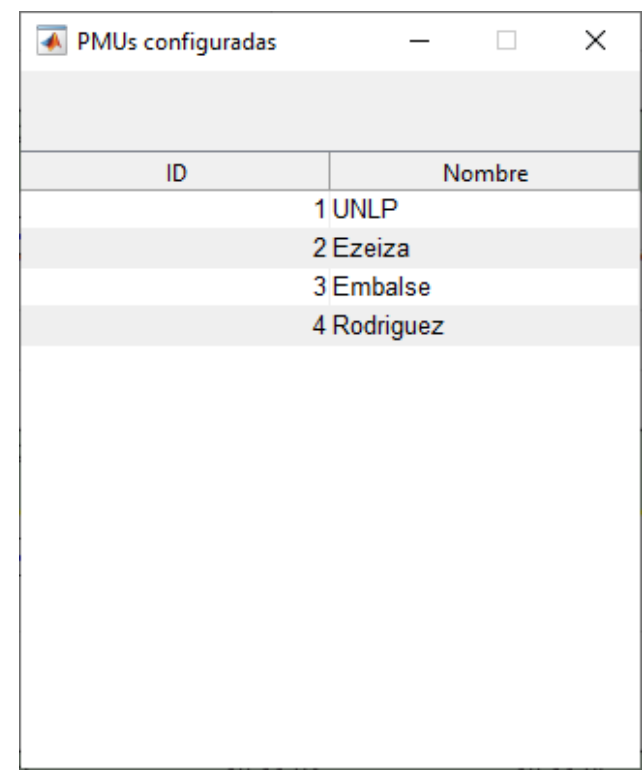

Figura 95. Listado de PMUs configuradas - Módulo Online.

\subsection{Ensayos de Evaluación}

\subsubsection{Descripción}

Con el objetivo de comprobar el correcto funcionamiento del Detector de Perturbaciones y el Procesamiento Prony integrados en el software de procesamiento 
Online, se llevaron a cabo pruebas con software específico de simulación de una PMU, ejecutable en una PC, que permitieran transmitir un registro de sincrofasores obtenidos por dos PMUs ubicadas en distintos puntos del SADI.

Las pruebas consistieron en realizar las transmisiones de dichos sincrofasores desde el simulador de PMUs hacia un concentrador al cual se encuentra conectado el software de procesamiento. De esta manera, dicho software recibiría los sincrofasores de la misma manera que lo haría en una aplicación real.

Una vez transmitidos los sincrofasores, se realizó un análisis de las perturbaciones detectadas junto a sus correspondientes modos de oscilación para luego compararlos con un procesamiento local de las mediciones registradas por las PMUs, con el objetivo de comparar resultados.

\subsubsection{Registros de sincrofasores}

Para realizar las pruebas mencionadas, se utilizaron registros de dos PMUs conectadas al SADI, ubicadas en dos puntos de dicha red.

Los registros analizados corresponden a un fenómeno producido el día 11 de mayo de 2017 a las 17:33 hs. donde se produjo una caída de la frecuencia del sistema ante la pérdida de generación. El registro en el libro de operaciones del sistema muestra la siguiente descripción:

\begin{tabular}{|lll|}
\hline OED & 17:29 & $\begin{array}{l}\text { BBLATV30: F/S intempestiva. Se encontraba realizando ensayos con } \\
\text { 180 MW. La frecuencia alcanzó los 49,79 Hz. }\end{array}$ \\
\hline OED 17:33 & $\begin{array}{l}\text { DSUDTV11: F/S intempestiva (125 MW). La frecuencia varió de 49,80 } \\
\text { Hz a 49,50 Hz. Causas: falla en bomba de aceite de control. Sin } \\
\text { afectación al servicio. }\end{array}$ \\
\hline & $17: 35$ & $\begin{array}{l}\text { SACME solicitó E/S la DSUDTG07/08 y RESCDI01 por reducir } \\
\text { sobrecarga de L. 132 kV Bosques - Dock Sud 1 y } 2 \text { (C. } 511 \text { y 512). }\end{array}$ \\
\hline $17: 36$ & $\begin{array}{l}\text { La frecuencia del SADI alcanzó nuevamente los } 50 \mathrm{~Hz} \text { luego de } \\
\text { poner E/S generación para compensar la pérdida. }\end{array}$ \\
\hline
\end{tabular}

El registro de la PMU 1 muestra una evolución temporal de la frecuencia y la potencia como la que se observa en las Figuras 96 y 97 respectivamente. 


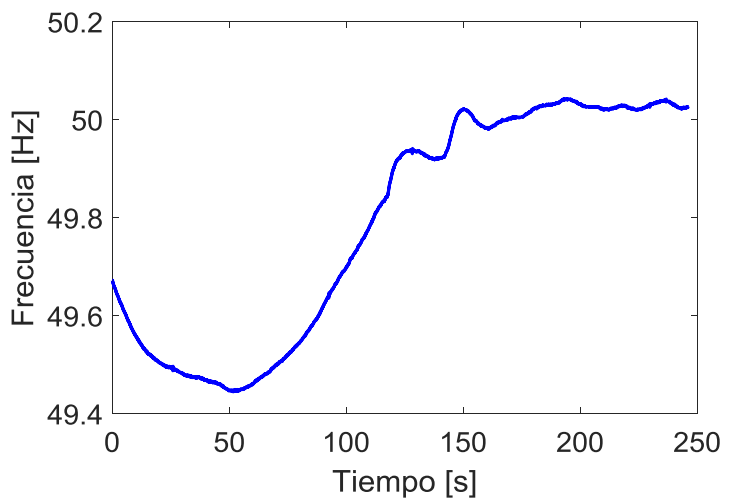

Figura 96. Traza de frecuencia - PMU 1.

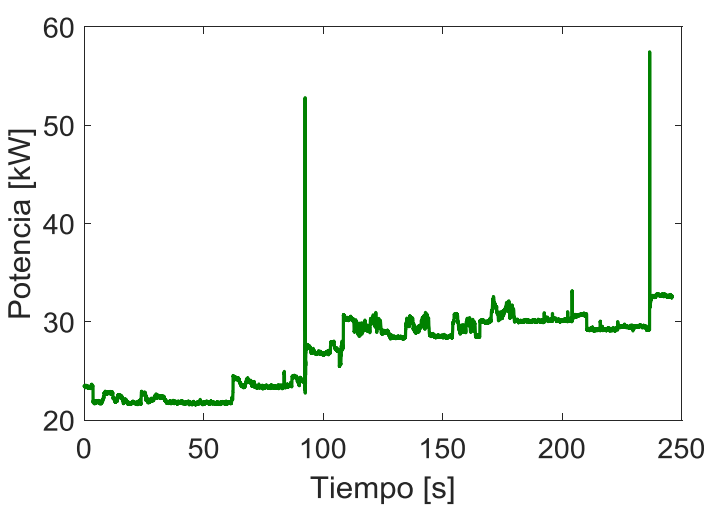

Figura 97. Traza de potencia - PMU 1.

En la traza de potencia pueden observarse, a simple vista, dos importantes perturbaciones correspondientes a un tiempo de 92 segundos y $236 \mathrm{~s}$.

En las Figuras 98 y 99 pueden observarse la evolución temporal de la frecuencia y la potencia respectivamente, correspondientes a la PMU 2.

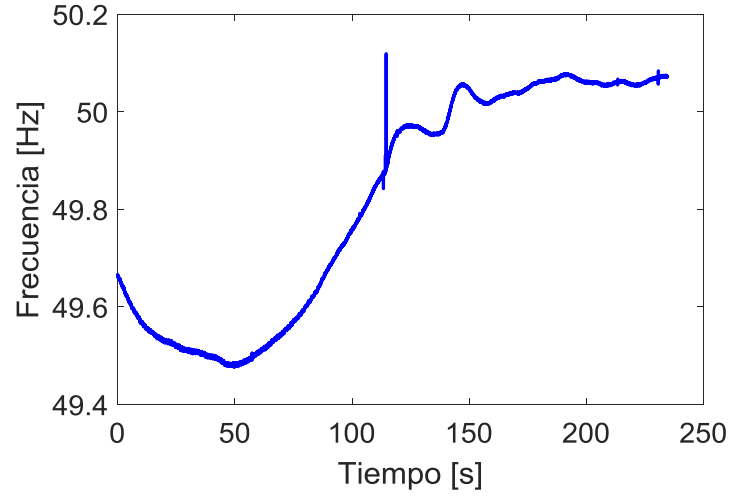

Figura 98. Traza de frecuencia - PMU 2.

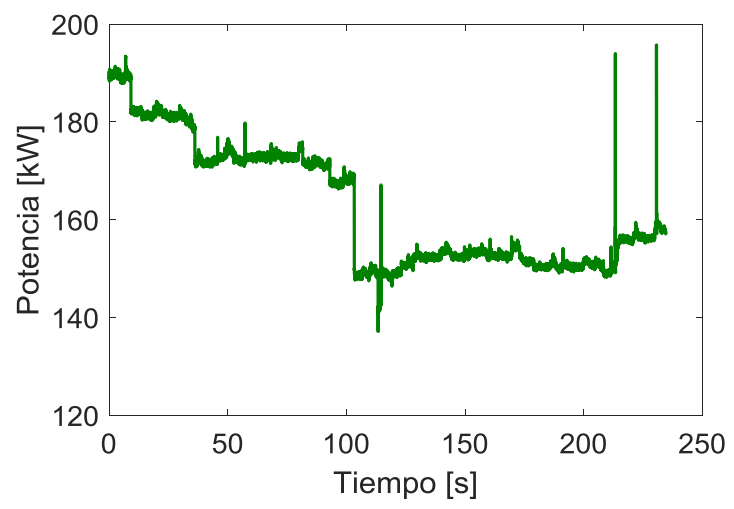

Figura 99. Traza de potencia - PMU 2.

En la traza de potencia pueden observarse, a simple vista, seis importantes perturbaciones correspondientes a un tiempo de $9,57,103,114,213$ y $230 \mathrm{~s}$.

\subsubsection{Mediciones y resultados}

El análisis de los resultados obtenidos mediante el procesamiento online fue comparado con un análisis local de las trazas de potencia realizado de manera offline utilizando el mismo algoritmo de detección de perturbaciones y el procesamiento Prony. Para ello, en ambos casos los parámetros de la detección y procesamiento se configuraron con los mismos valores, realizándose el análisis de los modos de oscilación para bandas centradas en $0,5 \mathrm{~Hz}, 1,5 \mathrm{~Hz}, 2,5 \mathrm{~Hz} \ldots$. 9,5 Hz cada una de ancho $\pm 0,5 \mathrm{~Hz}$. Dicho análisis se realizó sobre una ventana temporal de largo 1,2 s. y realizando 5 iteraciones, desplazando la ventana $40 \mathrm{~ms}$ entre iteraciones.

Es importante mencionar que pueden producirse diferencias apreciables entre ambos procesamientos, en lo que se refiere a la detección de modos que poseen amplitudes muy pequeñas o resultan fuertemente amortiguados. Según lo descripto en la sección 
7.2.1, la amplitud, frecuencia y amortiguamiento resultante de cada banda de frecuencia analizada son obtenidos a partir de un promedio pesado de todos los modos existentes en la banda. Cuando las amplitudes son muy pequeñas o los amortiguamientos muy grandes, pequeñas diferencias en el cálculo pueden provocar que se obtenga una magnitud de la banda muy cercana a la magnitud mínima configurada. Esto implica que si esta última es levemente mayor a la resultante del modo, el modo será considerado despreciable.

El efecto descripto anteriormente permite explicar el motivo por el cual un procesamiento puede considerar que un dado modo es despreciable mientras que el otro procesamiento no lo considera de esa manera.

\section{Análisis de PMU 1}

La prueba realizada sobre el registro de la PMU 1 arrojó la detección de dos perturbaciones. Estas perturbaciones son coincidentes con las detectadas por el análisis local y corresponden a las indicadas con líneas verticales en la traza de potencia que se observa en la Figura 100.

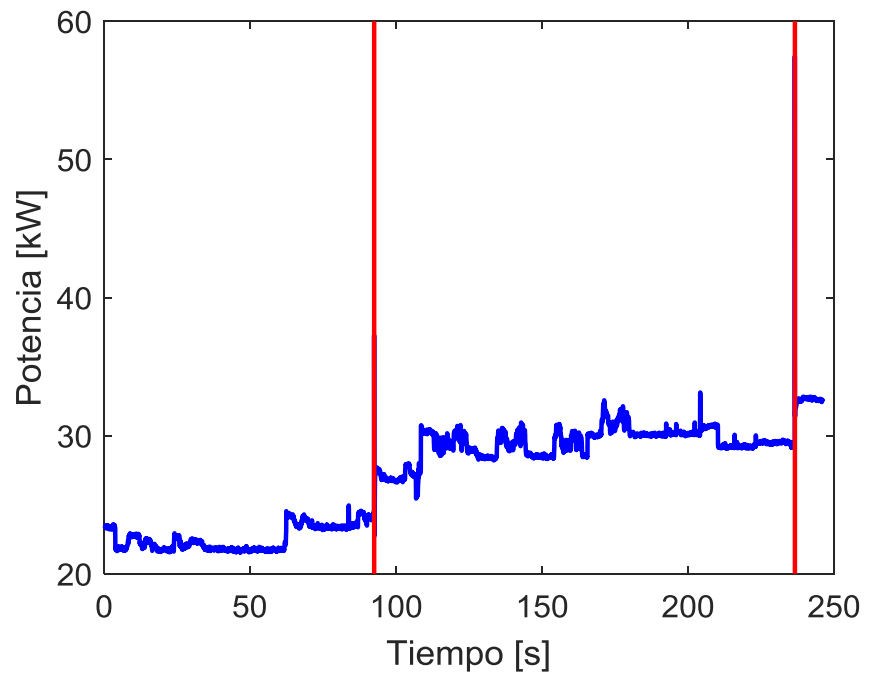

Figura 100. Perturbaciones detectadas - PMU 1.

En la Tabla IV, se muestran los modos de oscilación detectados para la primera perturbación tanto por el procesamiento online como por el análisis local en cada una de las 5 iteraciones del procesamiento. 
Tabla IV. Modos de oscilación en primer perturbación - PMU 1.

\begin{tabular}{|l|c|c|c|c|c|c|c|c|c|c|}
\hline & \multicolumn{9}{|c|}{$\mathbf{0 , 5} \mathbf{~ H z} \pm \mathbf{0 , 5}$} & \multicolumn{5}{c|}{$\mathbf{1 , 5} \mathbf{~ H z} \pm \mathbf{0 , 5}$} \\
\cline { 2 - 11 } & -1 & 2 & 3 & 4 & 5 & 1 & 2 & 3 & 4 & 5 \\
\hline Amplitud Online $[\mathrm{kW}]$ & --- & 4,092 & 0,716 & --- & --- & 8,115 & --- & --- & --- & --- \\
\hline Amplitud Local [kW] & --- & 4,22 & 0,807 & --- & --- & 8,056 & --- & --- & --- & --- \\
\hline Frecuencia Online [Hz] & --- & 0,544 & 0,672 & --- & --- & 1,583 & --- & --- & --- & --- \\
\hline Frecuencia Local [Hz] & --- & 0,525 & 0,647 & --- & --- & 1,582 & --- & --- & --- & --- \\
\hline Amortiguamiento Online & --- & 3,636 & 1,402 & --- & --- & 7,663 & --- & --- & --- & --- \\
\hline Amortiguamiento Local & ---- & 3,649 & 1,625 & --- & --- & 7,625 & --- & --- & --- & --- \\
\hline
\end{tabular}

\begin{tabular}{|l|c|c|c|c|c|c|c|c|c|c|}
\hline \multirow{2}{*}{} & \multicolumn{4}{|c|}{$\mathbf{2 , 5} \mathbf{~ H z} \pm \mathbf{0 , 5}$} & \multicolumn{5}{c|}{$\mathbf{7 , 5} \mathbf{~ H z} \pm \mathbf{0 , 5}$} \\
\cline { 2 - 12 } & 1 & 2 & 3 & 4 & 5 & 1 & 2 & 3 & 4 & 5 \\
\hline Amplitud Online [kW] & --- & 0,849 & 1,5102 & --- & --- & 21,207 & --- & --- & --- & --- \\
\hline Amplitud Local [kW] & --- & 0,858 & 1,488 & --- & --- & 21,58 & --- & --- & --- & --- \\
\hline Frecuencia Online [Hz] & --- & 2,523 & 2,2981 & --- & --- & 7,417 & --- & --- & --- & --- \\
\hline Frecuencia Local [Hz] & --- & 2,519 & 2,309 & --- & --- & 7,411 & --- & --- & --- & --- \\
\hline Amortiguamiento Online & --- & 4,41 & 7,1424 & --- & --- & 44,86 & --- & --- & --- & --- \\
\hline Amortiguamiento Local & --- & 4,43 & 7,127 & --- & --- & 45,18 & --- & --- & --- & --- \\
\hline
\end{tabular}

Se observa que los modos de oscilación detectados son coincidentes y que los valores obtenidos de amplitudes, frecuencias y amortiguamientos son completamente comparables.

En el caso de la segunda perturbación, es importante analizar con detenimiento la forma de la perturbación de la potencia, tal como se observa en la Figura 101.

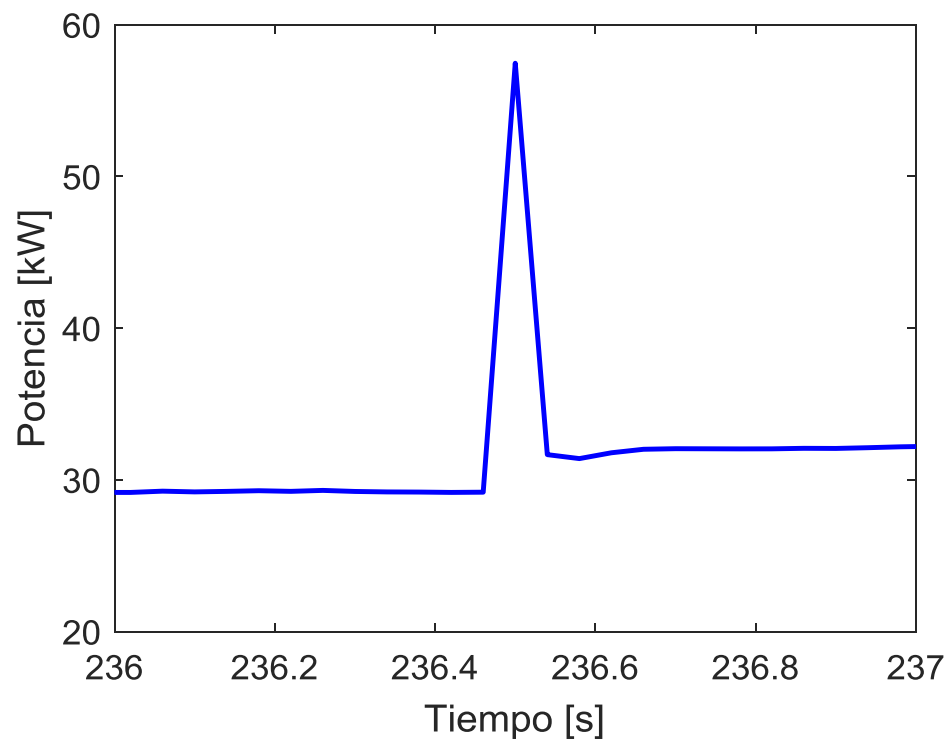

Figura 101. Detalle de la segunda perturbación - PMU 1.

Puede observarse que la segunda perturbación detectada es un fenómeno abrupto, cuyas componentes de frecuencia serán de "alta frecuencia". Esta característica es la 
que provoca que tanto en el procesamiento online como en el procesamiento local no se encuentren modos de oscilación en las bandas de frecuencias analizadas. De esta manera, se obtienen también resultados coherentes entre el procesamiento online y local.

\section{Análisis de PMU 2}

La prueba realizada sobre el registro de la PMU 2 correspondiente al mismo fenómeno que el analizado en el caso anterior arrojó la detección de seis perturbaciones. Estas perturbaciones son coincidentes con las detectadas por el análisis local y corresponden a las indicadas con líneas verticales en la traza de potencia que se observa en la Figura 102.

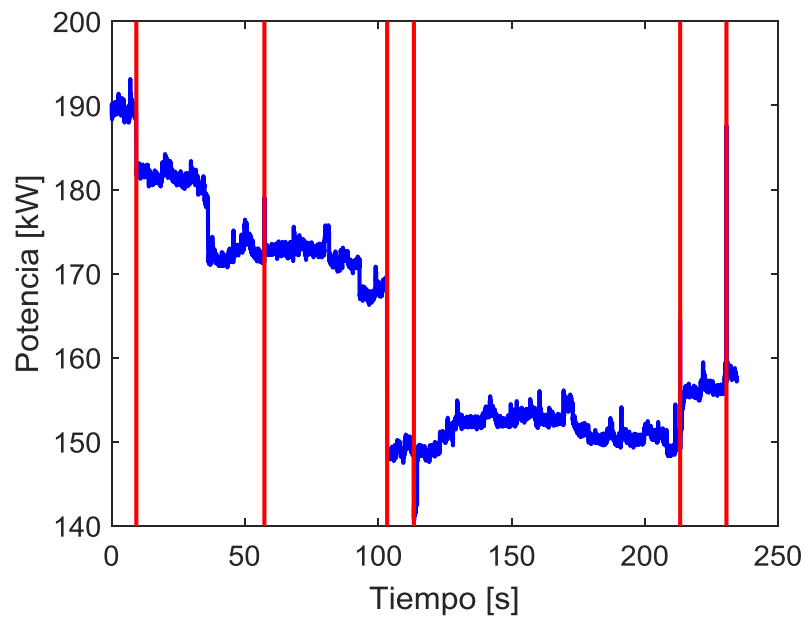

Figura 102. Perturbaciones detectadas - PMU 2.

En la Tabla V, se muestran los modos de oscilación detectados para la primera perturbación tanto por el procesamiento online como por el análisis local en cada una de las 5 iteraciones del procesamiento. 
Tabla V. Modos de Oscilación en primer perturbación - PMU 2.

\begin{tabular}{|l|c|c|c|c|c|c|c|c|c|c|}
\hline \multirow{2}{*}{} & \multicolumn{4}{|c|}{$\mathbf{1 , 5} \mathbf{H z} \pm \mathbf{0 , 5}$} & \multicolumn{5}{c|}{$\mathbf{2 , 5} \mathbf{~ H z} \pm \mathbf{0 , 5}$} \\
\cline { 2 - 11 } & 1 & 2 & 3 & 4 & 5 & 1 & 2 & 3 & 4 & 5 \\
\hline Amplitud Online [kW] & --- & 0,782 & --- & --- & --- & --- & --- & --- & --- & --- \\
\hline Amplitud Local [kW] & --- & 0,705 & --- & --- & --- & --- & --- & 0,897 & --- & --- \\
\hline Frecuencia Online [Hz] & --- & 1,217 & --- & --- & --- & --- & --- & --- & --- & --- \\
\hline Frecuencia Local [Hz] & --- & 1,295 & --- & --- & --- & --- & --- & 2,671 & --- & --- \\
\hline Amortiguamiento Online & --- & 12,17 & --- & --- & --- & --- & --- & --- & --- & --- \\
\hline Amortiguamiento Local & --- & 12,59 & --- & --- & --- & --- & --- & 14,17 & --- & --- \\
\hline
\end{tabular}

\begin{tabular}{|l|c|c|c|c|c|c|c|c|c|c|}
\hline \multirow{2}{*}{} & \multicolumn{4}{|c|}{$\mathbf{4 , 5} \mathbf{~ H z} \mathbf{0 , 5}$} & \multicolumn{5}{c|}{$\mathbf{7 , 5} \mathbf{~ H z} \pm \mathbf{0 , 5}$} \\
\cline { 2 - 11 } & 1 & 2 & 3 & 4 & 5 & 1 & 2 & 3 & 4 & 5 \\
\hline Amplitud Online [kW] & --- & --- & 0,634 & 0,633 & --- & -- & --- & 0,706 & --- & 0,672 \\
\hline Amplitud Local $[\mathrm{kW}]$ & --- & --- & 0,723 & 0,634 & --- & --- & --- & 0,671 & --- & --- \\
\hline Frecuencia Online [Hz] & --- & --- & 4,391 & 4,044 & --- & --- & --- & 7,908 & --- & 7,99 \\
\hline Frecuencia Local [Hz] & --- & --- & 4,421 & 4,044 & --- & --- & --- & 7,901 & --- & --- \\
\hline Amortiguamiento Online & --- & --- & 3,441 & 4,189 & --- & --- & --- & 2,923 & --- & 4,31 \\
\hline Amortiguamiento Local & --- & --- & 3,766 & 4,197 & --- & --- & --- & 2,793 & --- & --- \\
\hline
\end{tabular}

\begin{tabular}{|l|c|c|c|c|c|}
\hline \multirow{2}{*}{} & \multicolumn{5}{|c|}{$\mathbf{8 , 5} \mathbf{~ H z} \pm \mathbf{0 , 5}$} \\
\cline { 2 - 6 } & 1 & 2 & 3 & 4 & 5 \\
\hline Amplitud Online [kW] & --- & --- & --- & 0,958 & --- \\
\hline Amplitud Local [kW] & --- & --- & --- & 0,947 & 0,6719 \\
\hline Frecuencia Online [Hz] & --- & --- & --- & 8,322 & --- \\
\hline Frecuencia Local [Hz] & --- & --- & --- & 8,32 & 8,002 \\
\hline Amortiguamiento Online & --- & --- & --- & 3,98 & --- \\
\hline Amortiguamiento Local & --- & --- & --- & 3,94 & 4,293 \\
\hline
\end{tabular}

Se observa que los modos de oscilación detectados son coincidentes en la mayoría de los casos, y que los valores obtenidos de amplitudes, frecuencias y amortiguamientos son completamente comparables. En los casos donde el análisis online o local obtiene un modo de oscilación que no es detectado en el otro procesamiento, es importante observar que la amplitud de dicho modo es muy pequeña, lo que implica que el otro análisis puede estar obteniendo una amplitud relativamente menor aún, pero lo suficiente como para considerarla despreciable.

En la Tabla VI, se muestran los modos de oscilación detectados para la segunda perturbación tanto por el procesamiento online como por el local en cada una de las 5 iteraciones. 
Tabla VI. Modos de Oscilación en segunda perturbación - PMU 2.

\begin{tabular}{|l|c|c|c|c|c|c|c|c|c|c|}
\hline & \multicolumn{4}{|c|}{$\mathbf{1 , 5} \mathbf{~ H z} \pm \mathbf{0 , 5}$} & \multicolumn{7}{c|}{$\mathbf{5 , 5} \mathbf{~ H z} \mathbf{0 , 5}$} \\
\cline { 2 - 11 } & 1 & 2 & 3 & 4 & 5 & 1 & 2 & 3 & 4 & 5 \\
\hline Amplitud Online [kW] & --- & 1,247 & --- & --- & --- & 7,772 & --- & --- & --- & --- \\
\hline Amplitud Local [kW] & --- & 1,174 & --- & --- & --- & 7,958 & --- & --- & --- & --- \\
\hline Frecuencia Online [Hz] & --- & 1,793 & --- & --- & --- & 5,644 & --- & --- & --- & --- \\
\hline Frecuencia Local [Hz] & --- & 1,921 & --- & --- & --- & 5,632 & --- & --- & --- & --- \\
\hline Amortiguamiento Online & ---- & 6,374 & --- & --- & --- & 20,31 & --- & --- & --- & --- \\
\hline Amortiguamiento Local & ---- & 6,292 & --- & --- & --- & 20,82 & --- & --- & --- & --- \\
\hline
\end{tabular}

\begin{tabular}{|l|c|c|c|c|c|c|c|c|c|c|}
\hline & \multicolumn{4}{|c|}{$\mathbf{6 , 5} \mathbf{~ H z} \pm \mathbf{0 , 5}$} & \multicolumn{5}{c|}{$\mathbf{7 , 5} \mathbf{~ H z} \pm \mathbf{0 , 5}$} \\
\cline { 2 - 11 } & 1 & 2 & 3 & 4 & 5 & 1 & 2 & 3 & 4 & 5 \\
\hline Amplitud Online [kW] & --- & --- & 1,025 & --- & --- & --- & --- & --- & 0,666 & --- \\
\hline Amplitud Local [kW] & --- & --- & 1,008 & --- & --- & --- & --- & --- & 0,667 & --- \\
\hline Frecuencia Online [Hz] & --- & --- & 6,632 & --- & --- & --- & --- & --- & 7,175 & --- \\
\hline Frecuencia Local [Hz] & --- & --- & 6,633 & --- & --- & --- & --- & --- & 7,18 & --- \\
\hline Amortiguamiento Online & --- & --- & 6,112 & --- & --- & --- & --- & --- & 5,321 & --- \\
\hline Amortiguamiento Local & ---- & --- & 6,011 & --- & --- & --- & --- & --- & 5,324 & --- \\
\hline
\end{tabular}

\begin{tabular}{|l|c|c|c|c|c|}
\hline \multirow{2}{*}{} & \multicolumn{5}{|c|}{$\mathbf{8 , 5} \mathbf{~ H z} \pm \mathbf{0 , 5}$} \\
\cline { 2 - 6 } & 1 & 2 & 3 & 4 & 5 \\
\hline Amplitud Online $[\mathrm{kW}]$ & --- & --- & --- & --- & 1,128 \\
\hline Amplitud Local $[\mathrm{kW}]$ & --- & --- & --- & -- & 1,122 \\
\hline Frecuencia Online $[\mathrm{Hz}]$ & --- & --- & --- & --- & 8,612 \\
\hline Frecuencia Local $[\mathrm{Hz}]$ & --- & --- & --- & --- & 8,584 \\
\hline Amortiguamiento Online & --- & --- & --- & --- & 16,45 \\
\hline Amortiguamiento Local & --- & --- & --- & --- & 16,34 \\
\hline
\end{tabular}

Se observa que los modos de oscilación obtenidos son coincidentes y que los valores de amplitudes, frecuencias y amortiguamientos son completamente comparables.

En la Tabla VII, se muestran los modos de oscilación detectados para la tercera perturbación tanto por el procesamiento online como por el análisis local en cada una de las 5 iteraciones del procesamiento.

Tabla VII. Modos de Oscilación en tercera perturbación - PMU 2.
\begin{tabular}{|l|c|c|c|c|c|}
\hline & \multicolumn{5}{|c|}{$\mathbf{1 , 5} \mathbf{~ H z} \pm \mathbf{0 , 5}$} \\
\hline & 1 & 2 & 3 & 4 & 5 \\
\hline Amplitud Online [kW] & --- & --- & --- & --- & --- \\
\hline Amplitud Local [kW] & --- & 1,024 & --- & --- & --- \\
\hline Frecuencia Online [Hz] & --- & --- & --- & --- & --- \\
\hline Frecuencia Local [Hz] & --- & 4,554 & --- & --- & --- \\
\hline Amortiguamiento Online & --- & --- & --- & --- & --- \\
\hline Amortiguamiento Local & --- & 10,01 & --- & --- & --- \\
\hline
\end{tabular}


En el caso de la tercera perturbación, es importante analizar con detenimiento la evolución de la potencia, tal como se observa en la Figura 103.

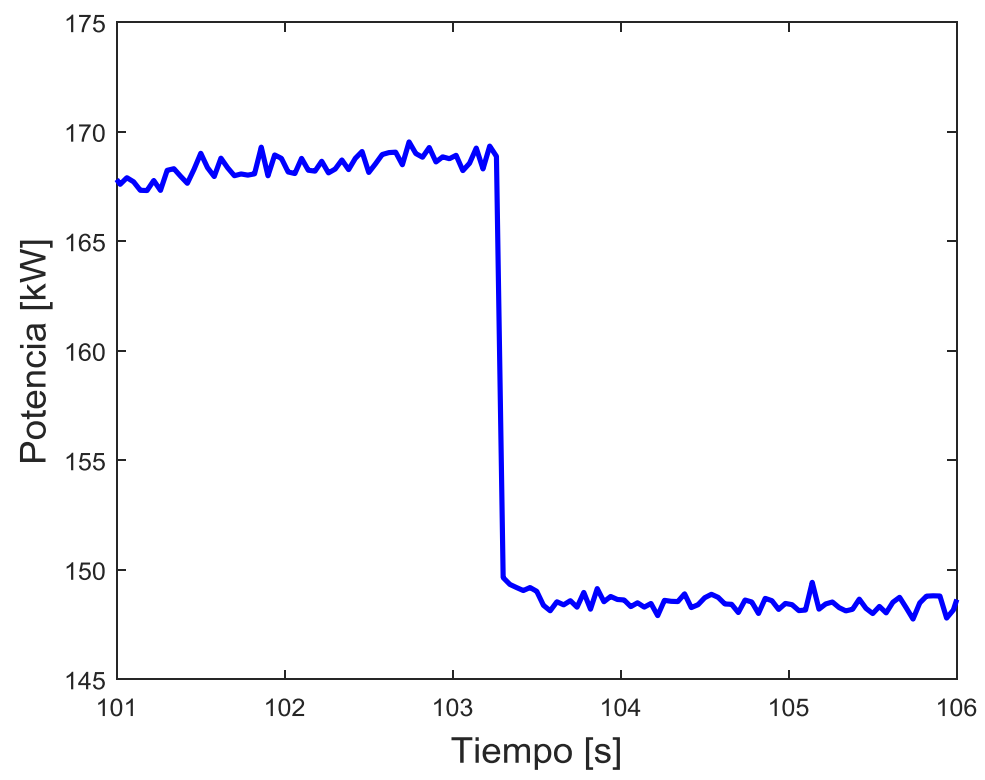

Figura 103. Detalle de la tercera perturbación - PMU 2.

Puede observarse que la tercera perturbación detectada es un fenómeno abrupto, cuyas componentes de frecuencia serán de "alta frecuencia". Esta característica es la que provoca que en el procesamiento online no se encuentren modos de oscilación en las bandas de frecuencias analizadas mientras que en el procesamiento local se encuentra un modo de oscilación en una única iteración que se amortigua rápidamente.

En la Tabla VIII, se muestran los modos de oscilación detectados para la cuarta perturbación tanto por el procesamiento online como por el análisis local en cada una de las 5 iteraciones del procesamiento.

Tabla VIII. Modos de Oscilación en cuarta perturbación - PMU 2.

\begin{tabular}{|l|c|c|c|c|c|c|c|c|c|c|}
\hline \multirow{2}{*}{} & \multicolumn{4}{|c|}{$\mathbf{0 , 5} \mathbf{H z} \pm \mathbf{0 , 5}$} & \multicolumn{5}{c|}{$\mathbf{2 , 5} \mathbf{H z} \pm \mathbf{0 , 5}$} \\
\cline { 2 - 12 } & 1 & 2 & 3 & 4 & 5 & 1 & 2 & 3 & 4 & 5 \\
\hline Amplitud Online [kW] & --- & 0,628 & --- & --- & --- & --- & --- & --- & 1,523 & 0,608 \\
\hline Amplitud Local [kW] & --- & 0,708 & --- & --- & --- & --- & --- & 3,98 & 1,726 & --- \\
\hline Frecuencia Online [Hz] & --- & 0,954 & --- & --- & --- & --- & --- & --- & 2,443 & 2,348 \\
\hline Frecuencia Local [Hz] & --- & 0,925 & --- & --- & --- & --- & --- & 2,934 & 2,357 & --- \\
\hline Amortiguamiento Online & --- & 0,314 & --- & --- & --- & --- & --- & --- & 8,089 & 0,475 \\
\hline Amortiguamiento Local & --- & 0,156 & --- & --- & --- & --- & --- & 25,81 & 8,743 & --- \\
\hline
\end{tabular}




\begin{tabular}{|l|c|c|c|c|c|c|c|c|c|c|}
\hline & \multicolumn{4}{|c|}{$\mathbf{4 , 5} \mathbf{H z} \pm \mathbf{0 , 5}$} & \multicolumn{5}{c|}{$\mathbf{9 , 5} \mathbf{H z} \pm \mathbf{0 , 5}$} \\
\cline { 2 - 12 } & 1 & 2 & 3 & 4 & 5 & 1 & 2 & 3 & 4 & 5 \\
\hline Amplitud Online [kW] & 1,854 & --- & --- & --- & --- & --- & --- & --- & 0,615 & --- \\
\hline Amplitud Local [kW] & 1,596 & --- & --- & --- & --- & --- & --- & --- & 0,637 & --- \\
\hline Frecuencia Online [Hz] & 4,625 & --- & --- & --- & --- & --- & --- & --- & 9,397 & --- \\
\hline Frecuencia Local [Hz] & 4,948 & --- & --- & --- & --- & --- & --- & --- & 9,399 & --- \\
\hline Amortiguamiento Online & 10,97 & --- & --- & --- & --- & --- & --- & --- & 6,257 & --- \\
\hline Amortiguamiento Local & 9,76 & --- & --- & --- & --- & --- & --- & --- & 6,472 & --- \\
\hline
\end{tabular}

Se observa que los modos de oscilación obtenidos son, en la mayor parte de los casos, coincidentes y que los valores obtenidos de amplitudes, frecuencias y amortiguamientos son completamente comparables. En los casos donde el análisis online o local detecta un modo de oscilación que no es detectado por el otro análisis, es importante observar que, o bien la amplitud de dicho modo es muy pequeña (lo que implica que el otro análisis puede estar detectando una amplitud relativamente menor aún, pero lo suficiente como para considerarla despreciable) o bien el amortiguamiento es elevado (provocando que el modo sea considerado despreciable).

En la Tabla IX, se muestran los modos de oscilación detectados para la quinta perturbación tanto por el procesamiento online como por el análisis local en cada una de las 5 iteraciones del procesamiento.

Tabla IX. Modos de Oscilación en quinta perturbación - PMU 2.

\begin{tabular}{|l|c|c|c|c|c|c|c|c|c|c|}
\hline \multirow{2}{*}{} & \multicolumn{5}{|c|}{$\mathbf{1 , 5} \mathbf{H z} \pm \mathbf{0 , 5}$} & \multicolumn{5}{c|}{$\mathbf{2 , 5} \mathbf{H z} \pm \mathbf{0 , 5}$} \\
\cline { 2 - 12 } & 1 & 2 & 3 & 4 & 5 & 1 & 2 & 3 & 4 & 5 \\
\hline Amplitud Online [kW] & 1,812 & --- & --- & 0,799 & --- & --- & 3,502 & --- & --- & --- \\
\hline Amplitud Local [kW] & 1,92 & --- & --- & 0,808 & --- & --- & 3,521 & --- & --- & --- \\
\hline Frecuencia Online [Hz] & 1,011 & --- & --- & 1,44 & --- & --- & 2,657 & --- & --- & --- \\
\hline Frecuencia Local [Hz] & 1,039 & --- & --- & 1,415 & --- & --- & 2,651 & --- & --- & --- \\
\hline Amortiguamiento Online & 1,024 & --- & --- & 1,556 & --- & --- & 11,25 & --- & --- & --- \\
\hline Amortiguamiento Local & 1,188 & --- & --- & 1,502 & --- & --- & 11,26 & --- & --- & --- \\
\hline
\end{tabular}

\begin{tabular}{|l|c|c|c|c|c|c|c|c|c|c|}
\hline \multirow{2}{*}{} & \multicolumn{4}{|c|}{$\mathbf{3 , 5} \mathbf{~ H z} \mathbf{0 , 5}$} & \multicolumn{5}{c|}{$\mathbf{4 , 5} \mathbf{H z} \pm \mathbf{0 , 5}$} \\
\cline { 2 - 11 } & 1 & 2 & 3 & 4 & 5 & 1 & 2 & 3 & 4 & 5 \\
\hline Amplitud Online [kW] & --- & --- & 1,525 & --- & 0,693 & --- & --- & --- & --- & 1,015 \\
\hline Amplitud Local [kW] & --- & --- & 1,589 & --- & 0,757 & --- & --- & --- & --- & 1,091 \\
\hline Frecuencia Online [Hz] & --- & --- & 3,392 & --- & 3,288 & --- & --- & --- & --- & 4,809 \\
\hline Frecuencia Local [Hz] & --- & --- & 3,355 & --- & 3,284 & --- & --- & --- & --- & 4,734 \\
\hline Amortiguamiento Online & --- & --- & 11,88 & --- & 2,833 & --- & --- & --- & --- & 9,32 \\
\hline Amortiguamiento Local & ---- & --- & 12,3 & --- & 3,026 & --- & --- & & --- & 9,48 \\
\hline
\end{tabular}

Se observa que los modos de oscilación detectados son coincidentes y que los valores de amplitudes, frecuencias y amortiguamientos son completamente comparables. 
Finalmente, en la Tabla X, se muestran los modos de oscilación detectados para la sexta perturbación tanto por el procesamiento online como por el análisis local en cada una de las 5 iteraciones del procesamiento

Tabla X. Modos de Oscilación en sexta perturbación - PMU 2.

\begin{tabular}{|l|c|c|c|c|c|c|c|c|c|c|}
\hline & \multicolumn{9}{|c|}{$\mathbf{5 , 5} \mathbf{H z} \pm \mathbf{0 , 5}$} & \multicolumn{5}{|c|}{$\mathbf{6 , 5} \mathbf{~ H z} \pm \mathbf{0 , 5}$} \\
\cline { 2 - 11 } & 1 & 2 & 3 & 4 & 5 & 1 & 2 & 3 & 4 & 5 \\
\hline Amplitud Online $[\mathrm{kW}]$ & --- & 1,336 & --- & --- & --- & 21,85 & --- & --- & --- & --- \\
\hline Amplitud Local $[\mathrm{kW}]$ & --- & 1,346 & --- & --- & --- & 21,79 & --- & --- & --- & --- \\
\hline Frecuencia Online $[\mathrm{Hz}]$ & --- & 5,729 & --- & --- & --- & 6,247 & --- & --- & --- & --- \\
\hline Frecuencia Local $[\mathrm{Hz}]$ & --- & 5,739 & --- & --- & --- & 6,296 & --- & --- & --- & --- \\
\hline Amortiguamiento Online & --- & 9,49 & --- & --- & --- & 32,16 & --- & --- & --- & --- \\
\hline Amortiguamiento Local & ---- & 9,68 & --- & --- & --- & 31,89 & --- & --- & --- & --- \\
\hline
\end{tabular}

\begin{tabular}{|l|c|c|c|c|c|}
\hline \multirow{2}{*}{} & \multicolumn{5}{|c|}{$\mathbf{8 , 5} \mathbf{~ H z} \pm \mathbf{0 , 5}$} \\
\cline { 2 - 6 } & 1 & 2 & 3 & 4 & 5 \\
\hline Amplitud Online [kW] & 0,735 & --- & --- & --- & 0,569 \\
\hline Amplitud Local [kW] & 0,724 & --- & --- & --- & 0,571 \\
\hline Frecuencia Online [Hz] & 8,321 & --- & --- & --- & 8,749 \\
\hline Frecuencia Local [Hz] & 8,328 & --- & --- & --- & 8,751 \\
\hline Amortiguamiento Online & 2,734 & --- & --- & --- & 5,15 \\
\hline Amortiguamiento Local & 2,699 & --- & --- & --- & 5,15 \\
\hline
\end{tabular}

Se observa que los modos de oscilación detectados son coincidentes y que los valores obtenidos de amplitudes, frecuencias $\mathrm{y}$ amortiguamientos son completamente comparables.

Con estos resultados, pudo validarse el funcionamiento del módulo online del software de Procesamiento, considerando tanto el Algoritmo para la detección de perturbaciones como el procesamiento Prony. 


\section{Software de procesamiento - Módulo Offline}

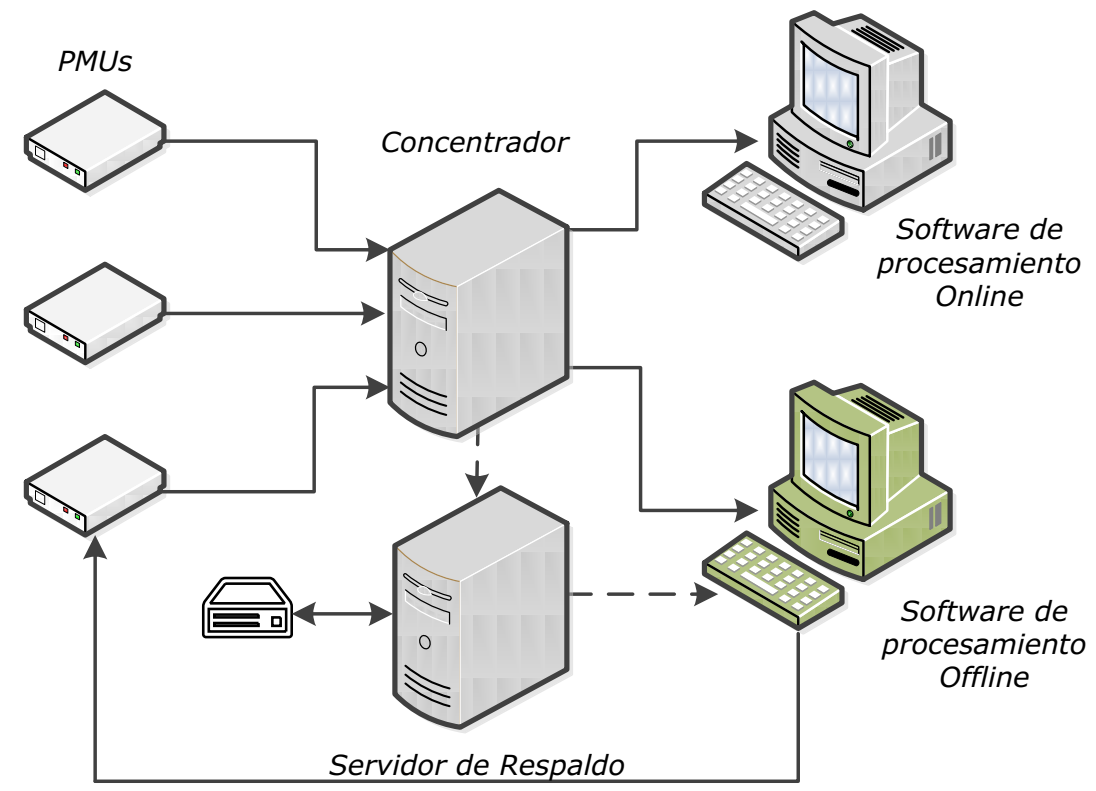

Figura 104. Software de Procesamiento Offline en el sistema de medición sincrofasorial.

\subsection{Descripción General}

El software de procesamiento de sincrofasores se compone, tal como se describió en el Capítulo 3 de dos grandes módulos, siendo uno de ellos el Módulo Offline.

El módulo de procesamiento Offline es el encargado del análisis y graficación de los registros de perturbaciones detectadas por las PMU o de una ventana temporal de sincrofasores almacenados en los archivos de respaldo. El análisis realizado, en forma general, se basa en diagramas de tendencias o trazas donde se puede observar la evolución temporal de las variables registradas (tensiones, corrientes, potencia, frecuencia, entre otras) junto con diferentes procesamientos matemáticos sobre las variables antes mencionadas. En la Figura 105 puede observarse un diagrama en bloques de éste módulo. 


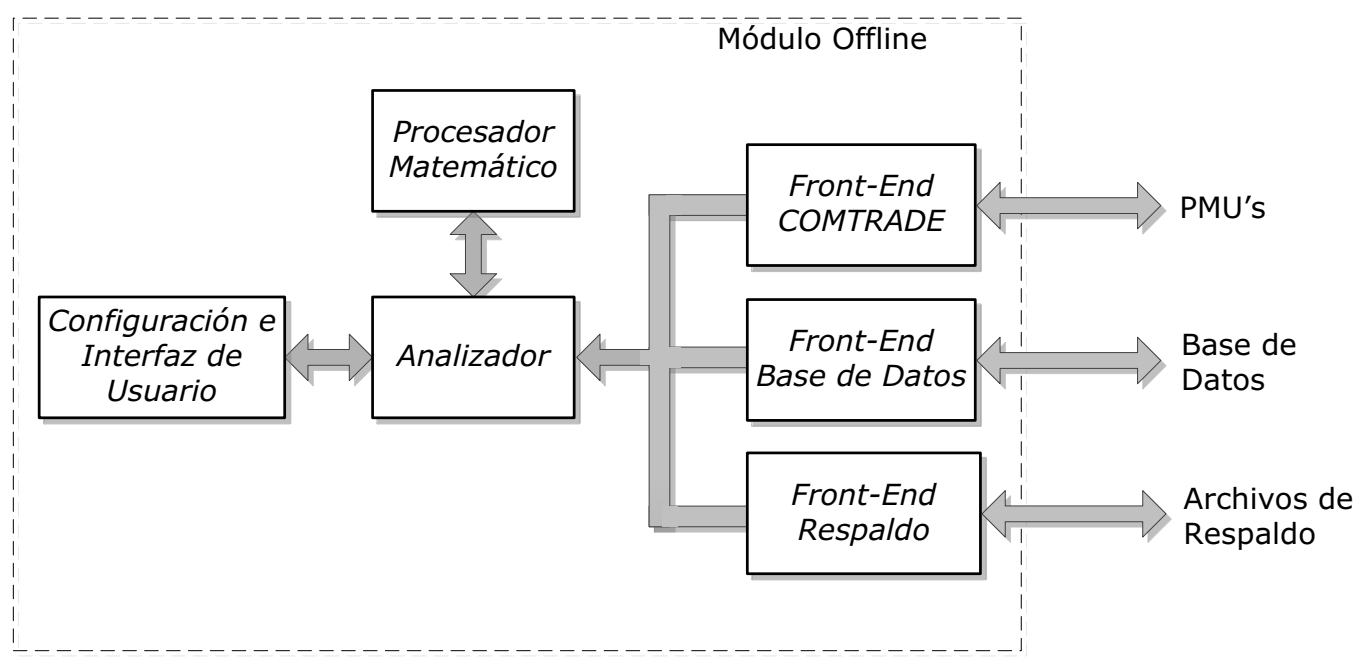

Figura 105. Diagrama en bloques - Módulo Offline.

El Analizador es el principal bloque del módulo offline. Dicho bloque se encarga de realizar las evaluaciones de los registros y su visualización, en base a las configuraciones y opciones seleccionadas por el usuario. En función de los procesamientos que el operador desee realizar, este bloque configura el módulo de procesamiento matemático para poner a disposición las herramientas de procesamiento necesarias.

El componente Procesador Matemático tiene como función principal la aplicación de algoritmos y cálculos matemáticos optimizados para evaluar los registros seleccionados. Este procesador es el encargado de realizar, por ejemplo, el cálculo optimizado del método de Prony para la ventana de datos asignada, el cálculo de la Transformada Rápida de Fourier, el cálculo de las componentes de Secuencia Directa, Inversa y Homopolar de la terna analizada, etc.

Para obtener las mediciones de los registros, el software de procesamiento offline cuenta con tres Front End. Cada uno de ellos está diseñado para obtener y decodificar los datos de una de las tres posibles fuentes de información. De esta manera, estos componentes actúan como la interfaz entre el software de procesamiento offline y las mediciones almacenadas.

El módulo offline del Software de Procesamiento está diseñado para ser utilizado bajo sistema operativo Windows de 64 bits y su diseño se realizó utilizando el entorno de programación y simulación MATLAB.

\subsection{Componentes del módulo Offline}

\subsubsection{Front-End/Decodificador}

Tal como se describió anteriormente, el software de procesamiento offline cuenta con tres Front-End/Decodificador diferenciados según la fuente de datos que utiliza para obtener las mediciones. El software, a partir de las configuraciones que ingresa el 
usuario, activa el Front-End correspondiente transfiriéndole todos los parámetros necesarios para realizar la obtención de los datos.

\section{Front-End COMTRADE}

El formato COMTRADE (Common Format for Transient Data Exchange) [29] es un formato de archivos destinado al almacenamiento de muestras de una medición definido por la IEEE. Este formato consta de 4 archivos donde se almacenan los valores medidos junto con otros parámetros y características del sistema de medición:

- Header File (xxxx.hdr): es un archivo opcional donde el equipamiento que genera u obtiene los datos incluye información adicional, como por ejemplo nombre del equipo, uso de memoria de almacenamiento, etc.

- $\quad$ Configuration File (xxxx.cfg): es el archivo de almacenamiento de los parámetros de configuración necesarios para la lectura de los datos almacenados. En este archivo se incluyen las tasas de muestreo, el número de canales almacenados, la frecuencia de línea, la etiqueta temporal de inicio del almacenamiento, etc.

- Data File (xxxx.dat): en este archivo se almacenan las mediciones para cada uno de los canales analizados.

- Information File (xxxx.inf): este archivo es un fichero opcional de información. En este archivo, el equipamiento de medición puede almacenar cualquier tipo de información que sea útil para ser leída por el usuario del registro.

Un diagrama en bloques del Front-End puede observarse en la Figura 106.

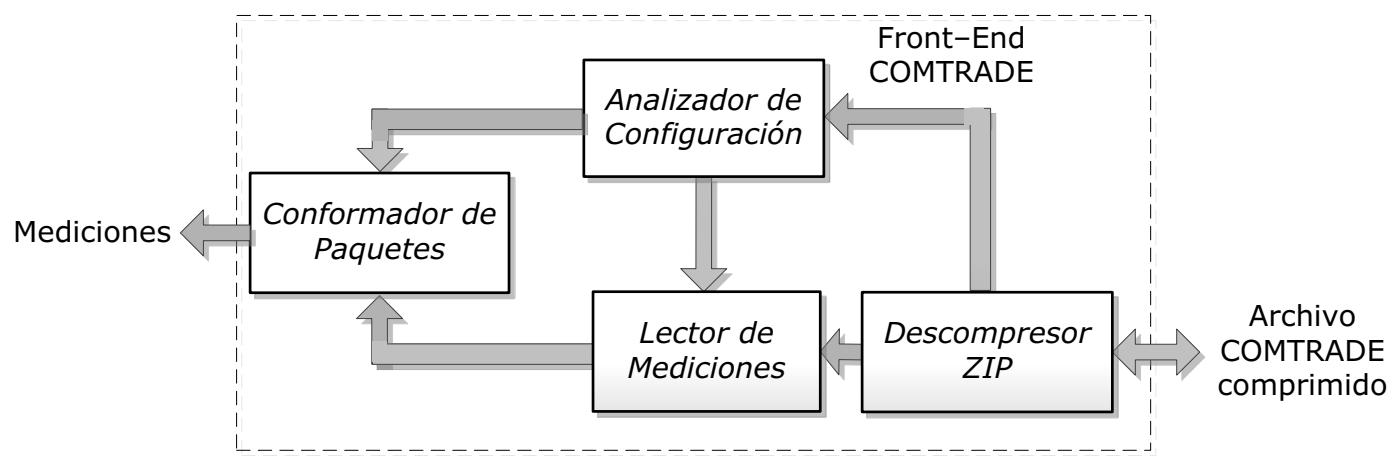

Figura 106. Diagrama en bloques Front-End COMTRADE - Módulo Offline.

Para una mejor organización de los archivos y evitar la pérdida de alguno de los ficheros que componen el registro, el software de procesamiento offline prevé que todos los archivos COMTRADE correspondientes a un registro se encuentren comprimidos en un archivo de tipo ZIP. De esta manera, la manipulación de un registro implica la manipulación de un único archivo, evitando las confusiones o pérdidas de archivos involuntarias. 
El Front-End descomprime el archivo seleccionado por el usuario en un directorio temporal con el Descompresor ZIP. Una vez descomprimido, el archivo de configuración es leído con el Analizador de Configuración. De esta manera, el módulo offline obtiene todos los datos necesarios para decodificar el archivo de datos, entre los que se puede mencionar el número de canales que componen el registro junto a su tipo y factor de escala, la cantidad de mediciones realizadas, la frecuencia nominal de la línea medida, la frecuencia de muestreo y la etiqueta temporal de inicio de las mediciones.

Con todos los datos mencionados anteriormente, el Lector de Mediciones realiza la lectura del archivo de datos (xxxx.dat). Cada uno de los canales de medición es separado y escalado según corresponda. Finalmente, el conformador de paquetes genera un paquete de datos por cada registro leído, donde se incluye cada medición junto con el instante de tiempo al que corresponden cada una de ellas.

\section{Front-End Base de Datos}

El sistema de medición sincrofasorial incluye, tal como se describió en la sección 3.2, un servidor para respaldo de datos. Este servidor almacena cada uno de los sincrofasores recibidos en el concentrador en una base de datos, donde además del sincrofasor se almacena el instante de tiempo al que corresponde, factores de escalamiento, etc. El Front-End de Base de Datos permite, entonces, obtener una ventana temporal de fasores almacenados en dicha base, a partir de la búsqueda según el rango temporal ingresado por el usuario.

Un diagrama en bloques del Front-End puede observarse en la Figura 107.

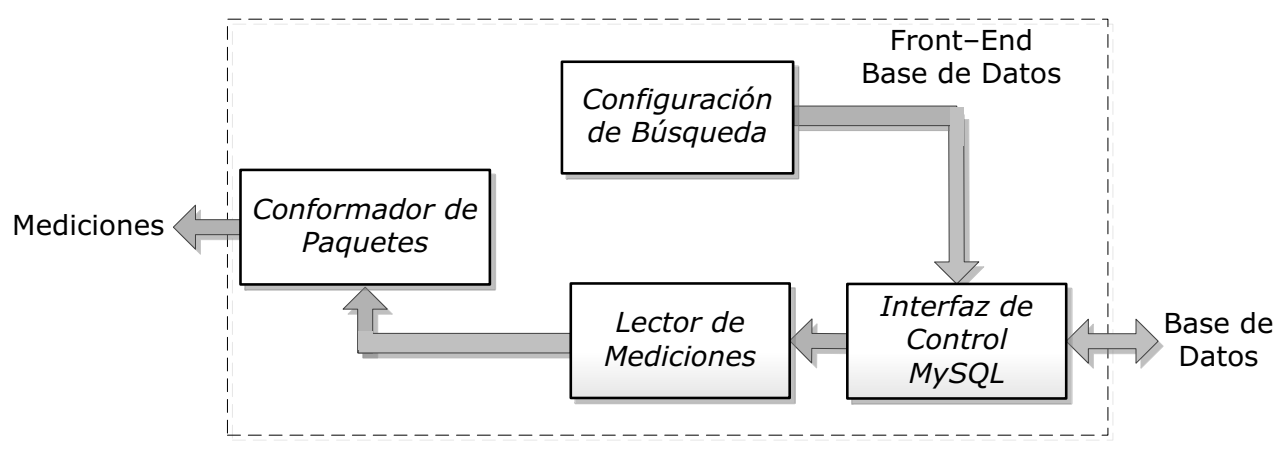

Figura 107. Diagrama en bloques Front-End Base de Datos - Módulo Offline.

El usuario selecciona el rango temporal que desea analizar, estableciendo fecha y hora de inicio y fin de la ventana temporal deseada junto con la PMU de la cual desea obtener la información. Dicha configuración es utilizada por la Interfaz de Control MySQL para realizar la búsqueda de dichos datos en la base de datos. De esta manera, la interfaz devuelve todos los sincrofasores almacenados de la PMU seleccionada que se encuentren dentro de la ventana temporal configurada. 
Todos los datos obtenidos son decodificados por el lector de mediciones, aplicando todos los escalamientos y conversiones de formato requeridas para que, finalmente, el conformador de paquetes organice los registros temporalmente.

\section{Front-End Respaldo de Sincrofasores}

A partir de lo descripto en el Capítulo 6, el servidor para respaldo de datos realiza un back-up de la base de datos de manera periódica en un disco secundario para luego realizar un vaciado de la base de datos. De esta manera, el usuario debe archivar el disco secundario según el criterio de manipulación de datos que corresponda.

El software de procesamiento Offline le da al usuario la posibilidad de realizar un análisis sobre los sincrofasores almacenados en los discos secundarios. Por lo tanto, es posible realizar un análisis de fenómenos que ocurrieron en el pasado.

Un diagrama en bloques del Front-End puede observarse en la Figura 108.

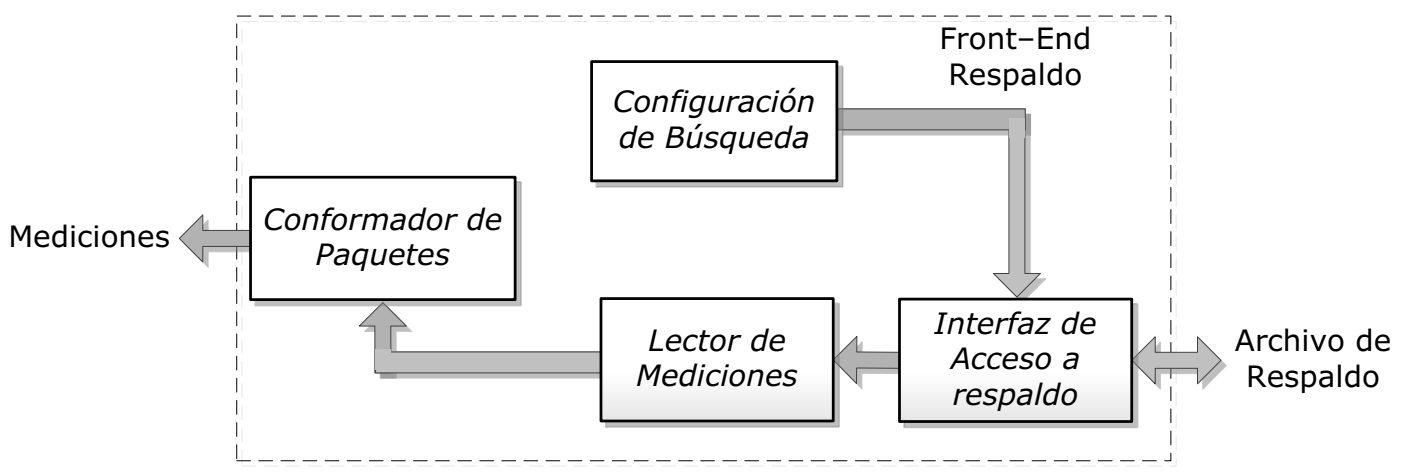

Figura 108. Diagrama en bloques Front-End Respaldo - Módulo Offline.

El usuario selecciona el rango temporal que desea analizar, estableciendo fecha y hora de inicio y fin de la ventana temporal deseada junto con la PMU de la cual desea obtener la información. Para ello, además, debe darle al software una vía de acceso al disco secundario de respaldo, proporcionándole la ruta de acceso a ese disco. Dicha configuración es utilizada por la Interfaz de Acceso a Respaldo para realizar la búsqueda de dichos datos en los archivos de respaldo. De esta manera, la interfaz retorna todos los sincrofasores almacenados de la PMU seleccionada que se encuentren dentro de la ventana temporal configurada.

Todos los datos obtenidos son decodificados por el lector de mediciones, aplicando todos los escalamientos y conversiones de formato requeridas para que, finalmente, el conformador de paquetes organice los registros temporalmente.

\subsubsection{Analizador}

El Analizador de datos es el bloque de evaluación y visualización de registros. En base a los registros obtenidos del Front-End correspondiente, este bloque realiza la 
graficación de las trazas de tensiones y corrientes ordenadas temporalmente. A su vez, es quien activa el bloque de Procesamiento Matemático para realizar los cálculos deseados, quedando a la espera de los resultados para generar la visualización correspondiente.

Este bloque proporciona diferentes visualizaciones según se trate de un registro COMTRADE o de un registro de sincrofasores. Los registros COMTRADE son mediciones realizadas a una tasa de muestreo mucho mayor que la que corresponde a los sincrofasores. Esto implica que por ciclo de la tensión de línea se tienen gran cantidad de muestras (256 por ej.). A partir de ello el analizador permite, en el caso de analizar registros COMTRADE, realizar las siguientes representaciones gráficas:

- Trazas de Tensión y Corriente por fase.

- Traza de Potencia.

- FFT de Tensión y Corriente por fase.

- Distorsión Armónica Total (THD en sus siglas en inglés) de Tensión y Corriente por fase.

- Modos de Oscilación de Tensión y Corriente por fase.

- Modos de Oscilación de Potencia.

En el caso del análisis de registros sincrofasoriales, el Analizador permite realizar la graficación de las siguientes variables:

- Trazas del módulo de Tensión y Corriente por fase.

- Traza de Potencia.

- Traza de Frecuencia y de Variación de Frecuencia (ROCOF en sus siglas en inglés)

- Modos de Oscilación de Potencia.

- Componentes de Secuencia Directa, Inversa y Homopolar en Tensión y Corriente.

- Desbalance de Tensión y Corriente

Se define, para los fines del análisis offline, al desbalance según la Ec. 6.1

$$
\text { Desb. }[\%]=\frac{\left|X_{\text {inv }}\right|}{\left|X_{\text {dir }}\right|} \times 100
$$

Donde $\mathrm{X}_{\mathrm{inv}}$ corresponde a la componente de secuencia inversa de la terna analizada $\mathrm{y}$ $\mathrm{X}_{\mathrm{dir}}$ corresponde a la componente de secuencia directa de la misma terna. 


\subsubsection{Procesador Matemático}

El Procesador Matemático tiene por objetivo llevar adelante todos los cálculos y procesamientos matemáticos configurados sobre un registro de datos determinado. Un diagrama en bloques del procesador puede observarse en la Figura 109.

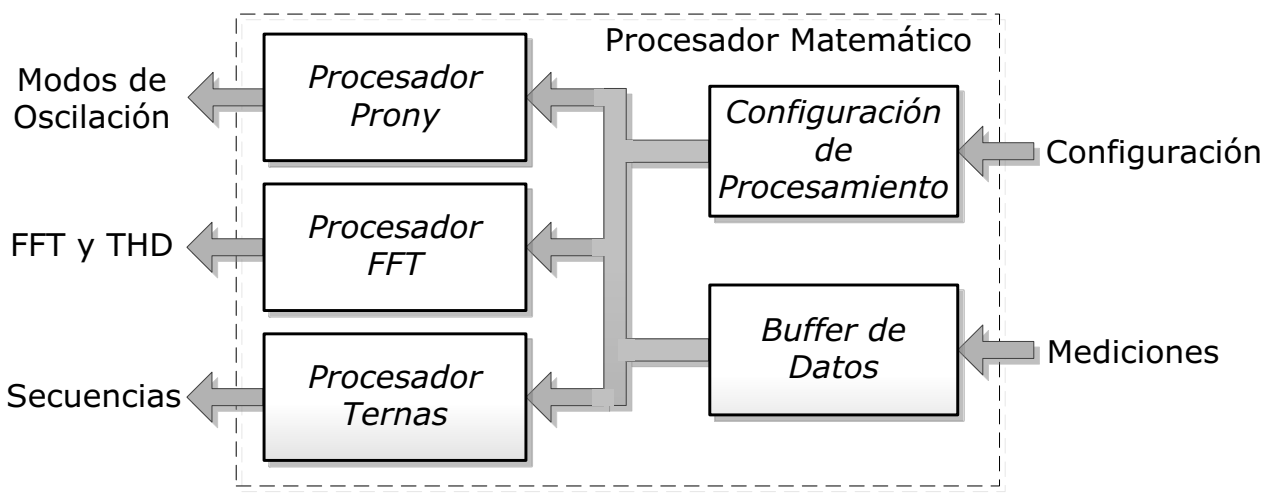

Figura 109. Diagrama en bloques Procesador Matemático - Módulo Offline

Este bloque recibe las configuraciones del procesamiento y las mediciones desde el Analizador. Una vez recibidos todos los datos, realiza los procesamientos seleccionados.

El Procesador Prony realiza el análisis y cálculo de los modos de oscilación en las tensiones, corrientes o potencia según corresponda.

El Procesador FFT calcula la Transformada Rápida de Fourier de los registros rápidos de tensión y corriente. A partir de los resultados obtenidos, calcula la Distorsión Armónica Total ciclo a ciclo de ambas variables.

El Procesador de Ternas efectúa el cálculo de las componentes de secuencia Directa, Inversa y Homopolar y el Desbalance ciclo a ciclo de los sincrofasores contenidos en la ventana temporal analizada.

\subsection{Interfaz de Usuario}

En la Figura 110 puede observarse la ventana principal de la interfaz de usuario. 


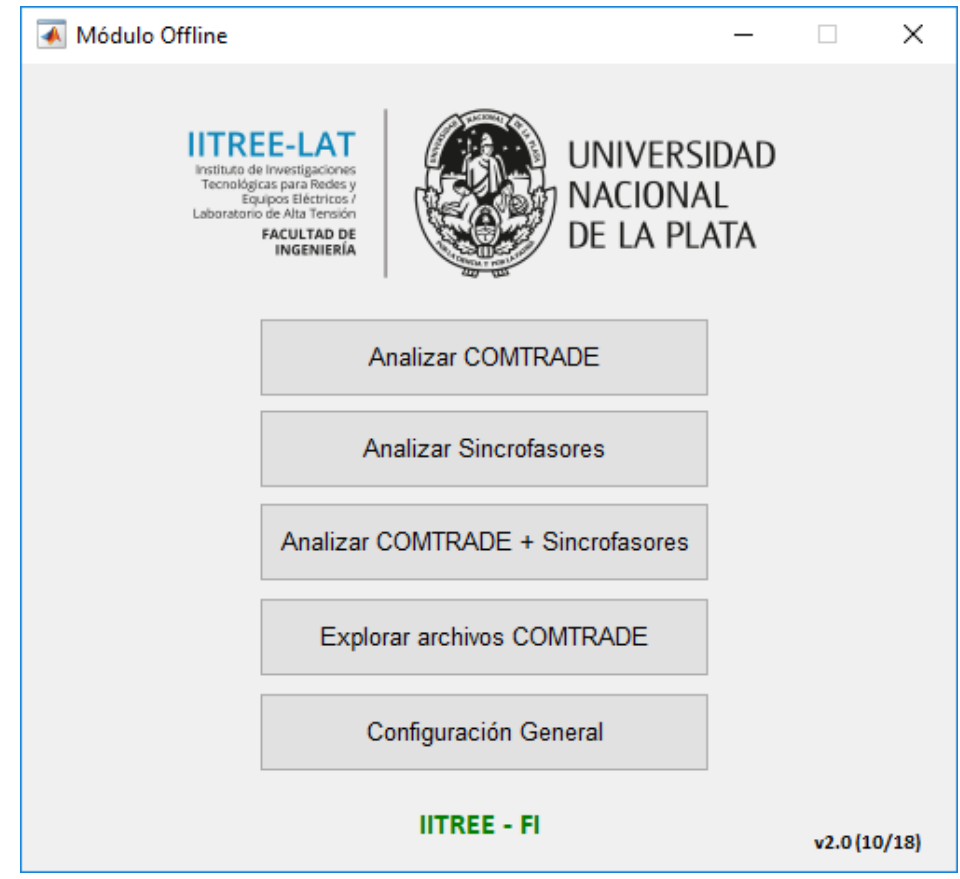

Figura 110. Interfaz de Usuario - Módulo Offline.

El software inicia dando al usuario la posibilidad de seleccionar el tipo de datos (COMTRADE, sincrofasores o ambos) a utilizar en el análisis que desea efectuar o realizar la configuración general del módulo offline. A su vez, permite utilizar el denominado Explorador de archivos COMTRADE, que será descripto en la sección 8.3.5.

\subsubsection{Configuración General}

La configuración general se refiere a los parámetros de comunicación con la Base de Datos para poder realizar la búsqueda de los sincrofasores. En la Figura 111 se muestra la ventana correspondiente.

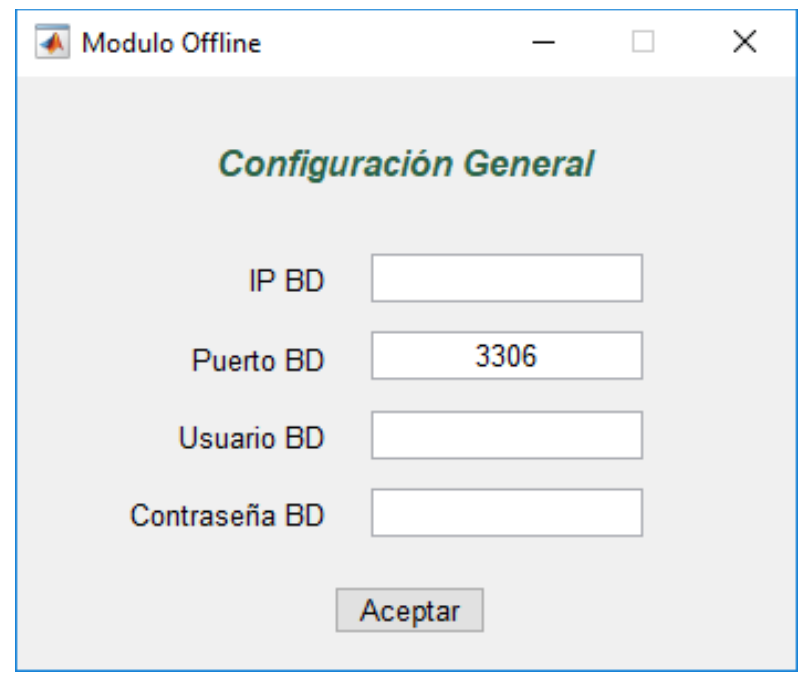

Figura 111. Configuración General - Módulo Offline. 
Los parámetros que deben configurarse son: la dirección IP donde se encuentra el servidor de Base de Datos, el puerto de comunicaciones y el nombre de usuario y contraseña de acceso al servidor. Dichos parámetros deben ser proporcionados por el Administrador del sistema.

\subsubsection{Análisis COMTRADE}

Para realizar el análisis de un registro rápido llevado a cabo por una PMU o registrador, que fue almacenado en formato COMTRADE, el usuario debe seleccionar el análisis de archivos COMTRADE en la ventana principal.

Una vez seleccionado dicho análisis, el operador deberá configurar diversos parámetros de procesamiento que se observan en la Figura 112.

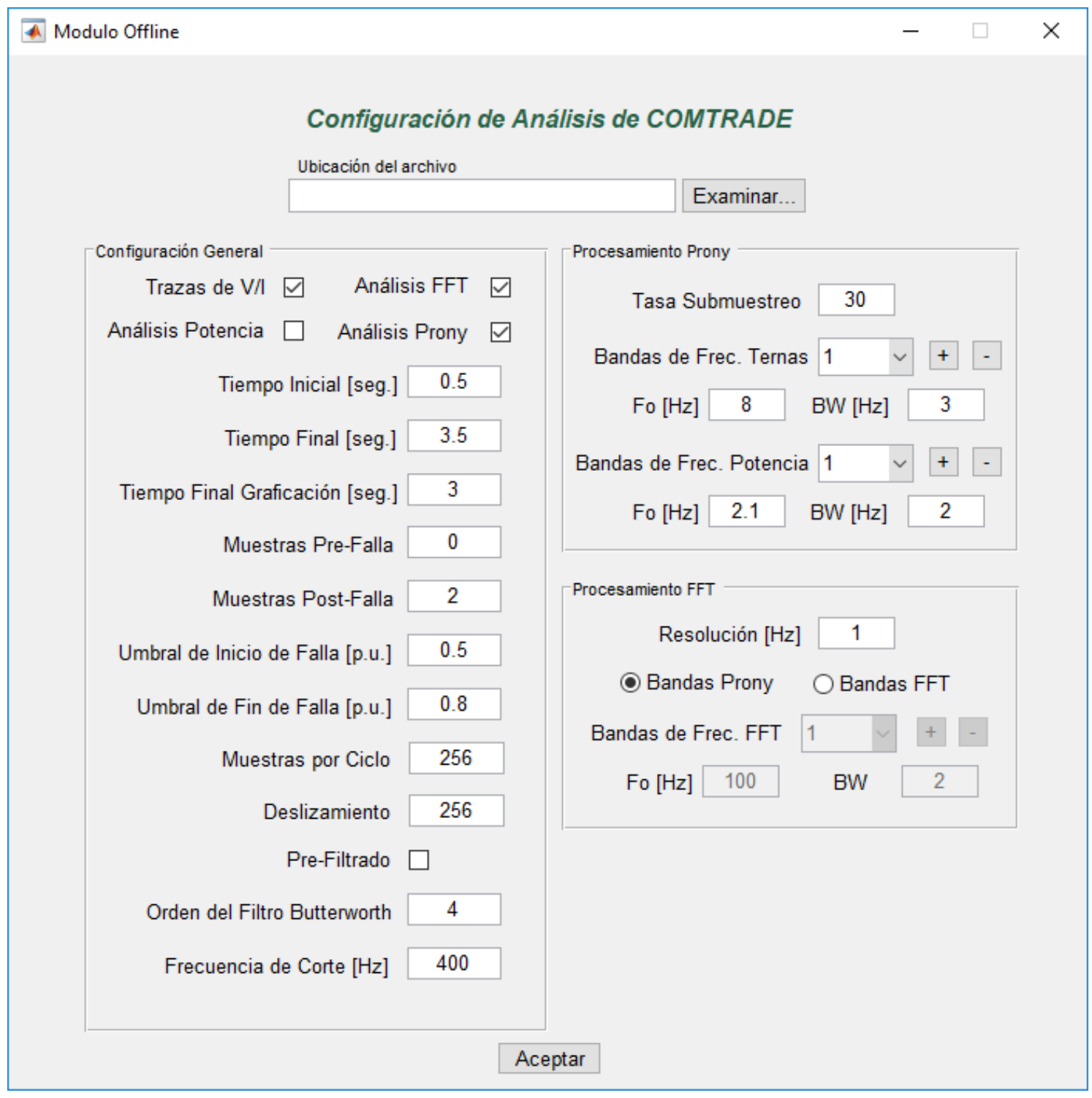

Figura 112. Configuración de análisis COMTRADE - Módulo Offline. 
En primer lugar, debe seleccionarse el archivo comprimido ZIP sobre el que desea realizar el análisis, utilizando el menú Examinar...

Posteriormente, el usuario debe establecer parámetros generales del procesamiento utilizando el apartado Configuración General. En dicho apartado, se seleccionan los procesamientos y visualizaciones que se desean ejecutar utilizando las 4 casillas disponibles (Trazas de V/I, Análisis FFT de tensiones y corrientes, Análisis de potencia incluyendo los modos de oscilación y Análisis con el método de Prony de las tensiones y corrientes).

A su vez, debe configurarse el tiempo inicial y final dentro del registro sobre el que se desea operar y el tiempo final de graficación (este será el máximo tiempo que se podrá observar en los gráficos sin realizar operaciones sobre los mismos).

El análisis COMTRADE tiene integrado un detector de falla, que permite analizar y hallar la primera falla de corriente que se encuentre en el registro. Los parámetros Muestras Pre-Falla y Muestras Post-Falla configuran, entonces, la cantidad de muestras antes y después de la falla propiamente dicha que se incluirán dentro de la ventana temporal de procesamiento.

El Umbral de Inicio de Falla y el Umbral de Fin de Falla son los parámetros que permiten determinar la ubicación de la falla, evaluando la variación por ciclo de la variable analizada.

Las Muestras por Ciclo establecen la cantidad de muestras que tiene el registro por ciclo de la tensión/corriente. El Deslizamiento configura la cantidad de muestras que debe desplazarse la ventana deslizante para conformar una nueva ventana y realizar nuevamente los cálculos correspondientes.

Finalmente, el usuario puede realizar un filtrado sobre las muestras obtenidas antes de realizar todos los procesamientos y graficaciones. Para ello, debe habilitarlo con la casilla correspondiente. El filtrado se realiza mediante un filtro de tipo Butterworth, cuyo orden y frecuencia de corte son también configurables mediante las casillas de configuración correspondientes.

En el caso de seleccionar la ejecución del Análisis Prony, el operador deberá configurarlo. Para ello, cuenta con el apartado Procesamiento Prony dentro de la ventana de configuración.

Las bandas de frecuencia corresponden a aquellas bandas donde se analizarán los modos de oscilación. Dado que es posible realizar el procesamiento Prony tanto para las ternas de tensión y corriente como para la potencia, existen en este software dos conjuntos de bandas. Las primeras, denominadas Bandas de Frecuencia Ternas, corresponden a las bandas que se analizarán en el caso de las tensiones y corrientes del registro rápido. Las segundas, denominadas Bandas de Frecuencia Potencia, corresponden a las bandas que se analizarán en el análisis de potencia. Esta diferenciación corresponde a que las componentes de frecuencia que pueden encontrarse 
en ambos análisis son completamente diferentes (por ej., las tensiones tendrán una fuerte componente de $50 \mathrm{~Hz}$ que la potencia carecerá).

Cada banda tiene su frecuencia central (Fo) y su semi-ancho de banda (BW). De esta manera, cada banda corresponde a las frecuencias [Fo-BW; Fo+BW].

En el caso de seleccionar la ejecución del Análisis FFT, el operador debe configurarlo. Para ello, cuenta con el apartado Procesamiento FFT dentro de la ventana de configuración.

La resolución establece la resolución en frecuencia con que se realizará el análisis. Esto, en base a las características propias de la FFT, define el ancho de la ventana deslizante que se utilizará para realizar el cálculo de la Transformada.

Las bandas de frecuencia corresponden a aquellas bandas donde se realizará el análisis de la FFT. El usuario cuenta, en este caso, con dos opciones. Por un lado, puede realizar el procesamiento FFT sobre las mismas bandas que utiliza para el procesamiento Prony. Caso contrario, puede realizarlo sobre bandas completamente diferentes debiendo configurarlas de la misma manera que se realiza para el caso del Procesamiento Prony.

Una vez llevada a cabo toda la configuración correspondiente, el usuario debe Aceptar la configuración para comenzar la visualización y procesamiento. En la Figura 113 puede observarse la ventana de visualización de resultados.

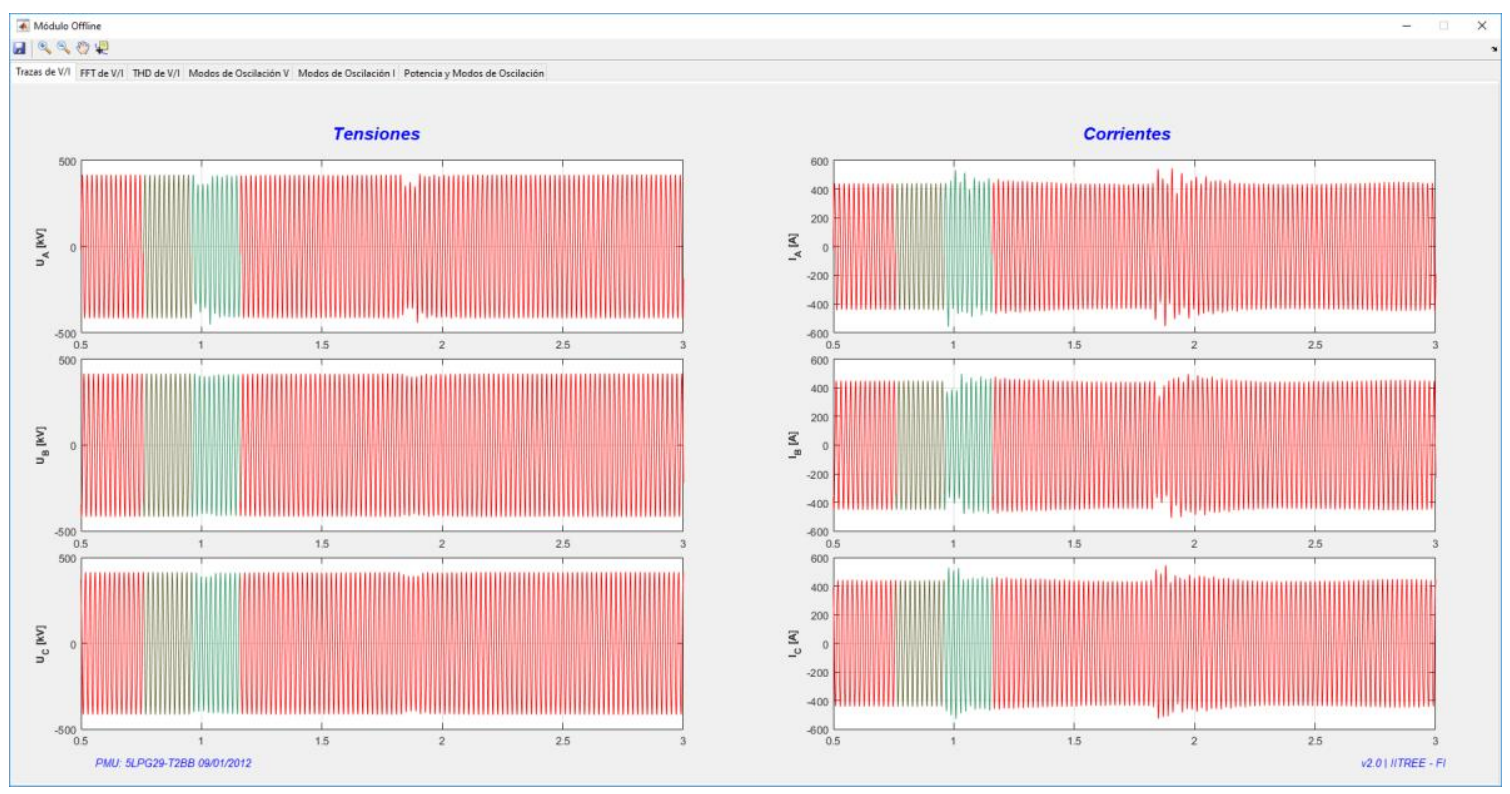

Figura 113. Ventana de Visualización de Análisis COMTRADE - Módulo Offline.

La visualización del análisis cuenta con diferentes pestañas. En ellas puede seleccionarse la visualización de las Trazas de Tensiones y Corrientes, la FFT de las Tensiones y Corrientes, su Distorsión Armónica Total, los modos de oscilación presentes en las Tensiones y Corrientes y el análisis de la Potencia. 
El usuario cuenta con diversas herramientas para la manipulación de las visualizaciones, incluyendo el zoom in y zoom out de los gráficos, la navegación de los mismos y el uso de marcadores para visualizar valores específicos dentro de los trazados.

A su vez, es posible guardar los resultados del procesamiento mediante imágenes de cada uno de los gráficos generados.

\subsubsection{Análisis Sincrofasores}

Para realizar el análisis de un registro de sincrofasores llevado a cabo por una PMU, el usuario debe seleccionar el análisis de Sincrofasores en la ventana principal.

Una vez seleccionado dicho análisis, el operador debe configurar diversos parámetros de procesamiento que se observan en la Figura 114.

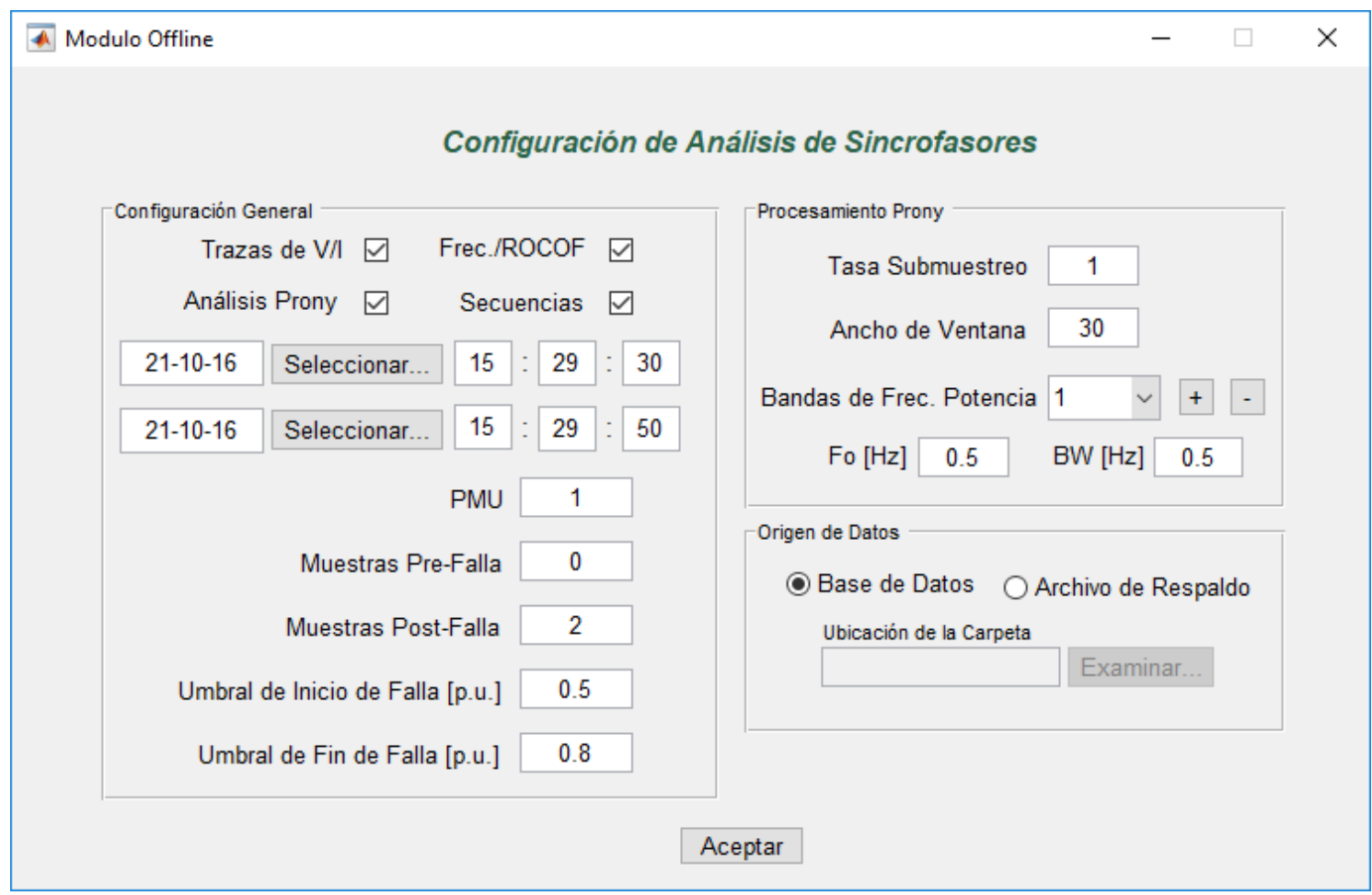

Figura 114. Configuración de análisis de sincrofasores - Módulo Offline.

En primer lugar, debe seleccionar diferentes opciones disponibles en el apartado Configuración General. El usuario puede elegir los procesamientos y visualizaciones que desea ejecutar utilizando las 4 casillas disponibles (Trazas de V/I, Trazas de Frecuencia o ROCOF, Análisis de los modos de oscilación de la potencia mediante el método de Prony y Análisis de las componentes de secuencia de tensión y corriente). Luego, debe configurar el intervalo de tiempo almacenado en los registros que desea analizar, estableciendo fecha y hora de inicio y fin de la ventana temporal a procesar. 
El análisis de Sincrofasores cuenta con un detector de falla integrado, que permite analizar y hallar la primera perturbación de corriente que se encuentre en el registro. Los parámetros Muestras Pre-Falla y Muestras Post-Falla configuran, entonces, la cantidad de muestras antes y después de la falla propiamente dicha que se incluirán dentro de la ventana temporal.

El Umbral de Inicio de Falla y el Umbral de Fin de Falla son los parámetros que permiten determinar la ubicación de la falla, evaluando la variación por ciclo de la variable analizada.

En el caso de seleccionar la ejecución del Análisis Prony, el operador debe configurarlo. Para ello, cuenta con el apartado Procesamiento Prony dentro de la ventana de configuración.

La tasa de submuestreo o paso de decimación define la frecuencia de muestreo a utilizar con los datos analizados por el Procesamiento Prony. Una tasa de submuestreo de valor 1 equivale a aplicar el muestreo original (F) mientras que una tasa mayor (de valor $\mathrm{N}$ ) equivale a una tasa de muestreo $\mathrm{F} / \mathrm{N}$. Se sugiere utilizar tasas entre 1 y 3.

El ancho de ventana establece la cantidad de muestras que tendrá contenida la ventana deslizante del análisis Prony. Es en cada una de esas ventanas donde se realiza la búsqueda de los modos de oscilación.

Las Bandas de Frecuencia Potencia, corresponden a las bandas que se analizarán en el análisis de potencia. Cada banda tiene su frecuencia central (Fo) y su semi-ancho de banda (BW). De esta manera, cada banda corresponde a las frecuencias [Fo-BW; $\mathrm{Fo}+\mathrm{BW}]$.

Finalmente, el usuario debe seleccionar la fuente de los datos. Si la ventana temporal que desea analizar se encuentra dentro de las ventanas temporales que ya fueron almacenadas en discos secundarios, debe seleccionar la opción Archivos de Respaldo y proporcionar al software la ruta de acceso a dicho disco. En el caso de que la ventana temporal se encuentre dentro de la base de datos vigente, el usuario debe seleccionar Base de Datos. Es importante mencionar que, en este caso, se debe haber realizado correctamente la configuración general del software para poder llevar a cabo la transferencia de datos con el Servidor de Base de Datos.

Una vez realizada toda la configuración correspondiente, el usuario debe Aceptar la configuración para comenzar la visualización y procesamiento. En la Figura 115 puede observarse la ventana de visualización de resultados. 


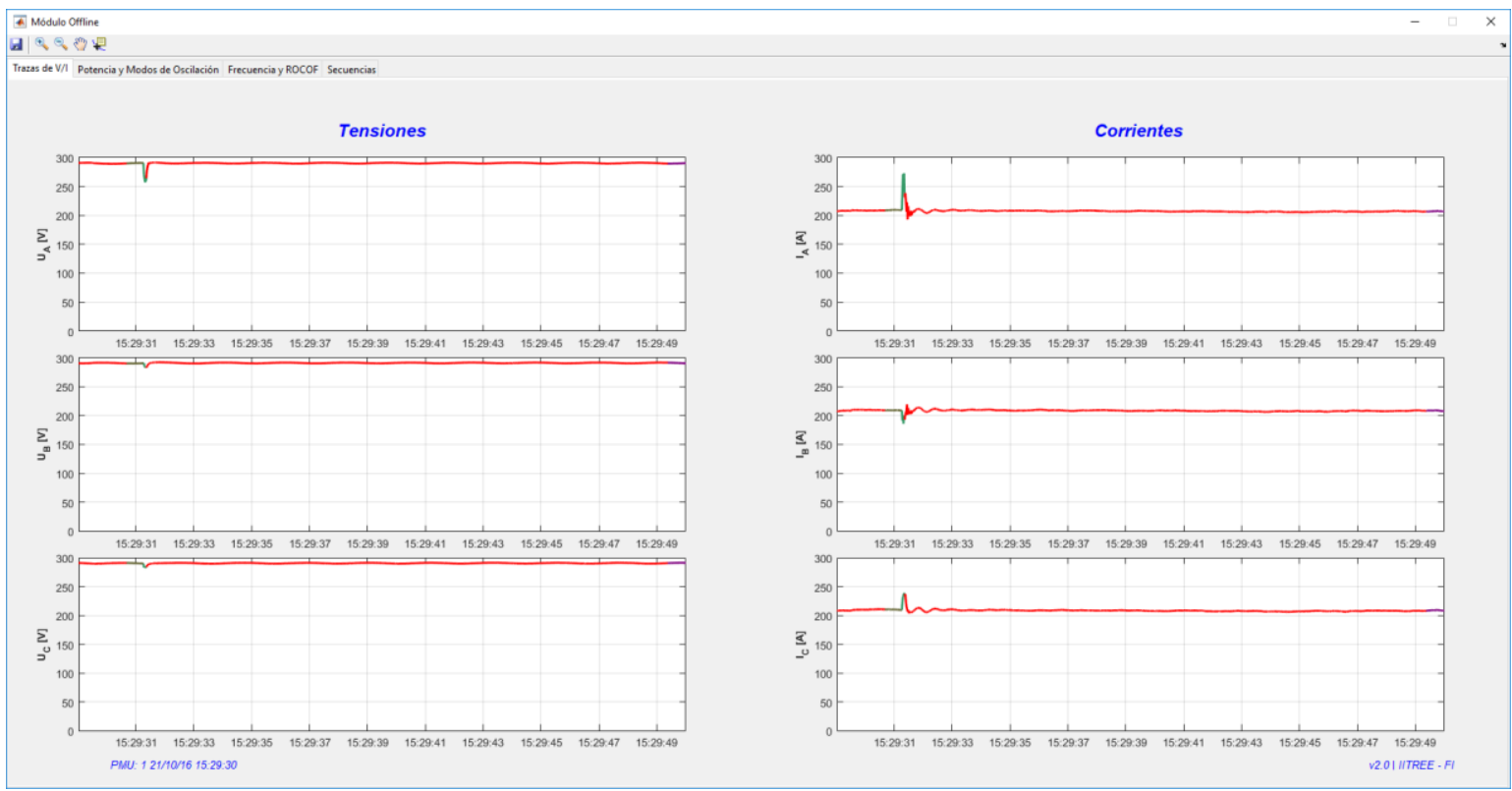

Figura 115. Ventana de Visualización de Análisis de Sincrofasores - Módulo Offline.

La visualización del análisis cuenta con diferentes pestañas. En ellas puede seleccionarse la visualización de las Trazas de Tensiones y Corrientes, el análisis de la Potencia con sus modos de oscilación, las Trazas de Frecuencia y ROCOF y las componentes de Secuencia en la Tensión y la Corriente junto con sus respectivos Desbalances.

El usuario cuenta con diversas herramientas para la manipulación de las visualizaciones, incluyendo el zoom in y zoom out de los gráficos, la navegación de los mismos y el uso de marcadores para visualizar valores específicos dentro de los trazados.

A su vez, es posible guardar los resultados del procesamiento mediante imágenes de cada uno de los gráficos generados.

\subsubsection{Análisis COMTRADE y Sincrofasores}

Para realizar el análisis en simultáneo de un registro de sincrofasores llevado a cabo por una PMU y un registro rápido almacenado en formato COMTRADE realizado por una PMU o registrador, el usuario debe seleccionar el análisis de COMTRADE + Sincrofasores en la ventana principal.

Una vez seleccionado dicho análisis, el operador debe configurar diversos parámetros de procesamiento que se observan en la Figura 116. 


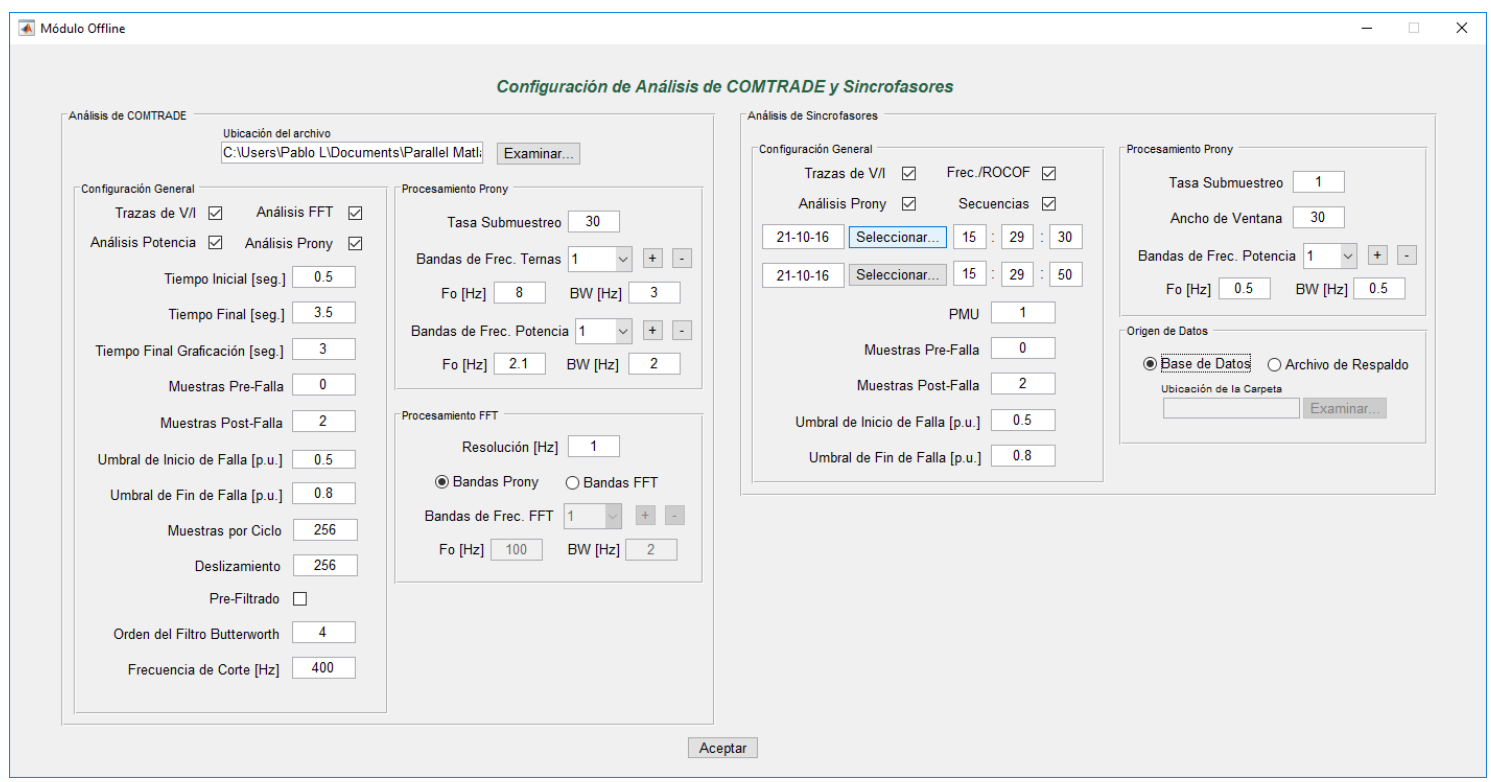

Figura 116. Configuración de análisis COMTRADE + Sincrofasores - Módulo Offline.

Las configuraciones que debe realizar el usuario en este caso son las mismas que las realizadas para cada uno de los procesamientos por separado, tal como se describe en las secciones 8.3.2 y 8.3.3.

Una vez llevada a cabo toda la configuración correspondiente, el usuario debe Aceptar la configuración para comenzar la visualización y procesamiento. En la Figura 117 puede observarse la ventana de visualización de resultados.

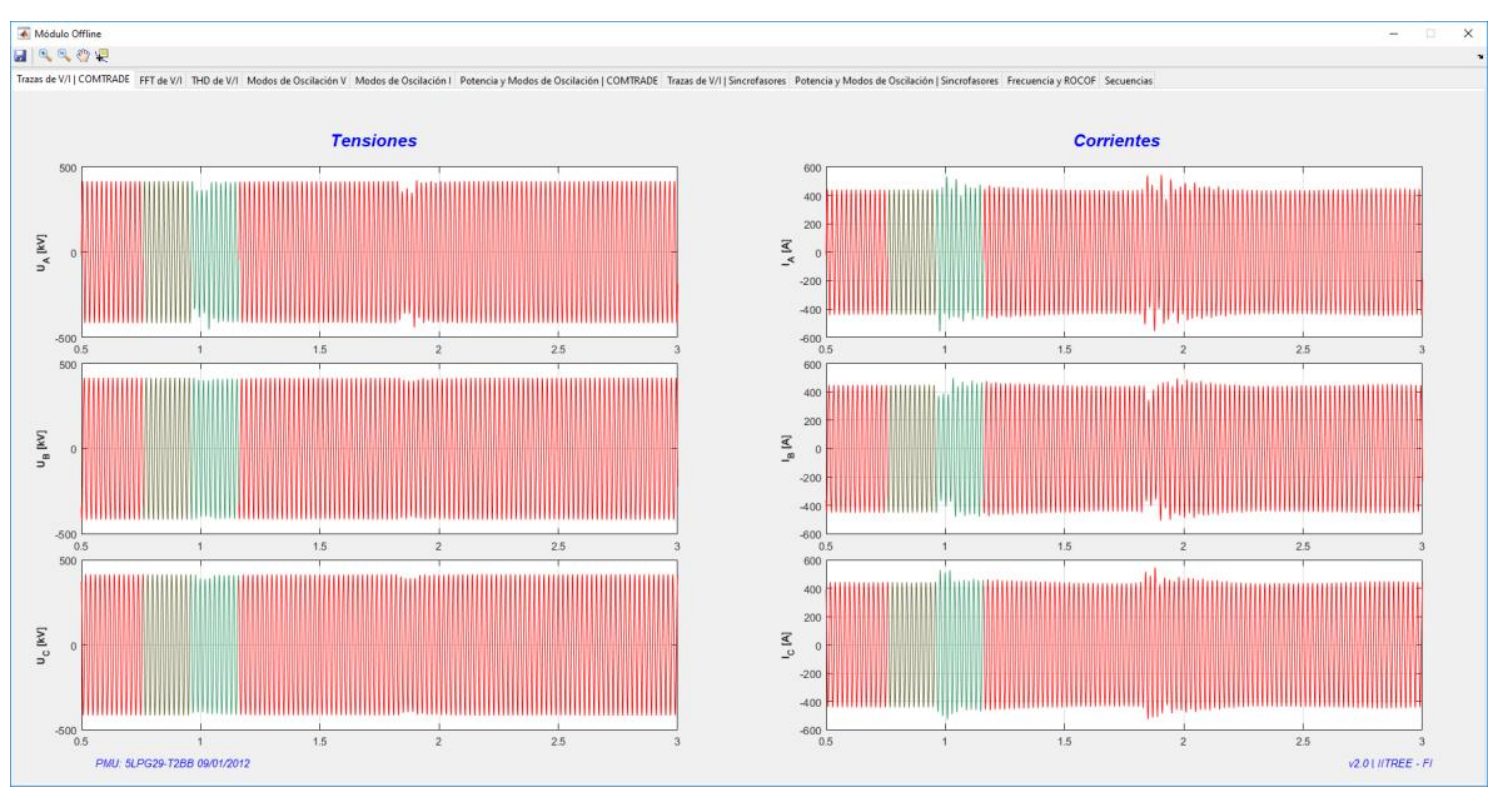

Figura 117. Ventana de Visualización de Análisis de COMTRADE + Sincrofasores - Módulo Offline.

La visualización del análisis cuenta con diferentes pestañas. En ellas puede seleccionarse la pestaña de graficación de las Trazas de Tensiones y Corrientes del registro COMTRADE, la FFT de las Tensiones y Corrientes, su Distorsión Armónica Total, los modos de oscilación presentes en las ternas, el análisis de Potencia del 
COMTRADE, las Trazas de Tensiones y Corrientes del registro de Sincrofasores, las Trazas de Frecuencia y ROCOF, el análisis de la Potencia calculada a partir de los Sincrofasores y las componentes de Secuencia en la Tensión y la Corriente junto con sus respectivos desbalances.

El usuario cuenta con diversas herramientas para la manipulación de las visualizaciones, incluyendo el zoom in y zoom out de los gráficos, la navegación de los mismos y el uso de marcadores para visualizar valores específicos dentro de los trazados.

A su vez, es posible guardar los resultados del procesamiento mediante imágenes de cada uno de los gráficos generados.

\subsubsection{Explorador de Archivos COMTRADE}

El Explorador de archivos COMTRADE es una utilidad adicional con que cuenta el software de procesamiento offline. El objetivo principal de la herramienta es realizar un pre-procesamiento de un conjunto de registros COMTRADE para obtener sus parámetros principales.

En la Figura 118 puede observarse la interfaz de usuario del explorador.

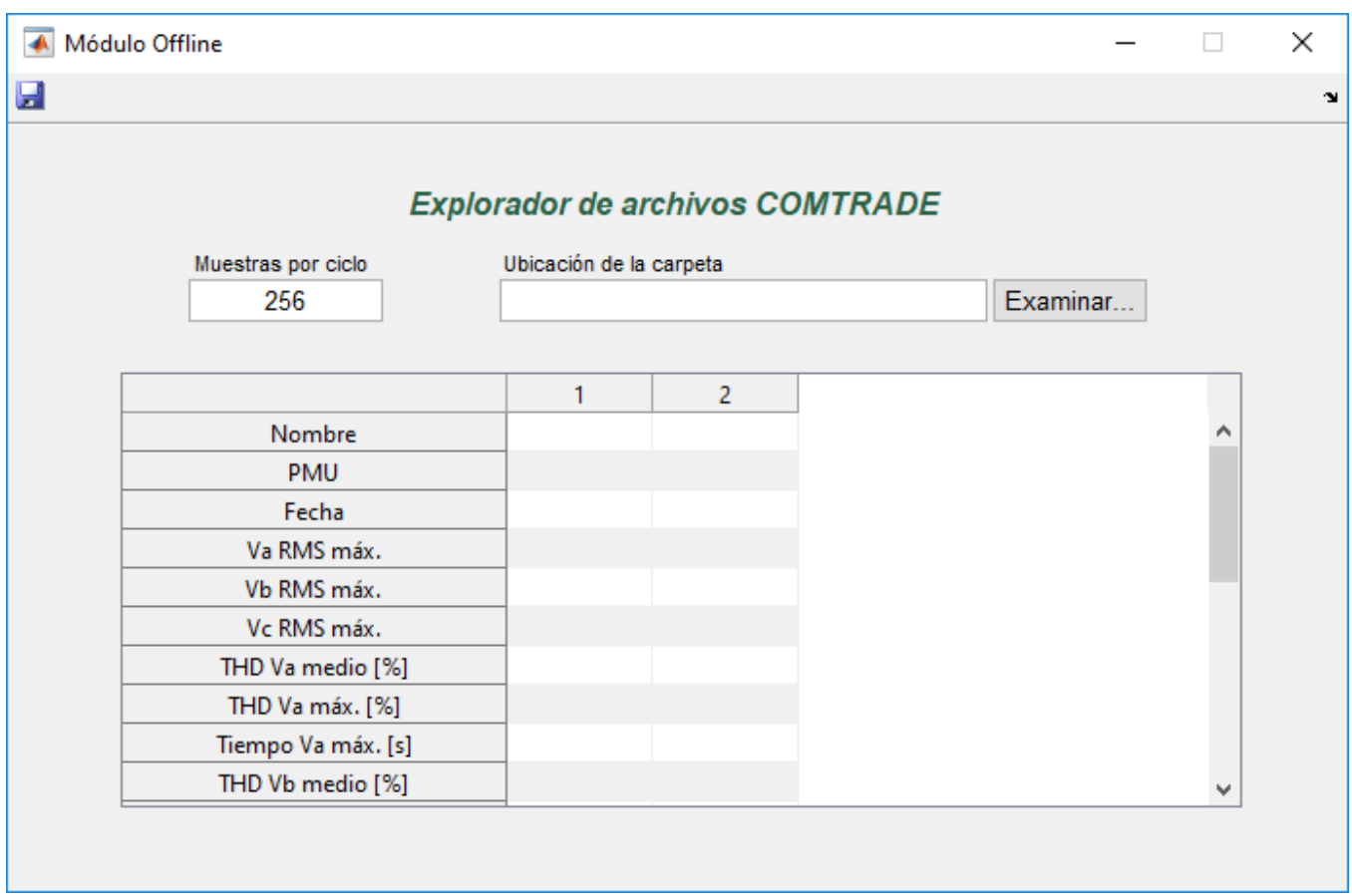

Figura 118. Interfaz de Usuario del Explorador de archivos COMTRADE- Módulo Offline.

El usuario debe establecer la cantidad de muestras por ciclo de las tensiones y/o corrientes almacenadas en los registros a analizar y, finalmente, dar la ruta de acceso a la carpeta donde se encuentran todos los archivos COMTRADE que desea preprocesar. Una vez determinados ambos parámetros, se observarán los resultados obtenidos, en una ventana similar a la que se muestra en la Figura 119. 


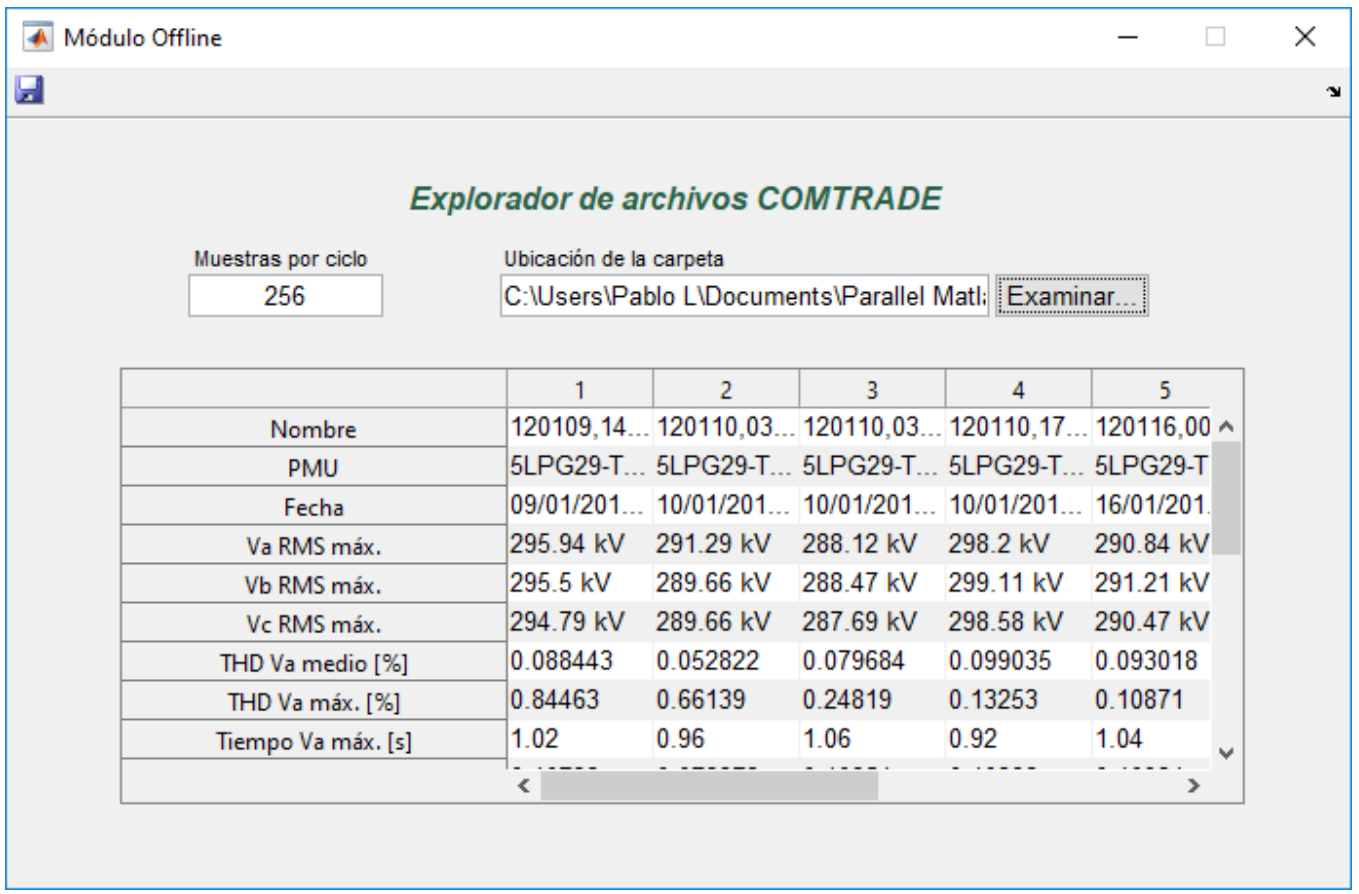

Figura 119. Visualización de resultados del Explorador de archivos COMTRADE- Módulo Offline.

Los parámetros que se obtienen mediante el Explorador de cada uno de los registros COMTRADE encontrados son:

- Nombre del registro.

- Identificación de la PMU.

- Máxima tensión eficaz por fase.

- Distorsión Armónica Total media de tensión por fase.

- Distorsión Armónica Total máxima de tensión por fase.

- Instante de tiempo del máximo de distorsión de tensión por fase.

- Distorsión Armónica Total media de corriente por fase.

- Distorsión Armónica Total máxima de corriente por fase.

- Instante de tiempo del máximo de distorsión de corriente por fase.

Mediante esta herramienta adicional, el usuario puede realizar la caracterización y búsqueda de ciertos parámetros dentro de un conjunto de registros para optimizar el análisis. A modo de ejemplo, pueden mencionarse las siguientes situaciones hipotéticas.

- Frente a una falla en el sistema, donde se disponen de una variedad de registros rápidos relacionados a la falla, el operador puede realizar una exploración sobre todos los registros existentes que corresponden a la fecha y hora de la falla con el objetivo de determinar en cuál de ellos existe una mayor distorsión armónica o una mayor desviación del valor esperado de tensión eficaz. De esta manera, el usuario luego puede efectuar un análisis offline del registro con fenómenos más 
significativos únicamente, evitando la necesidad de analizar todos los registros disponibles.

- En el caso de una PMU o registrador configurado con una sensibilidad excesiva, que provoque el disparo de gran cantidad de registros rápidos de los cuales sólo unos pocos son realmente significativos, el usuario puede explorar ese conjunto de registros y determinar en base a los parámetros obtenidos cuáles de ellos tienen contenido de interés y cuáles son producto de la alta sensibilidad del dispositivo. 


\section{Unidad de Medición Sincrofasorial}

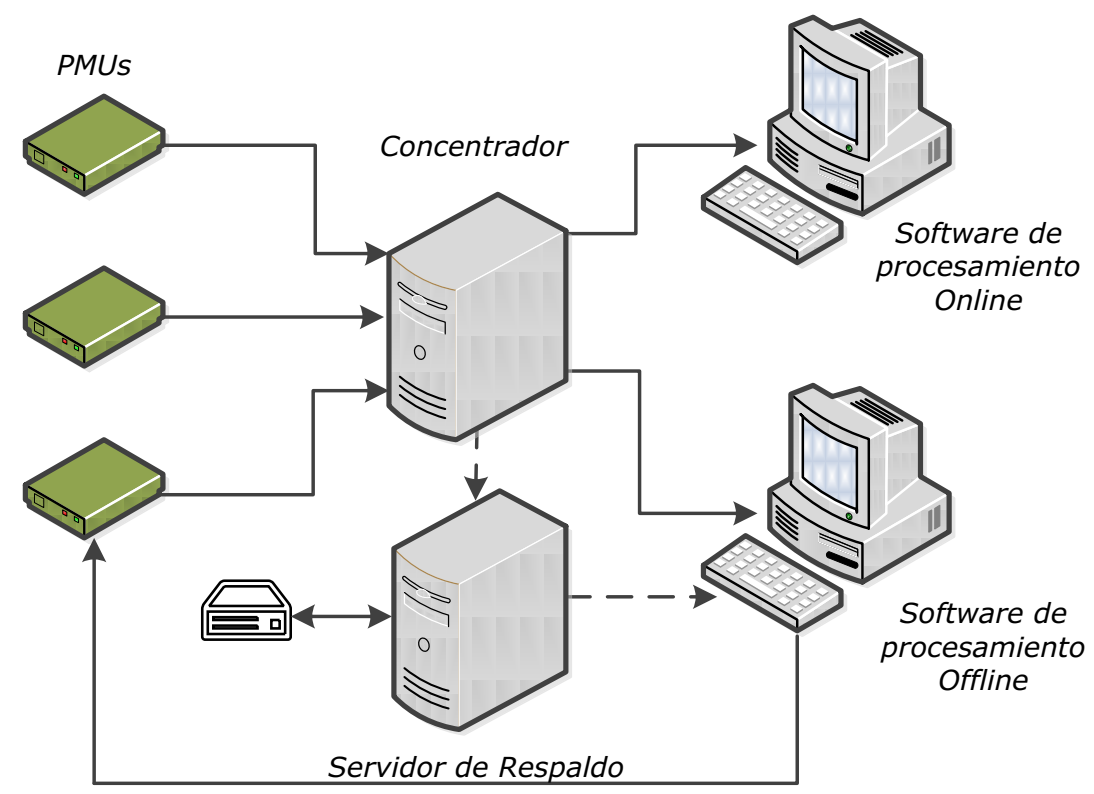

Figura 120. PMUs en el sistema de medición sincrofasorial.

\subsection{Descripción General}

La Unidad de Medición Sincrofasorial o PMU tiene como función principal la medición de tensiones y corrientes para la obtención de los fasores correspondientes, garantizando la sincronización temporal de las mediciones con la base de tiempo brindada por el sistema GPS. La PMU cuenta, a su vez, con una interfaz de comunicaciones que le permite realizar la transmisión de los sincrofasores obtenidos mediante un enlace Ethernet. En la Figura 121 puede observarse un diagrama en bloques de la PMU. 


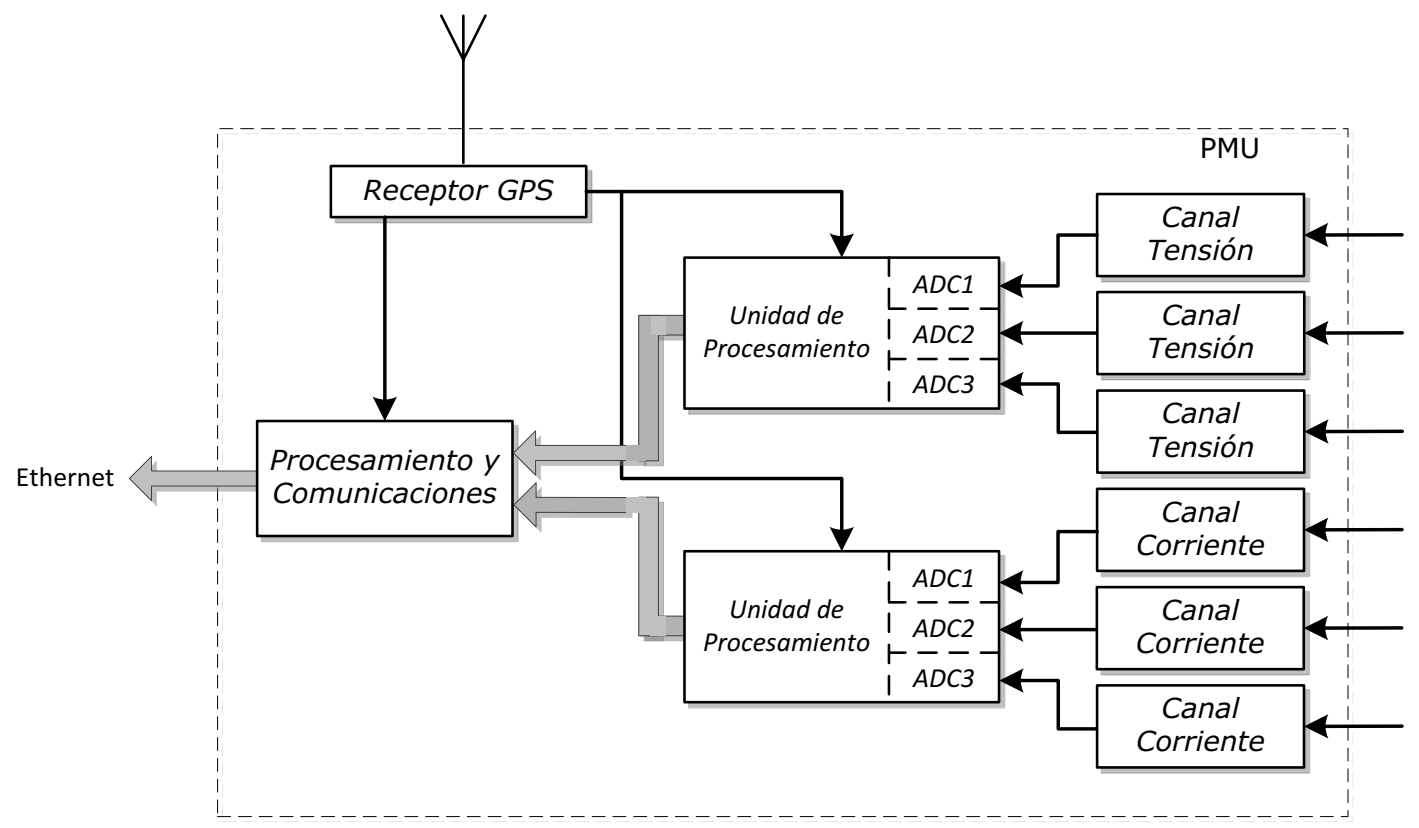

Figura 121. Diagrama en bloques - Unidad de Medición Sincrofasorial.

La PMU desarrollada cuenta con 3 canales para la medición de tensión y 3 canales para la medición de corriente, de manera tal que es capaz de realizar la medición de todas las variables de un sistema trifásico convencional. Tal como se observa en la Figura 121, los canales de tensión y corriente le permiten al equipamiento conectarse a las variables correspondientes, llevando a cabo la adecuación de señal necesaria para su posterior medición y procesamiento.

Cada uno de los canales es adquirido para su procesamiento por un conversor analógico-digital dedicado. El sistema cuenta con dos unidades de procesamiento funcionando en paralelo, cada una con 3 conversores analógico-digitales integrados. Dichas unidades permiten llevar a cabo todo el procesamiento, descripto en 9.2, necesario para la obtención de los sincrofasores a partir de las muestras de señal correspondientes.

Finalmente, la PMU cuenta con un módulo de procesamiento y comunicaciones. Dicho módulo permite procesar los sincrofasores recibidos, generando los paquetes de datos con el formato adecuado según [10] para su posterior transmisión mediante la interfaz Ethernet.

La PMU dispone, a su vez, de un receptor GPS integrado. Dicho receptor permite la obtención de la información del tiempo UTC así como las señales de temporización necesarias para realizar el muestreo y procesamiento de señal, garantizando de esta manera la sincronización de los fasores con la base temporal correspondiente. 


\subsection{Técnicas de Estimación de Sincrofasores}

Para llevar a cabo la elección del método de procesamiento para la obtención de los sincrofasores, se realizaron diversos análisis y pruebas sobre diferentes técnicas de estimación con el objetivo de evaluar su desempeño.

Existen diferentes técnicas de estimación de sincrofasores propuestas y evaluadas en la literatura afín e implementadas en PMUs de última tecnología. Dichas técnicas pueden ser clasificadas según el dominio donde se realiza la estimación, dividiéndose en técnicas en el dominio del tiempo y técnicas en el dominio de la frecuencia [8][47][62].

Las técnicas de estimación en el dominio temporal se apoyan en el análisis de las muestras de señal, basando su implementación en conversores de frecuencia y filtros junto a otros algoritmos de procesamiento para la obtención de los fasores. Este tipo de análisis es propuesto por [9] como referencia de un modelo de procesamiento. Las técnicas en el dominio de la frecuencia se basan en diferentes variantes de la Transformada Discreta de Fourier (TDF), procesada a través de la FFT. Este procesamiento se realiza sobre un conjunto de muestras de señal, representando medio ciclo, un ciclo o múltiples ciclos de la forma de onda correspondiente.

A partir de dicha clasificación, dos métodos de estimación de sincrofasores para la medición de tensiones y corrientes en sistemas trifásicos fueron simulados $\mathrm{y}$ comparados con el objetivo de seleccionar el algoritmo adecuado para implementar en la PMU. Uno de ellos, correspondiente a un análisis en el dominio del tiempo, se basa en el esquema descripto en [9], al que se lo denomina "Algoritmo de filtrado". E1 restante, correspondiente a un análisis en el dominio de la frecuencia, se basa en la aplicación de la TDF Interpolada presentada en [63], y se lo denomina "Algoritmo basado en FFT".

\subsubsection{Algoritmo basado en FFT}

La técnica de estimación en el dominio de la frecuencia utilizada se basa en el algoritmo descripto en [63]. La tensión en un nodo del sistema de potencia puede ser modelada como una señal sinusoidal con una frecuencia nominal $f_{n}$ (por ejemplo $50 \mathrm{o}$ $60 \mathrm{~Hz}$ ) y una desviación de frecuencia $\Delta \mathrm{f}$, un valor eficaz A y una fase inicial $\varphi$. Dicha señal es muestreada por la PMU con una frecuencia de muestreo fija $f_{s}$ múltiplo de $f_{n}$, obteniéndose una cantidad $\mathrm{N}$ de muestras durante una ventana temporal $\mathrm{T}=\mathrm{N} / \mathrm{f}_{\mathrm{s}}(\mathrm{N} \epsilon$ $\mathbb{N}$ ). El ancho $\mathrm{T}$ de la ventana temporal debe ser lo suficientemente grande como para obtener una buena resolución en frecuencia y lo suficientemente chico como para poder considerar a la señal en estado estacionario a lo largo de dicho período temporal.

$$
v[n]=\sqrt{2} A \cos \left[2 \pi\left(f_{n}+\Delta f\right) \frac{n}{f_{s}}+\varphi\right], \quad n \in[0, N-1]
$$


Normalmente, el ancho $\mathrm{T}$ de la ventana temporal corresponde a uno o dos ciclos nominales de la señal procesada. El algoritmo, entonces, supone que la desviación de frecuencia $\Delta \mathrm{f}$ satisface la condición expresada en la Ec. 9.2, donde $\delta_{\mathrm{f}}$ es la resolución en frecuencia de la TDF

$$
|\Delta \mathrm{f}|<\delta_{\mathrm{f}} / 2, \quad \delta_{\mathrm{f}}=1 / \mathrm{T}
$$

Con las consideraciones descriptas anteriormente, la Ec. 9.3 corresponde a la TDF de la señal muestreada, donde $w[n]$ es la ventana utilizada para reducir la fuga espectral. En este caso, se utiliza la ventana de Hanning.

$$
V[k]=\sum_{n=0}^{N-1} v[n] \cdot w[n] \cdot e^{-j \frac{2 n k \pi}{N}}, \quad k \in[0, N-1]
$$

Para realizar la estimación de la amplitud y fase de la señal, la TDF interpolada requiere, primero, estimar la frecuencia de la señal mediante la interpolación de la amplitud de las muestras de la TDF o bins. Dicha interpolación se realiza teniendo en cuenta la suposición de la Ec. 9.2 y una frecuencia de muestreo $f_{s}$ múltiplo de $f_{n}$. La frecuencia real de la señal $f_{n}+\Delta f$ puede corresponder a un valor de frecuencia intermedio entre dos bins de la TDF, donde uno de ellos corresponde a la frecuencia nominal de la señal. De esta manera, la frecuencia real puede ser expresada como:

$$
\mathrm{f}_{\mathrm{n}}+\Delta \mathrm{f}=\left(\mathrm{k}_{1}+\delta_{\text {bin }}\right) \delta_{\mathrm{f}}
$$

donde $-0.5<\delta_{\text {bin }} \leq 0.5$ es la desviación respecto al bin de frecuencia nominal cuyo índice resulta $\mathrm{k}_{1}=\mathrm{T}^{*} \mathrm{f}_{\mathrm{s}}$.

Si la frecuencia de muestreo $f_{s}$ es mucho mayor que la frecuencia nominal de la señal, $\delta_{\text {bin }}$ puede ser expresado como se indica en la Ec. 9.5:

$$
\delta_{\text {bin }}=\varepsilon(2-\alpha) /(1+\alpha)
$$

donde $\alpha$ es el cociente entre la amplitud del bin de frecuencia nominal (cuyo índice es $\mathrm{k}_{1}$ ), que es esperable sea el de mayor amplitud de la TDF, y el segundo bin de mayor amplitud:

$$
\alpha=\left|\mathrm{V}\left[\mathrm{k}_{1}\right]\right| /\left|\mathrm{V}\left[\mathrm{k}_{1}+\varepsilon\right]\right|
$$

$\varepsilon$ puede ser +1 ó -1 , estableciendo el segundo bin de mayor amplitud:

$$
\alpha=\operatorname{signo}\left(\mathrm{V}\left[\mathrm{k}_{1}+1\right]\right)-\operatorname{signo}\left(\mathrm{V}\left[\mathrm{k}_{1}-1\right]\right)
$$

Con los parámetros antes descriptos, la amplitud y fase del sincrofasor pueden ser estimadas con las siguientes expresiones.

$$
\mathrm{A}=2 /(\mathrm{N} / 2) \cdot\left|\mathrm{V}\left[\mathrm{k}_{1}\right]\right| \pi \delta_{\text {bin }}\left(1-\delta_{\text {bin }}^{2}\right) / \operatorname{sen}\left(\pi \delta_{\text {bin }}\right)
$$




$$
\varphi=\mathrm{V}\left[\mathrm{k}_{1}\right]-\pi \delta_{\text {bin }}
$$

Para la estimación final de frecuencia, se utiliza la estimación de secuencia directa del sistema trifásico. Siendo D la componente de secuencia directa, la desviación de frecuencia se puede estimar con la Ec. 9.10.

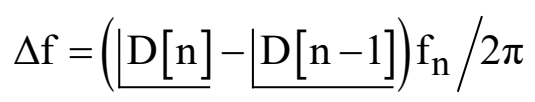

\subsubsection{Algoritmo de filtrado}

La norma [9] propone un método de estimación de sincrofasores correspondiente al dominio temporal basado en conversores de frecuencia, filtros y una frecuencia de muestreo fija $f_{s}$. Cada señal es muestreada y digitalizada mediante un conversor analógico-digital. Tal como se describió en el caso del Algoritmo basado en FFT, la tensión, muestreada con una frecuencia de muestreo fija $f_{s}$ múltiplo de la frecuencia nominal $f_{n}$, puede ser modelada mediante la Ec. 9.1.

La conversión de frecuencia de las señales muestreadas se realiza con un oscilador local en fase y cuadratura cuya frecuencia es, también, $f_{n}$. Las señales obtenidas se corresponden con las Ecs. 9.11 y 9.12

$$
\begin{aligned}
& \mathrm{v}_{\mathrm{p}}[\mathrm{n}]=\frac{\mathrm{A}}{\sqrt{2}}\left[\cos \left(2 \pi \Delta \mathrm{f} \frac{\mathrm{n}}{\mathrm{f}_{\mathrm{s}}}+\varphi\right)+\cos \left(2 \pi\left(2 \mathrm{f}_{\mathrm{n}}+\Delta \mathrm{f}\right) \frac{\mathrm{n}}{\mathrm{f}_{\mathrm{s}}}+\varphi\right)\right] \\
& \mathrm{v}_{\mathrm{q}}[\mathrm{n}]=\frac{\mathrm{A}}{\sqrt{2}}\left[\operatorname{sen}\left(2 \pi\left(2 \mathrm{f}_{\mathrm{n}}+\Delta \mathrm{f}\right) \frac{\mathrm{n}}{\mathrm{f}_{\mathrm{s}}}+\varphi\right)-\operatorname{sen}\left(2 \pi \Delta \mathrm{f} \frac{\mathrm{n}}{\mathrm{f}_{\mathrm{s}}}+\varphi\right)\right]
\end{aligned}
$$

El conjunto de muestras resultante de la conversión es filtrado mediante un filtro pasa bajos digital de tipo FIR, obteniéndose la parte real e imaginaria del sincrofasor. La norma [9] define el filtro pasa bajos que puede ser utilizado para una PMU de clase P. Si se obtienen $\mathrm{N}$ muestras por ciclo de la señal con frecuencia nominal, el filtro corresponde a un filtro FIR de orden $\mathrm{N}$ cuyos coeficientes responden a la expresión de la Ec. 9.13, donde $\mathrm{m}$ es el índice del coeficiente.

$$
\mathrm{W}[\mathrm{m}]=1-\frac{2}{\mathrm{~N}+2}|\mathrm{~m}|, \quad \mathrm{m} \in[-\mathrm{N} / 2, \mathrm{~N} / 2]
$$

En la Figura 122 se observa un diagrama en bloques del sistema de procesamiento. 


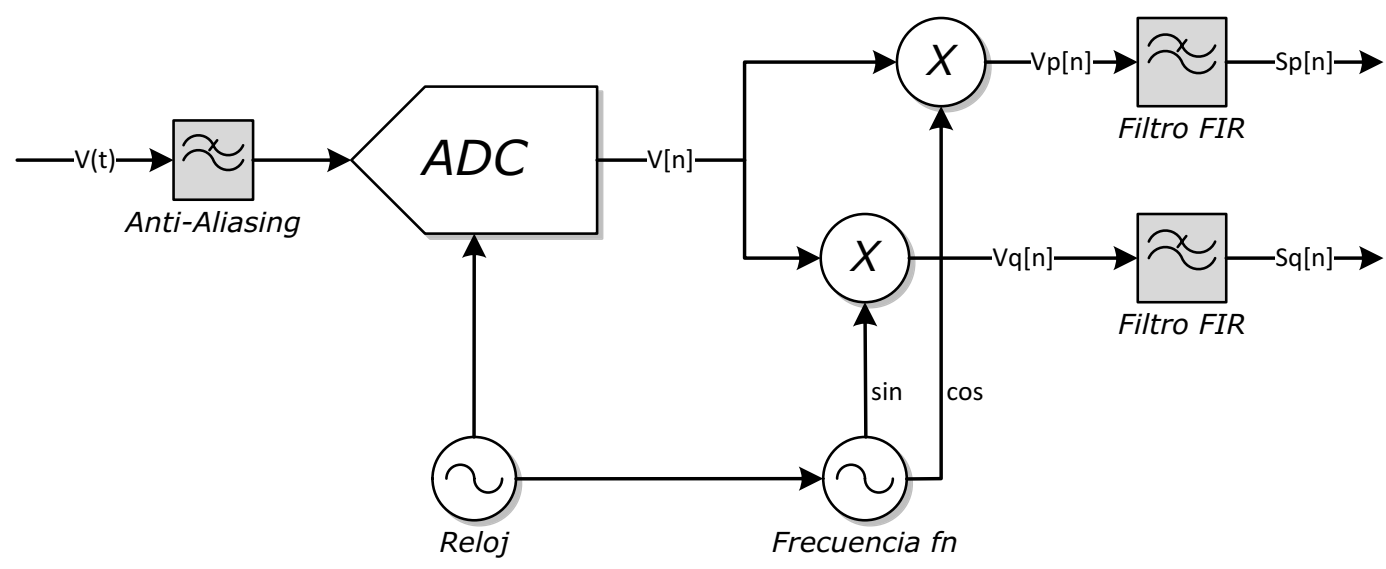

Figura 122. Diagrama en bloques - Algoritmo basado en filtrado.

Tal como se describe en [9], el filtro funciona correctamente para la estimación de frecuencia y fase, teniendo o no dichas magnitudes sus valores nominales. Sin embargo, la estimación de amplitud del sincrofasor debe ser compensada cuando el valor de frecuencia no es su valor nominal, debido a la respuesta propia del filtro. La norma, en consecuencia, define la Ec. 9.14 para realizar la estimación de amplitud, donde G es la suma de los coeficientes del filtro.

$$
A=\frac{\sqrt{2}}{G} \sqrt{s_{p}^{2}+s_{q}^{2}} \frac{2 f_{n}}{\operatorname{sen}\left(\pi\left(f_{n}+1.625 \Delta f\right)\right)}
$$

La estimación de fase puede obtenerse mediante la Ec. 9.15.

$$
\varphi=\mathrm{s}_{\mathrm{p}}+\mathrm{j} \mathrm{s}_{\mathrm{q}}
$$

Finalmente, para la estimación de frecuencia, se utiliza la estimación de secuencia directa del sistema trifásico. Siendo D la componente de secuencia directa, la desviación de frecuencia puede ser estimada según la Ec. 9.10.

\subsubsection{Simulación de Métodos de Estimación}

Para llevar a cabo una evaluación de las técnicas de medición, es importante considerar que existen múltiples factores de diferente naturaleza que pueden afectar los resultados obtenidos. Dichos factores pueden tener su origen en cuestiones propias de las técnicas evaluadas y en cuestiones ajenas a las mismas. Por ejemplo, la precisión de la frecuencia de la señal de muestreo corresponde a un factor que puede afectar la evaluación de las técnicas pero que no es una cuestión inherente a ellas.

En este contexto, y para poder analizar las técnicas propuestas sin verse afectada dicha evaluación por la influencia de errores debido a factores externos, se llevó a cabo la implementación de los métodos de medición propuestos en un sistema de simulación apropiado, que permitiera a su vez realizar un conjunto de pruebas para caracterizar las técnicas. 
Los algoritmos fueron desarrollados en el entorno de simulación Simulink, implementando tanto la etapa de procesamiento propiamente dicha como la etapa de adquisición, considerando el muestreo, la conversión analógico-digital y la cuantización

Para el Algoritmo basado en FFT, la frecuencia de muestreo fue configurada en $12800 \mathrm{~Hz}$, obteniéndose 256 muestras por ciclo de frecuencia nominal $50 \mathrm{~Hz}$. La FFT fue procesada sobre una ventana temporal de 2 ciclos, resultando una transformada de 512 muestras. La elección de la frecuencia de muestreo y el ancho de la ventana temporal responde a la búsqueda de obtener una buena resolución en frecuencia sin incrementar en forma desmedida el volumen de datos procesados.

Para el Algoritmo de filtrado, se utilizó una frecuencia de muestreo de $800 \mathrm{~Hz}$, obteniéndose 16 muestras por ciclo de frecuencia nominal $50 \mathrm{~Hz}$. La frecuencia de muestreo fue seleccionada en base a recomendaciones que se mencionan en la norma de medición sincrofasorial [9].

El conversor analógico-digital (ADC, por sus siglas en inglés) fue simulado con una resolución de 12 bits, correspondiente a la resolución disponible en los conversores integrados en la Unidad de Procesamiento.

La norma IEEE 60255-118-1-2018 [9] define diferentes ensayos que deben realizarse a las PMUs con el objetivo de validar su precisión. Dichos ensayos establecen límites al Error Vectorial Total, que no deben ser superados para que el equipamiento sea compatible con la normativa. Las pruebas evalúan a las PMUs cuando deben medir señales bajo la influencia de condiciones de estado estacionario, condiciones dinámicas, y otros tipos de situaciones.

Por lo tanto, las técnicas implementadas en el entorno de simulación fueron sometidas a las pruebas establecidas en la norma, para lo que dichos ensayos también fueron implementados en el mismo entorno. En todos los casos, el Error Vectorial Total, definido en la Ec. 3.10, fue utilizado para analizar y realizar comparaciones de los métodos propuestos. Las pruebas sobre las simulaciones se realizaron durante períodos de 4 segundos, obteniendo 200 estimaciones de sincrofasores.

\section{Condiciones de estado estacionario}

Mediante estas pruebas, se evaluaron las técnicas de estimación cuando las tensiones cuentan con amplitud nominal y frecuencia en un rango de $\pm 2 \mathrm{~Hz}$ alrededor de su valor nominal. A su vez, se analizaron las técnicas cuando se las aplica sobre señales sometidas a la influencia de armónicas simples con una amplitud del 1\% de la componente fundamental de la señal. En este caso, la segunda armónica fue utilizada debido a que dicha componente corresponde a la peor condición para realizar la estimación. El TVE obtenido para ambas técnicas sometidas a las pruebas descriptas puede observarse en las Figura 123, Figura 124 y Figura 125. La norma define que el TVE no debe superar el $1 \%$ en todos los casos analizados. 


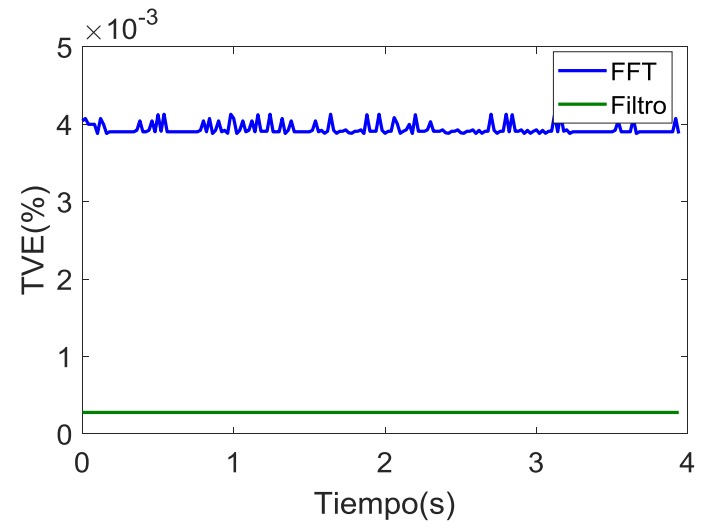

Figura 123. TVE para señal de amplitud y frecuencia nominal.

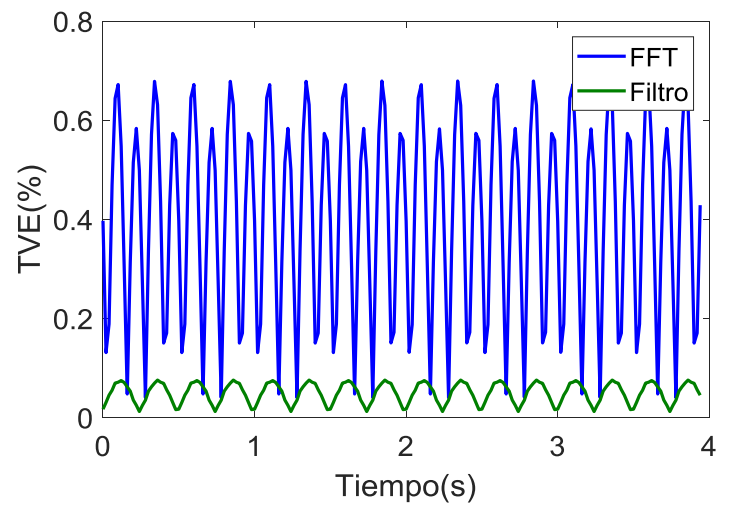

Figura 124. TVE para señal con desviación de frecuencia de $-2 \mathrm{~Hz}$

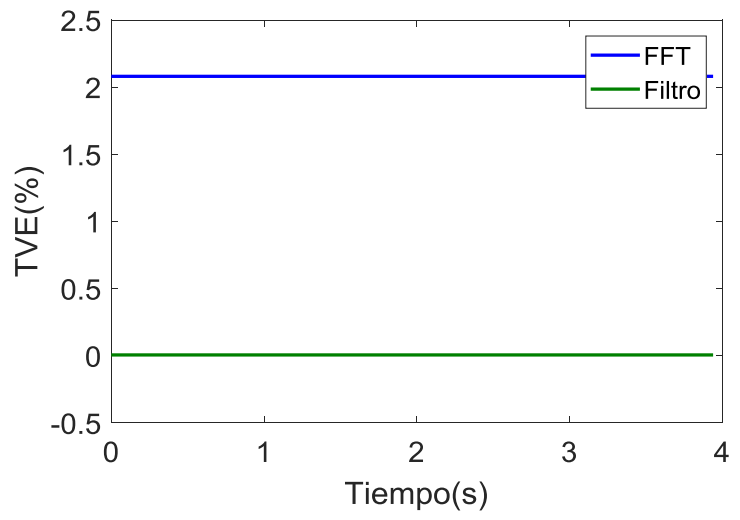

Figura 125. TVE para señal con $1 \%$ de 2 da armónica.

\section{Ancho de banda de medición: Modulación}

En este caso, las pruebas se realizaron sobre tensiones cuya amplitud y fase son moduladas por señales sinusoidales. La frecuencia de modulación fue configurada en 2 $\mathrm{Hz}$, con un índice de modulación de 0,1. Las modulaciones de amplitud y fase fueron evaluadas en forma separada, según se establece en [9]. El TVE obtenido para ambos métodos en el caso de las evaluaciones descriptas se puede observar en las Figuras 126 y 127. En este caso, la norma establece que el TVE no debe superar el 3\%.

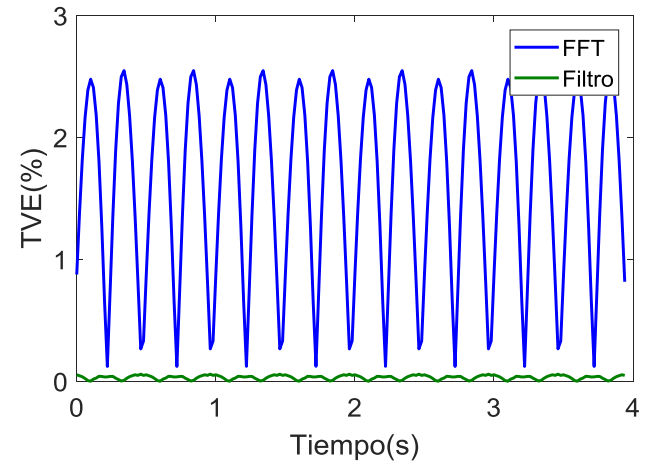

Figura 126. TVE para señal bajo modulación de amplitud.

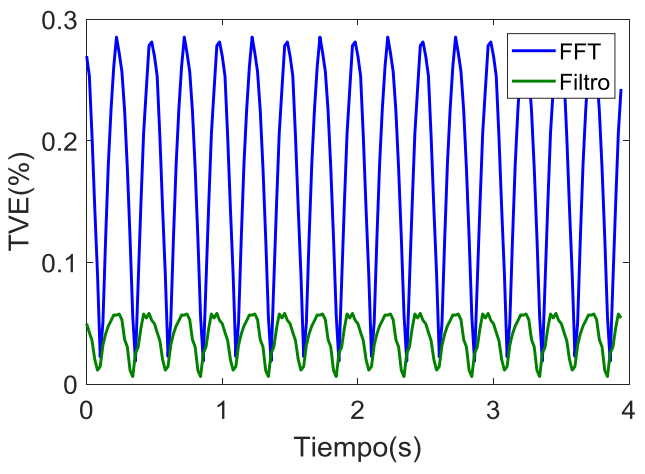

Figura 127. TVE para señal bajo modulación de fase. 


\section{Desempeño bajo rampas de frecuencia del sistema}

Las pruebas se realizaron sobre tensiones cuya frecuencia es afectada por una rampa de $\pm 1 \mathrm{~Hz} / \mathrm{s}$. La variación de frecuencia fue aplicada sobre todo el sistema trifásico y el rango de variación fue $\pm 2 \mathrm{~Hz}$. El TVE registrado se observa en la Figura 128. La norma establece que el TVE no debe superar el 1\% en este caso.

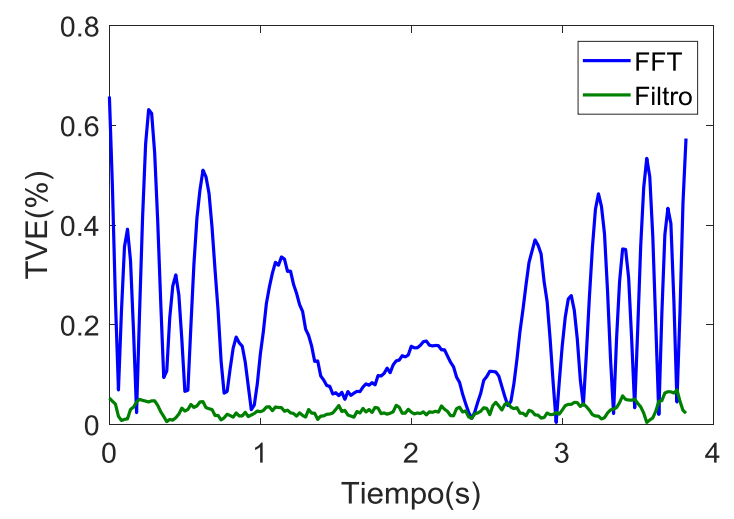

Figura 128. TVE para señal bajo rampa de frecuencia de $+1 \mathrm{~Hz} / \mathrm{s}$.

En la Tabla XI se presenta una síntesis de los resultados, considerando el máximo TVE obtenido en cada caso

Tabla XI. Resultados de simulación.

\begin{tabular}{|c|c|c|c|}
\hline \multicolumn{2}{|r|}{ Prueba } & \multicolumn{2}{|c|}{ Error Vectorial Total (\%) } \\
\hline Tipo & Características & FFT & Filtro \\
\hline \multirow{3}{*}{ A } & Condiciones Nominales & 0,004 & 0,0002 \\
\hline & Desviación de frecuencia $-2 \mathrm{~Hz}$ & 0,68 & 0,08 \\
\hline & Interferencia de $2^{\mathrm{da}}$ armónica & 2 & 0,006 \\
\hline \multirow{2}{*}{ B } & Modulación de amplitud & 2,55 & 0,06 \\
\hline & Modulación de fase & 0,29 & 0,06 \\
\hline $\mathrm{C}$ & Rampa de frecuencia $+1 \mathrm{~Hz} / \mathrm{s}$ & 0,65 & 0,07 \\
\hline
\end{tabular}

Analizando los resultados, pudo concluirse que las estimaciones obtenidas con el Algoritmo de filtrado son compatibles con el TVE máximo permitido para cada caso analizado. En el caso del Algoritmo basado en FFT, el TVE obtenido resultó compatible con la norma en la mayoría de los casos, excepto en el caso de la interferencia de la 2 da armónica.

\subsubsection{Evaluación en hardware de los Métodos de Estimación}

Bajo las consideraciones realizadas por los métodos propuestos, y con el objetivo de lograr resultados reales de estimación, las técnicas fueron implementadas en hardware 
real con características equivalentes al hardware de la PMU para realizar el muestro y procesamiento de las señales de manera tal de obtener los correspondientes sincrofasores.

El diseño del hardware de prueba se basó, al igual que la PMU, en tres conversores analógico-digitales independientes integrados en el microcontrolador STM32F407VG (ver descripción en la sección 9.5). Las conversiones son disparadas mediante una señal de reloj externo con la frecuencia correspondiente de manera tal que el microcontrolador muestrea y convierte simultáneamente [64] las tres señales del sistema trifásico, almacenando las muestras en un espacio de memoria destinado para cada fase. Una vez obtenidas la cantidad de muestras requeridas (256 para el Algoritmo basado en FFT y 16 para el basado en el filtrado), el microcontrolador calcula la FFT de ancho de ventana 2 ciclos o la salida del filtrado para ese conjunto de muestras.

En el caso del Algoritmo basado en FFT, el microcontrolador aplica la ventana de Hanning al conjunto de muestras y calcula la FFT. Finalmente, transmite el segundo, tercero y cuarto bin de la FFT (correspondientes a $25 \mathrm{~Hz}, 50 \mathrm{~Hz}$ y $75 \mathrm{~Hz}$ respectivamente) con sus partes real e imaginaria a una Raspberry PI mediante el Protocolo de circuitos inter-integrados (I2C) [7].

En el caso del Algoritmo basado en filtrado, el microcontrolador realiza la conversión de frecuencia de las muestras de señal, utilizando el oscilador interno correspondiente, y procesa la salida del filtrado tanto para la componente en fase como para la componente en cuadratura de cada señal.

Finalmente, los resultados obtenidos son transmitidos mediante una comunicación serial sincrónica a la computadora embebida Raspberry Pi (ver descripción en la sección 9.6). La Raspberry Pi finaliza el procesamiento calculando todos los parámetros y estimaciones descriptas en la sección 9.2.1 y 9.2.2. Utilizando la interfaz Ethernet integrada, la computadora embebida transmite los paquetes de datos con los resultados obtenidos.

El filtro anti-aliasing fue implementado con amplificadores operaciones bajo la configuración de filtros pasa bajos con una frecuencia de corte de $160 \mathrm{~Hz}$.

En la Figura 129 puede observarse un diagrama esquemático del sistema donde se muestran las etapas de procesamiento y las tareas realizadas por cada componente del hardware. 


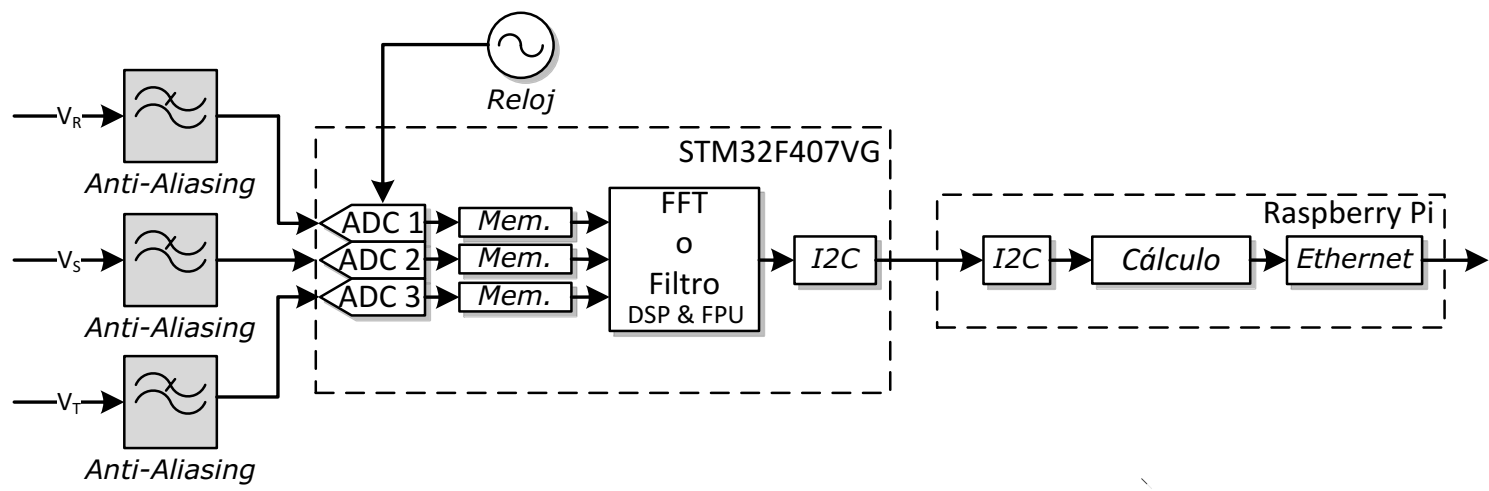

Figura 129. Esquema del hardware de procesamiento.

En la Figura 130 se observa la placa del microcontrolador STM32F407VG y la Raspberry PI con las conexiones correspondientes.

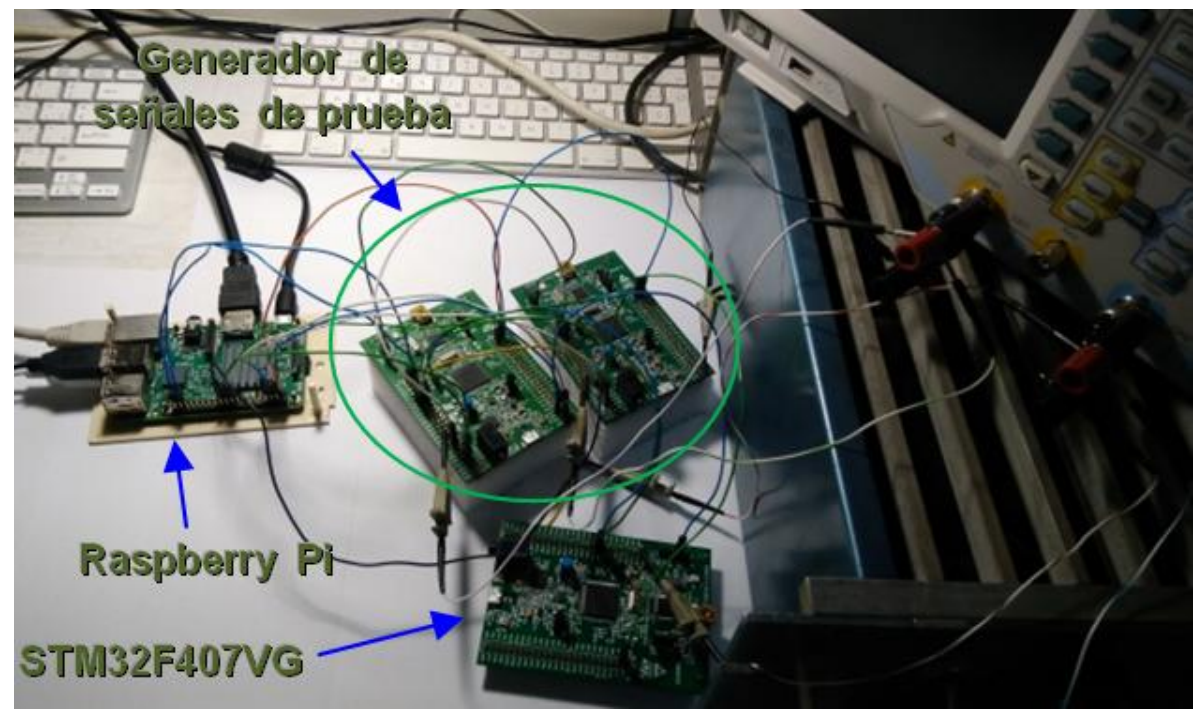

Figura 130. Implementación en hardware.

El hardware fue analizado con las mismas pruebas que se realizaron sobre la simulación en el entorno Simulink. Para generar las correspondientes señales de cada ensayo, se utilizaron los conversores digital-analógico (DAC) de dos microcontroladores STM32F407VG sincronizados. Con una señal de reloj externa de frecuencia $25600 \mathrm{~Hz}$, los microcontroladores generan las formas de onda del sistema trifásico almacenadas en un espacio de memoria de los dispositivos digitales.

En las Figuras 131 a 135 se observan los TVE obtenidos de las mismas pruebas descriptas en la Sección 3. En todos los casos, excepto la rampa de frecuencia, los ensayos se realizaron durante períodos de 4 segundos obteniéndose 200 estimaciones de sincrofasores. En el caso del ensayo con rampas de frecuencia, éste se realizo durante 2 segundos para generar una rampa de $-1 \mathrm{~Hz} / \mathrm{s}$ desde $50 \mathrm{~Hz}$ hasta $48 \mathrm{~Hz}$. 


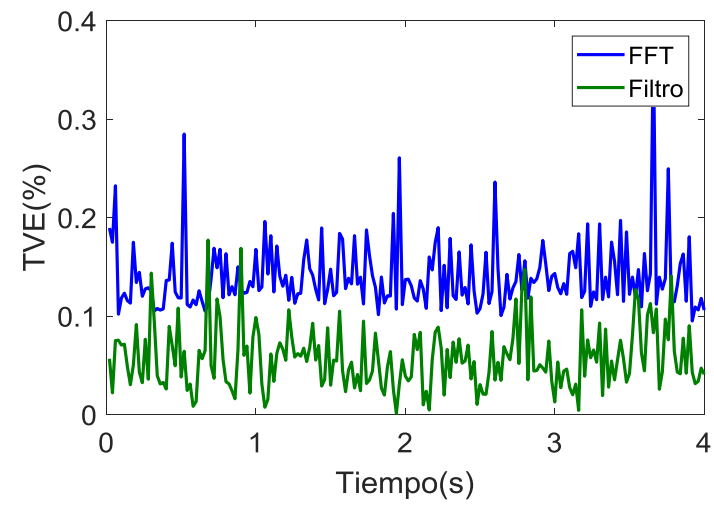

Figura 131. TVE para señal de amplitud y frecuencia nominal.

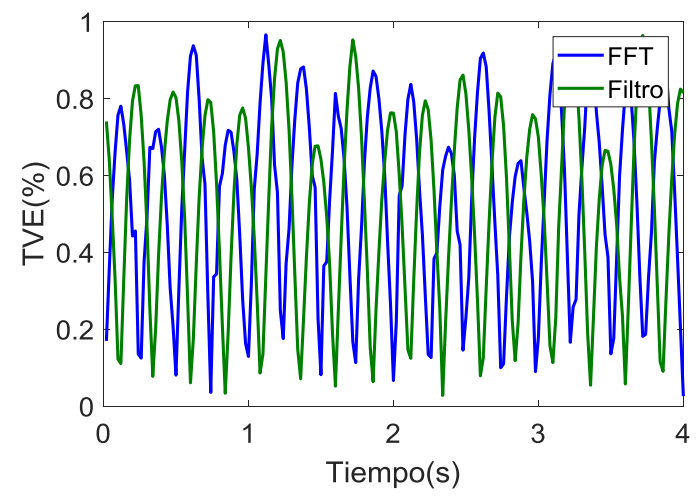

Figura 133. TVE para señal de amplitud y frecuencia nominal.

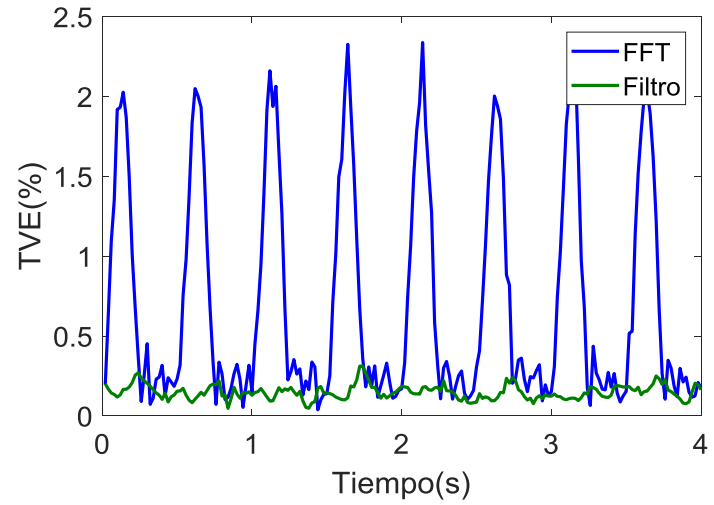

Figura 132. TVE para señal con desviación de frecuencia con $-2 \mathrm{~Hz}$.

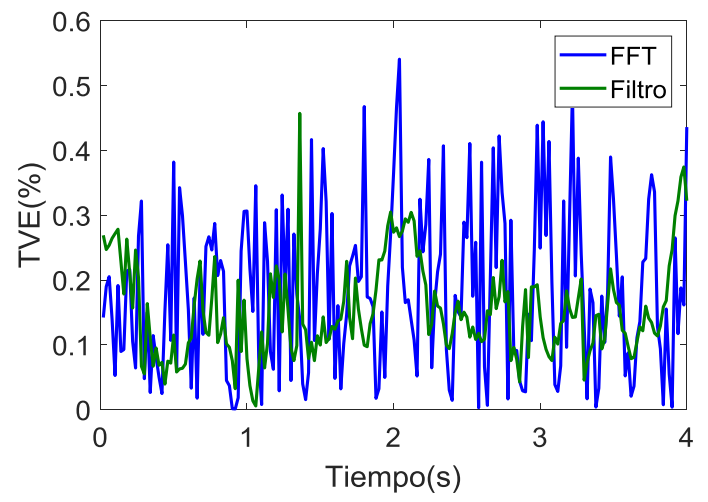

Figura 134. TVE para señal con desviación de frecuencia con $-2 \mathrm{~Hz}$.

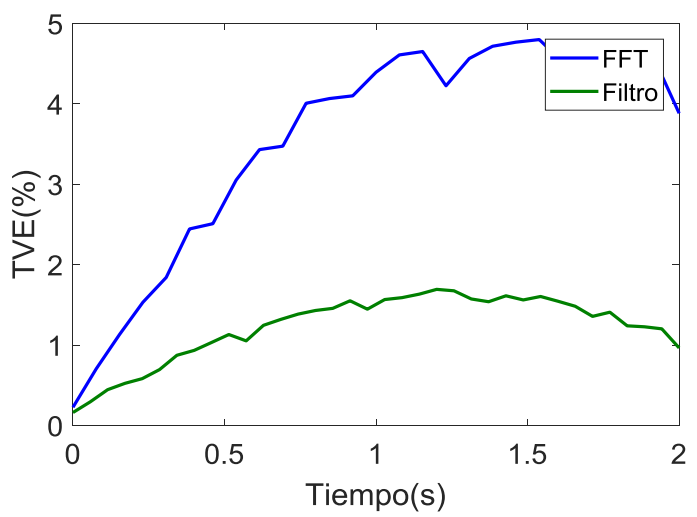

Figura 135. TVE para señal bajo rampa de frecuencia de $+1 \mathrm{~Hz} / \mathrm{s}$.

Los mismos ensayos fueron realizados por períodos de 10 segundos, registrando los TVE. En la Tabla XII se muestra una síntesis de los resultados obtenidos, considerando el máximo TVE registrado en cada caso. Del análisis de los resultados se pudo concluir que el Algoritmo basado en filtrado es compatible con los valores máximos previstos por la norma en la mayor parte de los casos, al igual que en el caso del Algoritmo basado en FFT. Sin embargo, se registran valores no compatibles para este último caso en las pruebas con frecuencias fuera de su valor nominal. 
Tabla XII. Resultados en hardware real.

\begin{tabular}{|c|c|c|c|}
\hline \multicolumn{2}{|c|}{ Prueba } & \multicolumn{2}{c|}{ Error Vectorial Total (\%) } \\
\hline \multirow{2}{*}{ Tipo } & Características & FFT & Filtro \\
\hline \multirow{2}{*}{ A } & Condiciones Nominales & 0,37 & 0,22 \\
\cline { 2 - 4 } & Desviación de frecuencia $-2 \mathrm{~Hz}$ & 2,34 & 0,35 \\
\cline { 2 - 4 } & Interferencia de $2^{\mathrm{da}}$ armónica & 0,57 & 0,36 \\
\hline \multirow{2}{*}{ B } & Modulación de amplitud & 0,98 & 0,96 \\
\cline { 2 - 4 } & Modulación de fase & 0,65 & 0,45 \\
\hline \multirow{2}{*}{ C } & Rampa de frecuencia $+1 \mathrm{~Hz} / \mathrm{s}$ & 4,80 & 1,69 \\
\hline
\end{tabular}

En los ensayos para frecuencias fuera de su valor nominal, el error mayor al permitido pudo deberse a la no obtención de un número entero de ciclos de señal dentro de la ventana temporal de procesamiento. Este efecto puede generar una fuga espectral que no alcanza a ser reducida por la ventana de Hanning. Sin embargo, teniendo en cuenta que dicho efecto no es detectado en las simulaciones, la más importante fuente de error puede corresponder a la fluctuación de la frecuencia de muestreo existente en el hardware real utilizado.

El tercer factor de error corresponde al método de generación de las señales de prueba, cuya frecuencia de muestreo es el doble de la frecuencia de muestreo del sistema de procesamiento. Si se produce una fluctuación en la frecuencia de muestreo de generación, la señal generada no estará en estado estacionario con la frecuencia deseada de manera tal que el algoritmo no arrojará los resultados esperados. Este efecto también permite explicar el TVE fuera de los límites previstos que se observa en el ensayo de rampa de frecuencia realizado sobre ambos métodos de procesamiento.

Como puede observarse, un error en la frecuencia de muestreo puede provocar grandes errores en los algoritmos de procesamiento, siendo el Algoritmo basado en FFT mucho más sensible a dichos efectos. La mayor sensibilidad de este método puede ser explicada en base a la alta frecuencia de muestreo que requiere, aumentando entonces la sensibilidad a fluctuaciones de dicha frecuencia.

Por lo tanto, si bien ambos métodos de estimación bajo estudio mostraron resultados similares en su implementación en hardware real en la mayoría de los casos, una comparación rigurosa entre ambas técnicas puso en evidencia una mayor sensibilidad a factores externos de error tales como ruido, redondeo de la unidad embebida de punto flotante e interferencia de armónicas, en el algoritmo basado en FFT con respecto al basado en filtrado. Éste análisis permitió seleccionar al algoritmo basado en filtrado como el que se utilizaría en la implementación de la PMU. 


\subsection{Canales de medición}

Para realizar la medición de las tensiones y corrientes correspondientes, la PMU cuenta con 6 canales de medición, 3 para la medición de tensión y 3 para la medición de corriente. Dichos canales cuentan con un diseño basado en la búsqueda de la aislación de las señales medidas respecto al equipamiento de medición y procesamiento.

En las Figuras 136 y 137 pueden observarse los diagramas en bloques de los canales de medición de tensión y corriente respectivamente.

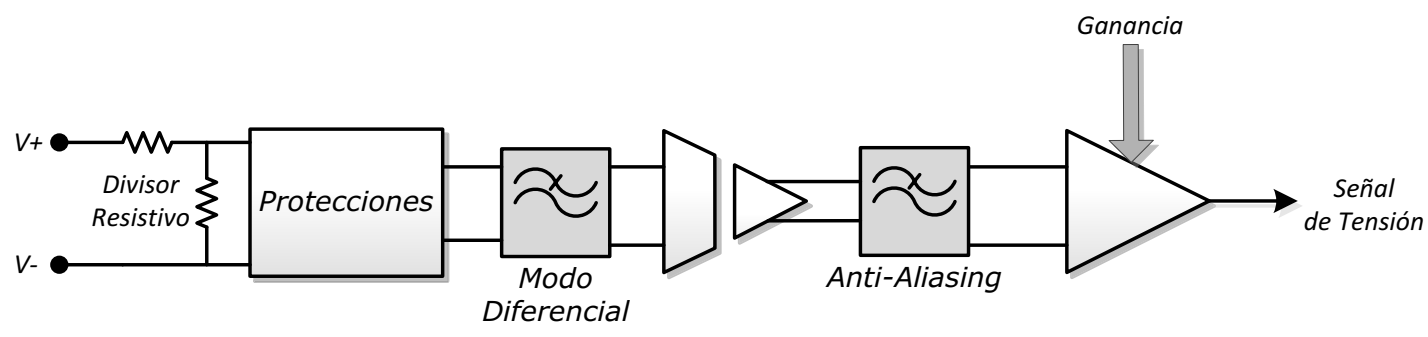

Figura 136. Diagrama en Bloques - Canal de medición de Tensión.

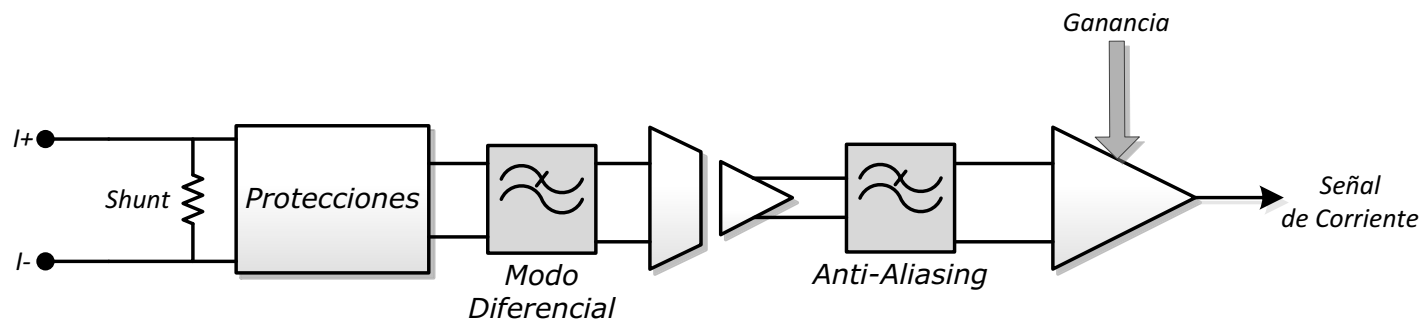

Figura 137. Diagrama en Bloques - Canal de Medición de Corriente.

Tal como muestra la Figura 136, la medición de tensión se basa en la utilización de un divisor resistivo que permita obtener los niveles de señal requeridos a partir de los niveles de señal típicos existentes a la salida de un transformador de tensión de una subestación eléctrica. Dicho divisor de tensión es construido con resistencias de precisión para reducir los errores de medición.

En el caso de la Figura 137, la medición de corriente se basa en la utilización de una resistencia de muy bajo valor de tipo shunt para la obtención de una tensión proporcional a la corriente medida. Dicha resistencia es de un valor lo suficientemente pequeño para no afectar el resto de las cargas que pudieran estar conectadas en cascada a la salida de un transformador de corriente de una subestación eléctrica.

La tensión obtenida mediante el divisor de tensión o la resistencia shunt es amplificada mediante un circuito integrado amplificador galvánicamente aislado, de manera tal que a la salida de dicho dispositivo se obtiene la señal requerida sin tener una vinculación galvánica con la conexión a la subestación ni una referencia de tensión común. A su vez, los canales cuentan con filtrado para el ruido de modo diferencial que pudiera acoplarse a la señal medida, de manera que junto al rechazo de modo común del 
propio amplificador (mayor a $80 \mathrm{~dB}$ ) conforman una etapa de filtrado para el posterior procesamiento.

A partir de lo descripto anteriormente, los canales diseñados permiten la conexión de las tensiones o corrientes obtenidas de los transformadores correspondientes a la PMU de manera "flotante". Por lo tanto, la PMU no impone a la subestación ningún nivel de referencia para las salidas de los transformadores de tensiones o corrientes, así como tampoco genera una vinculación entre ellos.

A su vez, la utilización del amplificador mencionado anteriormente le brinda a la PMU una aislación galvánica de $3,75 \mathrm{kV}$ respecto a la instalación de la subestación, dotando entonces a la unidad de medición de una protección respecto a fenómenos que pudieran producirse en el sistema eléctrico medido.

A la salida del amplificador-aislador, los canales cuentan con un filtrado anti-aliasing necesario para realizar el muestreo de la señal y un amplificador de ganancia variable digitalmente, con el corrimiento de offset requerido para la óptima utilización de los conversores analógico-digitales.

Dado que en las instalaciones de las subestaciones eléctricas pueden encontrarse transformadores de tensión con salidas de diferentes niveles $(110 / \sqrt{3} \mathrm{~V}, 110 \mathrm{~V}, 220 \mathrm{~V}$, entre otros) y transformadores de corriente con salidas de diferentes niveles (1 A, $2 \mathrm{~A}$, $5 \mathrm{~A}$, entre otros), el amplificador de ganancia variable permite ajustar la ganancia (x1 ó $\mathrm{x} 2$ en tensión y x1 ó x4 en corriente) de manera tal de obtener un nivel de señal que utilice el mayor rango posible de los conversores analógico-digitales.

Los canales de tensión son capaces de medir señales de hasta $400 \mathrm{~V}$ pico mientras que los canales de corriente son capaces de medir hasta $10 \mathrm{~A}$ pico.

De esta manera, los canales de tensión pueden medir salidas de $220 \mathrm{~V}$ con una ganancia $\mathrm{x} 1$ y señales de $110 \mathrm{~V}$ ó $110 / \sqrt{ } 3 \mathrm{~V}$ con una ganancia $\mathrm{x} 2$. Por otro lado, los canales de corriente pueden medir salidas de 5 A con una ganancia x 1 y salidas de 1 ó 2 A con ganancia $x 4$.

En las Figuras 138 y 139 pueden observarse imágenes de los canales de tensión y corriente respectivamente, con sus correspondientes circuitos esquemáticos. 


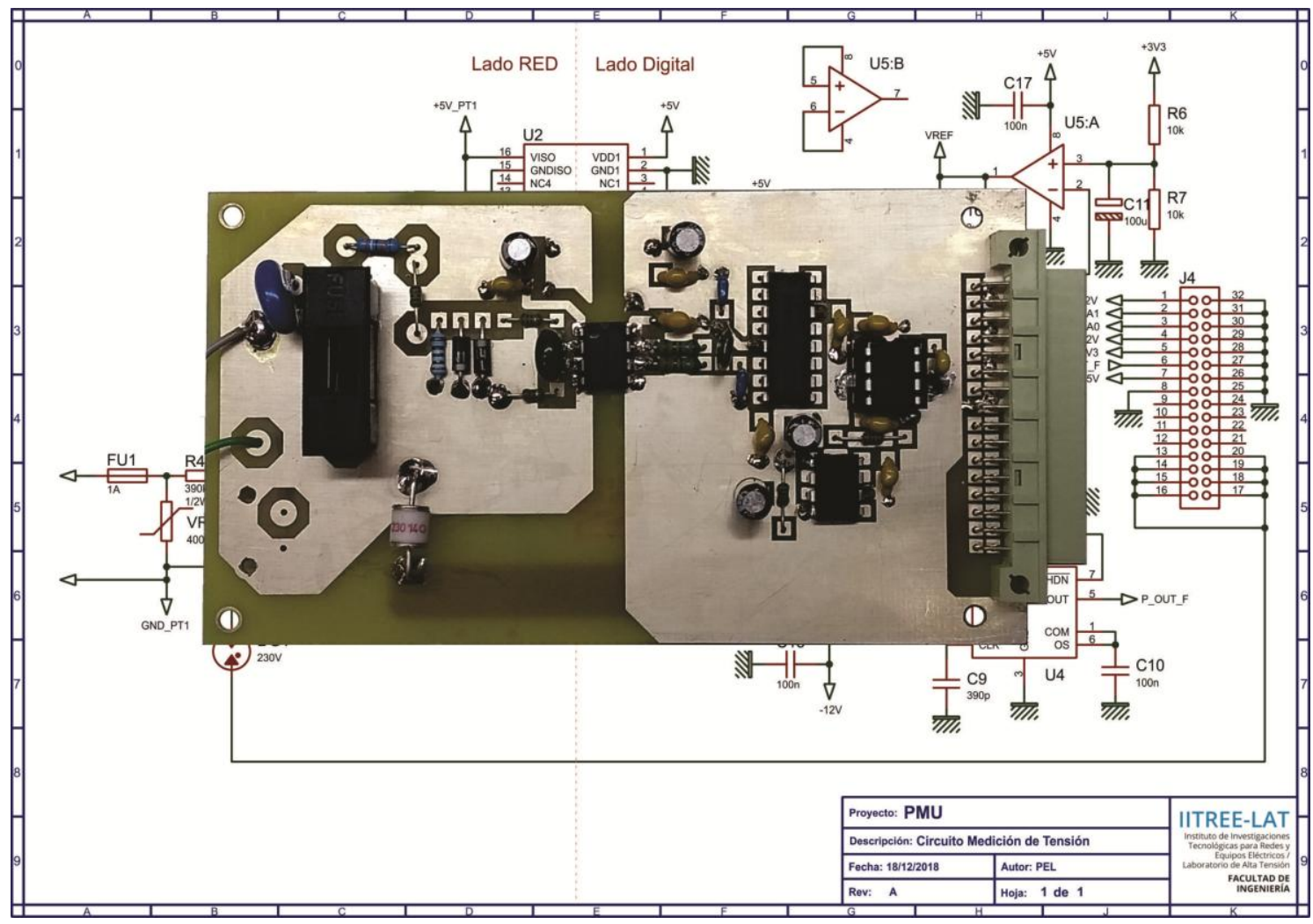

Figura 138. Placa y Circuito de medición de tensión.

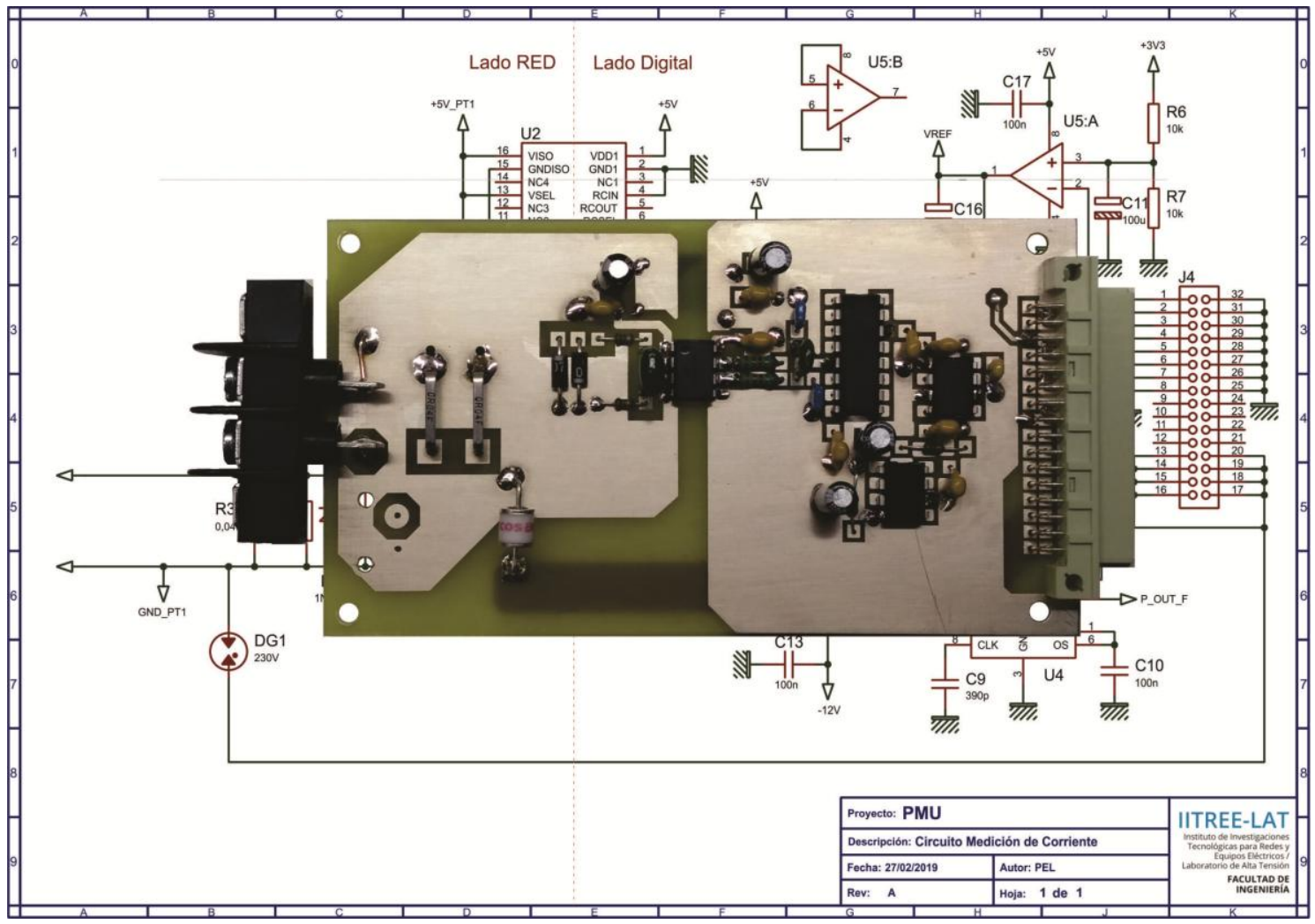

Figura 139. Placa y Circuito de medición de corriente. 


\subsection{Receptor GPS}

Para obtener las señales de temporización requeridas, la Unidad de Medición Sincrofasorial cuenta con un receptor GPS integrado que brinda toda la información temporal necesaria.

El receptor incluido es un receptor comercial de la firma U-BLOX, diseñado específicamente para aplicaciones donde se requiere señales de referencia temporal precisas. El receptor se provee encapsulado como un circuito integrado comercial, brindando de esa manera grandes ventajas para su montaje e integración con el resto del sistema.

El receptor es compatible con los sistemas de posicionamiento GPS, BeiDou, GLONASS y Galileo, siendo capaz de utilizar 3 sistemas en simultáneo. A su vez, cuenta con diversos modos de funcionamiento para reducir el consumo de potencia

La principal ventaja del receptor utilizado es la disponibilidad de dos señales de temporización independientes, estando ambas sincronizadas con el Tiempo Universal Coordinado (UTC). Una de ellas consiste en una señal que cuenta con un pulso por segundo, sincronizado el flanco creciente del pulso con el instante inicial del segundo correspondiente. Esta es la señal comúnmente llamada 1PPS (1 pulse per second, por sus siglas en inglés).

La señal restante puede ser configurada de manera tal de obtener la frecuencia deseada, con flancos sincronizados con el tiempo UTC. Dicha señal, entonces, puede ser configurada para obtener la frecuencia necesaria para realizar el muestreo de las señales con la sincronización requerida.

Para la recepción de las señales satelitales, el receptor cuenta, en forma integrada, con todo el control de alimentación y amplificación requerido para utilizar tanto antenas pasivas como activas.

El circuito integrado de la firma U-BLOX cuenta con diferentes interfaces de comunicaciones digitales que permiten realizar la configuración del receptor y la obtención de la información de posicionamiento y temporización. La PMU utiliza la interfaz de comunicaciones serial asincrónica (UART, por sus siglas en inglés) del receptor para realizar la transferencia de datos y configuración requerida.

Por otra parte, todas las señales (tanto de comunicaciones como de temporización) provenientes del receptor son acopladas mediante circuitos integrados aisladores digitales. Esta aislación permite mantener aislación galvánica entre el receptor y los demás elementos de la PMU, de manera tal de estar protegida la PMU respecto a descargas eléctricas y otras perturbaciones que pudieran ingresar a través de la antena del receptor. Es importante mencionar que los aisladores galvánicos utilizados garantizan la aislación sin reducir el ancho de banda para la transferencia de datos ni afectar a las señales de temporización. 
En la Figura 140 puede observarse una imagen del receptor GPS con su correspondiente circuito electrónico esquemático.

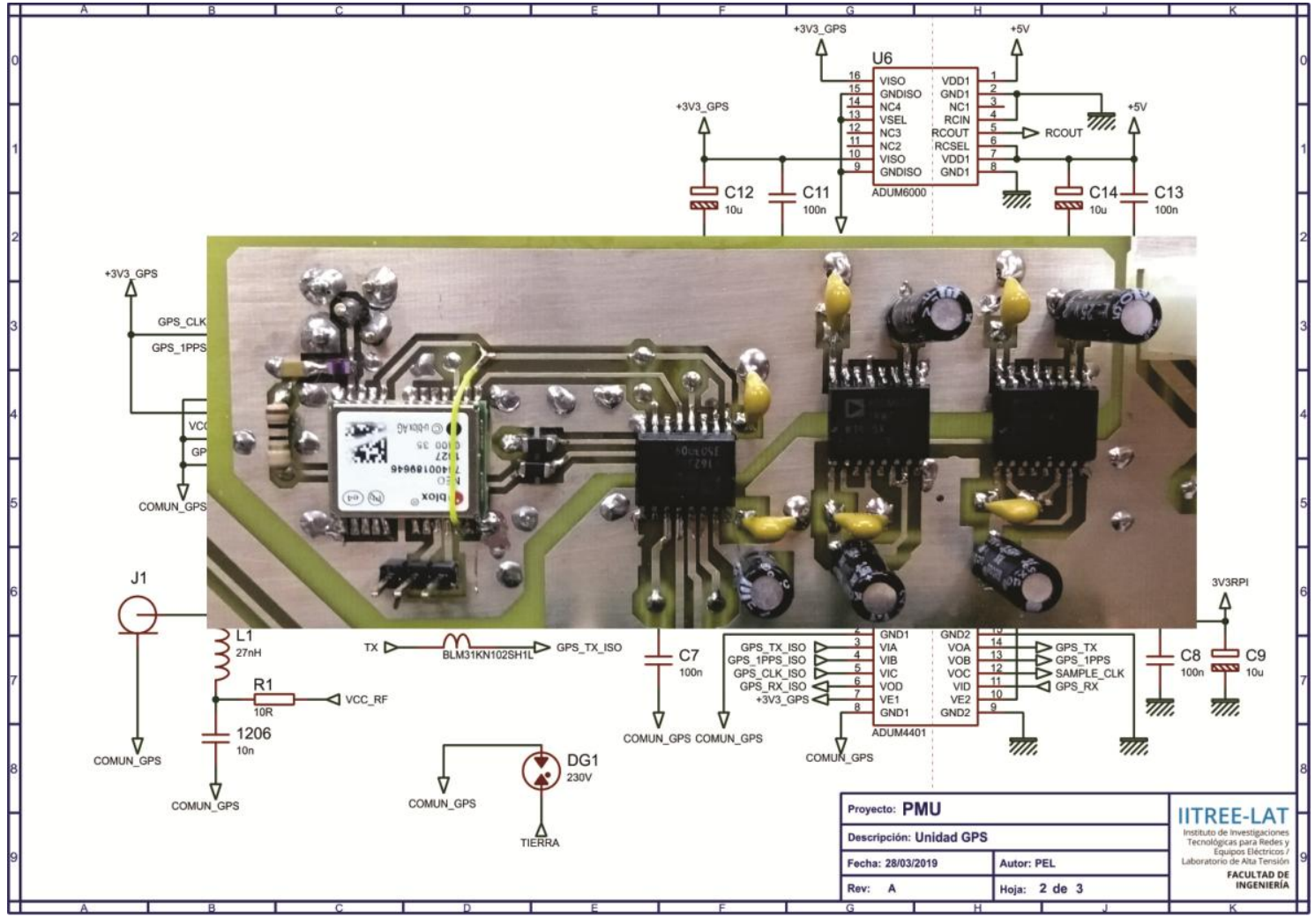

Figura 140. Placa y circuito de Receptor de GPS.

\subsection{Unidad de procesamiento}

Para llevar a cabo el muestreo y procesamiento de señal, la PMU incluye microcontroladores STM32F407VG [64]. Dichos circuitos integrados son microcontroladores de altas prestaciones del tipo $\mathrm{ARM}^{\mathrm{TM}}$ Cortex $^{\mathrm{TM}}-\mathrm{M} 4$ [65] desarrollados por la firma STMicroelectronics. Su arquitectura corresponde a un Computador con Conjunto de Instrucciones Reducidas (RISC) de 32 bits, operando a una frecuencia de $64 \mathrm{MHz}$. Cuenta con una unidad de punto flotante (FPU, por sus siglas en inglés) de simple precisión y tres conversores analógico-digitales simultáneos de aproximaciones sucesivas de 12 bits.

A partir de la disponibilidad de 3 conversores analógico-digitales por microcontrolador, la PMU incluye dos microcontroladores funcionando en paralelo destinados a procesar 3 señales cada uno provenientes de los 6 canales de tensión y corriente.

El muestreo de las señales se realiza sincronizado con la señal de frecuencia configurable proveniente del receptor GPS, la cual se programa para obtener la frecuencia de muestreo deseada.

En la Figura 141 puede observarse un diagrama en bloques de uno de los microcontroladores que conforman la unidad de procesamiento. 


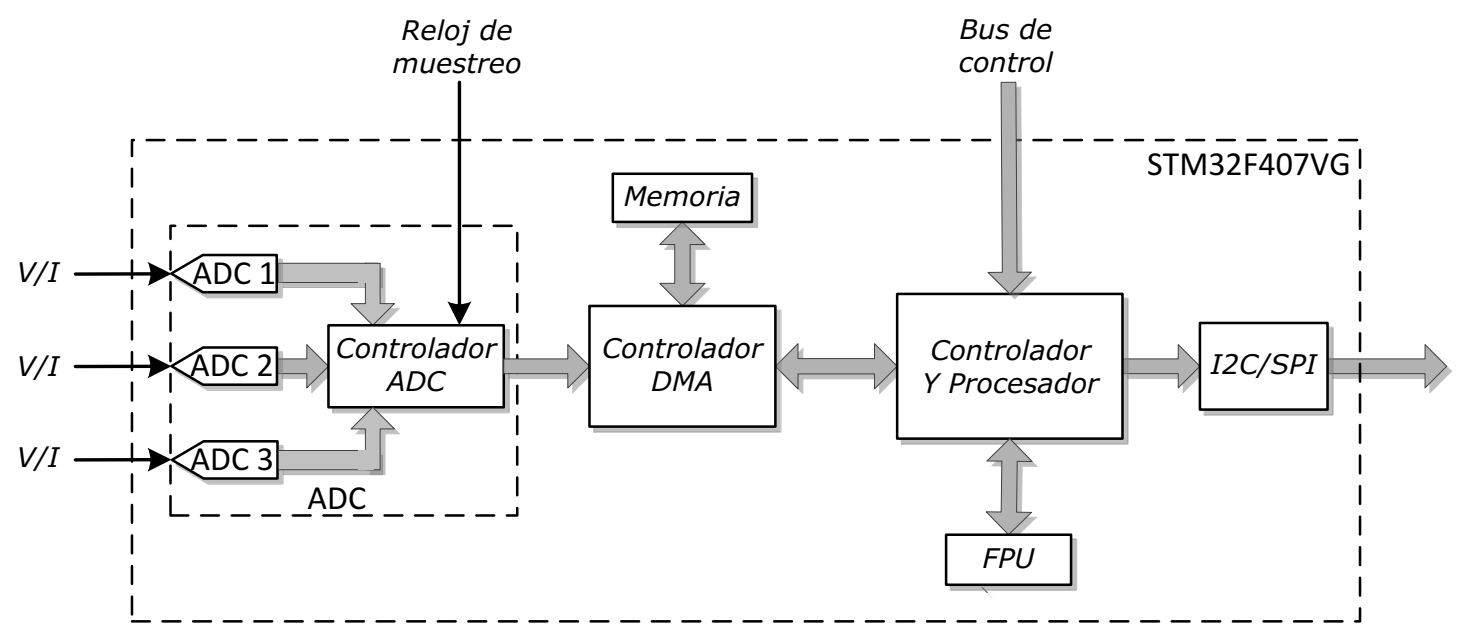

Figura 141. Diagrama en bloques - Unidad de Procesamiento.

Las señales (tensiones o corrientes) son muestreadas por los 3 conversores analógicodigitales utilizando la señal de reloj del receptor de GPS configurada con la frecuencia de muestreo correspondiente. Dichos conversores son gobernados por el controlador del ADC integrado en el microcontrolador.

Mediante el mecanismo de acceso directo a memoria (DMA), las muestras obtenidas de los 3 canales de conversión son almacenadas en la memoria RAM integrada del microcontrolador, utilizándola entonces como buffer de datos para acceder a las mediciones posteriormente.

La utilización de DMA permite al microcontrolador almacenar las muestras de señal en forma simultánea con el procesamiento y control realizado por el procesador del microcontrolador, sin ocupar tiempo de procesamiento en dicha tarea.

De la misma manera, a través de la interfaz DMA, el procesador obtiene las muestras de señal de la ventana temporal correspondiente y lleva a cabo el filtrado, según el Algoritmo de Filtrado descripto en 9.2.2, de cada una de las señales medidas. Para ello, cuenta con la Unidad de Punto Flotante (FPU, por sus siglas en inglés) integrada en el dispositivo que permite realizar todos los cálculos correspondientes de manera optimizada.

Finalmente, los resultados obtenidos son transmitidos al módulo de procesamiento y comunicaciones. Para ello, los microcontroladores utilizan los protocolos SPI o I2C con el objetivo de lograr una transmisión serial sincrónica de los datos con una alta velocidad de transferencia.

El controlador cuenta con un bus de líneas de control que permiten al módulo de comunicaciones comandar a la unidad de procesamiento y realizar diferentes acciones de control para el correcto funcionamiento de la PMU.

En la Figura 142 puede observarse una imagen de la Unidad de Procesamiento con su correspondiente circuito electrónico esquemático. 


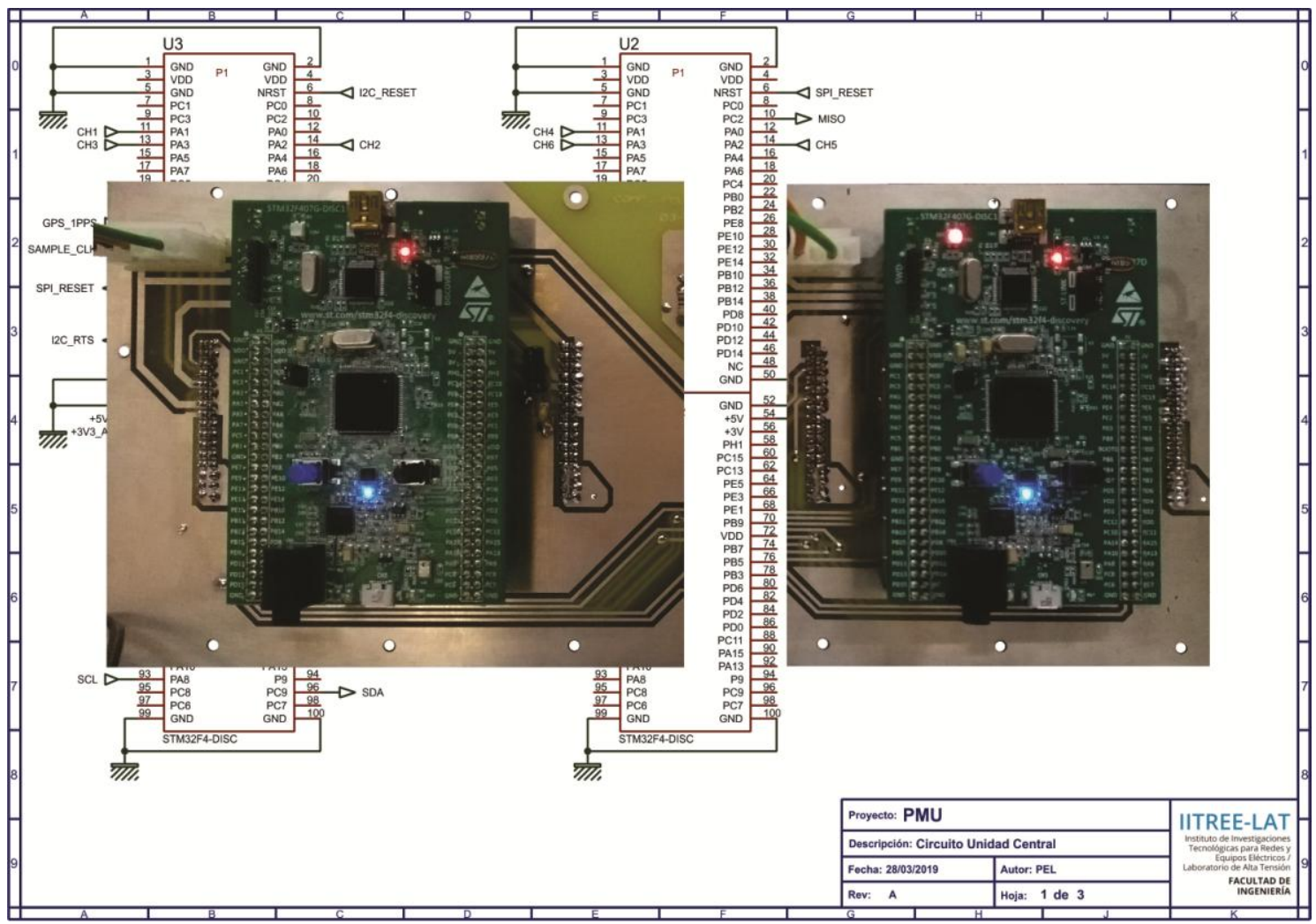

Figura 142. Placa y circuito de Unidad de Procesamiento.

\subsection{Módulo de Cálculo y Comunicaciones}

Con el objetivo de finalizar el procesamiento y llevar a cabo la transmisión de los sincrofasores, la PMU cuenta con un módulo de cálculo y comunicaciones integrado cuyo componente principal es la Raspberry Pi Modelo 3B [66].

La Raspberry Pi es una computadora embebida de bajo costo diseñada por la fundación Raspberry Pi y está basada en un microprocesador BCM2837 con arquitectura $\mathrm{ARM}^{\mathrm{TM}}$ Cortex $^{\mathrm{TM}}$-A53 funcionando a una frecuencia de 1,2 GHz [67]. La Raspberry Pi opera mediante un sistema operativo de distribución libre Linux diseñado para ser ejecutado por la computadora de manera optimizada.

En la Figura 143 puede observarse un diagrama en bloques del módulo de cálculo y comunicaciones. 


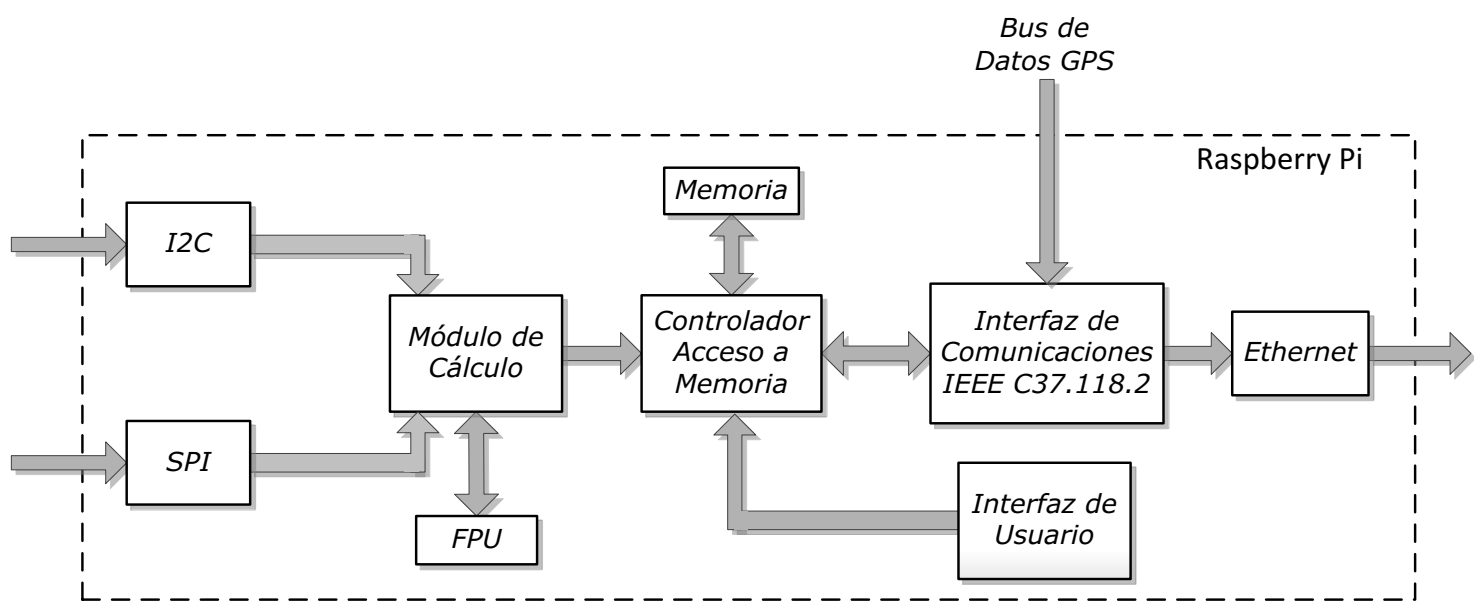

Figura 143. Diagrama en Bloques - Módulo de Cálculo y Comunicaciones.

Una vez disponibles las muestras de señal de los filtros digitales implementados en las unidades de procesamiento, las unidades transmiten las componentes en fase y cuadratura de la señal al módulo de cálculo mediante el protocolo I2C y SPI junto con un bus de señales de control para la sincronización de las unidades de procesamiento con el módulo de cálculo.

Con dichas muestras, el módulo lleva a cabo la estimación de amplitud, fase, desviación de frecuencia y ROCOF tanto para las tensiones como para las corrientes, según lo descripto en la sección 9.2.2. Dichos resultados, entonces, se encuentran disponibles para ser transmitido por la interfaz de comunicaciones.

La Raspberry Pi cuenta, entre otros periféricos, con un puerto Ethernet integrado compatible con transmisiones de 10/100 Mbit/s. La PMU basa sus transmisiones, entonces, en la disponibilidad de dicho puerto integrado para realizar todas las transferencias de datos requeridas mediante el método UDP espontáneo.

Con las mediciones disponibles, la interfaz de comunicaciones conforma el paquete de transmisión de sincrofasores tal como se establece en la norma [10] y lo transmite a todos los destinos configurados. A su vez, realiza también la transmisión periódica de su configuración según las características del paquete, también establecidas en [10].

La interfaz de comunicaciones, además, realiza la sincronización de las mediciones transmitidas con el tiempo obtenido del receptor GPS. Dado que en los paquetes de datos y configuración se incluye la etiqueta temporal con el tiempo UTC obtenido a través de dicho receptor, la interfaz obtiene del receptor la transmisión de las etiquetas temporales y realiza la sincronización necesaria para incluir la etiqueta temporal correspondiente en el paquete a transmitir.

El presente módulo es el que le brinda al usuario una interfaz para realizar toda la configuración de la PMU que se requiere. Mediante dicha configuración, el usuario establece los destinos (direcciones IP y puertos) a donde desea transmitir los sincrofasores. 
En la Figura 144 puede observarse una imagen del Módulo de Cálculo y Comunicaciones con su correspondiente circuito electrónico esquemático.

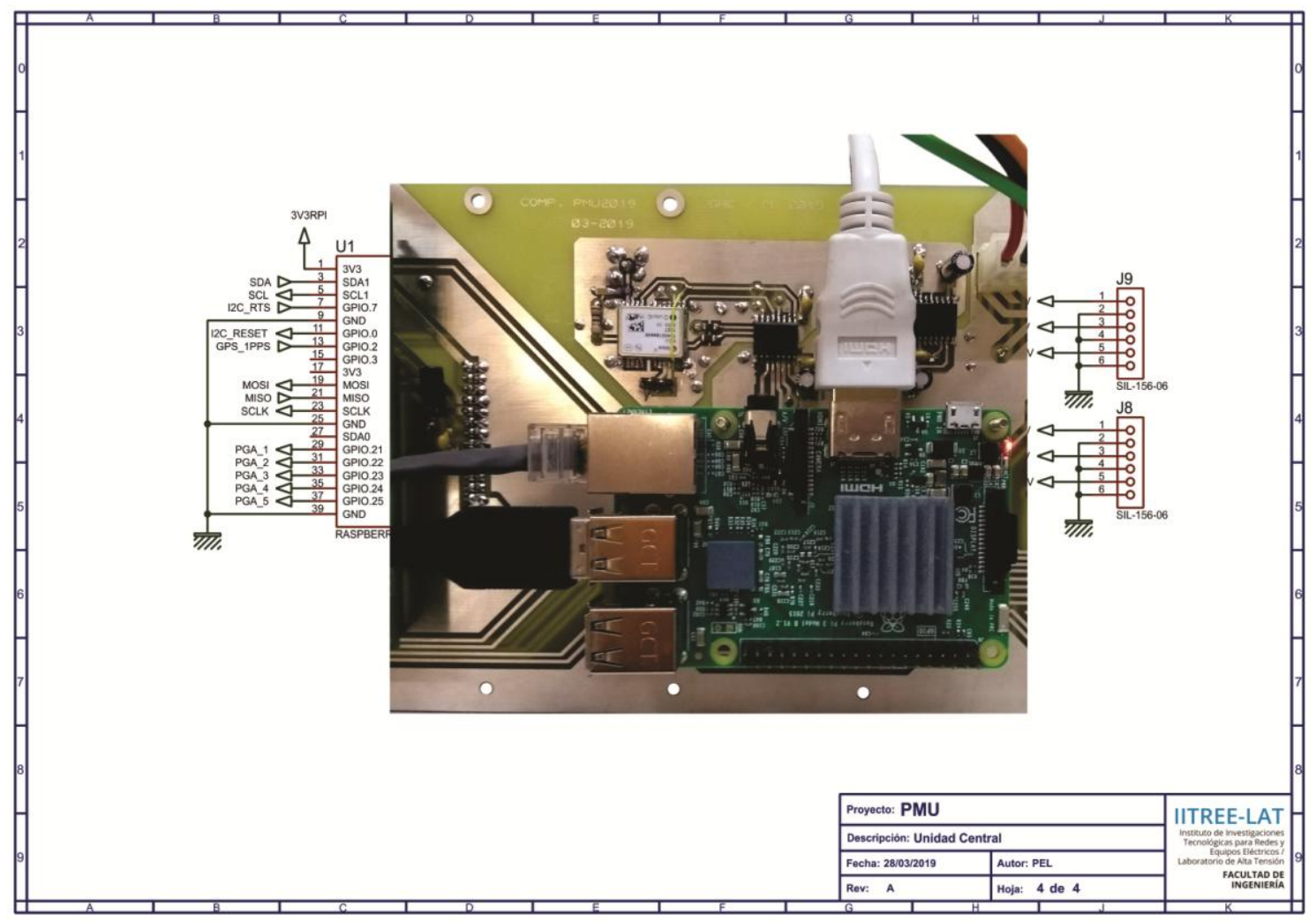

Figura 144. Placa y Circuito del Módulo de Cálculo y Comunicaciones.

\subsection{Descripción física e Interfaz de Usuario}

Considerando que la PMU es un equipamiento a ser instalado en subestaciones eléctricas de manera permanente o por períodos de tiempo de larga duración, el diseño de la PMU se realizó utilizando un gabinete que puede ser instalado en módulos racks comúnmente utilizados en este tipo de ámbitos eléctricos.

Dicho gabinete es compatible con la norma [68], de $4 \mathrm{U}$ de altura (173,6 mm), 482,6 $\mathrm{mm}$ de ancho y $265 \mathrm{~mm}$ de profundidad. La vista exterior puede observarse en la Figura 145 . 


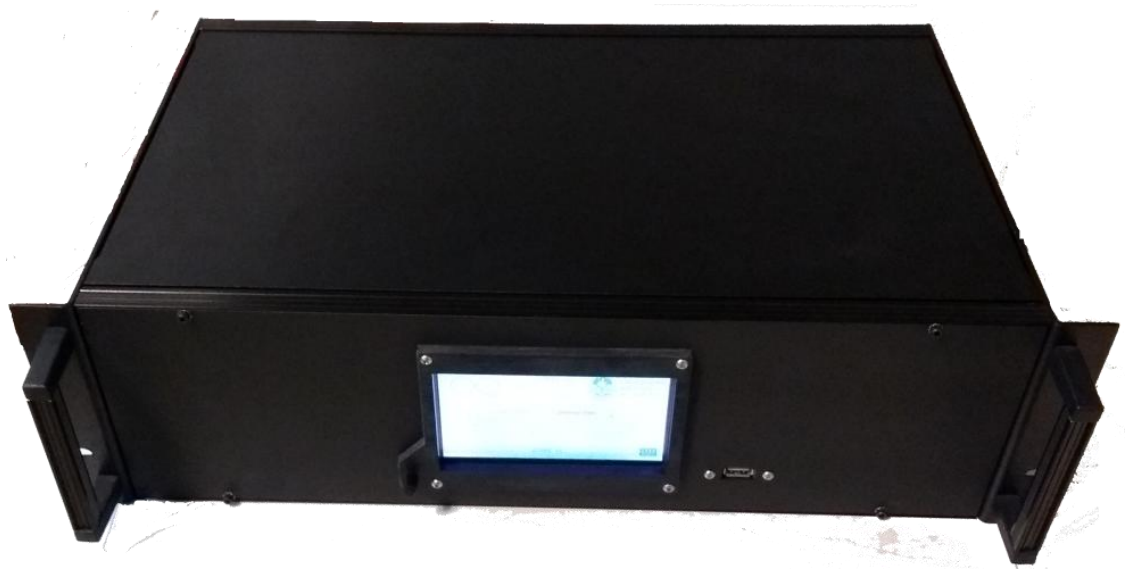

Figura 145. Vista exterior de la PMU.

En su parte posterior, la PMU cuenta con los 6 canales de medición en forma extraíble, de manera tal que el usuario pueda distribuir los canales según su conveniencia para el conexionado. Cuenta también con el conector correspondiente para realizar la conexión Ethernet, el conector correspondiente para la antena de recepción de señal GPS y la entrada de alimentación eléctrica. Las conexiones disponibles se observan en la Figura 146.

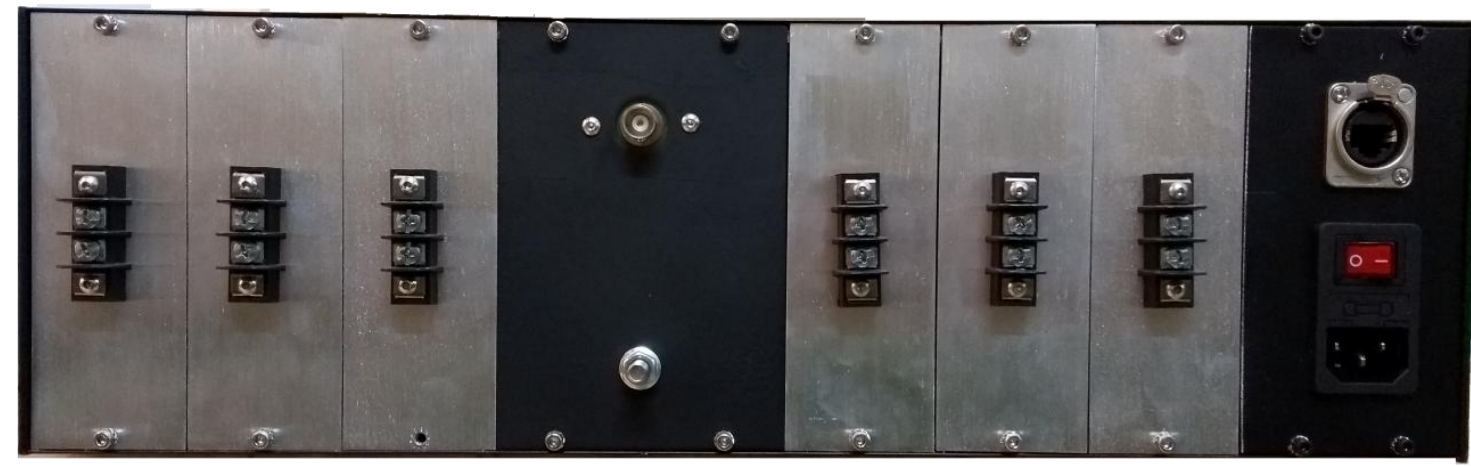

Figura 146. Panel posterior de la PMU.

La PMU incluye, para acceder a la interfaz de usuario, una pantalla táctil de 5" en su parte frontal, que cuenta con un teclado en pantalla para ingresar las configuraciones correspondientes. Dispone también de un puerto USB al que puede conectarse un mouse o teclado para facilitar el acceso a la interfaz, en el caso que el usuario lo desee. La Figura 147 muestra el panel frontal de la PMU. 


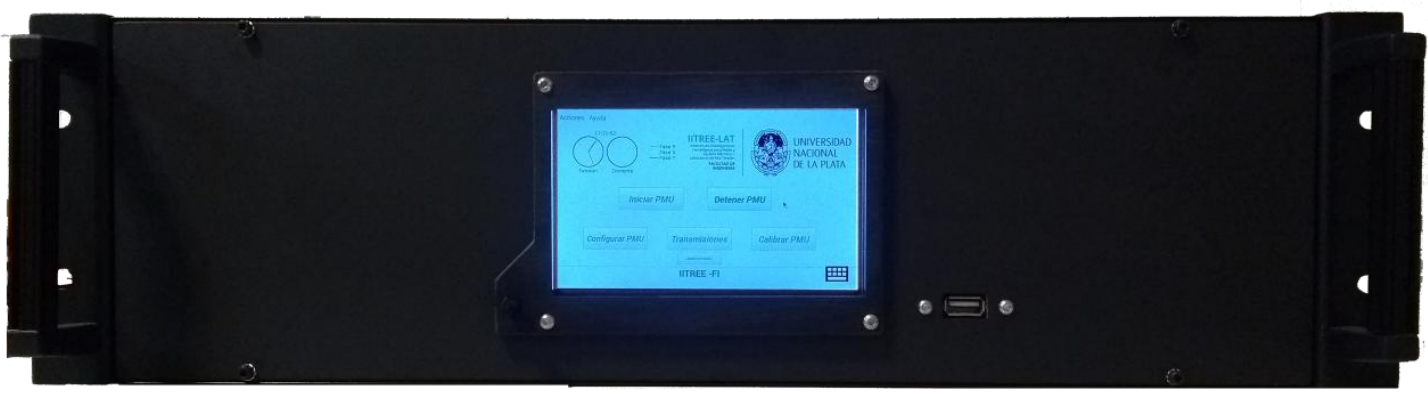

Figura 147. Panel frontal de la PMU.

En la Figura 148 puede observarse la pantalla principal de la interfaz de usuario.

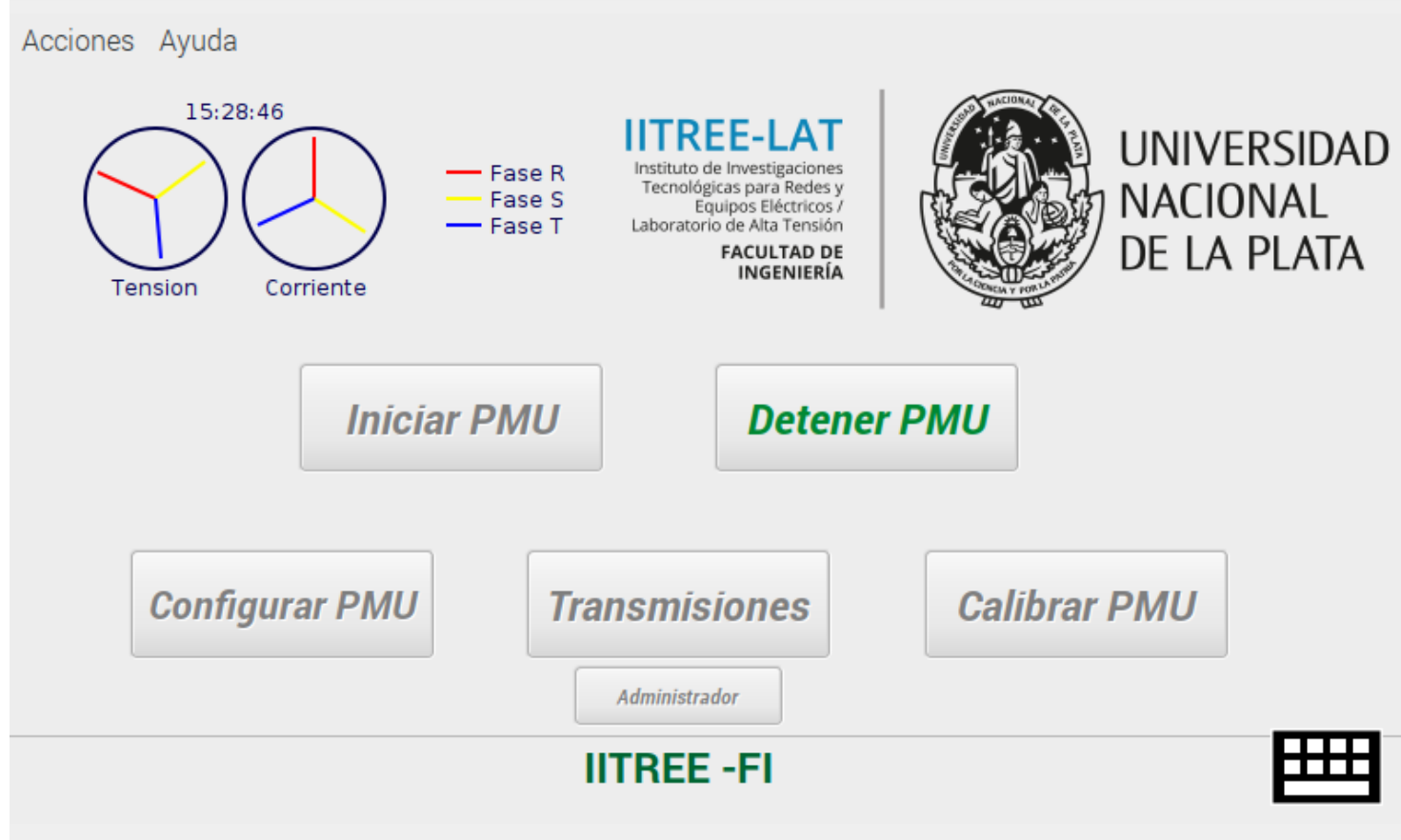

Figura 148. Interfaz de Usuario - PMU.

En su pantalla principal, la PMU muestra dos diagramas fasoriales indicando los fasores de tensiones y corrientes en tiempo real. Dichos diagramas permiten, entonces, verificar el estado de las mediciones y la correcta conexión de los canales a las variables correspondientes.

Tal como se puede observar, cuando la PMU se encuentra llevando a cabo las mediciones, la única acción habilitada al usuario corresponde a detener la medición, mediante el botón Detener PMU.

Para brindar mayor seguridad al sistema, la PMU requiere, para ser detenida y llevar a cabo las acciones de configuración correspondientes, ingresar un nombre de usuario y contraseña (que debe ser configurado previamente por el usuario). Dicho requerimiento se observa en la Figura 149. 


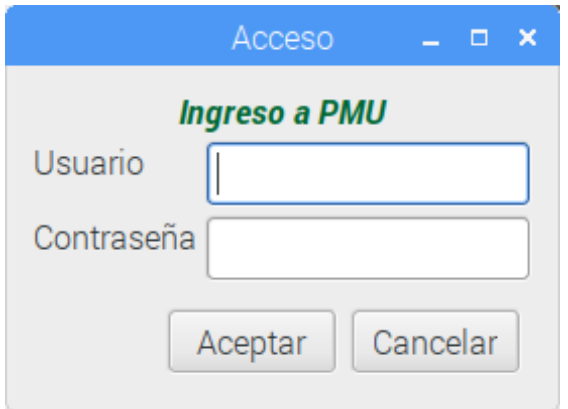

Figura 149. Ingreso de Usuario - PMU.

Una vez validado el usuario y contraseña, el usuario cuenta con todas las opciones disponibles para llevar a cabo las acciones correspondientes.

Finalmente, el usuario puede reanudar la operación de la PMU mediante el botón Iniciar PMU.

\subsubsection{Configurar PMU}

La configuración de la PMU se refiere al establecimiento de todos los parámetros que requiere una PMU para ser identificada en el sistema de medición sincrofasorial y poder realizar las mediciones correspondientes. En la Figura 150 se muestra la pantalla correspondiente.

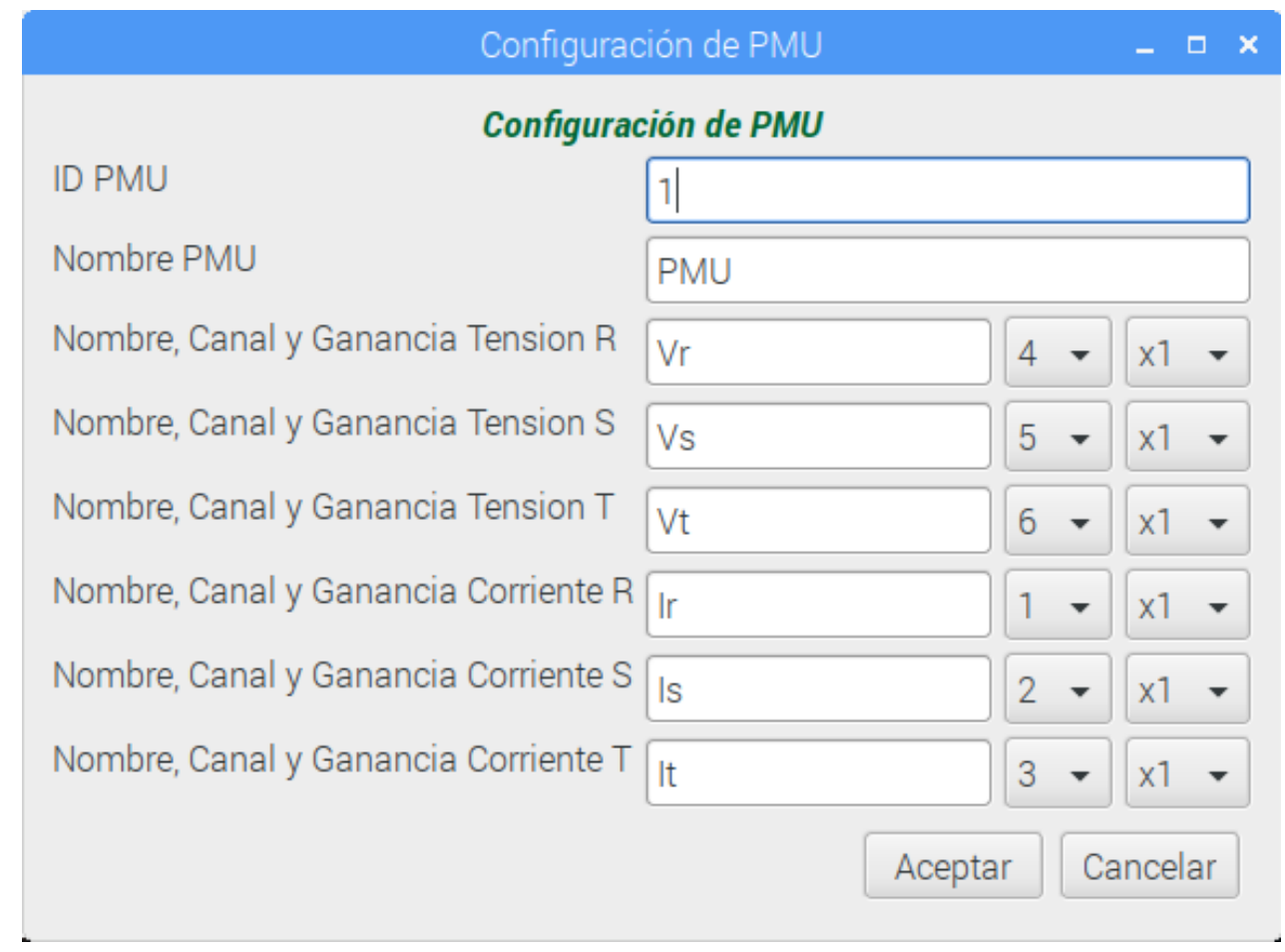

Figura 150. Configuración - PMU

Los parámetros que deben configurarse son: ID de la PMU, Nombre de la PMU y Nombre, número de canal y ganancia de cada una de las variables correspondientes. 
El ID de la PMU corresponde a un identificador numérico de la PMU, definido en [10]. Dicho identificador es único para cada dispositivo (PMU o PDC) que conforma el sistema de medición sincrofasorial y debe ser asignado por el administrador de dicho sistema.

El Nombre de la PMU refiere a un campo alfanumérico definido en [10] que permite asignar un nombre inteligible a la PMU dentro del sistema, que permita luego al usuario identificarla fácilmente.

Tal como se ha mencionado anteriormente, la PMU fue diseñada para llevar a cabo la medición de tres tensiones y tres corrientes del sistema trifásico analizado. A partir de dicho fundamento, y dada la capacidad de la PMU de reordenar la disposición de los canales de medición en su gabinete según la conveniencia del conexionado correspondiente, se requiere que se configure la ubicación de las tensiones y las corrientes en sus canales. Para ello, la configuración permite definir en qué canal de medición (1 a 6) se encuentra cada variable. A su vez, cada variable puede ser identificada mediante un campo alfanumérico inteligible ([10]).

Dado que los canales de medición cuentan con amplificadores de ganancia variable que permiten utilizar el mayor rango posible de los conversores analógico-digitales, se requiere configurar la ganancia correspondiente para los canales de tensión (x1 ó x2) y los canales de corriente (x1 ó x4) según las características de las señales conectadas a los canales correspondientes.

A partir de lo descripto anteriormente, la pantalla de configuración cuenta con un campo para la configuración del nombre, un menú para la selección del canal y un menú para la selección de la ganancia para cada una de las variables medidas.

\subsubsection{Transmisiones}

Para establecer y administrar los destinos a donde se realizará la transmisión de los sincrofasores, la PMU cuenta con un menú que permite establecer los parámetros requeridos. Dicho menú puede observarse en la Figura 151. 


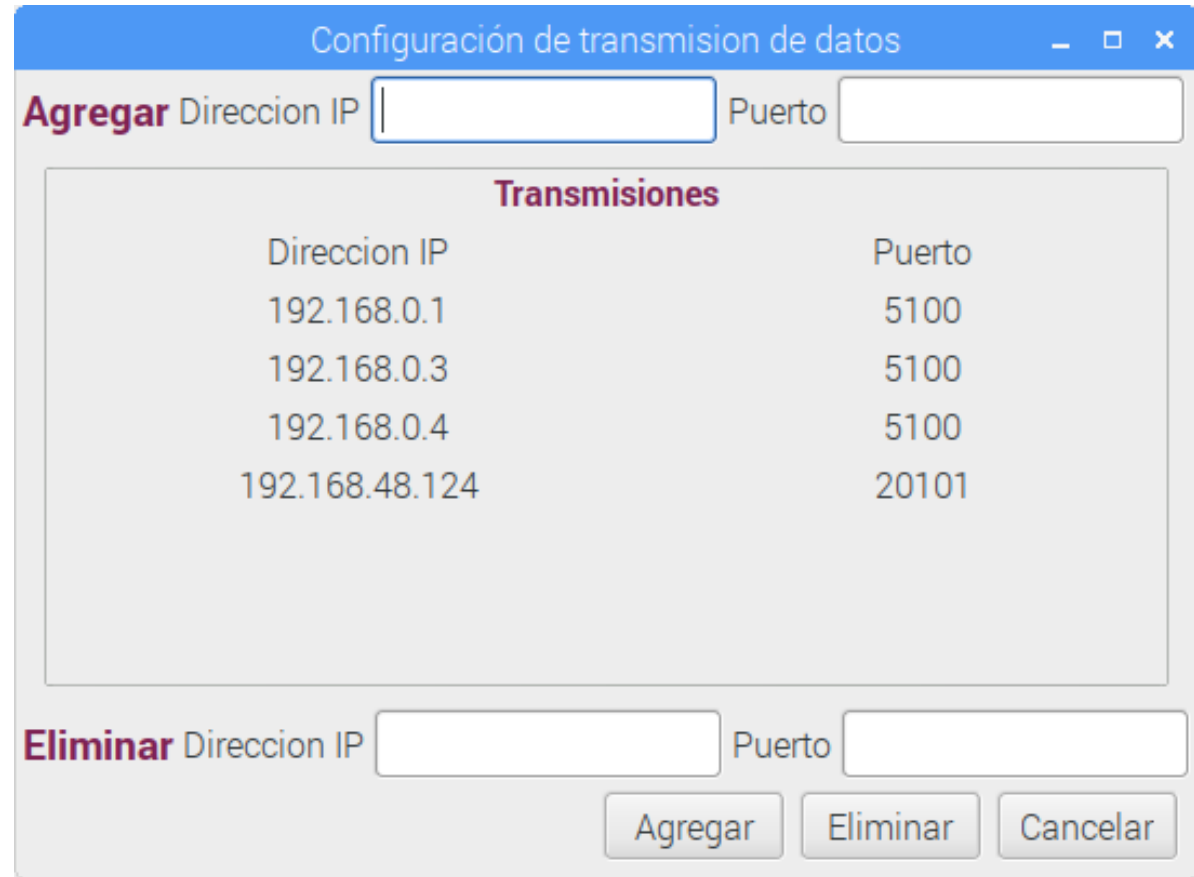

Figura 151. Transmisiones - PMU.

En primer lugar, en la tabla Transmisiones es posible observar las direcciones IP y los puertos a donde se están realizando, actualmente, los envíos de los sincrofasores mediante el método UDP espontáneo.

Si el usuario desea agregar un destino, sólo debe ingresar su dirección IP y puerto en la parte superior de la pantalla.

De la misma manera, si desea eliminar uno de los destinos listados en la tabla, sólo debe ingresar su dirección IP y puerto en la parte inferior de la pantalla.

\subsubsection{Administrador}

Tal como se describió anteriormente, la PMU requiere, para poder llevar a cabo cualquier acción, el ingreso de nombre de usuario y contraseña que permita detener la operación de la PMU y habilitar la operación del usuario.

Dicho nombre de usuario y contraseña puede ser modificado cuando sea requerido mediante la pantalla de configuración del Administrador, tal como muestra la Figura 152. 


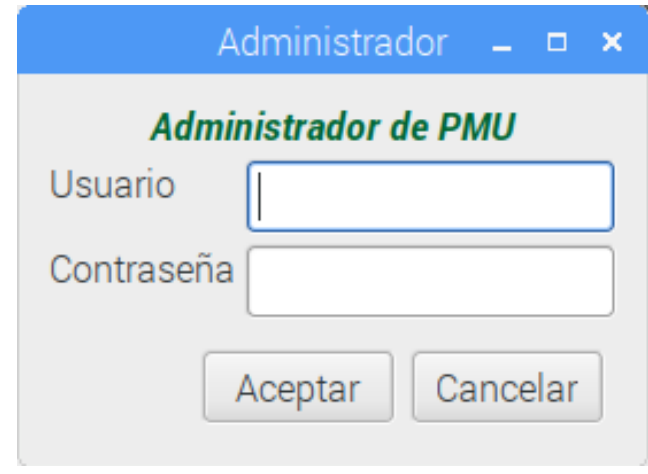

Figura 152. Administrador - PMU.

En el menú que se observa en la Figura 152, el usuario puede ingresar un nuevo nombre de usuario y contraseña.

\subsubsection{Calibración}

La PMU cuenta con un proceso de autocalibración, para lo que se requiere disponer de una fuente de tensión y corriente trifásica de $50 \mathrm{~Hz}$. Dicho proceso se inicia mediante el botón Calibrar PMU de la pantalla principal, a partir de lo cual se observa una pantalla como la muestra la Figura 153.

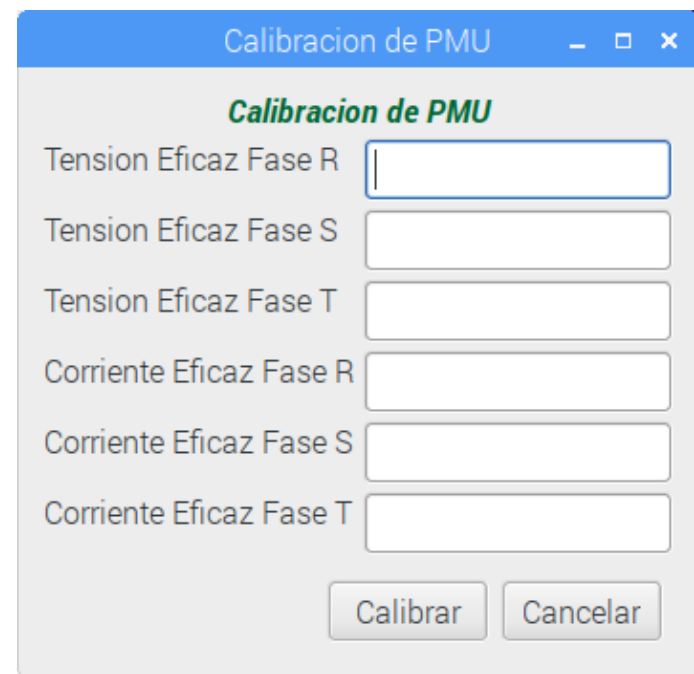

Figura 153. Calibración - PMU

En la primera etapa de la calibración, el usuario debe indicar la tensión eficaz por fase y la corriente eficaz por fase que ha configurado en las fuentes de tensión y corriente que se utilizarán. Ésta configuración debe realizarse sin conectar las fuentes a la PMU.

Una vez establecidos los parámetros de calibración, el proceso de autocalibración comienza con el cálculo del offset presente en la medición. Para ello, la PMU informa mediante la pantalla que se observa en la Figura 154 que el usuario debe cortocircuitar los bornes de entrada de cada uno de los canales de medición. 


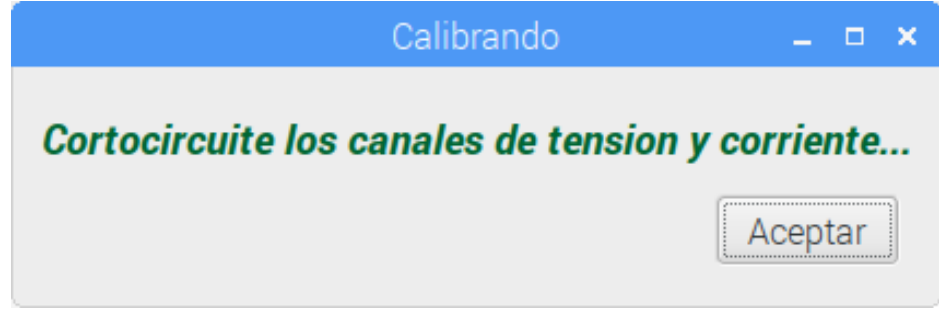

Figura 154. Instrucción para calibración de Offset - PMU.

Con los canales cortocircuitados, debe presionarse el botón Aceptar. De esta manera, la PMU comienza la calibración de offset.

Dicho proceso consiste en realizar 200 mediciones de tensiones y corrientes, correspondientes a una ventana temporal de $4 \mathrm{~s}$, a partir de las cuales la PMU obtiene el offset promedio presente en cada canal. Durante dicho procedimiento, la PMU muestra la pantalla que se observa en la Figura 155.

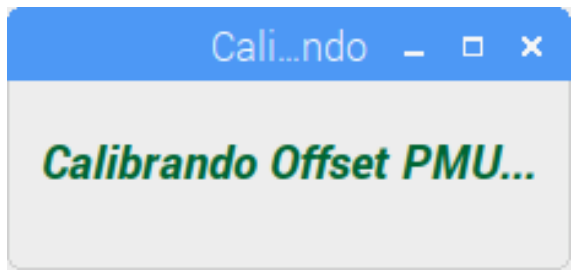

Figura 155. Calibración de Offset - PMU.

Una vez calibrado el offset de cada canal, el proceso de autocalibración finaliza con el cálculo de la ganancia adicional requerida en cada canal de medición. Para ello, la PMU informa mediante la pantalla que se observa en la Figura 156 que el usuario debe conectar las fuentes de tensión y corriente a los bornes de entrada correspondientes de cada uno de los canales de medición.

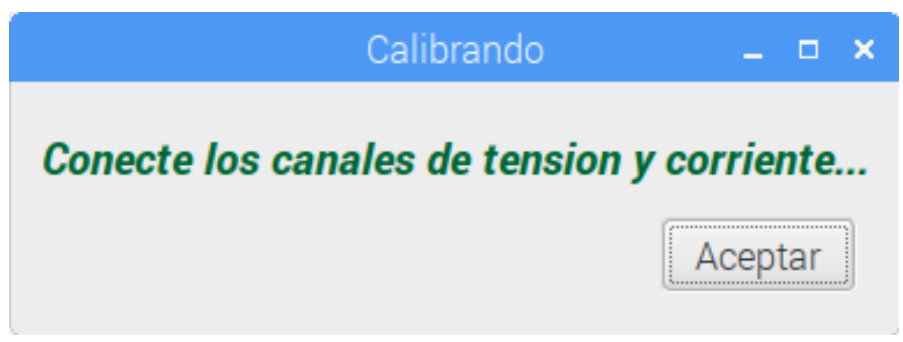

Figura 156. Instrucción para calibración de Ganancia - PMU.

Al igual que para la calibración de offset, el proceso consiste en realizar 200 mediciones de tensiones y corrientes, correspondientes a una ventana temporal de $4 \mathrm{~s}$, a partir de las cuales la PMU obtiene la ganancia adicional promedio requerida en cada canal. Durante dicho procedimiento, la PMU muestra la pantalla que se observa en la Figura 157. 


\section{Cali...ndo - $\square \times$}

Calibrando Offset PMU...

Figura 157. Calibración de Ganancia - PMU.

Una vez finalizada la calibración de ganancia adicional de cada canal, la PMU retorna a su pantalla principal de usuario.

\subsection{Ensayos y Resultados}

\subsubsection{Caracterización de los canales de medición}

Las PMUs son equipamientos destinados a la medición de tensiones y corrientes a partir de las cuales se pueden llevar a cabo diferentes procesamientos basados en dichas magnitudes. Dado que dichas magnitudes se miden en forma sincronizada, obteniéndose el módulo y la fase del fasor correspondiente, resulta de gran importancia caracterizar los retardos que afectan a las señales de tensión y corriente cuando las mismas son acondicionadas mediante los canales diseñados en la PMU.

Dichos retardos son de gran interés ya que conforman un error en la medición de tipo sistemático, que debe ser descontado a la hora de informar los resultados de medición.

Los canales de medición, descriptos en la sección 9.3, fueron diseñados con el objetivo de que tanto las tensiones como las corrientes fuesen afectadas por el mismo retardo, de manera tal que no exista un desfasaje adicional entre tensiones y corrientes que pudieran afectar, por ejemplo, el cálculo de potencias.

Para poder caracterizar cada canal de medición, se llevó a cabo un ensayo basado en la inyección de señal en la entrada del canal y la medición simultánea tanto de la entrada como de la salida con un osciloscopio registrador.

Dicho ensayo se realizó para las dos ganancias que dispone cada canal, y se midió en cada caso el retardo existente entre la señal de entrada y la señal de salida del canal.

A modo de ejemplo, en la Figura 158 puede observarse las mediciones realizadas con el osciloscopio para un canal de tensión. La señal con trazo amarillo corresponde a la señal inyectada mientras que el trazo celeste corresponde a la señal obtenida a la salida del canal. 


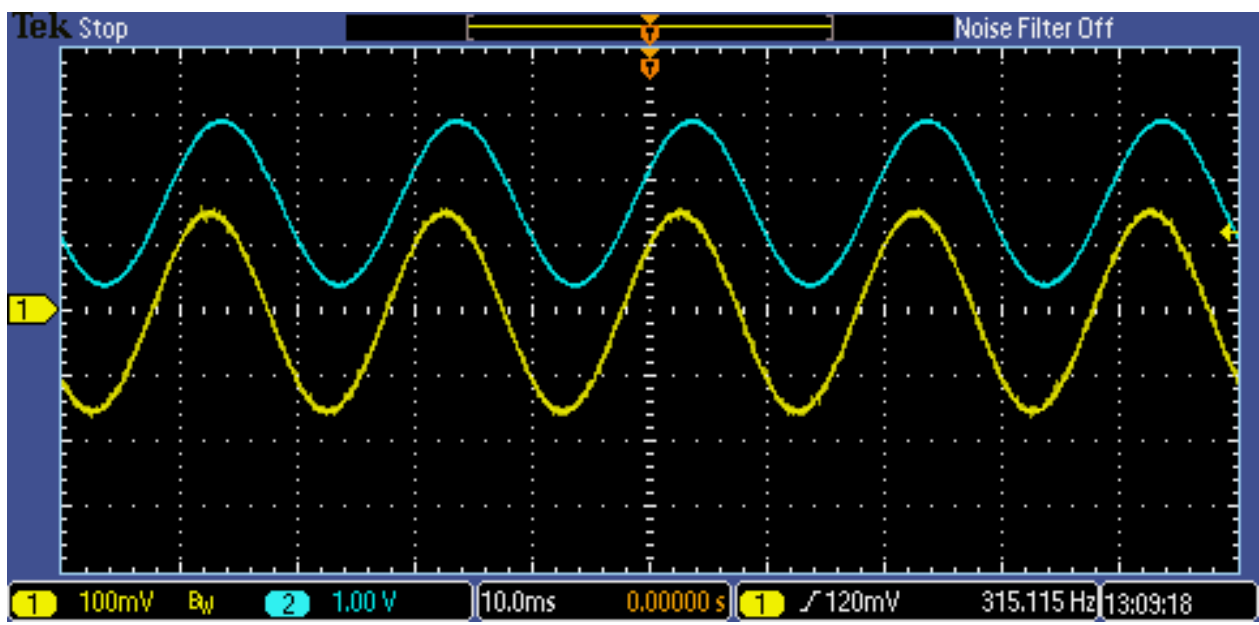

Figura 158. Caracterización de canales de medición.

La Figura 159 muestra el detalle de las señales observadas anteriormente, pudiéndose notar el retardo existente entre la señal de entrada y la señal de salida del canal analizado.

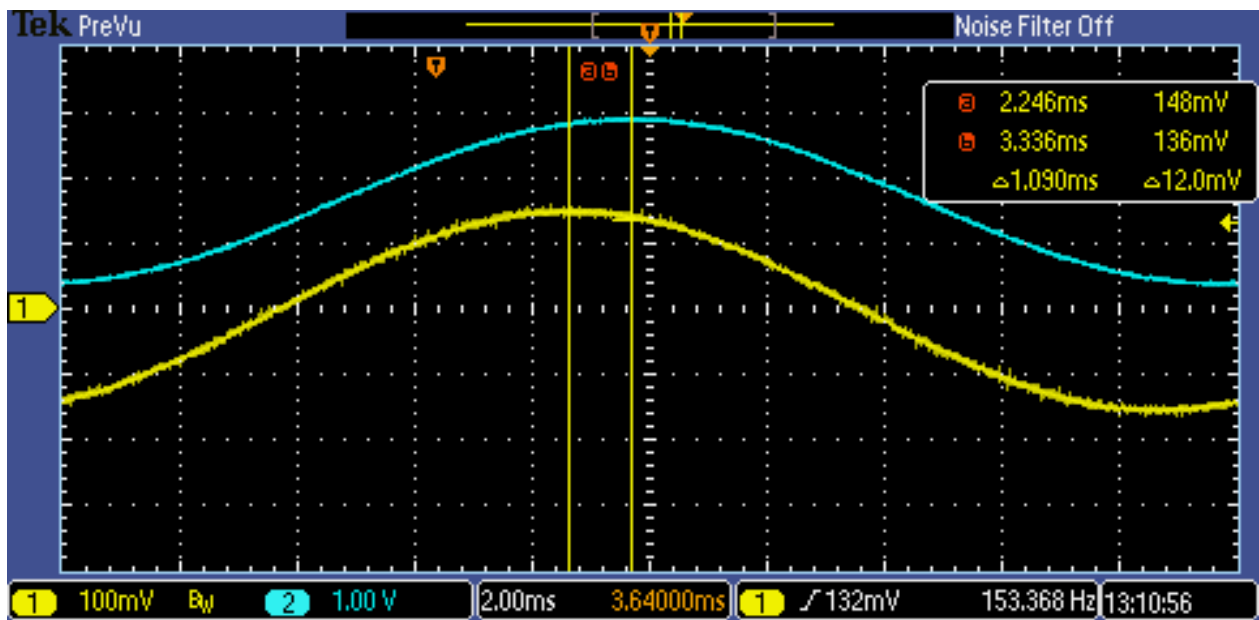

Figura 159. Detalle de las señales en el canal de medición.

Se obtuvo como resultado un retardo de 1,09 ms para los canales de tensión y 1,07 ms para las corrientes. La diferencia en los retardos se encuentra en el orden de la precisión de la medición que puede realizarse.

A partir de los resultados obtenidos, puede concluirse que tanto las tensiones como las corrientes experimentan el mismo retardo al ser acondicionadas por los canales correspondientes. De esta manera, puede desafectarse de los sincrofasores el desfasaje adicional que el retardo impone. 


\section{Ensayos y pruebas de conjunto}

\subsection{Evaluación de las mediciones realizadas por la PMU}

La norma [9] establece la necesidad de efectuar diferentes pruebas a una PMU que permitan certificar la precisión de las mediciones realizadas. Para cumplir con los requisitos establecidos, la PMU debe realizar las mediciones de sincrofasores, frecuencia y ROCOF con un error lo suficientemente pequeño para cumplir con las cotas máximas de error establecidas. La conformidad con la norma, a su vez, debe mantenerse a lo largo del tiempo y para cualquier configuración de la PMU o de la instalación a medir.

Los ensayos establecidos en la norma, a los que se debe someter toda PMU que sea evaluada, pueden clasificarse en dos tipos: ensayos de conformidad en estado estacionario, y ensayos de conformidad dinámica. Dichos ensayos determinan límites máximos al TVE y al error en la medición de frecuencia y ROCOF que pueden admitirse en las mediciones realizadas con la PMU.

Los ensayos de conformidad en estado estacionario consisten en comparar las mediciones de sincrofasores, frecuencia y ROCOF, realizadas sobre un sistema de tensiones y corrientes en condiciones de estado estacionario, con los correspondientes valores teóricos que dichas magnitudes tendrían al momento de realizar el ensayo. Esta condición implica que tanto los fasores como la frecuencia del sistema son constantes a lo largo del período de ensayo de la PMU.

Los ensayos de conformidad dinámica consisten en provocar variaciones controladas de los fasores (tanto en módulo como en fase) y de la frecuencia, con el objetivo de evaluar la respuesta de las mediciones realizadas por la PMU frente a los cambios de las variables medidas.

Para evaluar el ancho de banda de las mediciones realizadas por la PMU, se efectúa una modulación sinusoidal de los módulos y las fases de los sincrofasores, con parámetros de modulación establecidos por la norma. A su vez, los ensayos dinámicos incluyen la realización de mediciones sobre tensiones y corrientes cuya frecuencia es modificada mediante una rampa lineal de frecuencia así como también mediciones sobre tensiones y corrientes cuyas amplitudes y fases son modificadas mediante escalones de amplitud conocida.

La realización de estos ensayos requiere de un generador capaz de generar los sincrofasores con las variaciones necesarias y con el sincronismo respecto al tiempo UTC adecuado. El generador debe ser un dispositivo calibrado para tal fin, con un error 4 veces menor que el que se desea obtener con la PMU bajo estudio [9]. 
Dado que no se dispone de un generador compatible con la norma correspondiente [9], la PMU desarrollada en la presente tesis no pudo ser sometida a los ensayos correspondientes. Sin embargo, frente a la necesidad de caracterizar las mediciones realizadas por la PMU, se realizaron comparaciones de los sincrofasores y frecuencia medidos con aquéllos obtenidos mediante una PMU comercial, que cumple con los requerimientos establecidos por la norma.

Los ensayos consistieron en realizar mediciones de las tensiones de la red de baja tensión trifásica domiciliaria en forma simultánea con la PMU desarrollada y con la PMU comercial, de la cual se dispone del certificado de calibración correspondiente. Dichas mediciones fueron luego comparadas, teniendo por objetivo obtener una diferencia lo suficientemente pequeña en cada magnitud de manera tal de poder afirmar que las mediciones de la PMU bajo estudio son comparables con las obtenidas mediante un equipamiento comercial certificado.

La PMU comercial, de la firma Reason/General Electric, está compuesta por 3 módulos bien diferenciados [69]. El módulo RT430, con su correspondiente antena, es el receptor GPS y provee todas las señales de sincronización temporal requeridas. El módulo RA331 es el módulo de adquisición de señal, diseñado para llevar a cabo la medición de las 3 tensiones del sistema trifásico. Finalmente, el módulo RPV311 es el encargado de procesar las mediciones y conformar los paquetes de datos según [10].

Las mediciones fueron registradas mediante el servidor de respaldo durante períodos de 10 minutos para luego poder ser analizadas en forma offline.

En la Figura 160 se observan las mediciones de frecuencia obtenidas mediante la PMU desarrollada y las obtenidas a través de la PMU comercial, correspondientes a uno de los registros analizados.

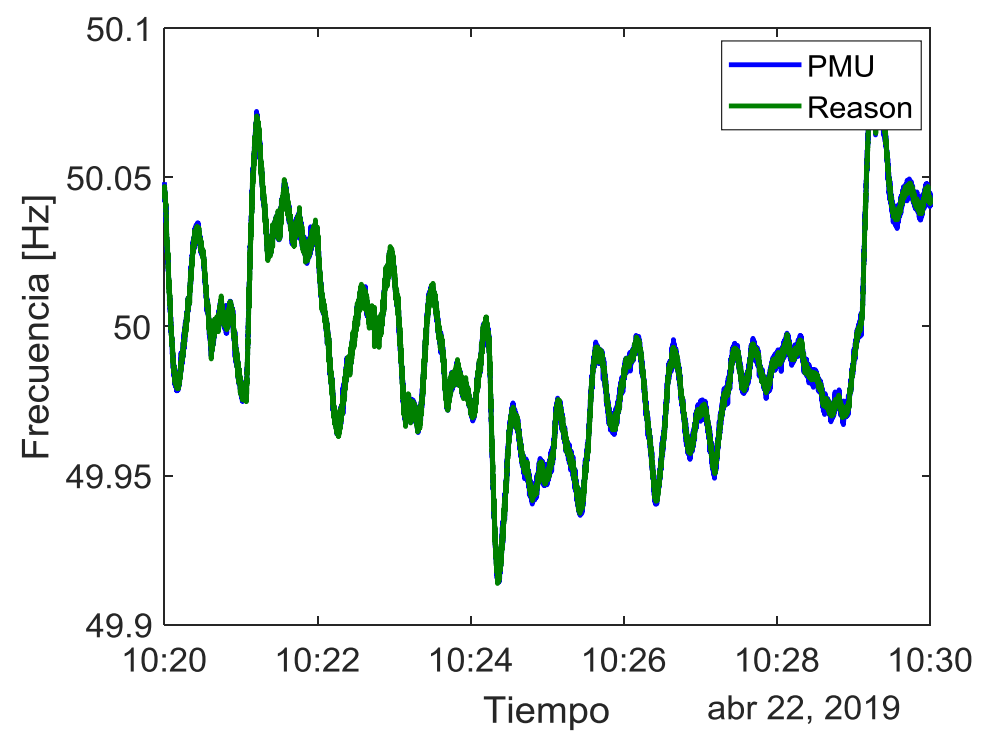

Figura 160. Comparación de la medición de frecuencia con PMUs. 
Puede notarse la similitud existente entre ambas PMUs, tanto en los valores absolutos medidos como en la dinámica que experimentaba la frecuencia de la red domiciliaria al momento de realizar los ensayos correspondientes. En la Figura 161 es posible notar la diferencia porcentual existente en las mediciones, que no supera el $0,02 \%$

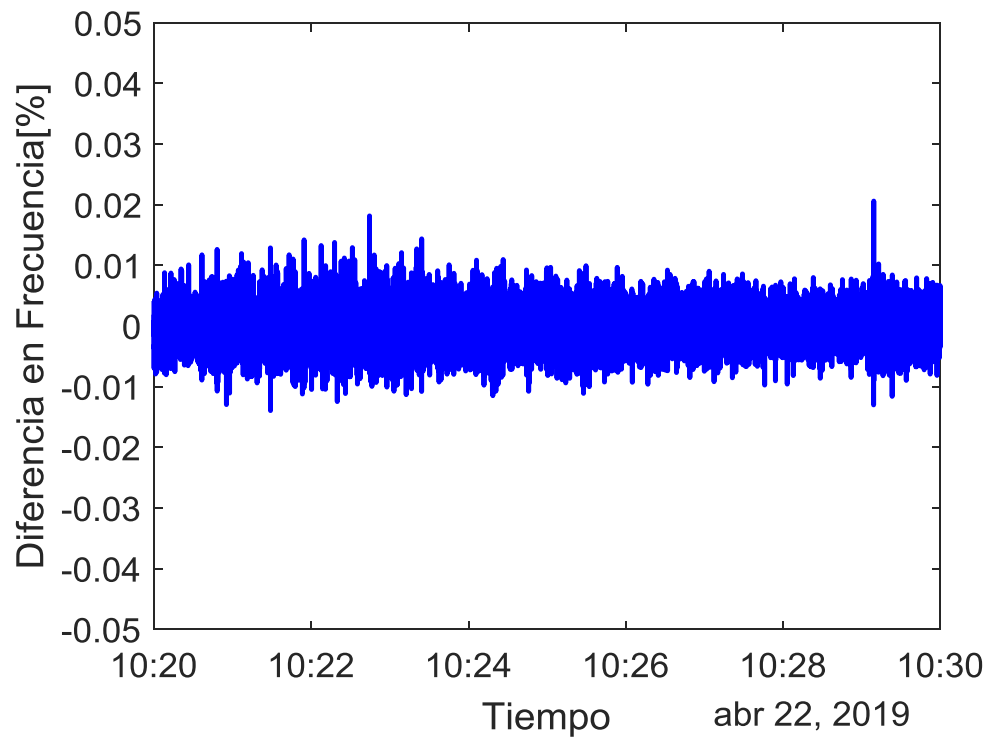

Figura 161. Diferencia en la medición de frecuencia.

Los resultados obtenidos permiten concluir que el algoritmo de medición de frecuencia implementado en la PMU funciona correctamente, obteniéndose importantes similitudes entre los valores medidos con un equipo calibrado y con la PMU implementada en la presente tesis.

En las Figuras 162 a 164 se observan las mediciones de ángulo de fase realizadas mediante la PMU desarrollada y las obtenidas a través de la PMU comercial para cada una de las fases de la red trifásica domiciliaria analizada.

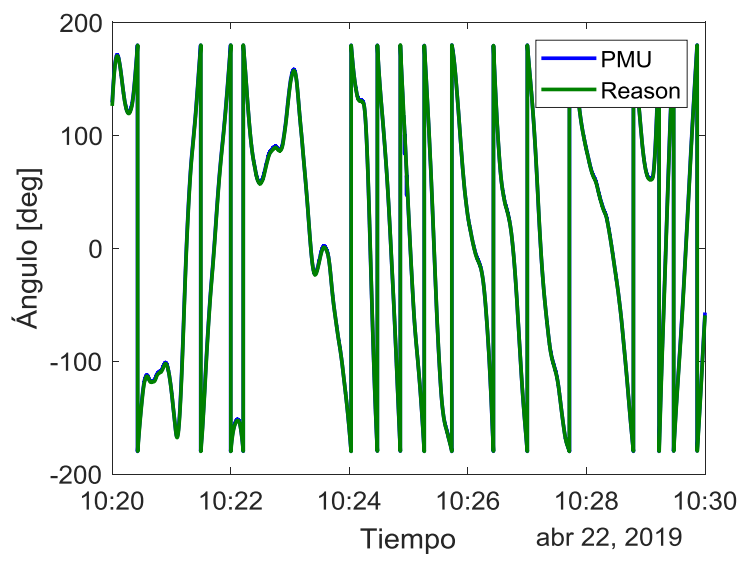

Figura 162. Comparación de la medición de ángulo de fase - Fase R.

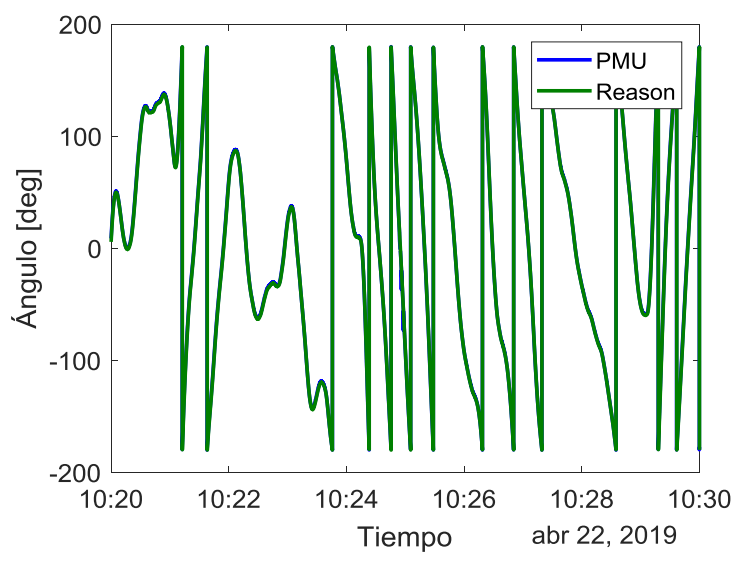

Figura 163. Comparación de la medición de ángulo de fase - Fase $\mathrm{S}$. 


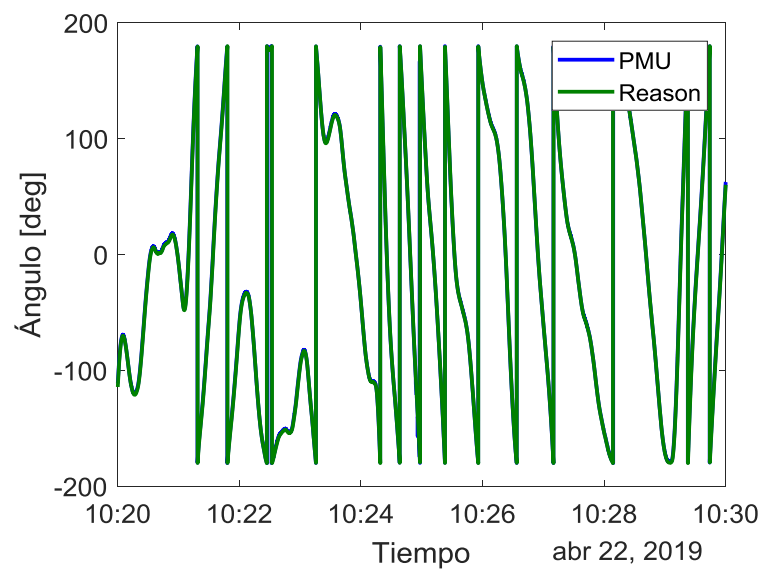

Figura 164. Comparación de la medición de ángulo de fase - Fase T.

Es posible notar que las mediciones obtenidas con ambas PMUs resultan muy semejantes en las tres fases analizadas; tanto es así que las respectivas trazas resultan superpuestas.

Cabe destacar que las variaciones de las fases medidas responden a las variaciones de frecuencia descriptas anteriormente. En un sistema ideal, donde la frecuencia es constante e igual a la nominal, las PMUs midiendo con una tasa igual a esa frecuencia nominal arrojarían sincrofasores de fase constante, tal como se describió en la Ec. 3.5. En los ensayos realizados, donde la frecuencia no resulta constante, la fase sufre las variaciones definidas por la integral de la variación de frecuencia medida (Ec. 3.5).

En las Figuras 165 a 167 se observan las mediciones del módulo de los sincrofasores obtenidas mediante la PMU desarrollada y las obtenidas a través de la PMU comercial para cada una de las fases de la red en estudio.

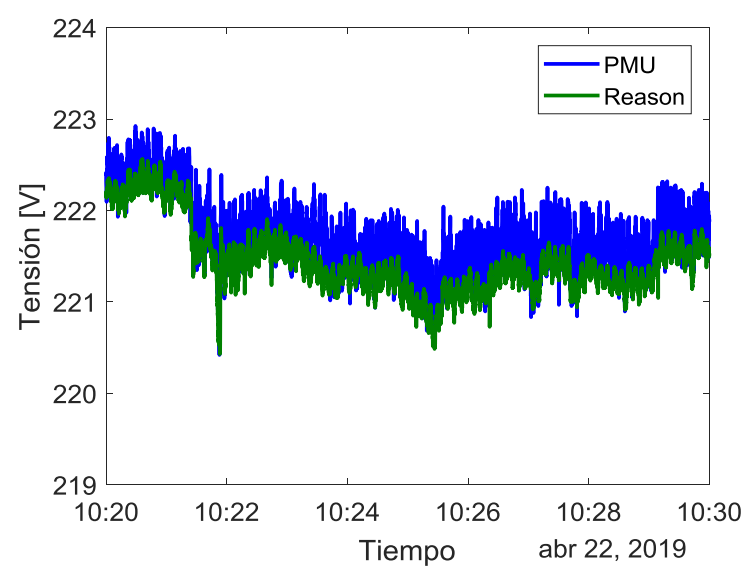

Figura 165. Comparación de la medición de módulo de fasor - Fase R.

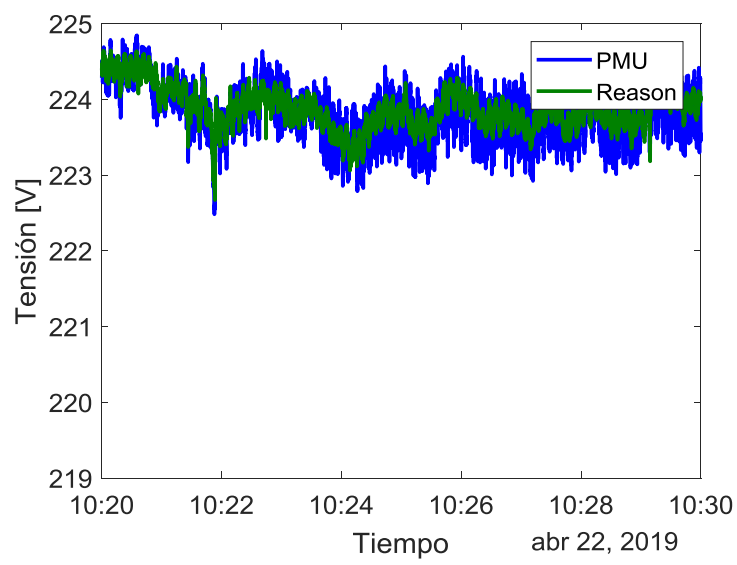

Figura 166. Comparación de la medición de módulo de fasor - Fase S. 


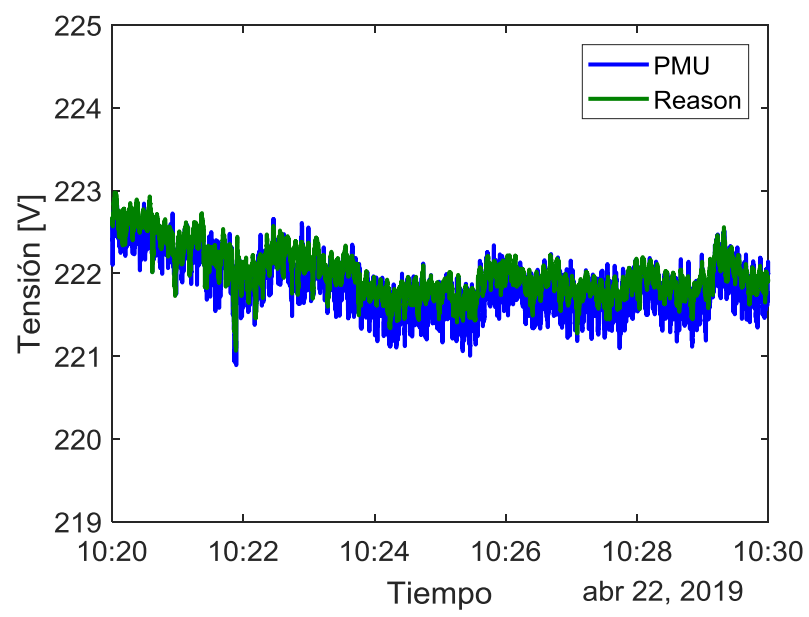

Figura 167. Comparación de la medición de módulo de fasor - Fase T.

Es posible notar que las mediciones obtenidas con ambas PMUs cuentan con un grado de similitud importante. Un mejor análisis de los resultados puede realizarse si se analiza la diferencia porcentual entre ellas, mediante las trazas que se observan en las Figuras 168 a 170.

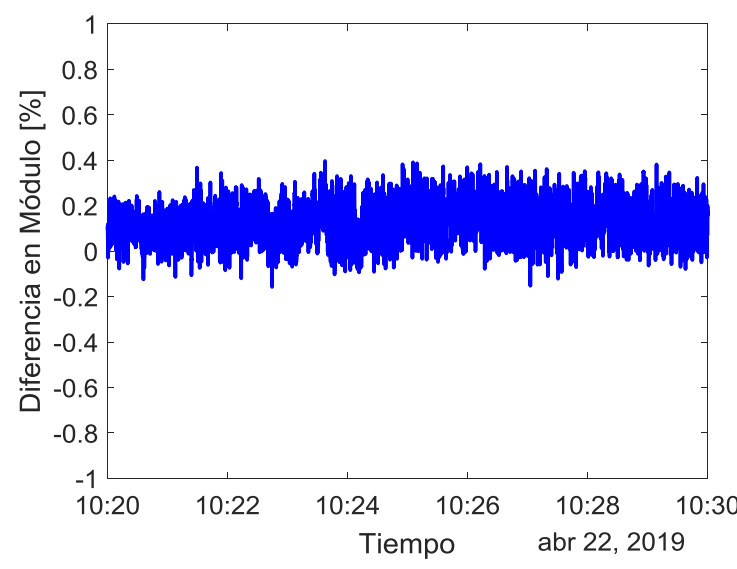

Figura 168. Comparación de la medición del módulo del fasor - Fase R.

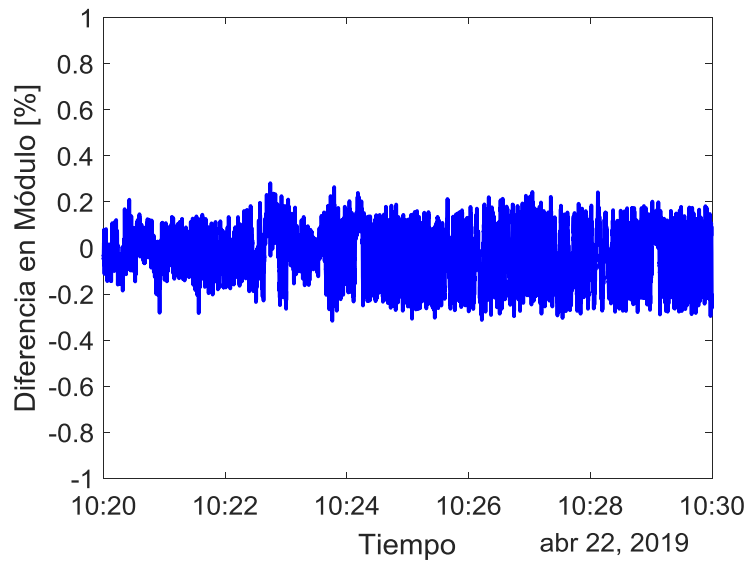

Figura 169. Comparación de la medición del módulo del fasor - Fase S.

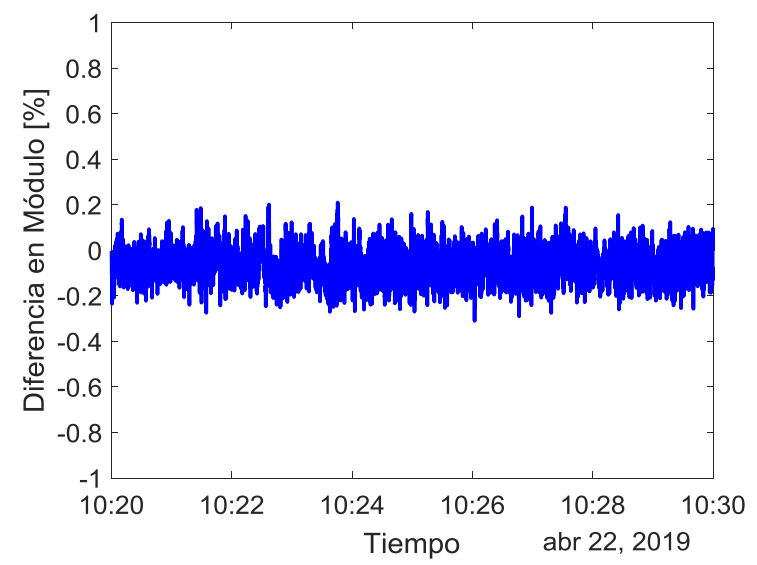

Figura 170. Comparación de la medición del módulo de fasor - Fase T. 
La diferencia en las mediciones del módulo del fasor de las fases correspondientes no supera el $0,4 \%$. Sin embargo, se destaca en los resultados obtenidos una mayor variabilidad en las mediciones en el caso de la PMU desarrollada en la presente tesis. Este fenómeno demuestra la necesidad de realizar un ajuste en los algoritmos de procesamiento que permitan reducir la variabilidad de los resultados arrojados $\mathrm{y}$, por lo tanto, una disminución de la diferencia porcentual obtenida.

En conclusión, los resultados obtenidos para cada una de las magnitudes analizadas son altamente favorables, disponiéndose en todos los casos de valores completamente semejantes a los que se obtienen mediante una PMU comercial calibrada. Esto permite afirmar que tanto el hardware diseñado como los algoritmos de procesamiento implementados resultan aptos para su utilización en una PMU comercial, requiriéndose solo de pequeños ajustes que permitan reducir los efectos antes mencionados.

\subsection{Evaluación del funcionamiento del sistema en conjunto}

Dado que la presente tesis abarca la implementación de un sistema de medición sincrofasorial completo, incluyendo todos los componentes que estos sistemas incluyen, resultó necesario llevar a cabo ensayos que permitieran evaluar el funcionamiento del sistema en su conjunto. Para ello, se evaluó al Concentrador, el Servidor de Respaldo, el Software de Procesamiento incluyendo sus módulos Online y Offline y la PMU cuando se los somete a perturbaciones en las tensiones o las corrientes medidas.

Para generar las perturbaciones necesarias, se utilizó el sistema de prueba de Relés MPRT 8430, también llamado Valija de Pruebas, de la firma Megger [70] que brinda la posibilidad de generar formas de onda de tensión y/o corrientes sintetizadas en la PC.

Los ensayos consistieron en medir las señales de tensión y corriente (generadas mediante la Valija) con la PMU para enviar los sincrofasores correspondientes al Concentrador de Sincrofasores. El Concentrador de Sincrofasores llevó a cabo la recepción y sincronización de las mediciones provenientes de la PMU.

Los datos concentrados se enviaron tanto al Servidor de Respaldo como al Software de Procesamiento Online para la visualización de las mediciones realizadas.

Finalmente, los datos registrados y almacenados con el Servidor de Respaldo fueron analizados mediante el Software de Procesamiento Offline.

El primer ensayo realizado consistió en evaluar la PMU cuando es sometida a una tensión cuya frecuencia experimenta una variación lineal. El segundo ensayo consistió en la evaluación de la PMU cuando es sometida a una potencia que sufre una oscilación amortiguada, con una frecuencia correspondiente a un modo de oscilación local.

Es importante mencionar que en todos los ensayos realizados, el Concentrador recibió tanto los sincrofasores medidos por la PMU como los sincrofasores medidos por la PMU comercial Reason, que se encontraba conectada a la red trifásica domiciliaria. El registro de los sincrofasores de la PMU comercial se realizó con el objetivo de 
demostrar la capacidad de recibir sincrofasores de PMUs que se encontraran midiendo sistemas eléctricos "independientes".

Las Figuras 171 y 172 muestran la configuración establecida en el Concentrador de Sincrofasores.

Tabla de Conexiones

$\times$

\begin{tabular}{|ccccc}
\hline \multicolumn{4}{|c}{ Conexiones con PMU/PDC } \\
\hline ID PMU/PDC & Dirección & Puerto & Puerto UDP & Protocolo \\
\hline 450 & localhost & 0 & 20101 & SUDP \\
302 & localhost & 0 & 20102 & SUDP
\end{tabular}

\section{Conexiones con PDC de destino}

IP PDC Puerto

$192.168 .48 .124 \quad 4720$

Aceptar

Figura 171. Dispositivos de entrada y salida del Concentrador de Sincrofasores.

\begin{tabular}{|c|c|}
\hline \multicolumn{2}{|c|}{ Configuración del Concentrador } \\
\hline ID Concentrador & 120 \\
\hline IP Base de Datos & 192.168 .48 .124 \\
\hline Puerto Base de Datos & 4721 \\
\hline Tiempo de espera & 5.00 \\
\hline & Aceptar \\
\hline
\end{tabular}

Figura 172. Configuración del Concentrador de Sincrofasores. 
Puede observarse la configuración de las PMUs conectadas al concentrador, con su correspondiente puerto de entrada de datos y su Identificador. En este caso, el identificador de la PMU evaluada era 450 mientras que el de la PMU comercial era 302.

A su vez, se destaca la configuración del destino de los datos. Dado que el software de Procesamiento Online recibe los sincrofasores como si fuera un concentrador, fue configurado como un PDC de orden superior con la dirección IP y puerto que le corresponden.

Finalmente, se configuró también la dirección IP y puerto correspondiente al Servidor de Respaldo así como el Identificador del Concentrador.

Por otro lado, en la Figura 173 es posible observar la configuración del Servidor de Respaldo.

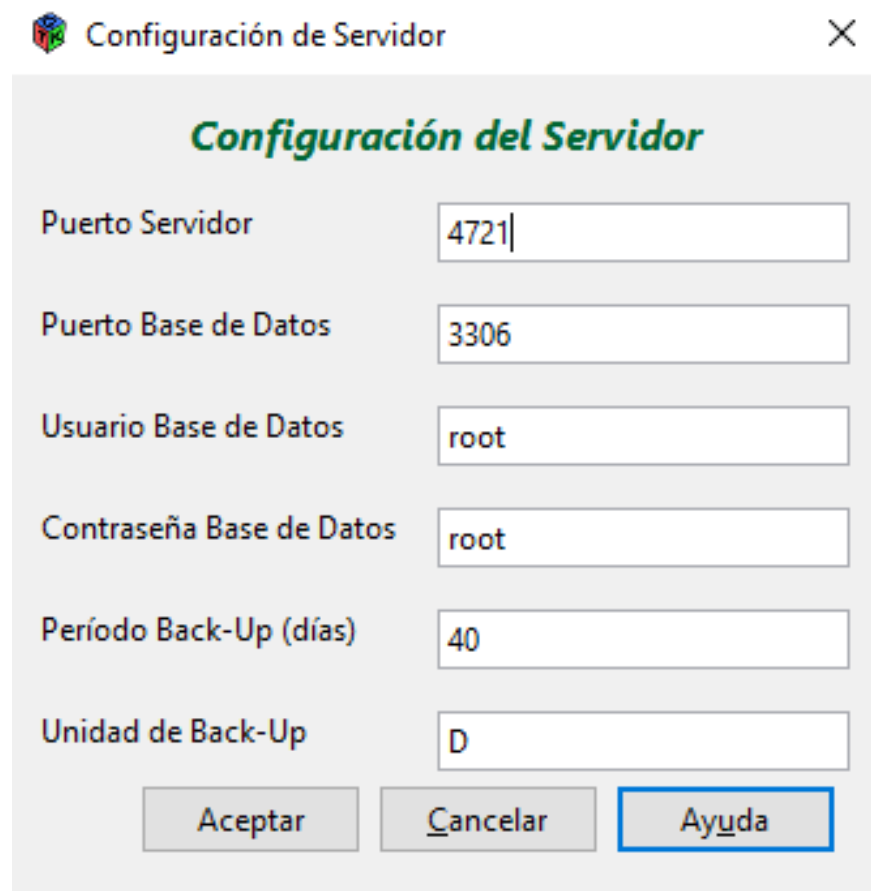

Figura 173. Configuración del Servidor de Respaldo.

Se configuró, en el Servidor de Respaldo, el puerto UDP a donde arriban los sincrofasores (denominado Puerto Servidor) así como toda la información requerida para llevar a cabo la conexión y comunicación con el servidor de base de datos correspondiente y la configuración necesaria para la administración de los datos almacenados.

\subsubsection{Evaluación con rampa de frecuencia}

El ensayo de evaluación con rampa de frecuencia consistió en llevar a cabo la medición de las tensiones de un sistema trifásico, cuando las mismas experimentan una variación lineal de su frecuencia. En la Figura 174 se observa la variación lineal de la 
frecuencia de las tensiones que fueron sintetizadas mediante la Valija de Pruebas. La rampa de frecuencia tiene una pendiente de $0,5 \mathrm{~Hz} / \mathrm{s}$.

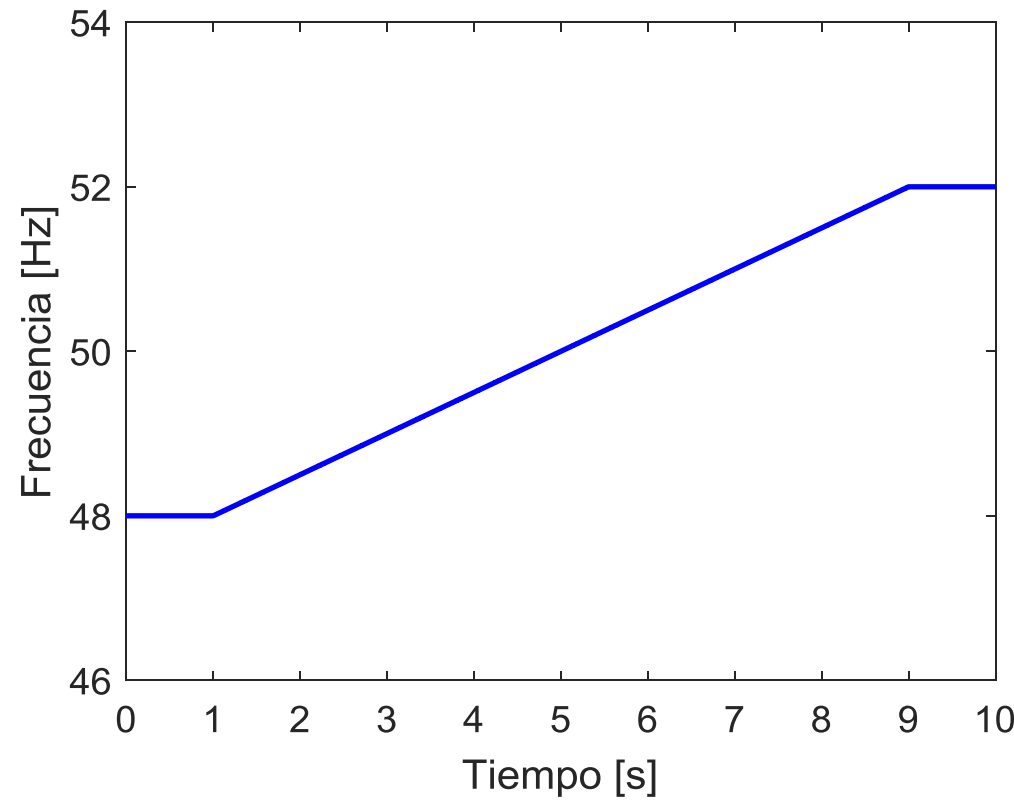

Figura 174. Rampa de Frecuencia.

La Valija de Pruebas fue configurada para sintetizar las formas de onda de las tensiones correspondientes en forma periódica. Por lo tanto, las tensiones experimentaron una variación lineal de la frecuencia entre 48 y $52 \mathrm{~Hz}$ para luego sufrir un cambio instantáneo de la frecuencia de 52 a $48 \mathrm{~Hz}$. La variación de frecuencia aplicada a la PMU corresponde, entonces, a la que se indica en la Figura 175.

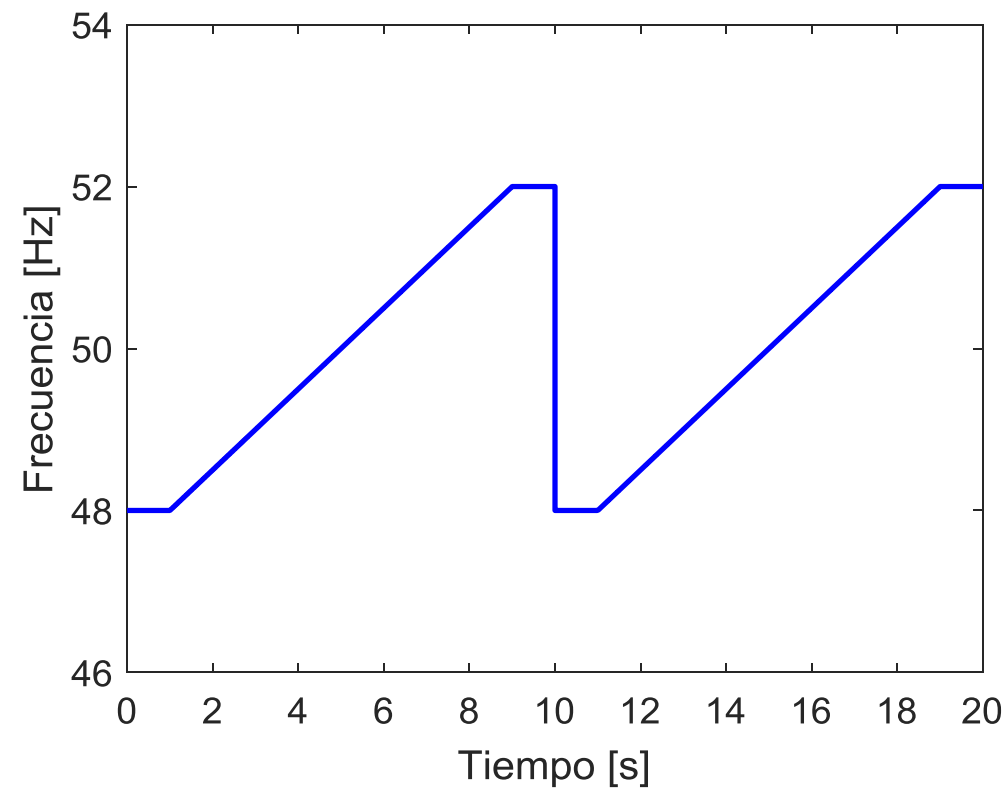

Figura 175. Rampa de Frecuencia periódica. 
En la Figura 176 puede observarse la pantalla principal del Software de procesamiento Online cuando la PMU era sometida a la variación de frecuencia antes descripta. La PMU en evaluación es identificada como IITREE mientras que la PMU comercial es identificada como Reason.

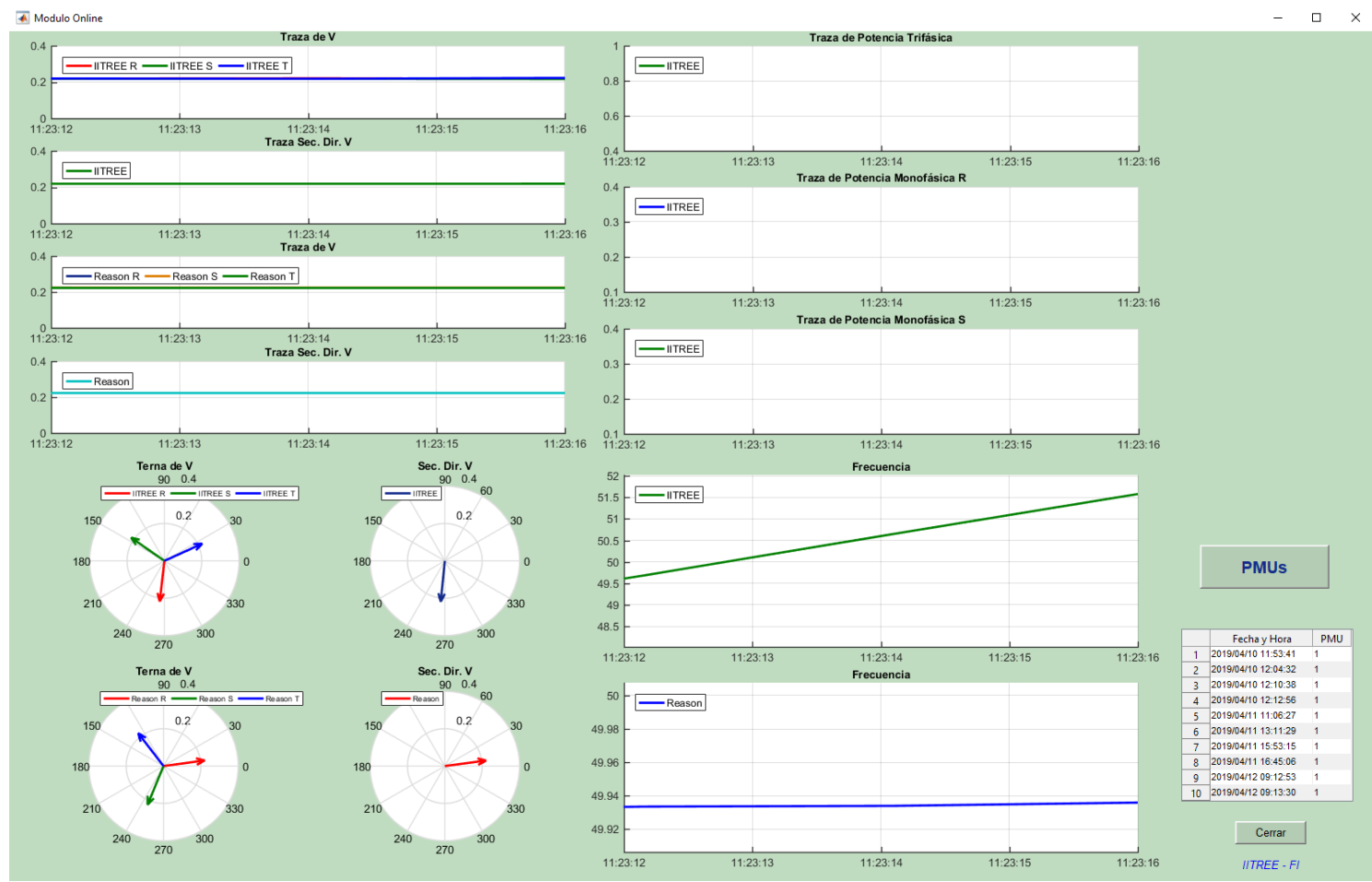

Figura 176. Software de procesamiento Online - Rampa de Frecuencia.

La Figura 177 muestra en detalle las frecuencias medidas tanto por la PMU desarrollada como por la PMU comercial.

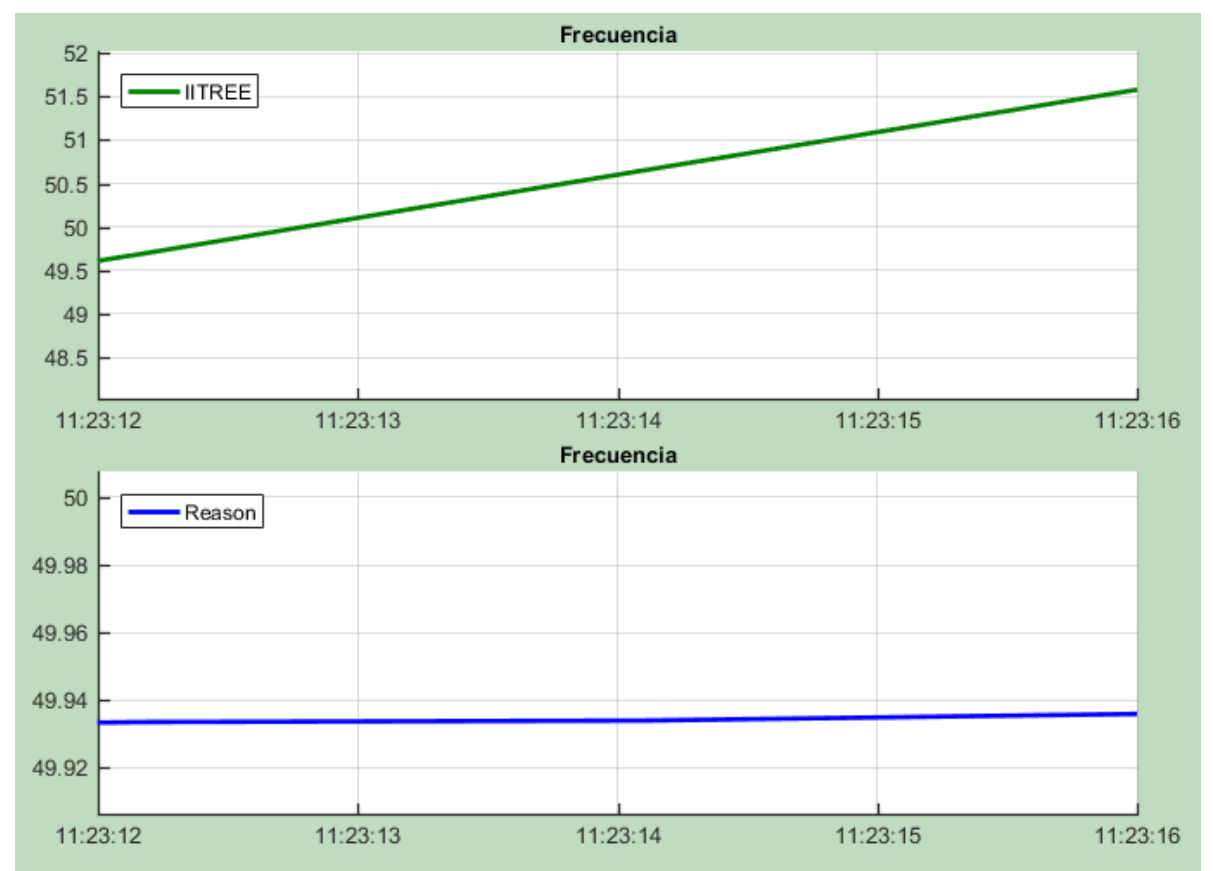

Figura 177. Detalle del Software de procesamiento Online - Rampa de Frecuencia. 
Resulta importante notar la variación lineal que experimenta la frecuencia en la PMU diseñada en la presente tesis mientras que la PMU comercial continuaba midiendo la frecuencia de la red trifásica.

A su vez, los gráficos fasoriales de las ternas de tensión y su Secuencia Directa demuestran la capacidad del Software de procesamiento Online de procesar sincrofasores correspondientes a sistemas eléctricos independientes. Esto puede concluirse gracias a la diferencia angular aleatoria que se obtiene entre los sincrofasores de ambas PMUs.

Una vez efectuado el ensayo sobre la PMU, se evaluaron las mediciones registradas por el Servidor de Respaldo utilizando el Software de Procesamiento Offline.

Para realizar el análisis offline se llevó a cabo la búsqueda, mediante el propio software de procesamiento, de los datos correspondientes en la base de datos. En la Figura 178 puede observarse las trazas de Frecuencia y ROCOF obtenidas mediante el procesamiento offline.

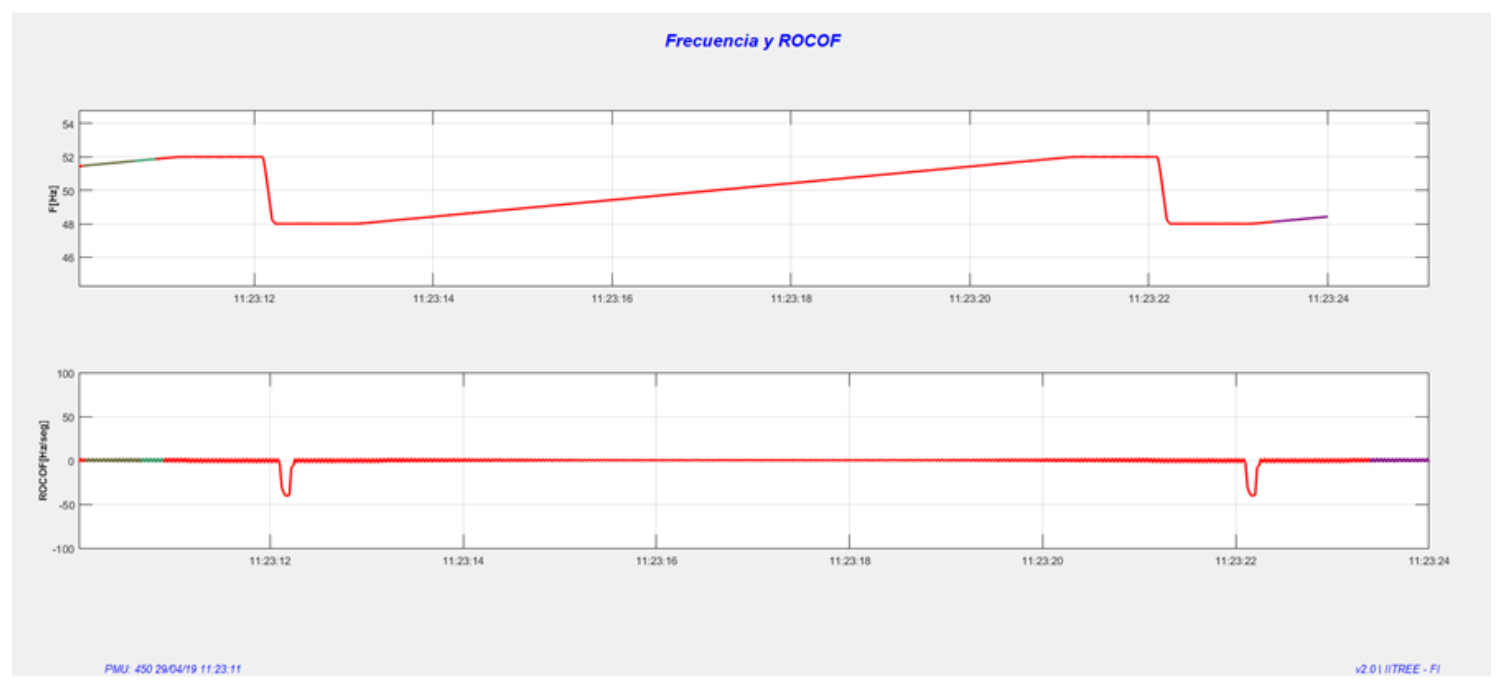

Figura 178. Frecuencia y ROCOF en Procesamiento Offline - Rampa de Frecuencia.

Puede observarse la rampa de frecuencia con la pendiente correspondiente, junto con los intervalos de tiempo donde la frecuencia se mantiene constante y los saltos de frecuencia propios de la generación periódica de las tensiones correspondientes.

El ROCOF medido por la PMU manifiesta lo descripto anteriormente, detectándose un valor de gran magnitud debido a los saltos de frecuencia.

En la Figura 179 puede observarse la medición de tensión realizada por la PMU. En ella puede notarse pequeñas variaciones en la tensión, producto de ruidos generados por la Valija de Pruebas. 


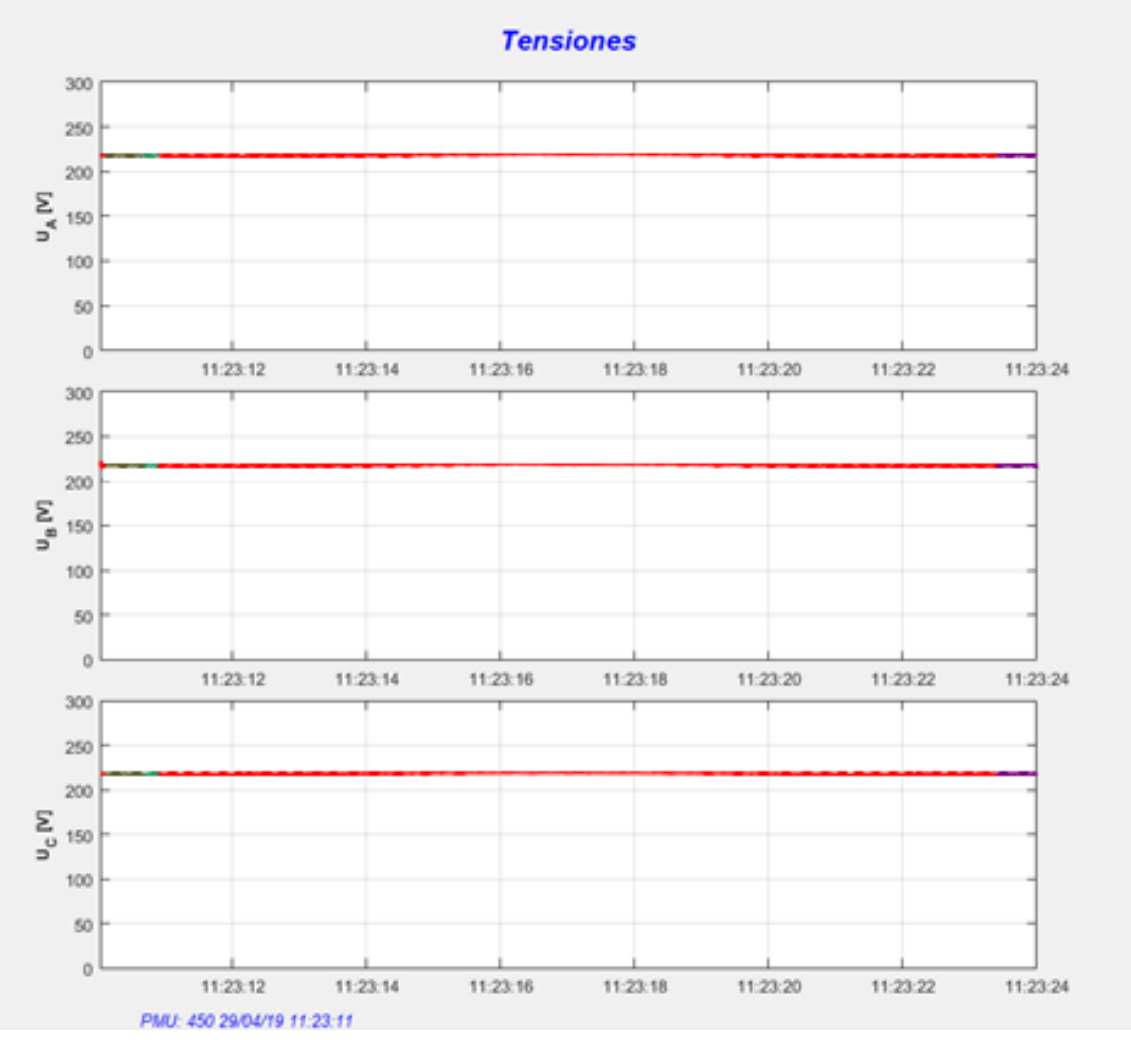

Figura 179. Traza de tensiones en Procesamiento Offline - Rampa de Frecuencia.

\subsubsection{Evaluación con potencia oscilante amortiguada}

El ensayo de evaluación con potencia oscilante amortiguada consistió en llevar a cabo la medición de las tensiones y corrientes de un sistema trifásico, cuando las mismas experimentan una oscilación amortiguada con una frecuencia correspondiente a un modo de oscilación local. En la Figura 180 se observa la potencia trifásica instantánea que fue sintetizada con la Valija de Pruebas mediante la generación de las correspondientes tensiones y corrientes. La frecuencia de oscilación fue configurada en $1,2 \mathrm{~Hz}$ y el amortiguamiento en $16,5 \%$.

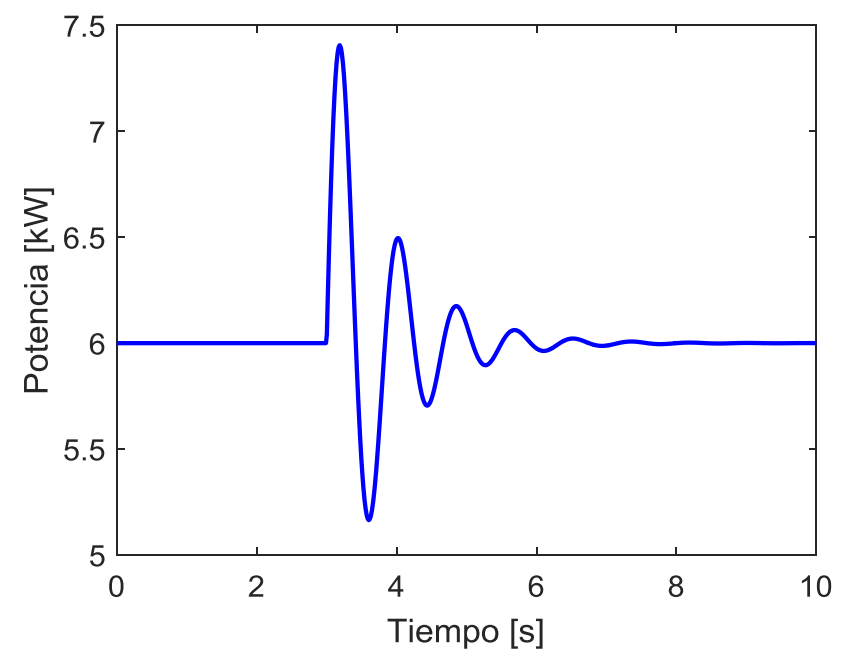

Figura 180. Potencia Oscilante Amortiguada. 
A los efectos de poder realizar el ensayo con la Valija de Pruebas disponible, se simuló un sistema de medición donde los transformadores de corriente utilizados tienen una relación 10:1. Por lo tanto, las corrientes generadas con la Valija tuvieron una amplitud 10 veces menor a la correspondiente al sistema eléctrico simulado y la PMU fue calibrada de manera tal de compensar la relación de transformación supuesta.

En la Figura 181 puede observarse la pantalla principal del Software de procesamiento Online cuando la PMU era sometida a la potencia oscilante antes descripta.

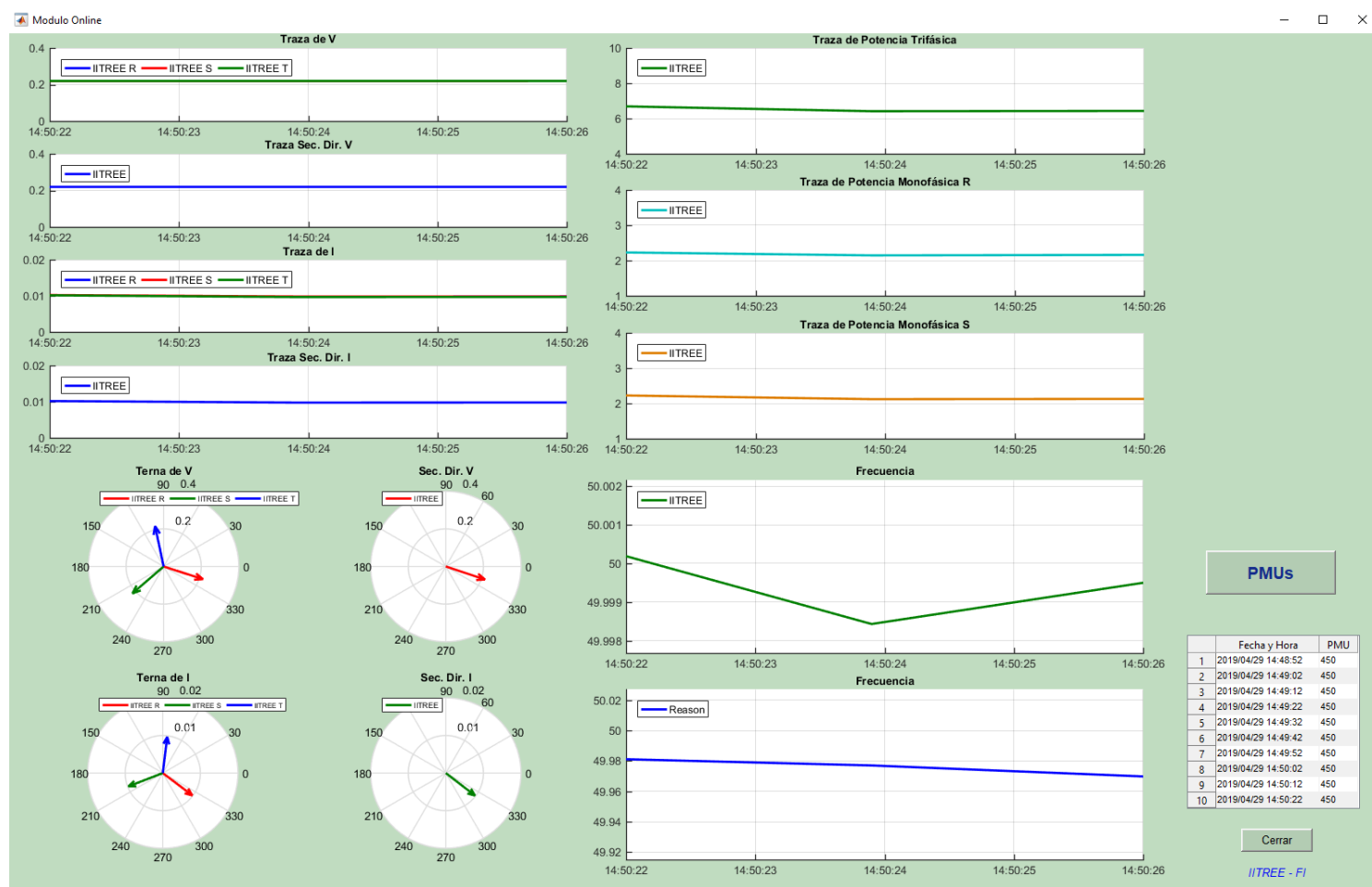

Figura 181. Software de procesamiento Online - Potencia Oscilante Amortiguada.

En la sección Traza de Potencia Trifásica puede observarse la presencia de una potencia variante en el tiempo. Debe tenerse en cuenta que, según como se la configure, la escala del gráfico correspondiente puede reducir la visibilidad del fenómeno.

Tal como se describe en la sección 7.3.2, el Software de procesamiento Online cuenta con un Detector de Perturbaciones que analiza en tiempo real la potencia trifásica medida con el objetivo de dar inicio al Procesamiento Prony cuando una perturbación es detectada.

El Detector de Perturbaciones localizó correctamente el inicio de la oscilación de potencia, de manera tal que se obtuvieron, mediante el procesamiento Prony, los resultados que se observan en la Figura 182. 


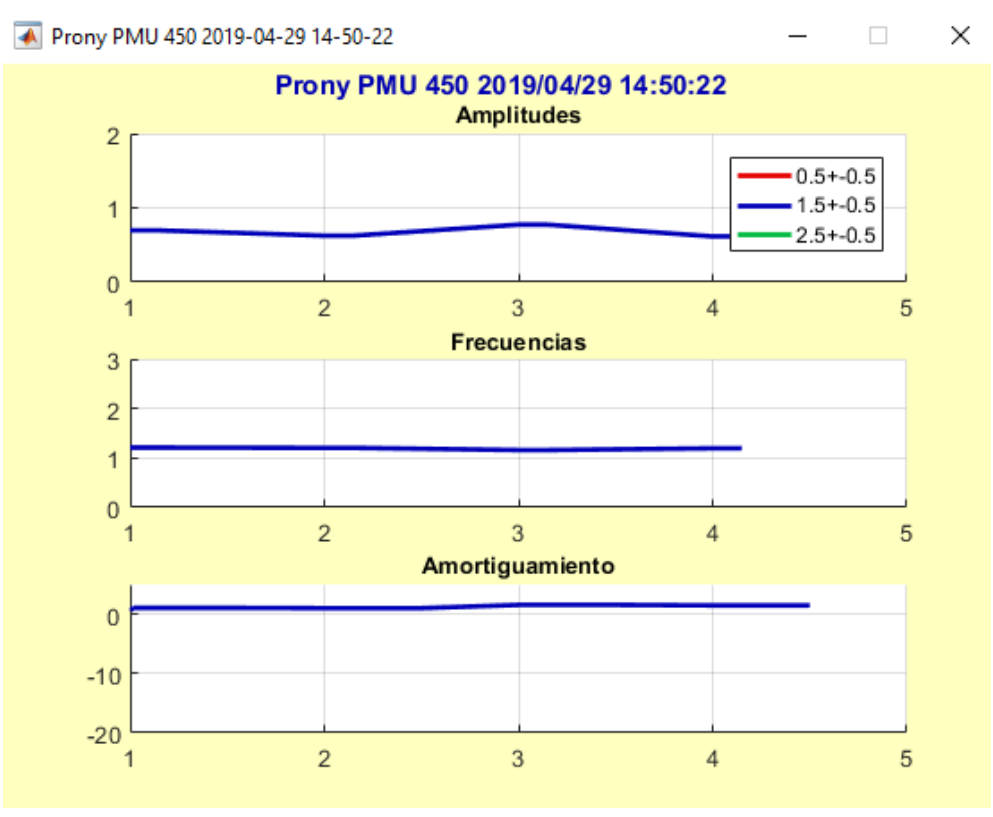

Figura 182. Procesamiento Prony Online - Potencia Oscilante Amortiguada.

Cabe mencionar que el procesamiento Prony fue configurado en el Software de Procesamiento Online para realizar 5 iteraciones del procesamiento sobre una ventana de datos de largo 1,2 s y desplazamiento $40 \mathrm{~ms}$ entre ventanas sucesivas. Las bandas de frecuencia analizadas fueron centradas en $0,5 \mathrm{~Hz}, 1,5 \mathrm{~Hz}$ y $2,5 \mathrm{~Hz}$, todas con un ancho de banda de $1 \mathrm{~Hz}$.

El procesamiento de la oscilación demostró la presencia de una frecuencia de aproximadamente 1,2 Hz con una aproximación del amortiguamiento (indicado como la inversa de la constante de tiempo del modo de oscilación) positivo, que también puede notarse en la evolución de la amplitud del modo.

Al igual que en el ensayo correspondiente a la variación de frecuencia, se evaluaron las mediciones registradas por el Servidor de Respaldo utilizando el Software de Procesamiento Offline.

Para realizar el análisis offline, se llevó a cabo la búsqueda mediante el propio software de procesamiento de los datos correspondientes en la base de datos. A su vez, se efectuó la configuración del procesamiento de las oscilaciones tanto en lo que se refiere a la detección automática de la misma como lo correspondiente al ancho de la ventana de procesamiento y las bandas de frecuencia analizadas. En la Figura 183 puede observarse la configuración del software de procesamiento offline. 


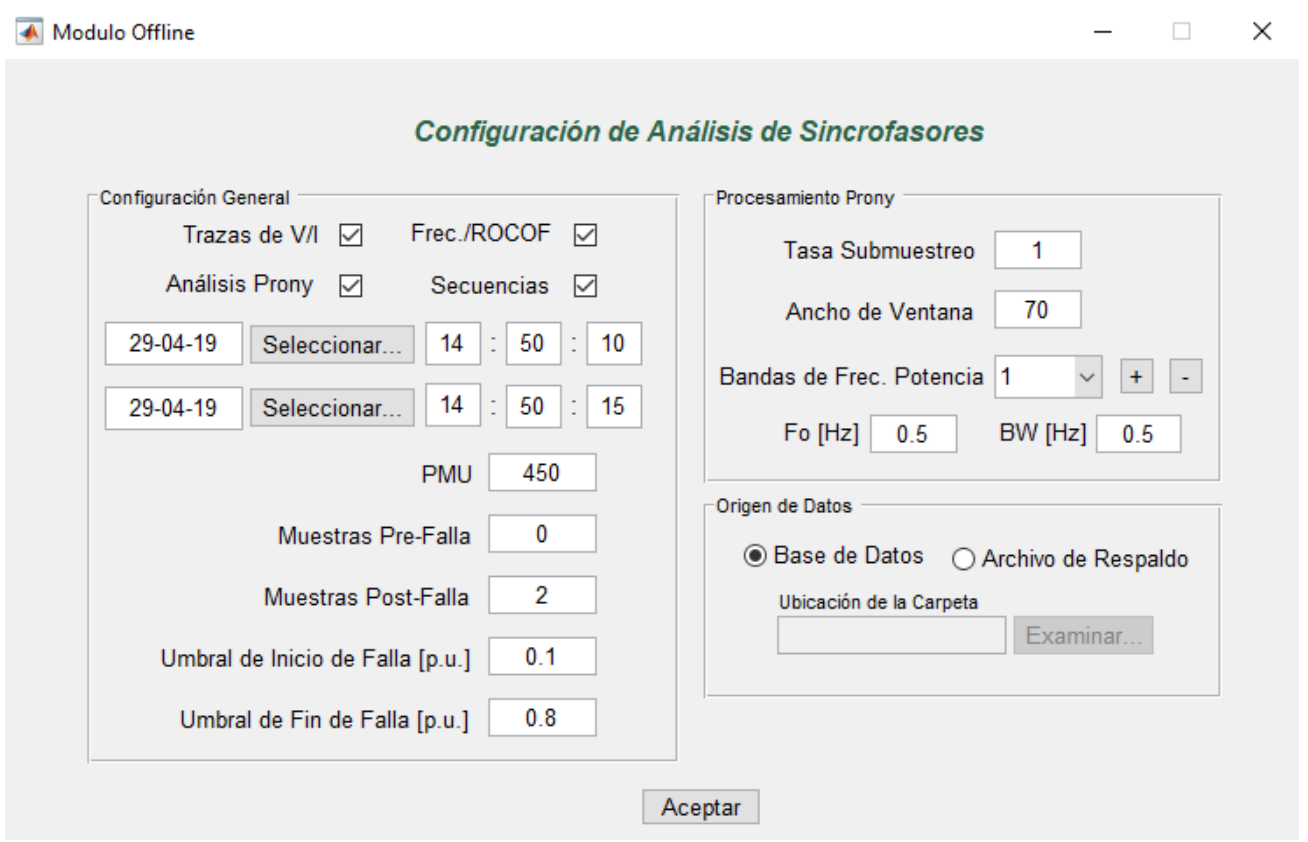

Figura 183. Configuración del procesamiento offline.

Se configuró el procesamiento Prony para llevar al cabo el procesamiento sobre una ventana de 70 muestras de longitud, correspondiente a 1,4 s analizando bandas de frecuencia centradas en $0,5 \mathrm{~Hz}, 1,5 \mathrm{~Hz}$ y $2,5 \mathrm{~Hz}$ y con un ancho de banda de $1 \mathrm{~Hz}$.

En las Figuras 184 y 185 puede observarse las trazas de tensión y corriente por fase obtenidas mediante el procesamiento offline.

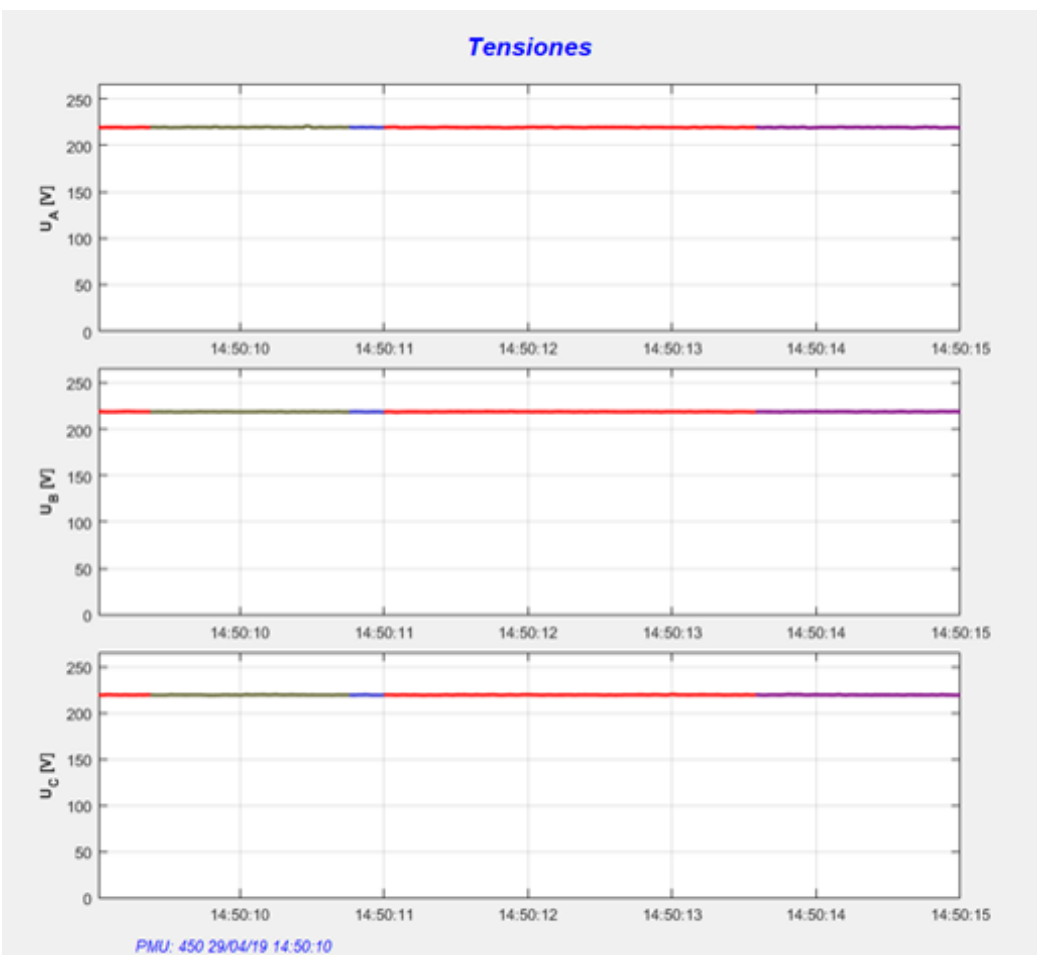

Figura 184. Trazas de tensión - Procesamiento Offline. 

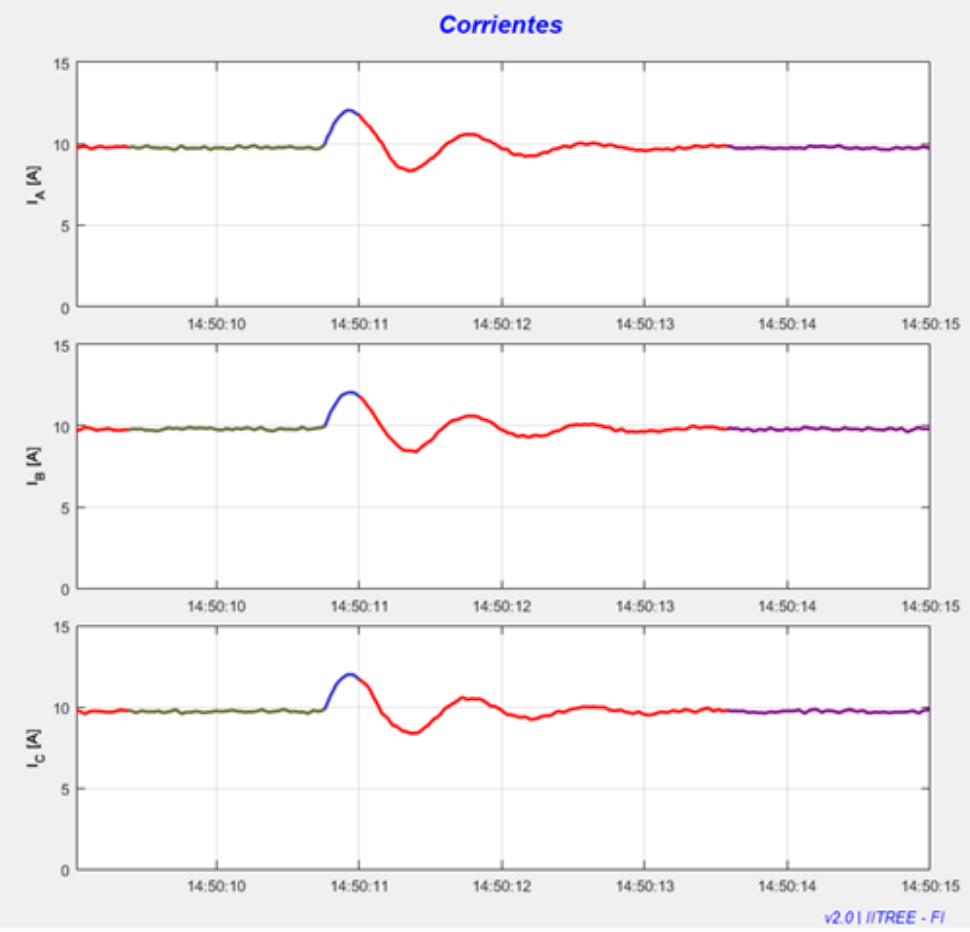

Figura 185. Trazas de corriente - Procesamiento Offline.

Puede notarse la oscilación amortiguada presente en la corriente, necesaria para simular la potencia correspondiente al presente ensayo.

La Figura 186 muestra la traza de potencia resultante del post-procesamiento de las tensiones y corrientes obtenidas con la PMU. Adicionalmente, se observa también el análisis Prony llevado a cabo sobre la potencia, pudiendo analizarse tanto las frecuencias detectadas como las amplitudes de los modos de oscilación presentes en el registro.

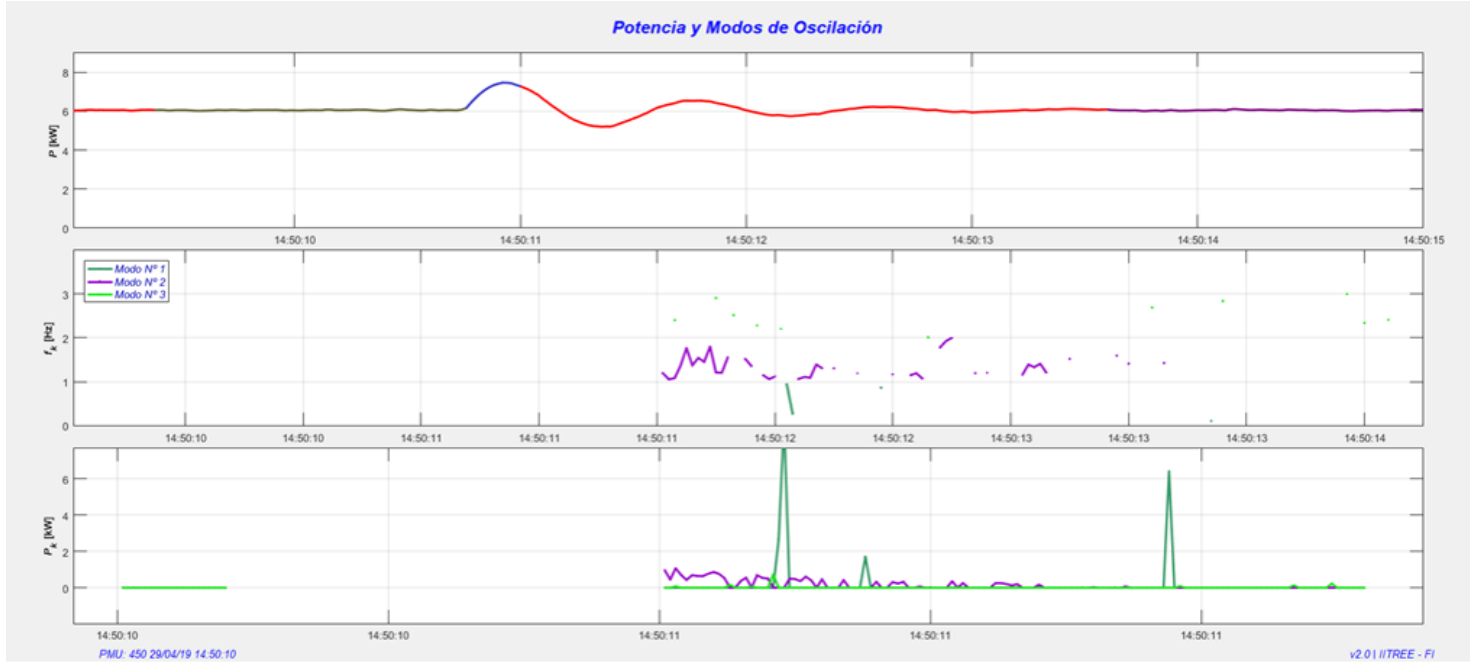

Figura 186. Trazas de potencia y modos de oscilación - Procesamiento Offline.

La potencia medida corresponde a la potencia que se esperaba medir según las señales generadas con la Valija de Pruebas. 
En los modos de oscilación, se detecta con presencia sostenible en el tiempo un modo de oscilación en la banda de 1,5 $\pm 0,5 \mathrm{~Hz}$, cuya frecuencia resulta aproximadamente 1,2 Hz. A su vez, las trazas de amplitud de los modos detectados demuestran el amortiguamiento del modo analizado, con el factor de amortiguamiento correspondiente.

El procesamiento Prony offline no realiza la exclusión de modos que puedan ser considerados despreciables. Es por ello que se aprecia la presencia de otros modos, cuya amplitud es extremadamente pequeña (en el caso del modo $\mathrm{N}^{\circ} 3$, en la banda 2,5 $\pm 0,5$ $\mathrm{Hz}$ ) o cuya presencia es de muy corta duración (en el caso del modo $\mathrm{N}^{\mathrm{o}}$ 1, en la banda $0,5 \pm 0,5 \mathrm{~Hz}$ ). Estos modos adicionales corresponden a ruido en la generación de las señales por parte de la Valija de Prueba.

En conclusión, los resultados obtenidos en los ensayos realizados al sistema de medición en su conjunto son altamente favorables. El sistema demostró su capacidad de funcionamiento continuo incluso cuando es sometido a perturbaciones en las variables medidas. A su vez, han podido medirse los fenómenos previstos sin inconvenientes.

La detección de perturbaciones en el software de procesamiento online demostró un correcto funcionamiento. El procesamiento Prony posterior para la obtención aproximada de los modos de oscilación presentes en la potencia también evidenció un funcionamiento apropiado.

El software de procesamiento Offline arrojó resultados correctos en cada uno de los ensayos realizados. Pudo llevarse a cabo sin inconvenientes la búsqueda de los datos almacenados en la base de datos correspondientes y su posterior procesamiento. Tanto la variación de frecuencia como la oscilación de potencia pudieron ser procesadas obteniéndose los resultados esperados.

El Concentrador de Sincrofasores y el Servidor de Respaldo demostraron un funcionamiento adecuado, sin pérdida de datos ni fallas en los registros de sincrofasores en la base de datos de respaldo.

Finalmente, el sistema de medición fasorial en su conjunto demostró, a su vez, la capacidad que dispone para medir, registrar y procesar los sincrofasores provenientes de sistemas eléctricos independientes, sin generarse interferencias entre ellos cuando son sometidos a perturbaciones en las variables registradas. 


\section{Conclusiones y Líneas Futuras}

\subsection{Conclusiones}

En la presente tesis, se ha estudiado, diseñado e implementado un Sistema de Medición Sincrofasorial completo. El mismo incluye todos los componentes necesarios para ser utilizado en una aplicación real, incluyendo la Unidad de Medición Fasorial, el Concentrador de Sincrofasores, el Servidor de Respaldo y el Software de Procesamiento con sus módulos Online y Offline.

Para llevar a cabo la implementación del sistema, se estudiaron los diferentes métodos de transmisión de sincrofasores existentes. Ante la falta de análisis acabados en la literatura afín que demostraran las ventajas y desventajas de un método frente al otro ni la viabilidad de aplicación de dichos métodos en aplicaciones específicas, se desarrollaron pruebas que permitieron evaluar el desempeño de los métodos y seleccionar el que mejor se adaptara a las condiciones de funcionamiento previstas.

Dadas las características del sistema eléctrico argentino, resulta de gran importancia el estudio de las oscilaciones subsincrónicas que pudieran presentarse. Frente a esta necesidad, se realizó un estudio y comparación de los métodos de procesamiento disponibles y analizados en la literatura afín con el objetivo de determinar el que mejor se adaptara a las necesidades de un sistema eléctrico real. Como resultado se seleccionó al método de Prony como el más apto para esta aplicación.

El software de procesamiento, tanto en sus módulos Online como Offline, fue implementado para ser capaz de detectar y analizar los modos de oscilación medidos. Como resultado, se obtuvo un software dotado con todas las capacidades necesarias para determinar la frecuencia, amplitud y amortiguamiento de los modos de oscilación detectados. Para ello, se implementaron diferentes herramientas de análisis y procesamiento de datos, incluyendo la Transformada de Fourier y el Método de Prony.

El módulo de procesamiento Online permite visualizar en forma gráfica los fasores utilizando diagramas fasoriales y gráficos con la evolución temporal de las variables registradas, como ser tensiones, corrientes, potencia y frecuencia. Este módulo cuenta con la capacidad de detectar perturbaciones de potencia y brindar, en un tiempo optimizado, información aproximada del fenómeno existente.

El módulo de procesamiento Offline le brinda al usuario la capacidad de procesar los fasores de una dada ventana de tiempo (seleccionable por el usuario) y extraer información asociada a los modos de oscilación presentes. Adicionalmente, este módulo de procesamiento cuenta con la capacidad de analizar archivos de datos COMTRADE. 
De esta manera, se obtuvo un módulo capaz de analizar los típicos archivos de registradores rápidos de eventos, tan comunes en los sistemas eléctricos de potencia.

Se desarrolló a su vez un software de concentración de fasores (PDC), capaz de ser instalado en cualquier computadora personal con sistema operativo Windows. Este software cuenta con la capacidad de recibir información de PMUs que implementen diferentes métodos de transmisión de datos, lo que lo hace completamente portable e independiente de un hardware específico. Se obtuvo, a su vez, una solución de baja complejidad, que permite reemplazar equipamiento comercial existente que no solo es de elevada complejidad técnica sino que también tiene un elevado costo económico.

Un software de almacenamiento de fasores fue implementado, capaz de almacenar todos los fasores que estén transmitiendo las PMUs en operación. Dicho software tiene la capacidad de generar un respaldo de toda la información en discos rígidos externos, tanto en forma automática y periódica como por orden del usuario.

Como etapa final de la presente tesis, se diseñó e implementó una Unidad de Medición Sincrofasorial completa. Para ello, se llevó a cabo una comparación de diferentes métodos de procesamiento para la obtención de los sincrofasores que permitió seleccionar el que mejor se adaptara al hardware y recursos disponibles.

Como resultado, se obtuvo una PMU implementada con tecnología de última generación, innovando en la adopción de los componentes utilizados. De esta manera, la PMU no solo posee un desempeño que puede satisfacer los principales requerimientos de las normas correspondientes, sino que además el costo de su fabricación resulta inferior en comparación con las PMUs comerciales existentes en la actualidad.

Adicionalmente se ha mostrado, con ensayos y comparaciones, que el software y hardware implementado arrojan resultados comparables con los que pueden obtenerse aplicando equipamiento comercial debidamente certificado por los organismos correspondientes.

El sistema de medición sincrofasorial, además, resulta portable y requiere de una infraestructura mínima. Con tan solo dos computadores personales es posible implementar la totalidad del sistema sin la necesidad de disponer de equipamiento adicional de uso específico y dedicado.

\subsection{Líneas Futuras}

El Sistema de Medición Fasorial ha demostrado estar listo para ser utilizado en un sistema eléctrico real. Sin embargo, restan aún trabajos que deben continuarse en el futuro:

- Optimizar los algoritmos de medición de módulo de los sincrofasores para mejorar la estimación de módulo. 
- Estudiar y evaluar la vinculación de las mediciones en tiempo real de las PMUs con un sistema que permita realizar acciones de control (sistemas eléctricos WAMPAC) [18][23].

- Analizar la viabilidad de utilización de las mediciones sincrofasoriales para realizar el ajuste en tiempo real de los parámetros de los sistemas de control que permiten amortiguar oscilaciones[24] (POD: Power Oscillation Damping) de SVCs, STATCOMs etc.

- Evaluar la vinculación de los sincrofasores con la determinación del estado de operación de un sistema de potencia, sobre la base de un número óptimo de PMUs emplazadas en nodos fundamentales del sistema (en función de la observabilidad de los modos de oscilación).

- Estudiar la utilización de las mediciones sincrofasoriales para llevar a cabo Análisis Modal de un sistema de potencia [19], complementando los resultados que pueden obtenerse mediante la herramienta de software SIAM. 


\section{Bibliografía}

[1] A. G. Phadke y J. S. Thorp, «Synchronized Phasor Measurements and Their Applications,» Springer, 2008.

[2] G. Rogers, «Power System Oscillations,» Kluwer Academic Publishers, 2000.

[3] CAMMESA S.A., «Los Procedimientos Versión XXVI - Anexo 24,» 2018.

[4] Cigré. B111., Analyisis and Control of Power System Oscillations, Task force 07 of Advisory Group 01 of Study Committee 38, 1996.

[5] P. Kundur, «Power System Stability and Control,» McGraw-Hill, 1994.

[6] J. Machowski, J. W. Bialek y J. Bumby, «Power Systems Dynamcs. Stability and Control,» Wiley, 2008.

[7] P. Sauer y M. Pai, Power System Dynamics and Stability, Springer, 2005.

[8] A. Monti, C. Muscas y F. Ponci, Phasor Measurement Units and Wide Area Monitoring Systems, Elsevier, 2016.

[9] IEEE Std. 60255-118-1-2018, «IEEE/IEC International Standard - Measuring relays and protection equipment - Part 118-1: Synchrophasor for power systems - Measurements,» 2018.

[10] IEEE Std C37.118.2-2011, «IEEE Standard for Synchrophasor Data Transfer for Power Systems,» 2011.

[11] J. A. de la O Serna, «Synchrophasor estimation using Prony's method,» IEEE Transactions on Instrumentation and Measurement, vol. 62, $\mathrm{n}^{\circ}$ 8, 2013.

[12] J. Peng y N. Nair, «Adaptive sampling scheme for monitoring oscillations using Prony analysis,» IET Generation, Transmission \& Distribution, vol. 3, n 12, 2009.

[13] L. Grigsby, Power System Stability and Control, Boca Rato, FL: CRC Press, 2006.

[14] B. Pal y B. Chaudhuri, Robust Control in Power Systems, Londes: Springer, 2005.

[15] C. Chen, Linear System Theory and Design, Oxford: Oxford University Press, 1999.

[16] Y. Hase, Handbook of Power System Engineering, West Sussex: J. Wiley \& Sons, 2007. 
[17] J. Agüero, V. Corasaniti, C. Biteznik, F. Issouribehere y J. Barbero, «Análisis Modal. Expansión del Sistema de Transmisión en $500 \mathrm{kV}$ del SADI-SIP,» XIV Encuentro Regional Iberoamericano de CIGRÉ (XIV ERIAC), Ciudad del Este, 2011.

[18] J. Cepeda y D. Colomé, «Evaluación inteligente de la vulnerabilidad del Sistema Eléctrico de Potencia en tiempo real usando técnicas de minería de datos y tecnología WAMS,» de XVI Encuentro Regional Iberoamericano de CIGRÉ (XVI ERIAC), Puerto Iguazú, 2015.

[19] X. Liang, «A Universal Synchrophasor Based Test Platform,» de IEEE Electrical Power and Energy Conference, Saskatoon, 2017.

[20] X. Liang y S. Wallace, «Processing Synchrophasor Data Using a Feature Selection Procedure,» de IEEE PES Asia-Pacific Power and Energy Conference, Xi'an, 2016.

[21] North American Electric Reliability Council, «1996 System Disturbances: Review of Selected 1996 Electric System Disturbances in North America,» Princeton, 2002.

[22] V. Venkatasubramanian y Y. Li, «Analysis of 1996 Western American Electric Blackouts,» de IREP SYMPOSIUM 2004 - Bulk Power System Dynamics and Control, Cortina d'Ampezzo, 2004.

[23] G. C. Patil y A. G. Thosar, «Application of synchrophasor measurements using PMU for modern power systems monitoring and control,» de International Conference on Computation of Power, Energy, Information and Communication (ICCPEIC), Melmaruvathur, 2017.

[24] D. Laverty, H. Kirkham, D. Morrow y X. Liu, «Estimation of Goodness of Fit of Synchrophasors during Transient Faults,» de IEEE Power \& Energy Society General Meeting, Chicago, 2017.

[25] J. Vives, D. Perrone y A. Musto, «Esquema de Sincrofasores: Aplicación para protección,» de XVI Encuentro Regional Iberoamericano de CIGRÉ (XVI ERIAC), Puerto Iguazú, 2015.

[26] C. P. Steinmetz, «Complex Quantities and their use in Electrical Engineering,» de International Electrical Congress, 1893.

[27] A. G. Phadke, «Synchronized phasor measurements - A historical overview,» de IEEE/PES Transmission and Distribution Conference and Exhibition, 2002.

[28] IEEE Std. 1344 (R2001), «IEEE Standard for Synchrophasors for Power Systems,» 2001.

[29] IEEE Std. C37.111-2013, «IEEE/IEC Measuring relays and protection equipment Part 24: Common format for transient data exchange (COMTRADE) for power systems,» 2013.

[30] I. Decker, A. Silva, R. d. Silva, M. Agostini, N. Martins y F. Prioste, «System Wide Model Validation of the Brazilian Interconnected Power System,» de IEEE PES General Meeting, Minneapolis, 2010. 
[31] Diario El Día, «Apagón puso en pausa a media ciudad y desató todasl las alarmas en la refinería la ciudad,» 20 Enero 2019. [En línea]. Available: https://www.eldia.com/nota/2019-1-20-4-14-55-apagon-puso-en-pausa-a-media-ciudad-ydesato-todas-las-alarmas-en-la-refineria-la-ciudad. [Último acceso: 2101 2019].

[32] Diario La Nación, «Un amplio apagón afectó a más de 300.000 usuarios en la ciudad,» 23 01 2019. [En línea]. Available: https://www.lanacion.com.ar/2213442-un-amplio-apagonafecto-a-mas-de-300000-usuarios-en-la-ciudad. [Último acceso: 2501 2019].

[33] Diario La Nación, «Cortes de luz: apagón en todo el país por "una falla masiva",» 1606 2019. [En línea]. Available: https://www.lanacion.com.ar/sociedad/la-argentina-sin-luzuna-falla-masiva-nid2258522. [Último acceso: 0107 2019].

[34] NASPI, «North American SynchroPhasor Initiative,» [En línea]. Available: http://www.naspi.org. [Último acceso: 2201 2019].

[35] NASPI, «Synchrophasor Monitoring for Distribution Systems,» 2018.

[36] C. Lu, B.Shi, X. Wu y H. Sun, «Advancing China's Smart Grid: Phasor Measurement Units in a Wide-Area Management System,» IEEE power \& energy magazine, vol. 13, $\mathrm{n}^{\circ}$ 5, pp. 60-71, 2015.

[37] Grid Protection Alliance, «GPA Grid Protection Alliance,» [En línea]. Available: https://www.gridprotectionalliance.org. [Último acceso: 2001 2019].

[38] IEEE Std. C37.244, «IEEE Guide for Phasor Data Concentrator Requirements for Power System Protection, Control, and Monitoring,» 2013.

[39] E. Hall, Internet Core Protocols: The Definitive Guide, Sebastopol: O’Reilly, 2000.

[40] General Electric’s Grid Solution, «MiCOM P40 Agile P847 Technical Manual,» 2015.

[41] Schweitzer Engineering Laboratories, «The Synchrophasor Report. Synchrophasors and Communications Bandwidth,» 2010.

[42] Arbiter Systems, «MODEL 1133A Power Sentinel GPS-Synchronized Power Quality Operation Manual,» 2012.

[43] ISO Std. 7498-1, «Information technology -- Open Systems Interconnection -- Basic Reference Model: The Basic Model,» 1996.

[44] M. Chenine, I. A. Khatib, J. Ivanovski, V. Maden y L. Nordström, «PMU Traffic Shaping in IP-Based Wide Area Communication,» de IEEE 2010 International Conference on Critical Infrastructure (CRIS), Beijing, 2010.

[45] B.Yang, K. Katsaros, W. Chai y G.Pavlou, «Cost-Efficient Low Latency Communication Infrastructure for Synchrophasor Applications in Smart Grids,» IEEE Systems Journal, vol. 
12, $\mathrm{n}^{\mathrm{o}} 1$, pp. 948-958, 2018.

[46] P. Kansal y A. Bose, «Bandwidth and Latency requirements for Smart Transmission Grid Applications,»IEEE Trans. on Smart Grids, vol. 3, n 1, pp. 948-958, 2012.

[47] A. Abdolkhalig y R. Zivanovic, «Evaluation of IEC 61850-9-2 Samples Loss on Total Vector Error of an Estimated Phasor,» de IEEE Student Conference on Research and Developement, Putrajaya, 2013.

[48] D. Cai, Wide Area Monitoring, Protection and Control in the future Great Britain Power System, Ph.D. dissertation, Univ. Manchester, Manchester, 2012.

[49] C. Martinez, M. Parashar, J. Dyer y J. Coroas, «Phasor data requirements for Real Time Wide-Area Monitoring, Control and Protection Applications,» Consortium for Electric Reliability Technology Solutions, Berkeley, 2005.

[50] Digi International Inc., «Digi Connect® WAN Family,» 2015.

[51] Oracle Corporation, «MySQL:: MySQL 5.7 Reference Manual:: 9.2.2.1 Speed of INSERT $\begin{array}{llllll}\text { Statements.,» } & 23 & 04 & 2013 . & \text { [En línea]. Available: }\end{array}$ https://dev.mysql.com/doc/refman/5.7/en/insert-optimization.html. [Último acceso: 1601 2019].

[52] Oracle Corporation, «MySQL :: MySQL 5.7 Reference Manual :: 4.5 .4 mysqldump - A Database Backup Program,» 201304 23. [En línea]. Available: https://dev.mysql.com/doc/refman/5.7/en/mysqldump.html. [Último acceso: 1601 2019].

[53] J. Proakis y D. Manolakis, Digital Signal Processing: Principles, Algorithms, and Applications, New Jersey: Prentice-Hall, Inc., 1996.

[54] A. Oppenheim y A. Willsky, Signals \& Systems, Harlow : Pearson Education, Inc., 2014.

[55] J. Agüero, F. Issouribehere y J. Barbero, «Poorly damped Electromechanical Oscillation in the $345 \mathrm{kV}$ interconnection between Argentina and Chile. Identification based on a sliding Prony analysis,» de 46 CIGRÉ Session (International Council On Large Electric Systems), París, 2016.

[56] P. Issouribehere, J. Barbero y F. Issouribehere, «Desarrollo de una herramienta computacional para la detección de Modos de Oscilación en Sistemas de Potencia basada en el análisis de Prony,» de XV Encuentro Regional Iberoamericano de CIGRÉ (XV ERIAC), Foz de Iguazú, 2013.

[57] M. Netto y L. Mili, «A robust prony method for power system electromechanical modes identification,» de IEEE Power \& Energy Society General Meeting, Chicago, 2017.

[58] C. K. Chui, An Introduction to Wavelets, San Diego: Academic Press, 1992. 
[59] D. Walnut, An Introdution to Wavelet Analysis, Boston: Birkhäuser, 2002.

[60] P. Ribeiro, Time-varying waveform distortions in power system, Wiley - IEEE, 2009.

[61] P. Issouribehere, J. Barbero, F. Issouribehere y J. Rodríguez, «Análisis de Oscilaciones Subsincrónicas derivadas de fallas en Sistemas de $500 \mathrm{kV}$. Experiencias de aplicación del Método de Prony,» de XIV Encuentro Regional Iberoamericano de CIGRÉ (XIV ERIAC), Ciudad del Este, 2011.

[62] P. Kumar y G. Gurrala, «IEEE C37.118.1a-2014 Compliance Testing of EPLL and DFACPLL for Synchrophasors,» de North American Power Symposium (NAPS), Fargo, 2018.

[63] P. Romano y M. Paolone, «Enhanced Interpolated-DFT for Synchrophasor Estimation in FPGAs: Theory, Implementation, and Validation of a PMU Prototype,» IEEE Transactions on instrumentation and measurement, vol. 63, $\mathrm{n}^{\circ}$ 12, pp. 2824 - 2836, 2014.

[64] STMicroelectronics, «STM32F405/415, STM32F407/417, STM32F427/437 and STM32F429/439 advanced ARM ${ }^{\circ}-$ based 32-bit MCUs Reference Manual, Rev. 13,» 2016.

[65] ARM Ltd., «ARM Cortex-M4 Processor - Technical Reference Manual,» Cambridge, 2015.

[66] Raspberry Pi Foundation, «Raspberry Pi Hardware - Raspberry Pi Documentation,» [En línea]. Available: https://www.raspberrypi.org/documentation/hardware/. [Último acceso: $08032019]$.

[67] Broadcom Corporation, «BCM2835 ARM Peripherals,» 2012.

[68] Electronic Industries Alliance Std. EIA/ECA-310, «Cabinets, Racks, Panels, and Associated Equipment,» 2005.

[69] Alstom Holdings, «Reason RPV311 Technical Manual,» 2014.

[70] Megger, «Megger Protective Relay Tester User Manual,» 2005.

[71] A. Abdolkhalig y R.Zivanovic, «Performance of Total Vector Error of an Estimated Phasor within Local Area Networks,» International Journal of Electrical and Computer Engineering, vol. VIII, nº 2, 2014. 